\title{
Reconstructing 15 Myr of environmental change in the McMurdo Dry Valleys through permafrost geochemistry
}

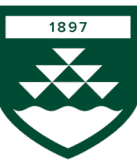

VICTORIA UNIVERSITY OF

\author{
Marjolaine Verret \\ Supervisors: Warren Dickinson \\ Kevin Norton
}

Antarctic Research Centre

School of Geography, Environment and Earth Sciences

Victoria University of Wellington

This dissertation is submitted for the degree of Doctor of Philosophy

June 2021 

To Maman et Papa, for igniting my curiosity and encouraging me to go on every adventure, especially this one. Je vous aime du plus profond de mon cœur. 



\section{Declaration}

I hereby declare that, except where specific reference is made to the work of others, the contents of this dissertation are original and have not been submitted in whole or in part for consideration for any other degree or qualification in this, or any other university. This dissertation is my own work and contains nothing which is the outcome of work done in collaboration with others, except as specified in the text and Acknowledgements. This dissertation contains fewer than 100,000 words including appendices, bibliography, footnotes, tables and equations.

Marjolaine Verret

June 2021 



\section{Acknowledgements}

The Friis Hills Drilling Project (2016-2017) was funded by the Past Antarctic Climate Programme. Funding support was provided by the New Zealand Ministry of Business, Innovation and Employment through contracts C05X1001 and ANTA1801. Financial support for this $\mathrm{PhD}$ was received through the Victoria University of Wellington Doctoral and Submission Scholarships. Laboratory analyses were in part funded by an Antarctic Science Ltd. International Bursary. A special thank you goes to the donors of the Endowed Development Fund who allowed me to attend courses and conferences.

I would like to first and foremost thank my primary supervisor, Warren Dickinson for offering me the opportunity to study Antarctic science. Rarely do you come about a scientist with as much passion and curiosity after decades of experience. You gave me the freedom to make this project unique, while remaining supportive throughout our three-year journey together. I would also like to thank my secondary supervisor, Kevin Norton. Your insightful feedback really brought my work to a higher level. I was also very fortunate to have the constant support from Denis Lacelle, from the University of Ottawa, throughout my $\mathrm{PhD}$. Merci pour ton aide et tes commentaires précieux. Tu as été une présence bienveillante tout au long de mon parcours académique. I truly wish all $\mathrm{PhD}$ candidates could have such seamless, pleasant and motivating experiences with their supervision.

I would like to express my sincere gratitude to my thesis examiners, Assoc. Prof. P. Almond (Lincoln University, New Zealand), Dr G. Dunbar (Victoria University of Wellington, New Zealand) and Prof. W.B. Lyons (Ohio State University, United States) for the staggering amount of time invested in this thesis and their insightful comments. This work would have not been possible without R. Levy and T. Naish, who, together, pioneered the Friis Hill Drilling Project. Thank you for welcoming me on-board and allowing me to work on the geochemistry of the cores. I would like to extent my gratitude to Antarctica New Zealand, A. Pyne, R. Pyne and Webster Drilling (T. Kingan and A. Rutten) for making fieldwork possible and retrieving the cores. For their constructive comments on my $\mathrm{PhD}$ proposal, I would also like to thank R. Levy and G. Dunbar. I would like to acknowledge the support received from 
the faculty and staff at the Antarctic Research Centre led by R. McKay, and the School of Geography, Environment and Earth Sciences at the Victoria University of Wellington.

I would also like to extend my appreciation to everyone who helped me put the puzzle pieces together along the way, starting with: D. Fisher, for your insight and deep understanding of ground ice; C. Lukens, for your patience and support in the laboratory; G. Dunbar, for taking your time to explain instrument protocols, D. Dickinson, for your help with the statistics; and, M. Harper, A. Homes and C. Trinh-Le for your dataset contributions.

Laboratory work was made possible with the help of the technical staff: J. Chewings (Sedimentology and Water Quality Laboratory, Victoria University of Wellington), L. Ashworth (Geochemistry and Cosmogenic Laboratory, Victoria University of Wellington), J. Bjornson (Geography Laboratory, University of Ottawa), N. De Silva and S. Mohanty (Geochemistry Laboratory, University of Ottawa), W. Abdy, P. Middlestead and P. Wickham (Jan Veizer Stable Icotope Laboratory, University of Ottawa), J. Dahl (Rafter Radiocarbon Laboratory, GNS Science), and, M. Christl and P. Gautschi (Ion Beam Physics Laboratory, ETH Zurich). A special thank you to N. Bertler and R. Pyne for allowing us to use the GNS Ice Core Facility in Lower Hutt, to store and sample the permafrost cores and to A. Philips at the GNS Science Stable Isotope Laboratory for allowing us to use the transition facility. I am also thankful to L. Verret for going over the draft version of my thesis with a fine-tooth comb.

A very special thank you to $\mathrm{H}$. Chorley for your support and the shared experiences throughout this $\mathrm{PhD}$. You made me feel welcomed in this project from the very first day. Thank you F. Isaacs and M. Tankersley for brightening my days in and out of the office. To F. Baldacchino, D. Lowry, L. Van Haastrecht and all the students at the Antarctic Research Centre, thank you for making this place a dynamic working environment.

To my family and friends in Canada, a special thank you for you for your endless support. Merci à Émilie et aux filles d' «élite». Je vous porte au fond de mon cœur malgré la distance. Merci à mes sœurs, Sara (Phil et les petits), Jo, Maud et Rosie, et la petite Léa pour vos encouragements, votre écoute et votre enthousiasme. À ma famille néo-zélandaise, Gab et Chris, merci pour votre présence de ce côté du globe. Maman et Papa, merci de m'avoir appris la détermination et la rigueur au travail mais aussi comment avoir du plaisir en travaillant. J'espère que cette thèse en est un bon exemple. Je vous aime tous du plus profond de mon cour.

Last but not least, Knutis, thank you for moving across the world with me and for your unconditional support in this adventure. Tusen og million takk! Jeg elsker deg uendelig. 


\begin{abstract}
The McMurdo Dry Valleys of Antarctica are the largest ice-free region in Antarctica. Valley downcutting by major outlet glaciers and post-glacial uplift since the mid-Miocene have resulted in predominantly younger surficial sediments in the low elevation, coastal areas and significantly older sediments in high elevation, inland areas. The hyper-arid conditions that prevail in the high elevations (> 1000 m a.s.l.) of the McMurdo Dry Valleys have protected these surfaces from alteration and weathering, and provide important sediment records of paleoenvironments dating back to the early Miocene. The Friis Hills $\left(77^{\circ} 45^{\prime} \mathrm{S}\right.$, $161^{\circ} 30^{\prime} \mathrm{E}, 1200-1500 \mathrm{~m}$ a.s.1.) are a $12 \mathrm{~km}$-wide inselberg situated at the head of Taylor Valley. This unique location allowed Miocene-age sediments to be preserved and protected from subsequent ice sheet expansions. Permafrost within these sediments is potentially the oldest on Earth.

As sediments accumulate in periglacial environments, permafrost aggrades with minimal lag time and potentially preserves sediments, organic material and ground ice. The 2016 Friis Hills Drilling Project retrieved a $\sim 50 \mathrm{~m}$ thick permafrost sequence, which not only consists of an archive of Antarctic environmental changes from approximately 14-15 Ma but also records the paleoenvironmental changes of the Neogene and provides insight on the modern hyper-arid environment. The main objective of this project is to understand the unique geochemical characteristics of these permafrost cores and document $15 \mathrm{Myr}$ of change in the upper elevations of the McMurdo Dry Valleys.

Paleoenvironmental reconstructions of interglacial periods suggest a tundra-like environment in the high elevations of continental Antarctica through the mid-Miocene. Plants such as lichens, liverworts, mosses, grasses and sedges, dicots and Nothofagaceae occupied the Friis Hills during the mid-Miocene. The $\delta^{13} \mathrm{C}$ signal of C3 plants $(-25.5 \pm 0.7 \%$ VPDB $)$ corresponds to a semi-arid environment with a mean annual precipitation ranging from 300 to $850 \mathrm{~mm} \mathrm{yr}^{-1}$. The unusually high $\delta^{15} \mathrm{~N}$ reflects an ecosystem with up to three trophic levels, supported by the presence of insect fragments, feathers barbs (birds) and tardigrades fragments within the sediment. The deep ice lenses and their meteoric signature suggest
\end{abstract}


a near-saturated active layer during the mid-Miocene. Temperature reconstructions based on the corrected $\delta^{18} \mathrm{O}$ value of the deep ground ice and change in paleogeography imply that the mid-Miocene (11.1-13.9 Ma) was $\sim 6$ to $12^{\circ} \mathrm{C}$ warmer. These paleoenvironmental conditions are comparable to those found in the modern Arctic, such as in west Greenland.

A dominant trend of literature suggests that the high elevations of the McMurdo Dry Valleys have remained under a hyper-arid polar climate since $\sim 13.8 \mathrm{Ma}$. However, the presence of ${ }^{10} \mathrm{Be}_{\text {met }}$ in the upper section of the Friis Hills and Table Mountain cores provides evidence for the translocation of clays, which is only possible under a warmer and wetter climate. The ${ }^{10} \mathrm{Be}_{\text {met }}$ concentrations imply that these conditions were present until $\sim 6.0 \mathrm{Ma}$ at Friis Hills and Table Mountain, consequently challenging the idea that the upper McMurdo Dry Valleys have remained frozen under hyper-arid climate since the mid-Miocene climate transition. Hence, this finding supports the hypothesis that the Miocene has undergone progressive cooling with onset of polar aridity between 7 and 5.4 Ma. The erosion-corrected paleo-active layer depth suggests mean annual air temperatures ranging from -12 to $-9^{\circ} \mathrm{C}$ $\sim 6.0 \mathrm{Ma}$. In other words, this thesis shows that the upper McMurdo Dry Valleys have been frozen under hyperarid conditions only since $\sim 6 \mathrm{Ma}$ and not for $14 \mathrm{Myr}$ as previously thought.

The ground ice in the uppermost $1 \mathrm{~m}$ originates from the modern freezing of evaporated snowmelt and the presence of high salt content which allows unfrozen water in the nearsurface. The conformity of dry permafrost samples to biological ratios suggests that the modern environment is regulated by biochemical processes and the current pool of organic carbon in the dry permafrost appears to be in equilibrium with a modern climate and ecosystem. These findings not only characterize the paleoenvironmental changes of continental Antarctica through the late Miocene but also provide a better understanding of the modern ultraxerous conditions of the McMurdo Dry Valleys. 


\section{Table of contents}

List of figures $\quad$ xvii

List of tables $\quad$ xxi

$\begin{array}{ll}\text { Nomenclature } & \text { xxv }\end{array}$

1 Introduction 1

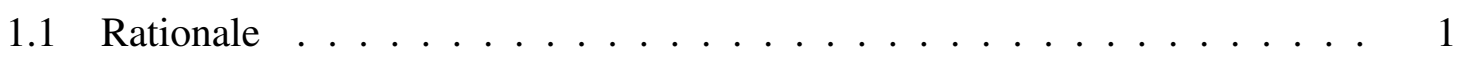

1.2 Research questions . . . . . . . . . . . . . . . . 2

1.3 Thesis outline ......................... 4

1.4 Associated publications . . . . . . . . . . . . . 8

2 Earth's oldest permafrost: Friis Hills, McMurdo Dry Valleys, Antarctica 11

2.1 Physical and geological setting . . . . . . . . . . . . . . . 12

2.2 Regional landscape evolution and paleoclimate . . . . . . . . . . . 13

2.2.1 Early Oligocene to mid-Miocene (34.0-12.9 Ma) . . . . . . . . . 13

2.2.2 Late Miocene cooling and Pliocene warm period (12.9 Ma - present) 16

2.3 The Friis Hills mid-Miocene sediment record . . . . . . . . . . . . . . 17

2.3.1 Geomorphic investigations: Lewis and Ashworth (2015) . . . . . 18

2.3.2 Stratigraphy of the 2016 Friis Hills Drilling Project . . . . . . . . . 21

2.3.3 Post-depositional uplift . . . . . . . . . . . . . . . . . 22

2.4 Modern-day climate, permafrost and ground thermal regime . . . . . . . 24 
2.5 Modern-day ecology . . . . . . . . . . . . . . . . . . 27

3 Organic geochemistry of mid-Miocene permafrost and modern biochemical processes 29

3.1 Provenance and cycling of organic carbon in the McMurdo Dry Valleys . . 31

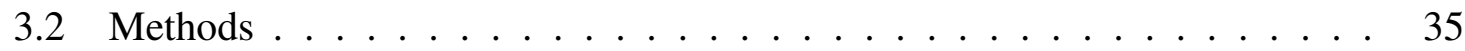

3.2.1 Core description and sampling . . . . . . . . . . . . 35

3.2.2 Grain-size and XRF analyses . . . . . . . . . . . . . 35

3.2.3 Bulk organic matter and carbonates . . . . . . . . . . . . 36

3.2.4 Soil organic carbon, total nitrogen, $\delta^{13} \mathrm{C}$ and $\delta^{15} \mathrm{~N}$ isotopes and radiocarbon dating . . . . . . . . . . . . . . 37

3.2.5 Diatoms and macrofragments . . . . . . . . . . . 38

3.2.6 Chronological control . . . . . . . . . . . . . . . 39

3.3 Results . . . . . . . . . . . . . . . . . . . 39

3.3.1 Sediment description . . . . . . . . . . . . . . 39

3.3.2 Sediment XRF geochemistry . . . . . . . . . . . . . . . 40 40

3.3.3 Organics, carbonates, $\mathrm{C}_{\text {org }}, \delta^{13} \mathrm{C}_{\text {org }}$ and $\delta^{15} \mathrm{~N}$ isotopes . . . . . 45

3.3.4 Radiocarbon dating . . . . . . . . . . . . . . . . . 50

3.3.5 Diatoms and macrofragments . . . . . . . . . . 50

3.4 Discussion . . . . . . . . . . . . . . . . 50

3.4.1 Sediment provenance . . . . . . . . . . . . . 50

3.4 .2 Interpretations of stratigraphic units $\ldots \ldots . \ldots 52$

3.4.3 The mid-Miocene tundra environment . . . . . . . . . . . 55

3.4.4 Provenance and cycling of organic carbon in the near-surface . . . . 63

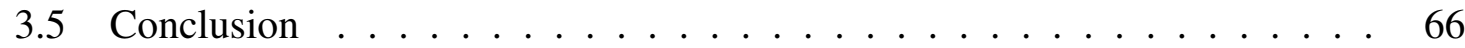

4 Cryostratigraphy of mid-Miocene permafrost at Friis Hills 69

4.1 Ground ice and associated processes: a review . . . . . . . . . . . . . . 70

4.1.1 Heat and moisture transfer processes . . . . . . . . . 70 
4.1.2 Ground ice content and cryofacies . . . . . . . . . . . . . 71

4.1.3 Cryostructures and origin of ground ice . . . . . . . . . . 73

4.1.4 Timing of ground ice formation $\ldots \ldots \ldots 76$

4.1.5 Distribution of ground ice in the McMurdo Dry Valleys . . . . . . . 86

4.2 Methods . . . . . . . . . . . . . . . . . . . . . 90

4.2.1 Water extraction . . . . . . . . . . . . . . 90

4.2.2 Stable water isotopes . . . . . . . . . . . . . . . . . . 90 90

4.2 .3 Soluble ion . . . . . . . . . . . . . . . . . . . 91

4.2.4 The REGO model . . . . . . . . . . . . . . . . . . . . . . . . 92

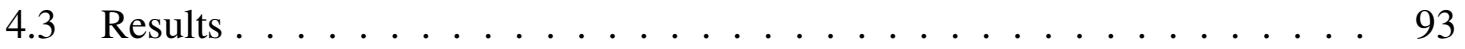

4.3.1 Cryostratigraphy and ground ice content . . . . . . . . . . . . 93

4.3.2 Geochemistry of ground ice . . . . . . . . . . . . . . . . . 94

4.4 Discussion . . . . . . . . . . . . . . . . . . . . . . . . 99

4.4.1 Origin of ground ice in the upper $1 \mathrm{~m} \mathrm{\ldots .} \mathrm{.} \mathrm{.} \mathrm{.} \mathrm{.} \mathrm{.} \mathrm{.} \mathrm{.} \mathrm{.} 99$

4.4.2 Origin of ground ice at $35-50 \mathrm{~m}$ depth . . . . . . . . . . . . . 103

4.4.3 Mid-Miocene paleotemperature reconstruction . . . . . . . . . 104

4.4.4 A model for ground ice content evolution since the mid-Miocene . . 105

4.5 Conclusion . . . . . . . . . . . . . . . . . 108

5 Meteoric Beryllium-10 in mid-Miocene permafrost and polar aridity in East Antarctica

5.1 Principles of the ${ }^{10} \mathrm{Be}_{\text {met }}$ tracer . . . . . . . . . . . . . . . . 112

5.1.1 Quantifying the atmospheric flux of ${ }^{10} \mathrm{Be}_{\text {met }}$ in the McMurdo Dry Valleys ........................... 113

5.1.2 ${ }^{10} \mathrm{Be}_{\text {met }}$ distribution with depth . . . . . . . . . . . . . 115

5.1.3 Erosion rates and soil ages from inventory of ${ }^{10} \mathrm{Be}_{\text {met }} \ldots \ldots . . .115$

5.1.4 ${ }^{10} \mathrm{Be}_{\text {met }}$ case studies in the McMurdo Dry Valleys and implications of leaching method . . . . . . . . . . . . . . . . . 120 
5.2 Methods . . . . . . . . . . . . . . . . . . . . . 121

5.2.1 Sequential ${ }^{10} \mathrm{Be}_{\text {met }}$ extraction, column chemistry, precipitation, oxydation and target packing . . . . . . . . . . . . . 122

5.2.2 AMS measurement and sample calibration . . . . . . . . . . 123

5.2.3 Calculation of closures ages using paleo-surface concentrations of ${ }^{10} \mathrm{Be}_{\mathrm{met}} \ldots \ldots \ldots \ldots \ldots \ldots 124 \ldots \ldots \ldots$

5.3 Results . . . . . . . . . . . . . . . . 126

5.3.1 Testing for grain-size dependency . . . . . . . . . . . 126

5.3.2 ${ }^{10} \mathrm{Be}_{\text {met }}$ distribution with depth . . . . . . . . . . . . 127

5.4 Discussion . . . . . . . . . . . . . . . . . . 131

5.4.1 Correction of Table Mountain samples and implications of leaching methods ....................... 131

5.4.2 Modelling ${ }^{10} \mathrm{Be}_{\text {met }}$ distribution with depth . . . . . . . . . . . 132

5.4 .3 Calculation of closure ages . . . . . . . . . . . . . 132

5.4.4 Timing of water percolation and onset of polar aridity . . . . . . 134

5.4.5 Paleo-active layer depth and climate at Friis Hills during the late Miocene (6.0 Ma) . . . . . . . . . . . . . . . . 135

5.4.6 The not so frozen Dry Valleys: late Quaternary processes . . . . . . 136

5.5 Conclusions . . . . . . . . . . . . . . . . 137

6 Synthesis and future research directions 139

6.1 Synthesis and paleoenvironmental implications . . . . . . . . . . . 139

6.1.1 Mid-Miocene sediment deposition in the Friis Hills basin and syn-

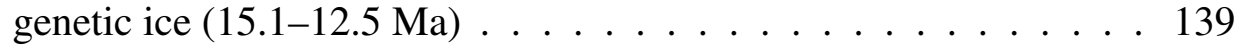

6.1.2 Mid to late Miocene and transition to a hyper-arid environment $(12.5-6.0 \mathrm{Ma}) \ldots \ldots \ldots$. . . . . . . . . . . . . 142

6.1.3 Modern hyper-arid conditions (6.0 Ma-present) . . . . . . . . . 143

6.1.4 Summary of mid-Miocene permafrost . . . . . . . . . . . . . . . 144

6.2 Future geochemical research directions in the McMurdo Dry Valleys . . . . 146 
6.2.1 Carbon stock and impacts of warming temperatures . . . . . . 146

6.2.2 Salt concentrations as an indicator for fjord-like conditions during the mid-Miocene . . . . . . . . . . . . . . . . . 147

6.2.3 Meteoric deep ground ice as a paleo-temperature proxy and dating ground ice . . . . . . . . . . . . . . . . . . . . 148

6.2.4 Refinement of the aggressive ${ }^{10} \mathrm{Be}_{\text {met }}$ leaching method . . . . . . . 149

6.3 The not-so stable upper McMurdo Dry Valleys . . . . . . . . . . . . . 150

$\begin{array}{ll}\text { References } & 151\end{array}$

$\begin{array}{lll}\text { Appendix A GRADISTAT Particle size classification } & 189\end{array}$

$\begin{array}{lll}\text { Appendix B Multiple comparison tests for grain-size } & 191\end{array}$

$\begin{array}{lll}\text { Appendix C Multiple comparison tests for major elements } & 193\end{array}$

$\begin{array}{lll}\text { Appendix D Multiple comparison tests for organics } & 197\end{array}$

$\begin{array}{lll}\text { Appendix E Diatom pictures and counts in core FHDP2C } & 201\end{array}$

$\begin{array}{lll}\text { Appendix F Radiocarbon calibration curve } & \mathbf{2 0 3}\end{array}$

Appendix G Input parameters for the REGO model 205

Appendix H Input parameters for the Craig-Gordon/ Sofer \& Gat model $\quad 207$ 



\section{List of figures}

1.1 Map of all locations mentioned in this thesis . . . . . . . . . . . . . 7

2.1 Location map of Friis Hills . . . . . . . . . . . . . . . . . . 12

2.2 Aerial photograph of Friis Hills from the west . . . . . . . . . . . . . 13

2.3 Compiled global and regional paleoclimatic indicators of the past $25 \mathrm{Myr}$. 14

2.4 Nothofagus wood fragment from Friis Hills . . . . . . . . . . . . . . . . . 15

2.5 Surficial geology map of Friis Hills and sampling/drilling sites from the 2016-17 Friis Hills Drilling Project . . . . . . . . . . . . . . 18

2.6 Mid-Miocene chronological sequence of glacial events and associated deposits in Friis Hills . . . . . . . . . . . . . . . . . . 20

2.7 Composite model of the Friis Hills Drilling Project cores . . . . . . . . . . 23

2.8 West Greenland as a modern landscape analogue for mid-Miocene interglacial periods at Friis Hills . . . . . . . . . . . . . . . . . . . 24

2.9 Temperature and snow accumulation at Friis Hills . . . . . . . . . . 25

2.10 Ice table conditions at Friis Hills . . . . . . . . . . . . . 26

3.1 Location of boreholes and shallow pits/outcrops of mid-Miocene age in the McMurdo Dry Valleys, Antarctica. . . . . . . . . . . . . . . . . 30

3.2 Mean $\delta^{13} \mathrm{C}$ and $\delta^{15} \mathrm{~N}$ for potential soil organic matter sources in the McMurdo Dry Valleys, based on the concept of ecological legacy . . . . . . . 34

3.3 Sedimentary log of core FHDP2C, grain size distribution profile and ternary plot of grain size distribution . . . . . . . . . . . . . . . . 41

3.4 Photos of stratigraphic units 1-7 and tephra layer in core FHDP2C . . . . . 41 
3.5 Profiles of major elemental concentrations of $\mathrm{Mg}, \mathrm{Al}, \mathrm{Si}, \mathrm{K}, \mathrm{Ca}, \mathrm{Ti}, \mathrm{Fe}$ and $\mathrm{Sr}$ in stratigraphic units of FHDP2C

3.6 Scatterplots showing relations between organic matter content and carbonates, $\mathrm{C}_{\text {org }}, \mathrm{N}, \mathrm{C}: \mathrm{N}, \delta^{13} \mathrm{C}_{\text {org }}$, and $\delta^{15} \mathrm{~N}$ in different FHDP2C stratigraphic units. . . . . . . . . . . . . . . . . .

3.7 Scatterplots showing relations between carbonates and $\mathrm{C}_{\text {org }}, \mathrm{N}, \mathrm{C}: \mathrm{N}, \delta^{13} \mathrm{C}_{\mathrm{org}}$, $\delta^{15} \mathrm{~N}$ and $\mathrm{Si} / \mathrm{Al}$ in different FHDP2C stratigraphic units.

3.8 Scatterplots showing relations between $\mathrm{C}_{\text {org }}$ and $\mathrm{N}, \mathrm{C}_{\text {org }}$ and $\delta^{13} \mathrm{C}_{\text {org }}, \mathrm{C}_{\text {org }}$ and $\delta^{15} \mathrm{~N}, \mathrm{~N}$ and $\delta^{15} \mathrm{~N}, \mathrm{~N}$ and $\mathrm{C}: \mathrm{N}$ and $\mathrm{C}_{\text {org }}$ and $\mathrm{C}: \mathrm{N}$ in different FHDP2C stratigraphic units. . . . . . . . . . . . . . . . .

3.9 Profiles of soil organic matter, carbonates, $\mathrm{C}_{\text {org }}, \mathrm{N}, \mathrm{C}: \mathrm{N}, \delta^{13} \mathrm{C}_{\text {org }}$ and $\delta^{15} \mathrm{~N}$ in stratigraphic units of FHDP2C . . . . . . . . . . . . . . . 49

3.10 Diatom genera abundance chart for FHDP2C . . . . . . . . . . . . . 49

3.11 Macrofragments found in FHDP cores . . . . . . . . . . . . . . . . 51

3.12 Geological units in the vicinity of Friis Hills with ice flow direction . . . . 52

3.13 Major elemental oxide diagrams . . . . . . . . . . . . . . . 53

$3.14 \delta^{13} \mathrm{C}_{\text {org }}$ and $\delta^{15} \mathrm{~N}$ biplots $\ldots \ldots \ldots \ldots \ldots$

3.15 The Chuck Creek Trail Valley in northern British Columbia (Canada) as a modern analogue to mid-Miocene Friis Hills . . . . . . . . . . . . . . . . 61

$3.16 \delta^{13} \mathrm{C}_{\text {org }}$ and $\mathrm{C}: \mathrm{N}$ in bulk sediment compared to organic matter pools $\ldots . .65$

3.17 Cumulative soil organic carbon density with depth below the ice table for FHDP2C and two sites in University Valley . . . . . . . . . . . . . . 66

4.1 Cryostructures classification . . . . . . . . . . . . . . . . 74

4.2 Classification of ground ice based upon the water source $\ldots . . \ldots$. . . 75

4.3 Basic concepts of the REGO model. . . . . . . . . . . . . . . . . 76

4.4 Isotopic enrichment in evaporating water and the effects of humidity . . . 79

4.5 Stable isotope data collected from Taylor Valley from December 1993 to January $1994 \ldots \ldots$. . . . . . . . . . . . . . . . . . . 82 
4.6 Stable isotope composition for selected buried ice, excess ice, pore ice and glacier ice in the McMurdo Dry Valleys . . . . . . . . . . . . . . .

4.7 Gravimetric water content in COMRAC permafrost cores surveyed in the

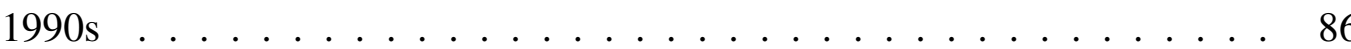

4.8 Gravimetric water content for selected surficial sites in the McMurdo Dry Valleys . . . . . . . . . . . . . . . . . . . . . .

4.9 Predicted distribution of ground ice compared to locations of drilled boreholes in icy permafrost in the McMurdo Dry Valleys, Antarctica. . . . . . . 88

4.10 Relation between stratigraphy and ground ice content at Friis Hills. . . . . . 94

4.11 Sedimentary, ground ice, $\delta^{18} \mathrm{O}$ and D-excess and major ion profiles in core FHDP2C . . . . . . . . . . . . . . . . . 95

4.12 Examples of lenticular cryostructures in Friis Hills sediments . . . . . . . . 95

$4.13 \delta \mathrm{D}-\delta^{18} \mathrm{O}$ of ground ice at Friis Hills compared to other sites in the McMurdo Dry Valleys. . . . . . . . . . . . . . . . . . . . . . 96

4.14 Tertiary graph of equivalent fractions of major anions and cations within ground ice samples of the Friis Hills Drilling Project compared to Table Mountain and lower Taylor Valley glaciers . . . . . . . . . . . . . . . . 97

4.15 Scatterplots comparing stable isotopes $\left(\delta \mathrm{D}-\delta^{18} \mathrm{O}\right)$ and anions $\left(\mathrm{Cl}^{-}, \mathrm{NO}_{3}{ }^{-}\right.$and $\mathrm{SO}_{4}{ }^{2-} \ldots \ldots \ldots \ldots \ldots \ldots$

4.16 Comparison between $\delta^{18} \mathrm{O}, \delta \mathrm{D}$ and D-excess profiles within the first meter of icy permafrost in University Valley site P1-C1 and FHDP2C . . . . . 100

4.17 Modelling the evaporation effect on the isotopic evolution of snowmelt and resulting near-surface ice. . . . . . . . . . . . . . . . . . . 102

4.18 Comparison of ground ice content profile at Friis Hills with the REGO model 106

4.19 Relation between accumulation time and ground ice accumulation rate in Friis Hills compared to University Valley and a site in the Low Arctic . . . 108

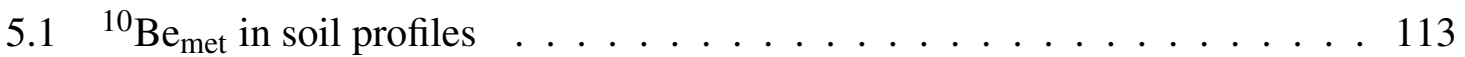

5.2 Distribution of modern ${ }^{10} \mathrm{Be}_{\text {met }}$ atmospheric flux . . . . . . . . . . 114

5.3 Locations of all Antarctic cosmogenic nuclide-derived erosion rate studies prior to $2015 \ldots \ldots \ldots$ 
$5.4{ }^{10} \mathrm{Be}_{\text {met }}$ concentration for different sites in the McMurdo Dry Valleys . . . . 122

5.5 Schematic representation of a ${ }^{10} \mathrm{Be}_{\text {met }}$ permafrost profile. . . . . . . . 125

$5.6{ }^{10} \mathrm{Be}_{\text {met }}$ and ${ }^{10} \mathrm{Be}_{\text {met }}{ }^{9} \mathrm{Be}$ biplot . . . . . . . . . . . . 126

5.7 ${ }^{10} \mathrm{Be}_{\text {met }}$ concentrations measured in both shallow and deep upper McMurdo Dry Valleys sites . . . . . . . . . . . . . . . . . . . . 128

5.8 Exponential regression equations for measured ${ }^{10} \mathrm{Be}_{\text {met }}$ concentrations of FHDP2C and TM01-97 . . . . . . . . . . . . . . . . . . . . . 133

6.1 Landscape comparison between west Greenland and Friis Hills . . . . . . . 141

6.2 Schematic representation of the $15 \mathrm{Myr}$ of paleoenvironmental changes at Friis Hills . . . . . . . . . . . . . . . . . . . . . . . . . 145

A.1 Particle size distribution classification for sand, silt and clay . . . . . . . . 189

D.1 Multiple comparison of average soil organic matter, carbonates, $\mathrm{C}_{\mathrm{org}}, \mathrm{N}$, $\delta^{13} \mathrm{C}_{\mathrm{org}}$ and $\delta^{15} \mathrm{~N}$ in different stratigraphic units of core FHDP2C . . . . 200

E.1 Pictures of diatoms in Friis Hills Drilling Project cores . . . . . . . . . . . 201

F.1 Radiocarbon age calibration plot . . . . . . . . . . . . . 203 


\section{List of tables}

2.1 Geographic coordinates and elevation of preliminary sampling sites and drilling sites at Friis Hills. . . . . . . . . . . . . . . . . . . 21

3.1 Mean or range of soil organic carbon, $\mathrm{N}, \mathrm{C}: \mathrm{N}, \delta^{13} \mathrm{C}$ and $\delta^{15} \mathrm{~N}$ concentrations in various sites in the McMurdo Dry Valleys . . . . . . . . . . . . 33

3.2 Grain-size characteristics and Munsell colour of the stratigraphic units in core FHDP2C . . . . . . . . . . . . . . . . . . 4 40

3.3 Pearson correlation $\left(\mathrm{r}^{2}\right.$-values) of major elements in core FHDP2C . . . . . 42

3.4 Mean values and range of major elements in stratigraphic units of core FHDP2C 44

3.5 Radiocarbon age from sample of dry permafrost . . . . . . . . . . . . . 50

3.6 Comparison between the mid-Miocene Friis Hills paleoenvironment and modern analogues. . . . . . . . . . . . . . . . . . 62

4.1 Ion composition of permafrost sediments and ice in the McMurdo Dry Valleys 85

4.2 Summary of ground ice isotope geochemistry case studies in the McMurdo Dry Valleys . . . . . . . . . . . . . . . . . . . . . . . . . . 89

5.1 Erosion or denudation rates based on bedrock and boulder samples in different locations of the McMurdo Dry Valleys . . . . . . . . . . . . . . . . 119

5.2 Erosion or denudation rates based on regolith in different locations of the McMurdo Dry Valleys . . . . . . . . . . . . . . . . . . . . . . 120

5.3 Concentrations of ${ }^{10} \mathrm{Be}_{\text {met }}$ in preliminary sites at Friis Hills . . . . . . . . . 129

5.4 Measured and calculated values of ${ }^{10} \mathrm{Be}_{\text {met }} \ldots \ldots \ldots \ldots$ 
5.5 Duplicate samples in TM01 showing ${ }^{10} \mathrm{Be}_{\text {met }}$ concentrations measured by aggressive and mild leaching methods . . . . . . . . . . . . . 132

5.6 Calculated erosion rates and closure ages for TM01-97 and FHDP2C . . . . 134

5.7 Values of parameters used in PERICLIMv1.0 model . . . . . . . . . . . . 136

B.1 Multiple comparison test of $\%$ clay of core FHDP2C . . . . . . . . . . . 191

B.2 Multiple comparison test of \% silt of core FHDP2C . . . . . . . . . . 191

B.3 Multiple comparison test of \% sand of core FHDP2C . . . . . . . . . . 192

B.4 Stratigraphic units that have statistically indistinct clay, silt and sand proportions in core FHDP2C . . . . . . . . . . . . . . . . . . . . . . 192

C.1 Multiple comparison test of Mg of core FHDP2C . . . . . . . . . . . 193

C.2 Multiple comparison test of Al of core FHDP2C . . . . . . . . . . . . . 193

C.3 Multiple comparison test of Ca of core FHDP2C . . . . . . . . . . . . . . 194

C.4 Multiple comparison test of Fe of core FHDP2C . . . . . . . . . . . . . . . 194

C.5 Multiple comparison test of Si of core FHDP2C . . . . . . . . . . . . . . 194

C.6 Multiple comparison test of Sr of core FHDP2C . . . . . . . . . . . . . . 195

C.7 Multiple comparison test of Ti of core FHDP2C . . . . . . . . . . . . . . . 195

C.8 Element concentrations that are statistically indistinct in stratigraphic units . 195

D.1 Multiple comparison test of soil organic matter of core FHDP2C . . . . . . 197

D.2 Multiple comparison test of carbonates of core FHDP2C . . . . . . . . 197

D.3 Multiple comparison test of $\mathrm{C}_{\mathrm{org}}$ of core FHDP2C . . . . . . . . . 198

D.4 Multiple comparison test of N of core FHDP2C . . . . . . . . . . . . 198

D.5 Multiple comparison test of C:N of core FHDP2C . . . . . . . . . . . 198

D.6 Multiple comparison test of $\delta^{13} \mathrm{C}_{\text {org }}$ of core FHDP2C . . . . . . . . . . 198

D.7 Multiple comparison test of $\delta^{15} \mathrm{~N}$ of core FHDP2C . . . . . . . . . . . 199

E.1 Diatom counts per genera in samples of FHDP2C . . . . . . . . . . . 202 
G.1 Values of parameters used in REGO ensemble modelling . . . . . . . . 205

H.1 Input parameters for the evaporation isotope model . . . . . . . . . . . . . 207 



\section{Nomenclature}

\section{Greek Symbols}

$\alpha \quad$ isotopic fractionation factor

$\delta^{13} \mathrm{C}$ ratio of ${ }^{13} \mathrm{C}$ and ${ }^{12} \mathrm{C}$

$\delta^{15} \mathrm{~N}$ ratio of ${ }^{15} \mathrm{~N}$ and ${ }^{14} \mathrm{~N}$

$\delta^{18} \mathrm{O}$ ratio of ${ }^{18} \mathrm{O}$ and ${ }^{16} \mathrm{O}$

$\delta \mathrm{D} \quad$ ratio of ${ }^{2} \mathrm{H}(\mathrm{D})$ and ${ }^{1} \mathrm{H}$

$\lambda$ radioactive decay constant

$\mu \quad$ micro- factor of $10^{-6}$

$\rho \quad$ density

$\sigma \quad$ standard deviation

$\varepsilon \quad$ erosion rate

\section{Subscripts}

am-ox amorphous oxide

ex-ox crystalline oxide

met meteoric

org organic

vol volume

\section{Other Symbols}


$\infty \quad$ infinity

$\%$ permil

$\sim$ approximately

\section{Acronyms / Abbreviations}

a.s.l. above sea level

AIS Antarctic Ice Sheet

AMS accelerator mass spectrometer

ANDRILL Antarctic drilling project

ANOVA analysis of variance

at atom

avg. average

BD bulk density

BP before present

BV Beacon Valley

cal calibrated

CIROS Cenozoic Investigations of the Ross Sea

$\mathrm{CN}$ cosmogenic nuclide

COMRAC Coring for microbial records of Antarctic climate

DP dry permafrost

DVDP Dry Valleys Drilling Project

EA East Antarctica

EAIS East Antarctic Ice Sheet

EDOM endolith-derived organic matter

eq. equation 
ETV Eastern Taylor Valley Drilling Project

FA Friis Hills ash

FHDP Friis Hills Drilling Project

gdw gram dry weight

GMWL global meteoric water line

GV Garwood Valley

GWC gravimetric water content

ICP-AES inductively coupled plasma atomic emission spectrometer

IRMS isotope ratio mass spectrometer

LDOM lacustrine-derived organic matter

LMWL local meteoric water line

LOI loss on ignition

MAAT mean annual air temperature

MAGT mean annual ground temperature

Ma million years ago

MAP mean annual precipitation

MCO Miocene Climatic Optimum

MDOM marine-derived organic matter

MDV McMurdo Dry Valleys

MIS marine isotope stage

MMCT mid-Miocene climate transition

MP-AES microwave plasma-atomic emission spectrometer

MSAT mean summer air temperature

Mt Mount 
Mtn Mountain

MWAT mean winter air temperature

Myr million years (duration)

OOM ornithogenic organic matter

POC particulate organic matter

ppm parts per million

ppmv parts per million per volume

PZA point of nearly zero thermal amplitude

$r^{2} \quad$ coefficient of determination

REGO regolith

RH relative humidity

$\mathrm{SOC}_{\mathrm{d}}$ soil organic carbon density

SOC soil organic carbon

SOM soil organic matter

TAM Transantarctic Mountains

TGA thermo-gravimetric analyzer

TIWA triple isotope water analyzer

TM Table Mountain

TOC total organic carbon

TV Taylor Valley

UVP University Valley polygon

UV University Valley

Vdw Van der Waals

VIC volumetric ice content 
VPDB Vienna Pee-Dee Belemnite

VSMOW Vienna Standard Mean Ocean Water

VV Victoria Valley

weq water equivalent

WS water speed

wt\% percentage by weight

WV Wright Valley

XRF $\mathrm{x}$-ray fluorescence

yr year 



\section{Chapter 1}

\section{Introduction}

\subsection{Rationale}

The McMurdo Dry Valleys (MDV) are a series of east-west trending, glacially eroded valleys in southern Victoria Land between $76^{\circ}-79^{\circ} \mathrm{S}$ and $158^{\circ}-170^{\circ} \mathrm{E}$. They are constrained between the East Antarctic Ice Sheet (EAIS) and the western coast of the Ross Sea. Valley downcutting by major outlet glaciers and post-glacial uplift since the Miocene have resulted in predominantly younger surficial sediments in the low elevation, coastal areas and significantly older sediments in high elevation, inland areas. These valleys comprise the largest ice-free area in Antarctica and are amongst the coldest and driest environments on Earth, with mean annual air temperatures around $-20^{\circ} \mathrm{C}$ (Doran et al., 2002) and less than $10 \mathrm{~cm}$ (water equivalent) of precipitation per year (Witherow et al., 2006, Fountain et al., 2010). In the high elevations (> $1000 \mathrm{~m}$ a.s.1.) of the MDV, also called the ultraxerous or stable upland zone, maximum air temperatures do not exceed $0^{\circ} \mathrm{C}$, resulting in little or no melting of snow and/or ice (e.g. Marchant and Denton, 1996, Marchant and Head III, 2007). These ambient conditions make the stable uplands inhospitable, supporting exclusively endolithic microbial communities and heterotrophic microbial communities in the sediment (Faucher et al., 2017).

The hyper-arid conditions that prevail in the MDV have protected the high elevation surfaces from alteration and weathering, and allow for an important sediment archive dating back to the early Miocene (e.g. Lewis et al., 2007, Lewis and Ashworth, 2015). The Friis Hills ( $77^{\circ} 45^{\prime} \mathrm{S}, 161^{\circ} 30^{\prime} \mathrm{E}, 1200-1500 \mathrm{~m}$ a.s.l.) are a $12 \mathrm{~km}$-wide inselberg situated at the head of Taylor Valley. This location has allowed Miocene-age sediments to be preserved and protected from subsequent ice sheet expansions. The early to mid-Miocene time interval (2312.9 Ma) spanned two very important climatic periods: (1) the Miocene Climatic Optimum 
(MCO; 17-14.8 Ma), the warmest period since the onset of Antarctic glaciation (e.g. Zachos et al., 2008), when a tundra-like environment occupied the MDV (Raine and Askin, 2001, Warny et al., 2009, Feakins et al., 2012); and (2) the mid-Miocene climate transition (MMCT; 14.8-12.9 Ma) a period which initiated progressive cooling in Antarctica and resulted in the extinction of tundra in the high elevations of the MDV (e.g. Miller et al., 2005, Zachos et al., 2008, Levy et al., 2016). Many studies suggest that the MMCT marked the onset of permanent polar aridity in the high elevations of the MDV (e.g. Marchant et al., 1993a, Marchant and Denton, 1996, Sugden, 1996, Lewis et al., 2008, Valletta et al., 2015), and that these environments have remained frozen for $12.9 \mathrm{Ma}$. However, this has been challenged by other studies (e.g. Dickinson et al., 2012). Whether or not the MDV have remained frozen through the late Miocene to Pliocene has implications on the local and global response to future climate change.

As sediments accumulate in periglacial environments, permafrost aggrades and pores are infilled with minimal lag time, which potentially preserves: (1) sediments, recording past geologic conditions; (2) organic material, recording past and present ecosystems; and (3) ground ice, recording past and present atmospheric and ground conditions (Murton et al., 2017). Permafrost cores retrieved during the 2016 Friis Hills Drilling Project (FHDP) likely contain the oldest permafrost on Earth and potentially record major paleoenvironmental changes over $15 \mathrm{Myr}$, including the tundra-dominated environment of the mid-Miocene, the transition to permanent polar aridity and the modern hyper-arid environment. The ground ice and organics in these cores have unique geochemical signatures which provide valuable information on paleoenvironmental changes of terrestrial Antarctica through the Neogene (15 Ma to today) and help us to understand the modern hyper-arid environment. This thesis uses geochemical environmental proxies that have rarely been applied to Antarctic terrestrial records to characterize the sediments, organics and ground ice of the FHDP cores.

\subsection{Research questions}

1. From the geochemistry of the sediment, organics and ground ice of the terrestrial record recovered by the 2016 Friis Hills Drilling Project (FHDP), what are the paleoenvironmental conditions at the Friis Hills during the mid-Miocene interglacials?

The MCO coincides with high global atmospheric $\mathrm{CO}_{2}$. It was the last period to experience $\mathrm{CO}_{2}$ levels greater than 400 ppmv for several million years, making it an essential period to understand the present global response of rising atmospheric $\mathrm{CO}_{2}$ (e.g. Foster et al., 2012, Zhang et al., 2013, Greenop et al., 2014). Several marine cores from the Ross Sea provide 
an extensive record of the mid-Miocene period, such as CIROS-1 (Barrett, 1989), Cape Roberts Project sites 1 and 2/2A (Naish et al., 2001, Levy et al., 2012) and ANDRILL-2A (Fielding et al., 2011, Passchier et al., 2011, Levy et al., 2016). However, until now, there has been no terrestrial counterpart to fully understand mid-Miocene paleoenvironments across the Transantarctic Mountains. Combining terrestrial and marine records provides a more comprehensive paleoenvironmental reconstruction than on its own. The terrestrial record is limited to shallow surface pits and sporadic outcrops in the Olympus Range, the Asgard Range and in Wright Valley (e.g. Marchant et al., 1996, Lewis et al., 2007, 2008). Lewis and Ashworth (2015) uncovered a 34 m thick stratigraphic sequence within the central section of Friis Hills. Cores retrieved by the FHDP provide important information on the evolution of the EAIS during the mid-Miocene. Chorley's (2020) thesis reports a detailed sedimentological and stratigraphic description of the cores, including paleomagnetic measurements, ${ }^{40} \mathrm{Ar} /{ }^{39} \mathrm{Ar}$ dating and paleoenvironmental indicators such as macrofossils, diatoms, along with a regional interpretation of glacial evolution at the Friis Hills. The present thesis uses geochemical proxies and focuses on organic matter and ground ice contained in the FHDP cores to provide a better understanding of the mid-Miocene tundra environment at Friis Hills.

2. Has the transition to permanent polar aridity following the middle Miocene climate transition been recorded in the Friis Hills sediment cores and if so, when did it occur in the high elevation of the McMurdo Dry Valleys?

Many studies suggest that at high elevations, the MDV have remained frozen under a hyper-arid polar climate since 12.9 Ma (Denton et al., 1993, Sugden et al., 1995, Summerfield et al., 1999, Valletta et al., 2015). However, other studies question this hypothesis and suggest that polar aridity may have not occurred until after 6-9 Ma in high elevations of the MDV (e.g. Dickinson et al., 2012). Ground ice is ubiquitous in subsurface sediments at these elevations, and its presence in sediments dating back to the mid-Miocene ( $\sim 14 \mathrm{Ma})$ is at the center of the debate regarding the onset of permanent aridity. Recent studies using ${ }^{10} \mathrm{Be}_{\text {met }}$ as a tracer for water infiltration in two nearby high elevation sites yielded conflicting results. Dickinson et al. (2012) found significant ${ }^{10} \mathrm{Be}_{\text {met }}$ concentrations down to $4.5 \mathrm{~m}$ at Table Mountain $\left(77^{\circ} 57^{\prime} \mathrm{S}, 161^{\circ} 57^{\prime} \mathrm{E}, 1945 \mathrm{~m}\right.$ a.s.1) suggesting infiltration of liquid water during warmer periods well after 12.9 Ma, whereas Valletta et al. (2015) did not detect ${ }^{10} \mathrm{Be}_{\text {met }}$ within 60 $\mathrm{cm}$ at Friis Hills $\left(77^{\circ} 45^{\prime} \mathrm{S}, 161^{\circ} 30^{\prime} \mathrm{E}, 1200-1500 \mathrm{~m}\right.$ a.s.l), supporting persistent polar aridity and opened a debate on ${ }^{10} \mathrm{Be}_{\text {met }}$ leaching methods. The long-term stability of high elevation surfaces has many implications in our understanding of the landscape evolution of the MDV and associated paleoclimate reconstructions. This thesis reports around 40 new ${ }^{10} \mathrm{Be}_{\text {met }}$ measurements from mid-Miocene permafrost and ground ice to shed light on the timing 
of the onset of polar aridity and the response of the EAIS during late Miocene and early Pliocene warm periods.

3. What is the biogeochemical signature of the modern ultraxerous environment and what is the origin of the near-surface ground ice?

The environment of the stable uplands of the MDV is dominated by ice and vapour exchange, with minimal liquid water. According to sublimation models, Antarctic ground ice should disappear at rates of order $0.1 \mathrm{~mm} \mathrm{yr}^{-1}$ (e.g. Hindmarsh et al., 1998, McKay et al., 1998, Schorghofer and Aharonson, 2005, Hagedorn et al., 2007), yet ice is found at shallow depths throughout the MDV. The presence and origin of ground ice at high elevations in the MDV is not fully understood and remains a major challenge in understanding the paleoclimate of the MDV. Ground ice plays a central role in landscape development of permafrost environments and has major implications in microbiology. By investigating the origin of both near-surface ice and carbon using stable oxygen and hydrogen isotope geochemistry and the REGO vapour-diffusion model, this thesis provides a better understanding of the modern ultraxerous conditions that prevail in the MDV, one of the most inhospitable environments on Earth.

\subsection{Thesis outline}

To address these research questions, this thesis is constructed as follows, with three main research chapters (Chapters 3 to 5):

\section{Chapter 2 - Earth's Oldest Permafrost: Friis Hills, McMurdo Dry Valleys, Antarctica}

This chapter consists of a literature review of the study site at Friis Hills. It presents its geographical and geological setting. It also discusses the landscape and paleoclimate evolution since the Early Oligocene, with a focus on the MCO (17-14.8 Ma), the MMCT (14.8-12.9 Ma) and the uncertainty of when the onset of permanent polar aridity occurred in the upper MDV. The chapter then provides the stratigraphic context of the Friis Hills sediment record, based on two studies at Friis Hills: (1) the geomorphic investigations by Lewis and Ashworth (2015) and (2) the 2016 Friis Hills Drilling Project. The five cores spanning down to $50 \mathrm{~m}$ deep are described, along with the chronostratigraphy established by Chorley et al. (in review). The modern hyper-arid climate, permafrost, thermal regime of the ground and ecology are then outlined to provide a better understanding of the site. 


\section{Chapter 3 - Organic geochemistry of mid-Miocene permafrost and modern ultraxer- ous biochemical processes}

This chapter focuses on a shallow $5 \mathrm{~m}$ core (FHDP2C) at Friis Hills. The main objective of this chapter is to use the sediments and organic matter contained within FHDP2C to infer midMiocene paleoenvironmental conditions compared to the modern ultraxerous environment. To establish the context of the extreme cold and dry conditions, the chapter starts with a brief literature review on the provenance and cycling of organic carbon in the MDV. FHDP2C is then described in detail, using ecological stoichiometry and $\delta^{13} \mathrm{C}_{\text {org }}$ and $\delta^{15} \mathrm{~N}$ to infer mid-Miocene paleoenvironmental conditions at Friis Hills. The biogeochemical signature of the mid-Miocene is then compared to the near-surface signature to understand the extent of modern processes.

External contributions to this chapter are as follows: chronostratigraphy of the FHDP cores was provided by $\mathrm{H}$. Chorley and detailed description of the FHDP cores (other than FHDP2C) are presented in Chorley (2020). A. Holmes (Victoria University of Wellington) carried-out the palynological analyses. Diatom counts were conducted by M. Harper (Victoria University of Wellington). All other work is by the author.

\section{Chapter 4 - Cryostratigraphy of mid-Miocene permafrost at Friis Hills, upper Mc- Murdo Dry Valleys of Antarctica}

The objective of this chapter is to understand the origin and evolution of ground ice over $\sim 15 \mathrm{Myr}$ in a $\sim 50 \mathrm{~m}$ permafrost column. This objective is accomplished by investigating the cryostratigraphy of the permafrost sediments and determining the ground ice content, major soluble ions and $\delta \mathrm{D}-\delta^{18} \mathrm{O}$ composition of the ground ice. The chapter is separated in two sections. The first section of the chapter presents a review of ground ice and associated processes focusing on the stable uplands of the MDV. The second section discusses the cryostratigraphy of the FHDP cores and investigates the origin of both near-surface ice and deep ground ice (>30 m), using the geochemistry of the ice and the REGO vapour-diffusion model.

External contributions to this chapter are as follows: D. Lacelle and D. Fisher created the WATERREGO and REGO models and generated model outputs. W. Dickinson, D. Lacelle, K. Norton and D. Fisher contributed to data analysis/interpretation and writing the manuscript. All other work is by the author. 
Chapter 5 - Meteoric Beryllium-10 in mid-Miocene permafrost and polar aridity in East Antarctica

The concept of using ${ }^{10} \mathrm{Be}_{\text {met }}$ as a tracer for water infiltration is explained in the first section of this chapter. The chapter then reports new ${ }^{10} \mathrm{Be}_{\text {met }}$ measurements from mid-Miocene permafrost in the upper MDV (Friis Hills and Table Mountain) and calculates closure ages for both these sites. The results are compared to the REGO model of ice content evolution by migrating water which constrains the timing and extent of water infiltration in permafrost sediments since the mid-Miocene.

External contributions to this chapter are as follows: C. Trinh-Le (Victoria University of Wellington) analyzed the preliminary samples from Friis Hills (FA, C1 and C2) for ${ }^{10} \mathrm{Be}_{\text {met }}$. W. Dickinson, K. Norton and D. Lacelle contributed to data analysis/interpretation and writing the manuscript. All other work is by the author.

\section{Chapter 6 - 15 Myr of changes in the Friis Hills: synthesis and future research direc- tions}

This chapter ties the conclusions from the other research chapters chronologically to construct the $15 \mathrm{Myr}$ of geological history of the high elevations of continental Antarctica over three important periods: (1) the mid-Miocene (15.1-12.5 Ma), a period when the high elevations of the MDV transitioned from tundra-dominated interglacial periods to the extinction of vegetation; (2) the mid-late Miocene (12.5-6.0 Ma), a period when the high elevations transitioned to a hyper-arid environment with minimal liquid water; and (3) the modern (6.0 present) period, when the high elevations have essentially remained under frozen hyper-arid conditions. Future research directions, which were outside the scope of this thesis, are then highlighted. 

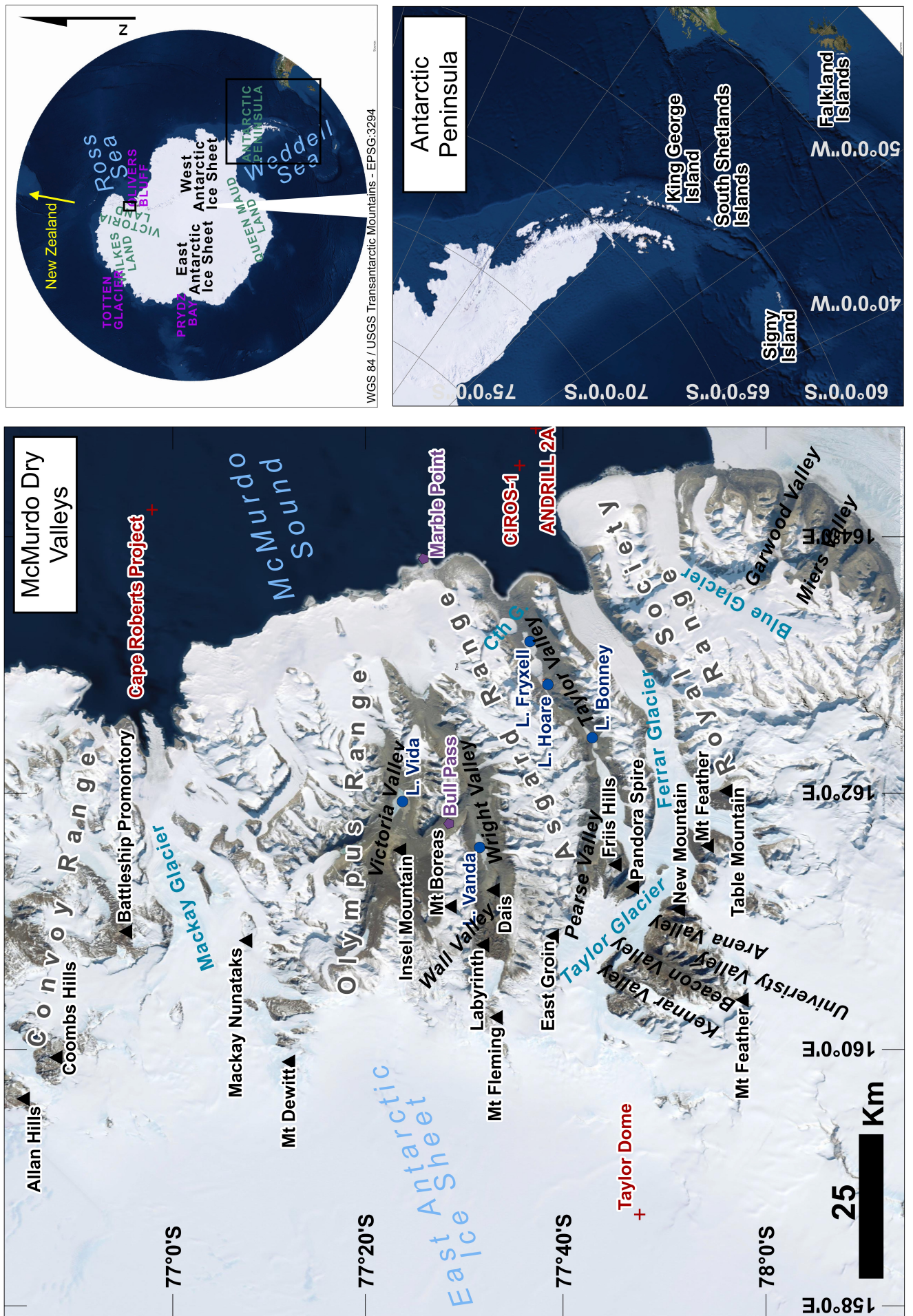

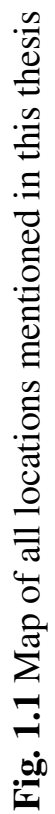




\subsection{Associated publications}

\section{Peer-reviewed publications}

Verret, M., Dickinson, W., Lacelle, D., Fisher, D., Norton, K., Chorley, H., Levy, R., Naish, T. (2021), Cryostratigraphy of mid-Miocene permafrost at Friis Hills, McMurdo Dry Valleys, Antarctic Science, 33(2), 174-188. (based on Chapter 4)

\section{Publications, in preparation (for peer-reviewed journals)}

Verret, M., Dickinson, W., Norton, K., Lacelle, D., Trinh-Le, C., Christl, M., Levy, R., Naish, T. (in preparation), Meteoric Beryllium-10 in Miocene permafrost and polar aridity in East Antarctica, Nature Geoscience. (based on Chapter 5)

Chorley, H., Levy, R., Naish, T., Lewis, A., Cox, S., Hemming, S., Ohneiser, C., Gorman., A., Harper, M., Hopkins, J., Prebble, J., Verret, M., Dickinson, W., Florindo, F., Golledge, N., Halberstadt, A., Kowalewski, D., McKay, R., Myers, S.,... Pyne, R. (in preparation). Antarctic Ice Sheet evolution and variability during the mid-Miocene Climate Transition (15.1-13.8 Ma), from the Friis Hills, Antarctica. Geological Society of America Bulletin. (includes work from Chapter 3)

\section{Non-peer reviewed publications}

Verret, M., Dickinson, W., Norton, K., Lacelle, D., Naish, T., Levy, R., Christl, M. (2019), Onset of permanent aridity in the Friis Hills: ${ }^{10} \mathrm{Be}_{\text {met }}$ as a tracer for water infiltration, McMurdo Dry Valleys Antarctica, Ion Beam Physics, ETH Zurich, Annual Report 2019. p.77. (based on Chapter 5)

\section{Conference publications}

Chorley, H., Levy, R., Naish, T., Dickinson, W., Verret, M., Hemming, S., Harper, M., Prebble, J., Ohneiser, C., Duncan, B., Halberstadt, A., Kowalewski, D., Florindo, F., Lurcock, P. (2018). Early to mid-Miocene East Antarctic Ice Sheet variability from the Friis Hills drilling project drillcore. American Geophysical Union, Washington D.C., USA, 10-14 December 2018. (includes work from Chapter 3) 
Verret, M., Dickinson, W., Lacelle, D., Norton, K., Levy, R., Naish, T. (2019). Origin of ground-ice in Miocene sediments, Friis Hills, Antarctica. 1st Southern Hemisphere Conference on Permafrost (SouthCOP), Queenstown, New Zealand, 4-14 December 2019. (based on Chapter 4)

Chorley, H., Levy, R., Naish, T., Hemming, S., Ohneiser, C., Prebble, J., Harper, M., Halberstadt, A.R., Verret, M., Duncan, B., Florindo, F. (2020). Orbital-scale, glacial evolution of the Transantarctic Mountains during the Miocene Climatic Optimum and its termination (15.5-13.8 Ma). SCAR Open Science Conference (online), 3-7 August 2020. (includes work from Chapter 3)

Verret, M., Dickinson, W., Norton, K., Lacelle, D., Christl, M., Levy, R., Naish, T. (2020). Presence of ${ }^{10} \mathrm{Be}_{\text {met }}$ in Miocene sediments challenges permanent polar aridity in the McMurdo Dry Valleys. SCAR Open Science Conference (online), 3-7 August 2020. (based on Chapter 5)

Verret, M., Dickinson, W., Lacelle, D., Fisher, D., Norton, K., Levy, R., Naish, T. (2020). Meteoric ground ice in mid-Miocene permafrost: a paleo-temperature proxy, upper McMurdo Dry Valleys of Antarctica. Geoscience Society of New Zealand Annual Conference, Christchurch, New Zealand, 22-25 November 2020. (based on Chapter 4) 



\section{Chapter 2}

\section{Earth's oldest permafrost: Friis Hills, McMurdo Dry Valleys, Antarctica}

The McMurdo Dry Valleys (MDV) are a series of east-west trending, glacially eroded valleys in southern Victoria Land, Antarctica (between $73^{\circ}-79^{\circ} \mathrm{S}$ and $160^{\circ}-164^{\circ} \mathrm{E}$ ). They are constrained between the East Antarctic Ice Sheet (EAIS) and the western coast of the Ross Sea and span an area of $6700 \mathrm{~km}^{2}$. The MDV comprise the largest ice-free area in Antarctica (Bockheim et al., 2007). Although the glacial history of the Transantarctic Mountains (TAM) is complex, valley down-cutting by major outlet glaciers and post-glacial uplift since the midMiocene has resulted in predominantly younger surficial sediments in the lower elevation and coastal areas (e.g. Stern et al., 2005, Paxman et al., 2019) and significantly older sediments in higher elevation and inland areas (e.g. Marchant and Denton, 1996). The hyper-arid conditions that prevail in the upper elevations of the MDV (>1000 m a.s.l.) have essentially protected these surfaces from alteration and weathering via precipitation or ice melt since the deposition of sediment; thus providing important sediment records of paleoenvironments dating back to the early Miocene (e.g. Marchant et al., 1993a, Marchant and Denton, 1996, Lewis et al., 2007, 2008, Lewis and Ashworth, 2015). The Friis Hills (7745'S, 161 $30^{\circ}$ 'E, 1200-1500 m a.s.1.) are a $12 \mathrm{~km}$ wide inselberg situated at the head of Taylor Valley, rising 900-1100 m above surrounding topography. This unique location has allowed Miocene-age sediment to be preserved and protected from subsequent EAIS ice sheet expansions (Lewis and Ashworth, 2015). This first chapter discusses how the paleoclimate and landscape evolution in the MDV since the early Oligocene along with the modern hyper-arid desert environment have shaped and preserved the oldest known permafrost on Earth. 


\subsection{Physical and geological setting}

The Friis Hills are situated at the head of Taylor Valley, about $50 \mathrm{~km}$ from the Ross Sea, and are delimited to the north by the Pearse Valley (Fig. 2.1). Taylor Glacier, an eastward flowing glacier, which drains ice from Taylor Dome, bounds the west facing margin and flows southward in a wide arc terminating in upper Taylor Valley, $16 \mathrm{~km}$ to the east (Fig. 2.1; Lewis and Ashworth, 2015). Taylor Valley is one of the major trunk valleys of the MDV and is punctuated by three terminal lakes that are fed by ephemeral glacial meltwater streams that form during the austral summer: Lake Bonney in the west (inward), Lake Hoare in the center and Lake Fryxell in the east (coast-ward) (Fig. 2.1; Fountain et al., 1999). The Friis Hills plateau (avg. $1325 \mathrm{~m}$ a.s.l.) is punctuated by three small hills (150-250 $\mathrm{m}$ above this surface) from which the name is derived (Fig. 2.2; Lewis and Ashworth, 2015). Lewis and Ashworth (2015) correlated the elevation and morphology of the Friis Hills plateau with a bedrock platform on Solitary Rocks (4 km to the south) and to several benches in the Asgard Range to the north (Fig. 2.2).

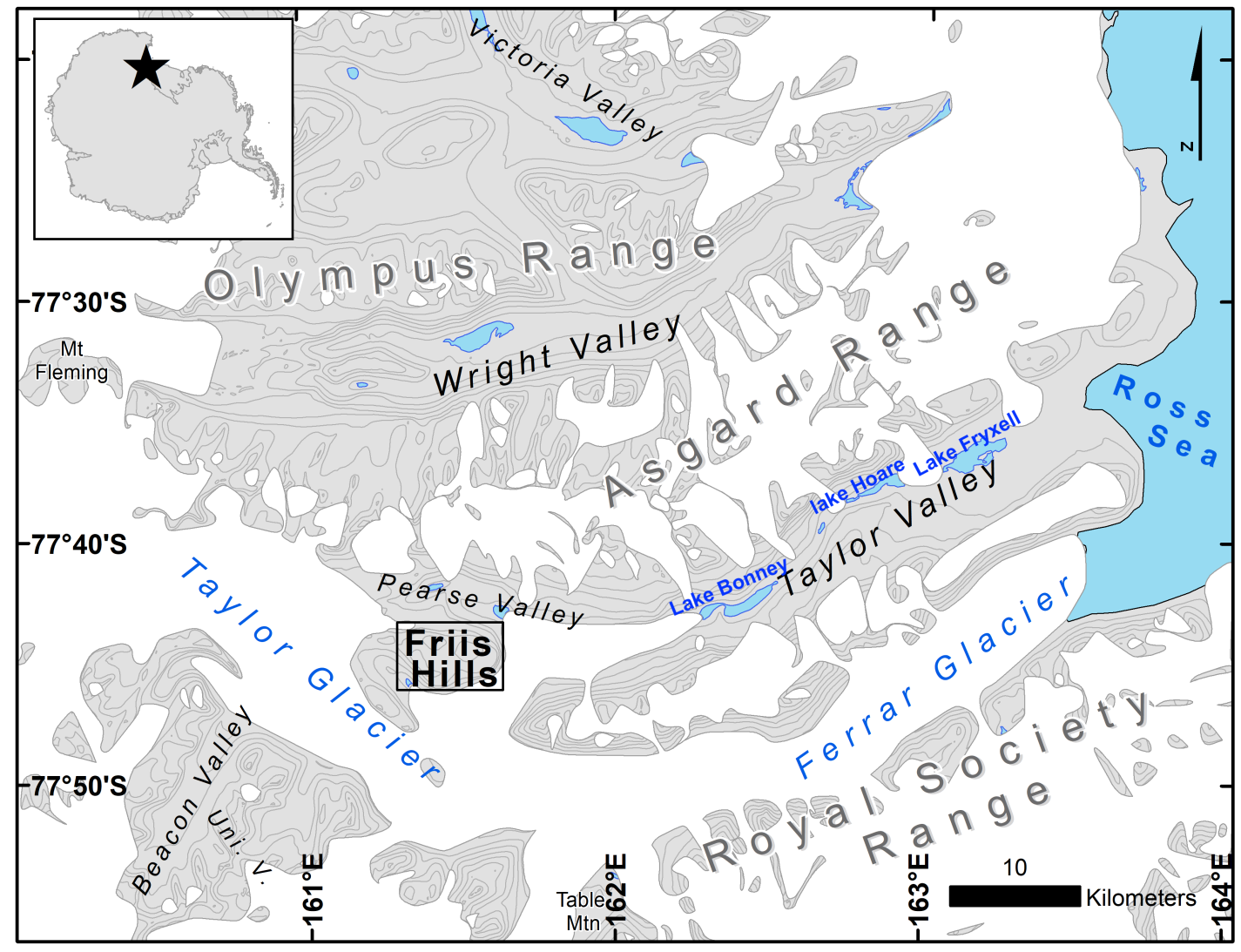

Fig. 2.1 Location map of Friis Hills within the McMurdo Dry Valleys of Antarctica with features discussed in text. (Contour lines at $200 \mathrm{~m}$ intervals) 
The geology of the Friis Hills comprises an assemblage of sedimentary and intrusive igneous rocks. The Pearse Pluton, consisting of Ordovician-age quartz-monzonite to quartzpoor granite, crops out extensively on the lower and upper faces of the near-vertical cliffs surrounding Friis Hills (Allibone et al., 1993). On the eastern face, the Pearse Pluton contains intrusions of Vanda felsic porphyry (Allibone et al., 1993). The middle section of the outcrop is crosscut by a sill of Jurassic-age Ferrar Dolerite 150-200 m thick (Lewis and Ashworth, 2015). A second $200 \mathrm{~m}$ thick sill is also exposed in higher elevations (Lewis and Ashworth, 2015). This sill is intruded along a planar disconformity, the Kukri erosion surface, which separates the Pearse Pluton basement rock from the overlying Devonian-age sandstones and siltstones of the Beacon Supergroup (Barrett, 1981, Lewis and Ashworth, 2015).

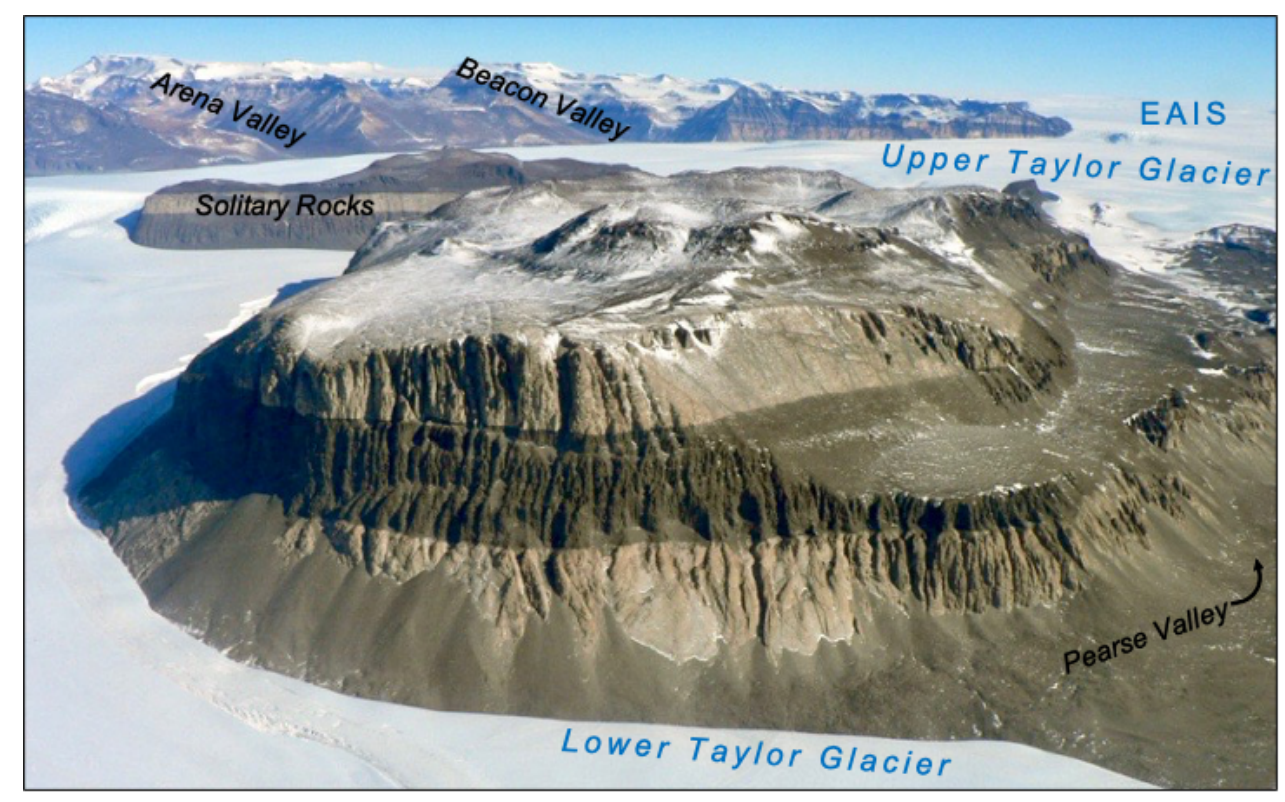

Fig. 2.2 Friis Hills from the west, at an elevation of $1900 \mathrm{~m}$ a.s.l. above Taylor Glacier, with Asgard Range in the background (modified from Lewis and Ashworth, 2015). Pearse Pluton is exposed in the upper and lower faces of the outcrop and Ferrar Dolerite is crosscutting the middle section.

\subsection{Regional landscape evolution and paleoclimate}

\subsubsection{Early Oligocene to mid-Miocene (34.0-12.9 Ma)}

The early Oligocene to mid-Miocene was a period characterized by dynamic Antarctic ice sheets, with major fluctuations in both volume and extent of terrestrial and marine ice sheets (e.g. Gasson et al., 2016). The marine isotopic record suggests that ice-volume 
ranged between 50\% and 125\% of the present day EAIS (Pekar and DeConto, 2006, Pekar et al., 2006). Shallow terrestrial deposits and outcrops in the Olympus Range (Lewis et al., 2007, 2008) and Asgard Range (Sugden et al., 1991, Marchant et al., 1993a, 1996) suggest that the mid-Miocene marked a shift in glacial dynamics, vegetation and paleoclimate. Furthermore, glaciogenic sediments retrieved from the Ross Sea drilling projects such as CIROS-1 (Barrett, 1987, 1989), Cape Roberts (Naish et al., 2001, Barrett et al., 2007b, Levy et al., 2012) and ANDRILL-2A (Fielding et al., 2011, Passchier et al., 2011, Levy et al., 2016) provide extensive records for glaciations during this interval. Ice flowed from the interior of East Antarctica through the McMurdo trunk valleys, grounded on the Ross Sea continental shelf, and advanced and retreated periodically (Naish et al., 2001, Dunbar et al., 2008, Kulhanek et al., 2019). The ANDRILL-2A core suggests that the mid-Miocene was punctuated by episodes of major advances and retreats of ice. One of these episodes of ice retreat corresponds to the Miocene Climatic Optimum (MCO; 17.0-14.8 Ma; Fig. 2.3) and represents the warmest period since the onset of Antarctic glaciation (e.g. Zachos et al., 2008). This period was followed by the mid-Miocene climate transition (MMCT; 14.8-12.9 Ma; Fig. 2.3), a period which marked the onset of progressive cooling (e.g. Miller et al., 2005, Zachos et al., 2008, Levy et al., 2016).

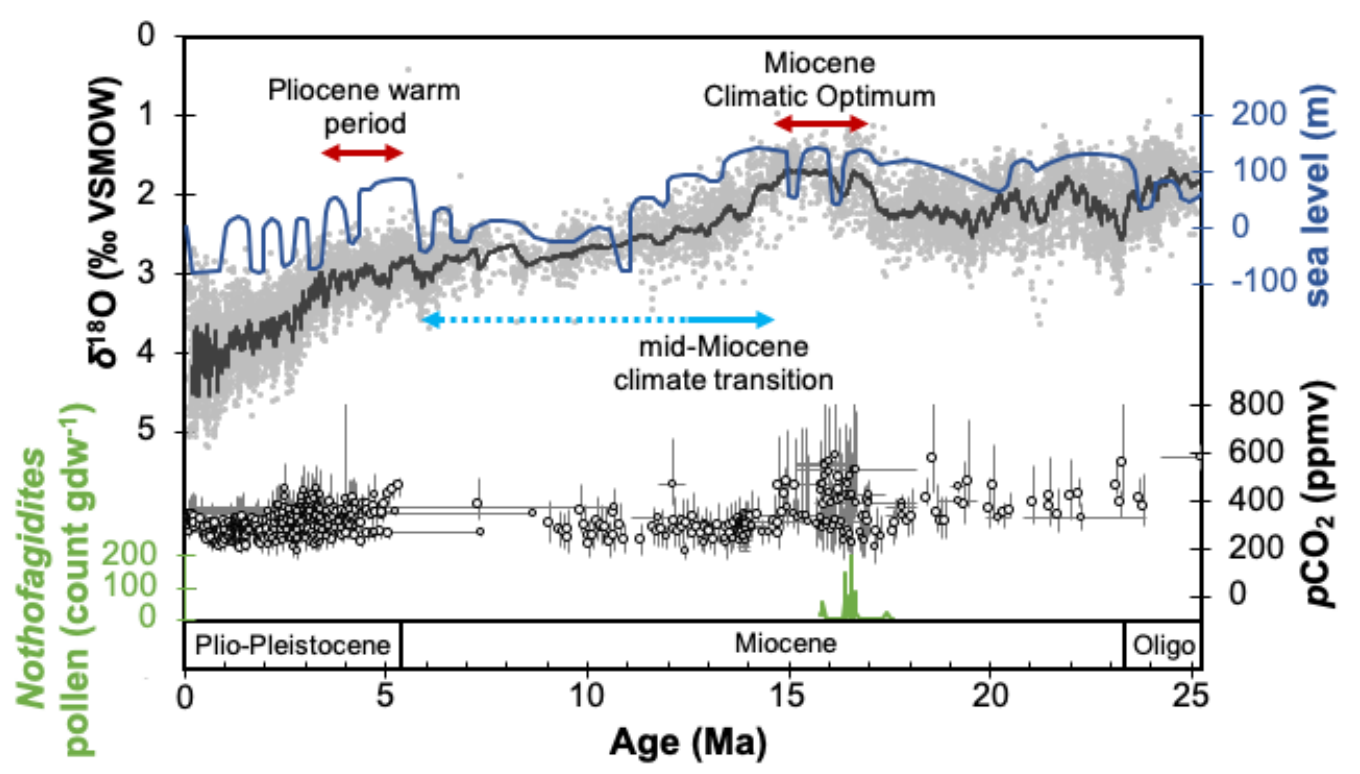

Fig. 2.3 Compiled global and regional paleoclimatic indicators of the past $25 \mathrm{Myr}$. Benthic $\delta^{18} \mathrm{O}$ from Zachos et al. (2008) with moving average in dark grey. Nothofagidites pollen abundance measured in ANDRILL-2A from Feakins et al. (2012). Sea level curve from Miller et al. (2005). Compilation of $\mathrm{CO}_{2}$ proxies from Foster et al. (2017) with the addition of Super et al. (2018). Major warming events (red arrows) and major cooling event (blue arrow followed by progressive cooling in dotted blue) are labelled. 


\section{Miocene Climatic Optimum (17.0 - 14.8 Ma)}

The MCO was characterized by warmer marine and terrestrial temperatures and reduced global ice coverage (Zachos et al., 2008). Benthic $\delta^{18} \mathrm{O}$ values ranged from $0.67-1.93 \%$ VPDB and $\mathrm{CO}_{2}$ concentrations varied between 300 and 600 ppmv (Fig. 2.3). Numerical models suggest that ice volume ranged $30-80 \%$ of the present day AIS (e.g. De Boer et al., 2010, Liebrand et al., 2011) and sea level increased up to $50 \mathrm{~m}$ (Miller et al., 2005). The ANDRILL-2A core provides extensive evidence of a warmer climate in the lithostratigraphic, palynological and leaf wax records; suggesting that at their warmest, mean summer air temperatures (MSAT) were about $11^{\circ} \mathrm{C}$ warmer than today, with a substantial moisture increase (Feakins et al., 2012, Passchier et al., 2011, Warny et al., 2009). Autochthonous ostracods have also been recorded in sediments of Paleolake Boreas, in the Olympus Range, supporting a warmer, tundra-like environment in Antarctica prior to 14.1 Ma (Williams et al., 2008). Pollen and spores from Friis Hills also provide evidence that the climate remained warm enough to support vegetation at least until the mid-Miocene (Raine and Askin, 2001, Warny et al., 2009, Feakins et al., 2012). Nothofagus (southern beech) wood and leaves, now extinct in Antarctica, were also found at Friis Hills (Fig. 2.4; Lewis and Ashworth, 2015). Based on the minimum climatic tolerances of Nothofagus, other plant taxa, a beetle, and a chironomid species, MSAT were estimated to be $6-7^{\circ} \mathrm{C}$, and the precipitation as much as $3000 \mathrm{~mm}$ at Friis Hills (Lewis and Ashworth, 2015).

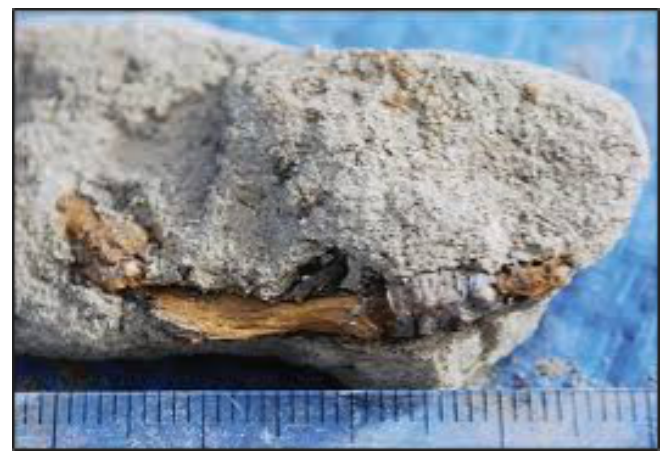

Fig. 2.4 Nothofagus wood fragment from Friis Hills (scale in mm; Lewis and Ashworth, 2015)

\section{Mid-Miocene climate transition (14.8-12.9 Ma)}

The MMCT was the period that followed the MCO around 14.8 Ma. This period was characterized by ice sheet expansion, a rapid MSAT cooling of $8^{\circ} \mathrm{C}$ on land (14.07-13.85 Ma) and the extinction of terrestrial plants in the high elevations of the TAM, based on paleoecology and glaciological modelling (Denton and Sugden, 2005, Lewis et al., 2007, 
2008). In addition, Shevenell et al. (2004) showed a $6-7^{\circ} \mathrm{C}$ cooling in the southern Pacific Ocean (14.2-13.8 Ma), based on $\mathrm{Mg} / \mathrm{Ca}$ of planktonic foraminifera. Glaciogenic deposits in the Olympus and Asgard Ranges record a transition from wet-based glaciation to monotonous cold and dry conditions beginning 13.9 Ma (Marchant et al., 1993a, Lewis et al., 2007). The MMCT also coincides with the widespread occurrence of glacially-molded clasts and striated surfaces in the MDV (Marchant et al., 1996). Studies by Denton et al. (1984) and Marchant et al. (1996) suggest that an extensive north-eastward ice-sheet from East Antarctica flowed through the MDV, overriding and stripping older tills. A $50 \mathrm{~km}$ long network of glaciallyscoured channels in the upper Wright Valley, called the Labyrinth, was dated between 14.4 and 12.4 Ma and provides additional evidence for large subglacial outburst flood during this period (Lewis et al., 2006). A similar feature was also identified at the head of Pearse Valley, neighbouring Friis Hills (Lewis and Ashworth, 2015). The advancement of the EAIS was accompanied by a global sea level drop of $\sim 60 \mathrm{~m}$ (John et al., 2011). Many studies suggest that the MMCT marked the onset of permanent polar aridity in the high elevations of the MDV (e.g. Marchant et al., 1993a, Marchant and Denton, 1996, Sugden et al., 1999, Lewis et al., 2008, Valletta et al., 2015). However, recent paleoclimate reconstructions suggest that instead of a sharp transition at $12.9 \mathrm{Ma}$, the MMCT marked the beginning of progressive cooling through the late Miocene (Fig. 2.3).

\subsubsection{Late Miocene cooling and Pliocene warm period (12.9 Ma - present)}

The early to mid-Pliocene was a period of relative warmth following the progressive cooling of the late Miocene ( 5.3-3.0 Ma; e.g. Salzmann et al., 2011). The discovery of marine Pliocene diatoms in warm-based glacial deposits (Sirius Group) in high elevations of the TAM in the 1980s opened a long-standing debate over the stability of the EAIS through the Neogene (Barrett, 2013). The dynamic hypothesis stipulates that the EAIS underwent major retractions during the Pliocene warm period $\sim 3 \mathrm{Ma}$; with global temperatures $2-3^{\circ} \mathrm{C}$ warmer, $\mathrm{CO}_{2}$ concentrations between 350-450 ppmv and sea levels $\sim 10-20 \mathrm{~m}$ higher than present (Fig. 2.3) all of which are consistent with significant ice loss from the EAIS (e.g. Wilson, 1995, Hambrey and McKelvey, 2000, Rebesco et al., 2006, Miller et al., 2012). The other hypothesis argues that the EAIS has remained relatively stable since the mid-Miocene, with minimal melting through the Pliocene and that the Miocene-age diatoms were reworked into Pliocene-age deposits (e.g. Marchant et al., 1993b, Sugden, 1996, Lewis et al., 2008). The stable hypothesis suggests that the high elevations of the MDV have remained virtually frozen under a hyper-arid polar climate since the MMCT ( 13.9 Ma). Essentially, the 
dynamic/stable debate centres on the timing of the onset of polar aridity of the upper MDV (e.g. Denton et al., 1993, Sugden et al., 1995, Summerfield et al., 1999, Valletta et al., 2015).

It is now widely accepted that the marine diatoms found in the Sirius deposits originated from aeolian deposition and subsequent recycling (e.g. Stroeven and Prentice, 1997) and that the Sirius deposit is mid-Miocene or older in age (e.g. Barrett, 2013). Although the debate has been widely moderated with recent modelling efforts which suggest intermediate ice-sheet configurations, unifying ideas from leading sides (e.g. Scherer et al., 2016), the response of the EAIS to the late Miocene cooling and the Pliocene warm period and their effect on the aridity of the upper MDV remain uncertain. Certain studies suggest that polar aridity happened somewhere between the MMCT and the Pliocene warm period 9-6 Ma in high elevations of the MDV (e.g. Dickinson et al., 2012). Recent paleoclimate reconstructions also suggest that instead of a sharp transition at 12.9 Ma, the Miocene has undergone sustained cooling with onset of polar aridity between 7 and 5.4 Ma (Herbert et al., 2016). This period coincides with glaciations in southeast Greenland, southeastern Alaska, South America and with pulses of ice-rafted debris off Wilkes Land and Adelie Land (Herbert et al., 2016). Dry Valleys Drilling Project cores 10-11 in Taylor Valley also suggest that vegetation persisted in the low elevations of the MDV through the early Pliocene, indicating that conditions remained favourable to sustain vegetation through the late Miocene (e.g. Fielding et al., 2012, Ohneiser et al., 2020).

After the Pliocene warm period, the climate underwent global cooling and the initiation of Northern Hemisphere continental ice sheets (e.g. Ravelo et al., 2004). The ANDRILL-1B core suggests open water conditions in the Ross Sea during the Pliocene warm period, with mean annual surface sea temperatures of $\sim 5^{\circ} \mathrm{C}$ followed by a decline to $1^{\circ} \mathrm{C}$ by $\sim 2.5 \mathrm{Ma}$ (McKay et al., 2012). Conversely, geomorphic evidence in the MDV suggests cold-based glacial regimes and minimal fluctuation in Taylor Dome since 3.1 Ma (e.g. Swanger et al., 2011). This disparity highlights the complex response of Antarctic ice to climate change. The late Pleistocene marked the final transition to a cold, polar glacial regime and a persistent Ross Ice Shelf during interglacial periods (McKay et al., 2012).

\subsection{The Friis Hills mid-Miocene sediment record}

Although the early to mid-Miocene periods have been extensively studied in the marine record, the terrestrial record is limited to shallow surface pits and sporadic outcrops in the Olympus Range, the Asgard Range and in Wright Valley. Following the geomorphic position of the well-dated (14.1 Ma) Mount Boreas deposit, Lewis and Ashworth (2015) 
searched specifically for a well preserved fossiliferous glacial sequence in the high elevation of the MDV, which they found at Friis Hills. Their work provides a general geomorphic and lithologic map of the Friis Hills drifts, based on surficial pits and field observations (Fig. 2.5). Within the central section of Friis Hills, they discovered a thick stratigraphic sequence, which had the potential to provide important information on the evolution of the EAIS during the mid-Miocene. The Friis Hills Drilling Project (FHDP; 2016-17) was undertaken a few years later to recover the full sedimentary sequence (Fig. 2.5). The FHDP reveals the sedimentologic and paleoenvironmental significance of this terrestrial record, with a rigorous chronologic constraint, allowing correlation with existing marine global climate records for the mid-Miocene period (Chorley et al., in review).

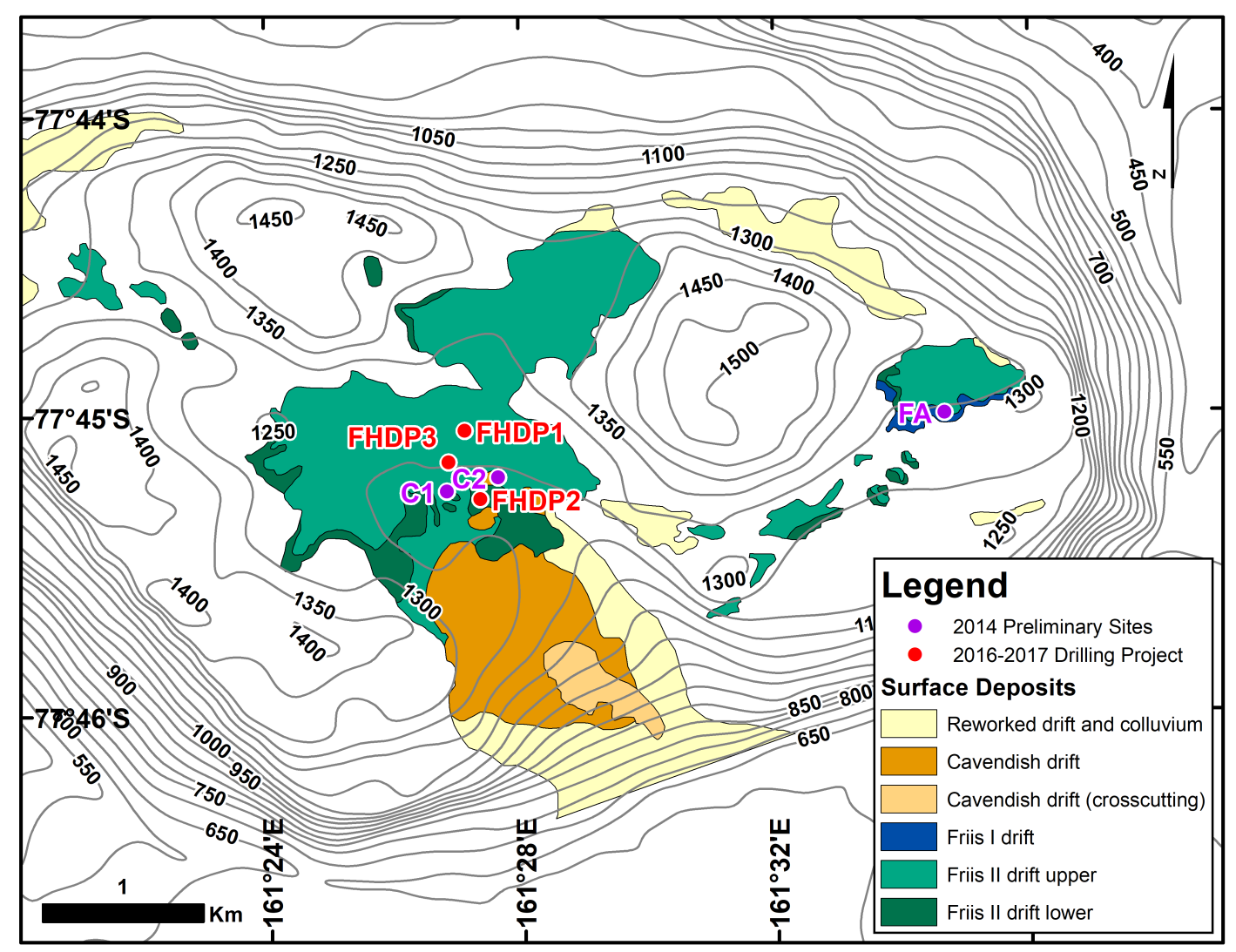

Fig. 2.5 Surficial geology map of Friis Hills (modified from Lewis and Ashworth, 2015) and sampling/drilling sites from the 2016-17 Friis Hills Drilling Project

\subsubsection{Geomorphic investigations: Lewis and Ashworth (2015)}

Lewis and Ashworth (2015) conducted an extensive study on mid-Miocene landscape evolution in the Friis Hills and identified five phases: (1) the early alpine phase, (2) the late 
alpine phase, (3) the transitional phase, (4) the ice sheet phase and (5) the ice sheet reduction phase (Fig. 2.6). These different phases were inferred through the lithology, sedimentology and ice-flow direction of three units within a $34 \mathrm{~m}$ thick sediment sequence: (1) the Friis I drift, (2) the Friis II drift and (3) the Cavendish drift (Fig. 2.5). They first constrained the age of Friis Hills using large-scale regional stratigraphy. They established that Friis Hills had a morphologically similar, and therefore synchronous, erosional phase to other areas in the MDV due to extensive glaciation between 13.6-12.4 Ma (Marchant et al., 1993a, Lewis et al., 2006, 2007). This erosional surface situated below the Cavendish Drift, indicates that the Friis I and Friis II drifts are older than this erosional phase, whereas the Cavendish drift is younger. Additionally, they found a tephra layer in the Friis I deposit dated at 19.9 Ma, providing a maximum age for all underlying deposits. They also reported an assemblage of Nothofagus pollen in fossiliferous beds of Friis Hills similar to that reported in the early Miocene-age section of CRP-1 (Cape Roberts Projects; Raine, 1998) and that had not been recorded in MDV terrestrial deposits younger than 14 Ma.

Only present on the most eastern part of Friis Hills, the Friis I drift consists of a lower (1.8 $\mathrm{m}$ ) and upper (2.5 m) matrix-supported diamict, separated by a horizon of fluvio-lacustrine interbedded mud, sand and gravel (Lewis and Ashworth, 2015). As previously noted, a tephra within the drift was ${ }^{40} \mathrm{Ar} /{ }^{39} \mathrm{Ar}$ dated at $19.76 \mathrm{Ma}$ (Lewis and Ashworth, 2015). The drift, which overlays a polished and striated basement, also contains locally derived faceted and striated clasts of dolerite, sandstone and granite. This drift is interpreted as lodgment till, which was deposited by wet-based alpine glaciers cutting the shallow valleys, which flowed southwest during an early alpine glacial phase ( 19 Ma; Fig. 2.6).

The lower Friis II unit consists of a succession of dolerite-dominated diamicts, deposited over at least five episodes of glaciation, with interbeds of fine-grained fossiliferous lacustrine and fluvial sediments (Lewis and Ashworth, 2015). The scattered fossiliferous beds and lenses could be associated with small ponds and bogs that strewed the landscape during ice-free periods (Lewis and Ashworth, 2015). The fossil assemblage, notably the presence of Nothofagus, of these beds and its modern equivalent indicate a MSAT of $6-7^{\circ} \mathrm{C}$ and precipitation up to $3000 \mathrm{~mm}$ (Lewis and Ashworth, 2015). Lewis and Ashworth (2015) describe this as the late alpine glacial phase, where wet-based glacier ice and small streams flowed southeastward in major valley cuts (Fig. 2.6). These environmental conditions indicate that the deposition of the Friis II drift occurred before the MMCT, approximately 14.1 Ma.

The upper Friis II drift marks a transitional phase and differs from the lower Friis II unit in respect to clast lithology, sedimentology and fossil content of non-glacial interbeds. 


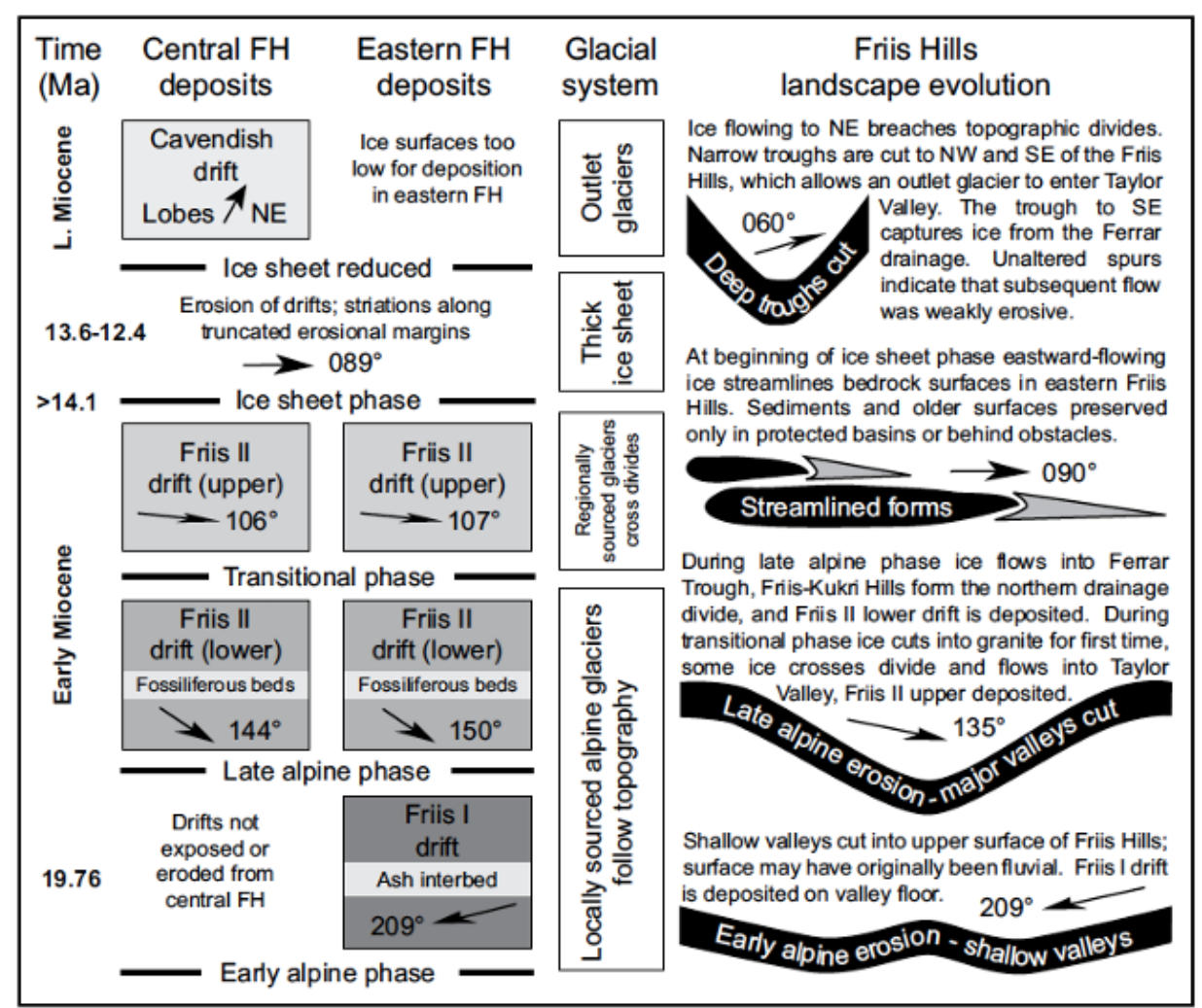

Fig. 2.6 Mid-Miocene chronological sequence of glacial events and associated deposits in Friis Hills (Lewis and Ashworth, 2015)

The upper Friis II is characterized by the presence of regionally sourced clasts of siltstone, rounded quartzite pebbles and granite in a loose gravelly muddy-sand matrix (Lewis and Ashworth, 2015). Interbeds of silt, sand and gravel often show a coarsening-upward sequence and record ice-free conditions, that probably formed in subaqueous fans in ice proximal lakes (Fig. 2.6). During this phase, the ice would have breached a topographic divide through Pearse Valley and flowed into Taylor Valley.

The Cavendish drift, which occurs only along the southern margin of the central Friis Hills, is composed of 1 to $6 \mathrm{~m}$ thick massive diamicts, with dolerite, granite and sandstone clasts. This drift is non-fossiliferous and lacks evidence of water transport, which indicates a shift to a cold-based glaciation. Based on the orientation of ridges on the eastern portion of the inselberg, Lewis and Ashworth (2015) suggest that the ice streamlined the bedrock surfaces of eastern Friis Hills in an eastward direction during the development of the ice sheet phase (Fig. 2.6).

Overall, Lewis and Ashworth (2015) describe a sequence of at least nine cycles of glacial advances and retreats during the early to mid-Miocene. The assemblage of glacial drifts 
Table 2.1 Geographic coordinates and elevation of preliminary sampling sites (2014) and drilling sites (2016-17) at Friis Hills.

\begin{tabular}{|c|c|c|}
\hline Site & Coordinates & Elevation (m a.s.l.) \\
\hline \multicolumn{3}{|c|}{2014 Preliminary Sampling Sites } \\
\hline $\mathrm{C} 1$ & $161^{\circ} 26^{\prime} 49.098^{\prime \prime E}, 77^{\circ} 45^{\prime} 15.467^{\prime \prime S}$ & 1241 \\
\hline $\mathrm{C} 2$ & $161^{\circ} 27^{\prime} 37.555^{\prime \prime E}, 77^{\circ} 45^{\prime} 12.737^{\prime \prime S}$ & 1245 \\
\hline FA & 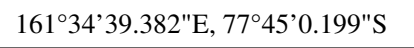 & 1294 \\
\hline \multicolumn{3}{|c|}{ 2016-17 Friis Hills Drilling Project } \\
\hline FHDP1 & $161^{\circ} 26^{\prime} 57.646^{\prime \prime E}, 77^{\circ} 45^{\prime} 2.681^{\prime \prime S}$ & 1259 \\
\hline FHDP2 & $161^{\circ} 27^{\prime} 20.632^{\prime \prime E}, 77^{\circ} 45^{\prime} 17.028^{\prime \prime S}$ & 1244 \\
\hline FHDP3 & $161^{\circ} 26^{\prime} 46.439^{\prime \prime E}, 77^{\circ} 45^{\prime} 8.587^{\prime \prime S}$ & 1252 \\
\hline
\end{tabular}

registers multiple stages in the evolution of the East Antarctic cryosphere and reorganization of glacial system at Friis Hills. The fossil assemblage, composed of pollen and plant cuticles, found within interglacial deposits is indicative of a considerably warmer and wetter climate typically found in modern temperate alpine environments.

\subsubsection{Stratigraphy of the 2016 Friis Hills Drilling Project}

Three drilling sites were chosen based on a seismic survey conducted in November 2014 with the objective of recovering a complete $50 \mathrm{~m}$ deep stratigraphic sequence (72\% recovery). Sites were numbered FHDP1, FHDP2 and FHDP3 with a suffix A, B and C at sites where more than one hole were drilled (Fig. 2.5 and Table 2.1). Overall, five successful cores were drilled: FHDP1A, FHDP1B, FHDP2A, FHDP2C, FHDP3A. The cores reveal a succession of sedimentary facies consisting of subglacial (e.g. diamictites), fluvial-deltaic (e.g. interstratified, graded or cross-stratified sandstones and/or mudstones) and ice-distal lacustrine environments (e.g. massive mudstones; Chorley et al., in review). The sediment cores retrieved ranged from 15.10-13.95 Ma, based on magnetostratigraphy constrained by the radiometric ages of two tephras (Fig. 2.7; Chorley et al., in review). The ${ }^{40} \mathrm{Ar} /{ }^{39} \mathrm{Ar}$ dating of a tephra found at the base of core FHDP2C (5.15 m; and at $5.60 \mathrm{~m}$ in FHDP2A) and at $27.2 \mathrm{~m}$ depth in FHDP3A provide ages of $14.4 \pm 0.01 \mathrm{Ma}$ and $15.08 \pm 0.04 \mathrm{Ma}$, respectively (Fig. 2.7; Chorley et al., in review). These ages are within the range of the Friis II drift from Lewis and Ashworth (2015). The Friis I drift, which corresponds to the early Miocene period, is absent from the central basin, where the FHDP was undertaken and was therefore not recovered. 
FHDP3A, FHDP2A and FHDP2C are correlated to the lower Friis II drift (15.2-14.6 $\mathrm{Ma})$. A total of 13 vertically stacked glacial-interglacial sedimentary cycles were identified; 8 and a half cycles in FHDP3A and 4 and a half in FHDP2A (Fig. 2.7; Chorley et al., in review). The base of FHDP3A, which is situated directly on the basement, is the oldest section of the sequence and is correlated to magnetozone 3N2 (C5Bn.2n; 15.160-15.032 Ma). The interval from 50.3 to $21.9 \mathrm{~m}$ is associated with C5Bn.1r (15.032-14.870 Ma) and has a sedimentation rate of $16 \mathrm{~cm} \mathrm{kyr}^{-1}$ (Chorley et al., in review). The section from 21.9 to $20.87 \mathrm{~m}$ is correlated to zone $3 \mathrm{~N} 1$ (C5Bn.1n; 14.870-14.775 Ma) and above 20.87 Ma, to 3R1 (C5ADr; 14.775-14.609 Ma). The tephra in FHDP2A and FHDP2C indicates a normal magnetozone $2 \mathrm{~N} 1$, establishing that the section from $\sim 1$ to $4 \mathrm{~m}$ most likely correlates to the lower part of C5ADn $(<14.609 \mathrm{Ma})$. The section between 7 and $10 \mathrm{~m}$ is poorly constrained but the interval from 11.22 to $13.68 \mathrm{~m}$ is correlated to magnetozone 2R1 (C5ADr; 14.775-14.609 Ma). The base of FHDP2A correlates with $15 \mathrm{~m}$ in FHDP3A. The sediment sequence in both FHDP3A and FHDP2A is similar to that described in the lower Friis II drift (Fig. 2.7; Chorley et al., in review).

Chronostratigraphic constraints are sparse within FHDP1A and FHDP1B but based on sedimentological and glaciological characteristics of the diamicts, they are correlated to the upper Friis II drift, and therefore are stratigraphically above FHDP2A and FHDP2C. The base of FHDP1B is assigned to the top of FHDP2A and FHDP2C and the top of the section is correlated to magnetozone $1 \mathrm{~N} 1$ (C5ACn; 14.070 to $13.739 \mathrm{Ma}$ ). Based on sedimentation rates of FHDP3A, FHDP1A is hypothesized to be younger than $\sim 14.25 \mathrm{Ma}$ and older than 13.95 Ma (Fig. 2.7).

Overall, based on the age model, the Friis Hills sequence is discontinuous, with a major disconformity (up to $400 \mathrm{kyr}$ ) between the records from sites FHDP1 and FHDP2 (Fig. 2.7; Chorley et al., in review). The interglacial periods are indicative of a temperate environment with vegetation and flowing water, similar to present-day West Greenland (Fig. 2.8). The diamicts show evidence of a transition to a colder climate and more extensive ice cover across the Friis Hills during glacial episodes between 14.6 and 13.9 Ma.

\subsubsection{Post-depositional uplift}

The TAM range are the highest uplifted continental rift-flank on Earth (up to $4500 \mathrm{~m}$ ) and were formed over three main episodes of rifting from the Early Cretaceous to the Early Cenozoic (Fitzgerald, 2002). While the evidence for uplift in the TAM is unequivocal, the uplift mechanisms and rates are widely disputed. Rising surfaces in the TAM could have 


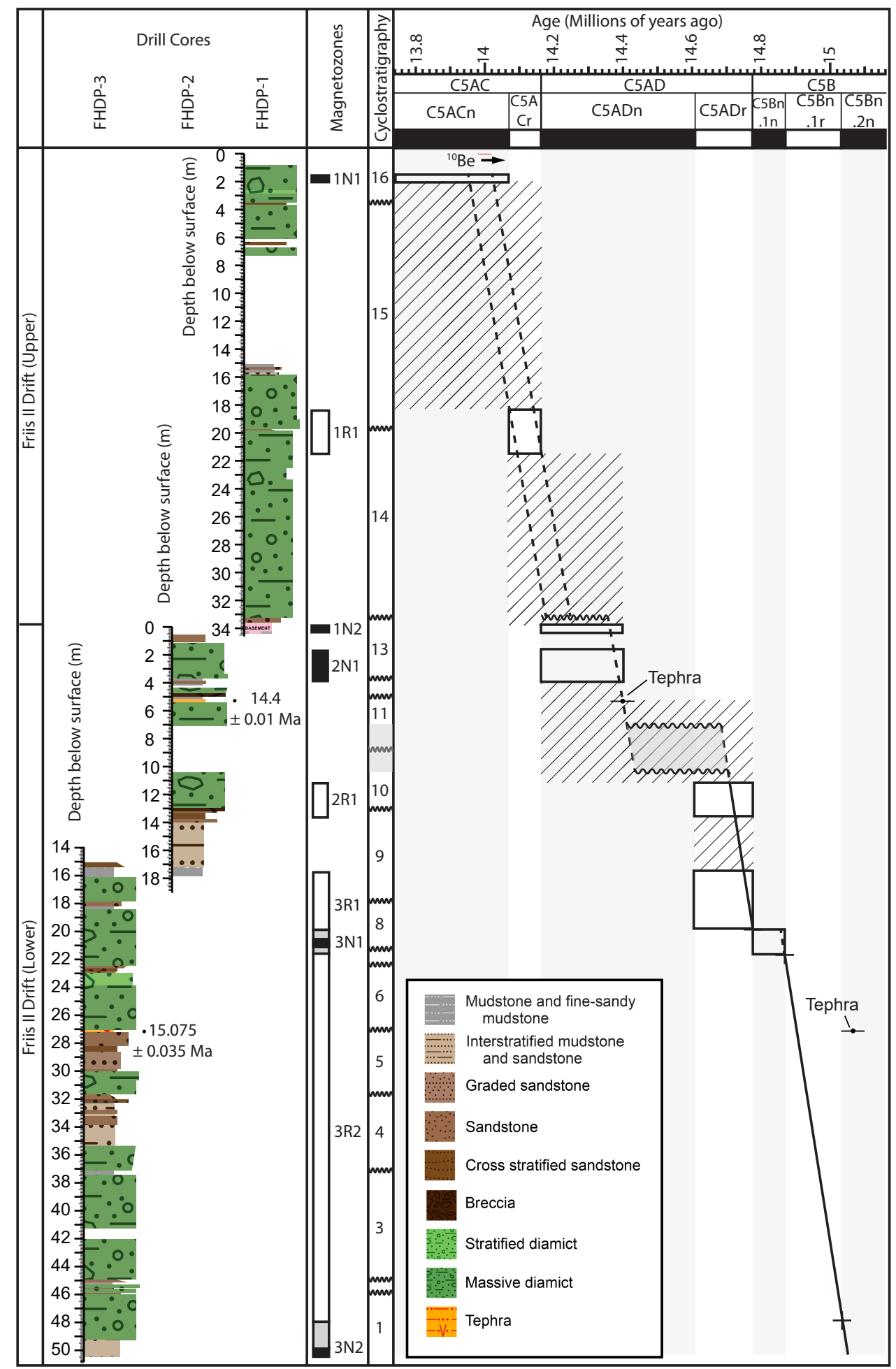

Fig. 2.7 Composite model of the Friis Hills Drilling Project cores compared to Lewis and Ashworth (2015) Friis II drift (Chorley, 2020) 


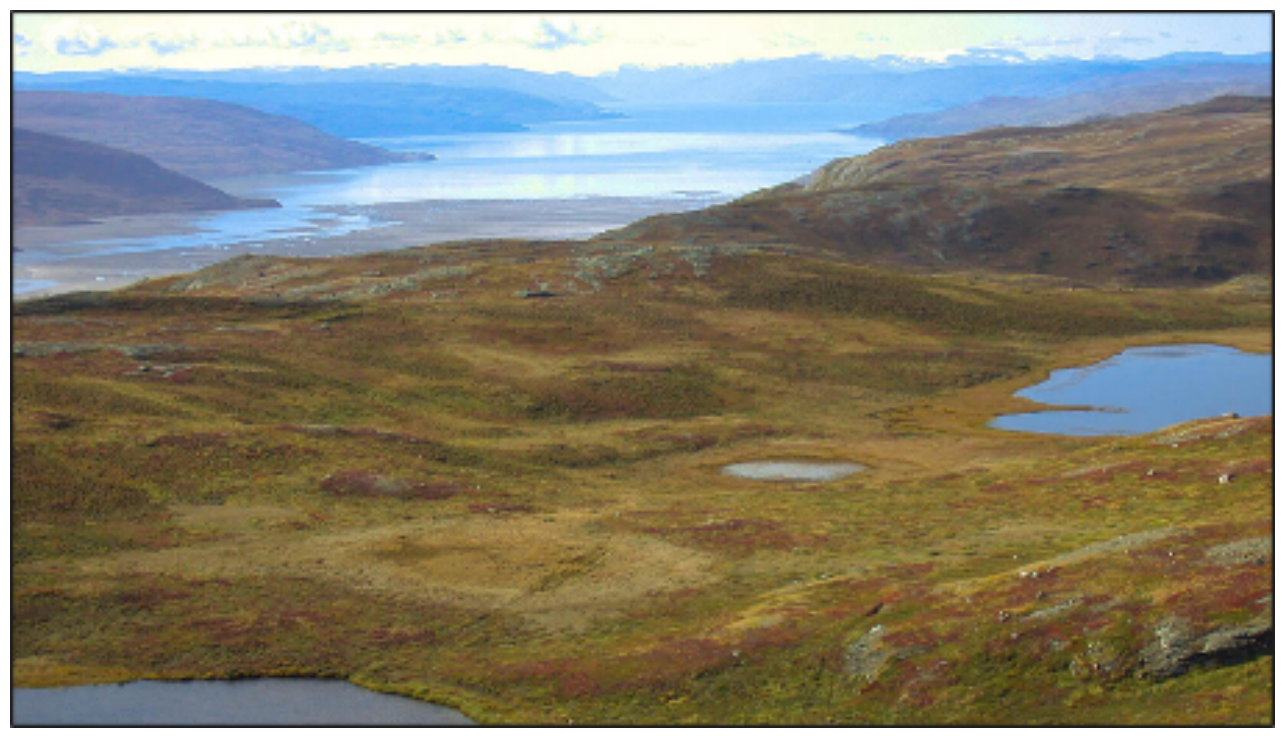

Fig. 2.8 West Greenland as a modern landscape analogue for mid-Miocene interglacial periods at Friis Hills (photo credit: University of Maine)

played a major role in the shift in ice sheet dynamics experienced during the MMCT (e.g. Behrendt and Cooper, 1991, Denton et al., 1993, Sugden et al., 1995) and coupled with changes in atmospheric $\mathrm{CO}_{2}$, participated in the demise of plants in the high elevations of the MDV (e.g. Chorley, 2020).

Early estimates of uplift rates based on fission-track thermochronology suggest that the Friis Hills were near sea level during the time of sediment deposition $\left(\sim 100 \mathrm{~m} \mathrm{Ma}^{-1}\right.$ uplift rate; Fitzgerald, 1992). Conversely, the latest large scale paleotopographic reconstruction based on 3D flexural modelling suggests that the region experienced little to no uplift (100$300 \mathrm{~m}$ ) since the early Miocene (Stern et al., 2005, Paxman et al., 2019). More traditional field-based estimates suggest less than $800 \mathrm{~m}$ surface uplift since the MMCT (e.g. Wilch et al., 1993, Miller et al., 2010) and less than $300 \mathrm{~m}$ since the late Miocene (e.g. Wilch et al., 1993). The uncertainty regarding uplift rates confounds paleoenvironmental reconstructions in the MDV.

\subsection{Modern-day climate, permafrost and ground thermal regime}

The MDV are in a hyper-arid polar desert environment with mean annual air temperatures (MAAT) of $-20^{\circ} \mathrm{C}$ with less than $10 \mathrm{~cm}$ (water equivalent) of precipitation per year (Fig. 2.9). 
The limited snowfall is often displaced to lower valleys by katabatic winds, reaching up to $37.8 \mathrm{~m} \mathrm{~s}^{-1}$, making upper elevations even more deprived of liquid water (Fountain et al., 2010). There are three climatic zones, based on summer climate conditions, in the MDV: (1) the coastal or subxerous zone, where summer temperatures regularly exceed $0^{\circ} \mathrm{C}$ resulting in a phase of seasonal melt, (2) the intermediate, inland or xerous zone, where temperatures may rise above $0^{\circ} \mathrm{C}$ only for short periods resulting in the periodical presence of liquid water and (3) the polar plateau or ultraxerous zone, where maximum air temperatures do not exceed $0^{\circ} \mathrm{C}$ resulting in little or no melting of snow and/or ice (Marchant and Denton, 1996, Marchant and Head III, 2007). Friis Hills are situated within the ultraxerous zone. Modern climatic conditions are extremely cold and arid. The MAAT is $-22^{\circ} \mathrm{C}$ and the MSAT $-13^{\circ} \mathrm{C}$, while the average annual relative humidity $62 \%$, with lows below $16 \%$ registered (Friis Hills Meteorological Station 2011-2015; Fountain and Doran, 2016). The average wind speed at Friis Hills is $4.7 \mathrm{~m} \mathrm{~s}^{-1}$ (Bliss et al., 2011).
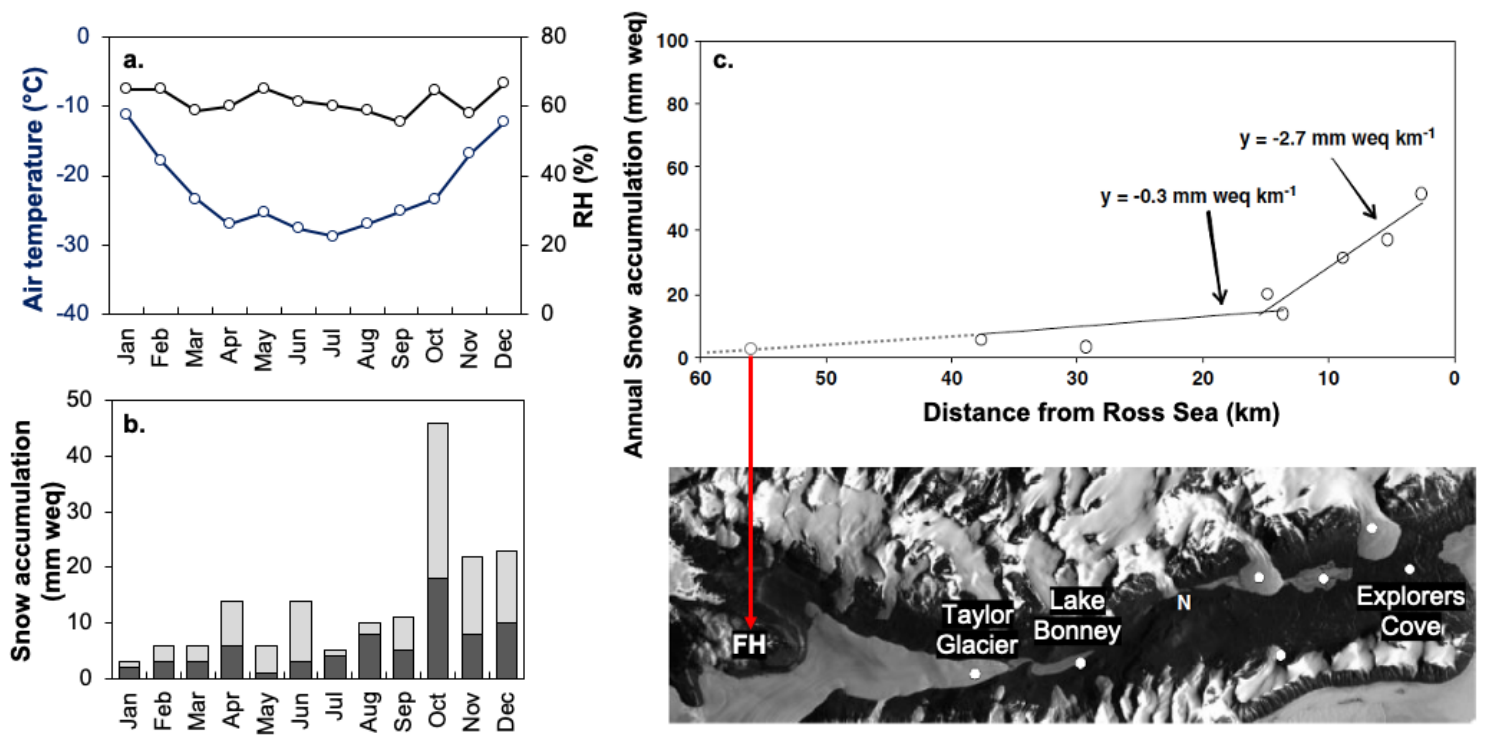

Fig. 2.9 a. Monthly average air temperature and average relative humidity from Friis Hills meteorological station (2011-2015), 7744'50.64'S, 161 $30^{\circ}$ '58.32'E, $1591 \mathrm{~m}$ a.s.l (data from Fountain and Doran, 2016). b. Average monthly snow accumulation at Lake Bonney (1995-2006), $25 \mathrm{~km}$ east of Friis Hills. Light gray is total snow accumulation and dark gray is snow accumulation corrected for katabatic events (data from Fountain et al., 2010) c. Spatial gradient of snow accumulation in Taylor Valley in 2004. Best fit lines extrapolated to location of Friis Hills and shown on Landsat image for horizontal scale (modified from Fountain and Doran, 2016).

Permafrost is defined as ground (i.e. soil and/or rock) that remains at or below $0^{\circ} \mathrm{C}$ for at least two consecutive years (e.g. Harris et al., 1988). There are two types of permafrost in Antarctica: (1) ice-cemented permafrost and (2) dry permafrost (e.g. Campbell and Claridge, 
2006). Dry permafrost is ground that never exceeds $0^{\circ} \mathrm{C}$ but has negligible ice content resulting in a loose and non-cohesive aspect (Bockheim et al., 1998). Dry permafrost is unique to Antarctica, although it is widespread on Mars (Heldmann et al., 2013). Like most high elevations in the MDV, the ice-cemented permafrost at Friis Hills is overlain by a 20-50 cm-thick layer of dry permafrost (Fig. 2.10). The depth of the ice table, which is the transition from dry permafrost to ice-cemented permafrost, is dependant on ambient conditions and vapour exchanges with the atmosphere. The ice table is in equilibrium with modern conditions throughout the MDV (Fisher et al., 2016).
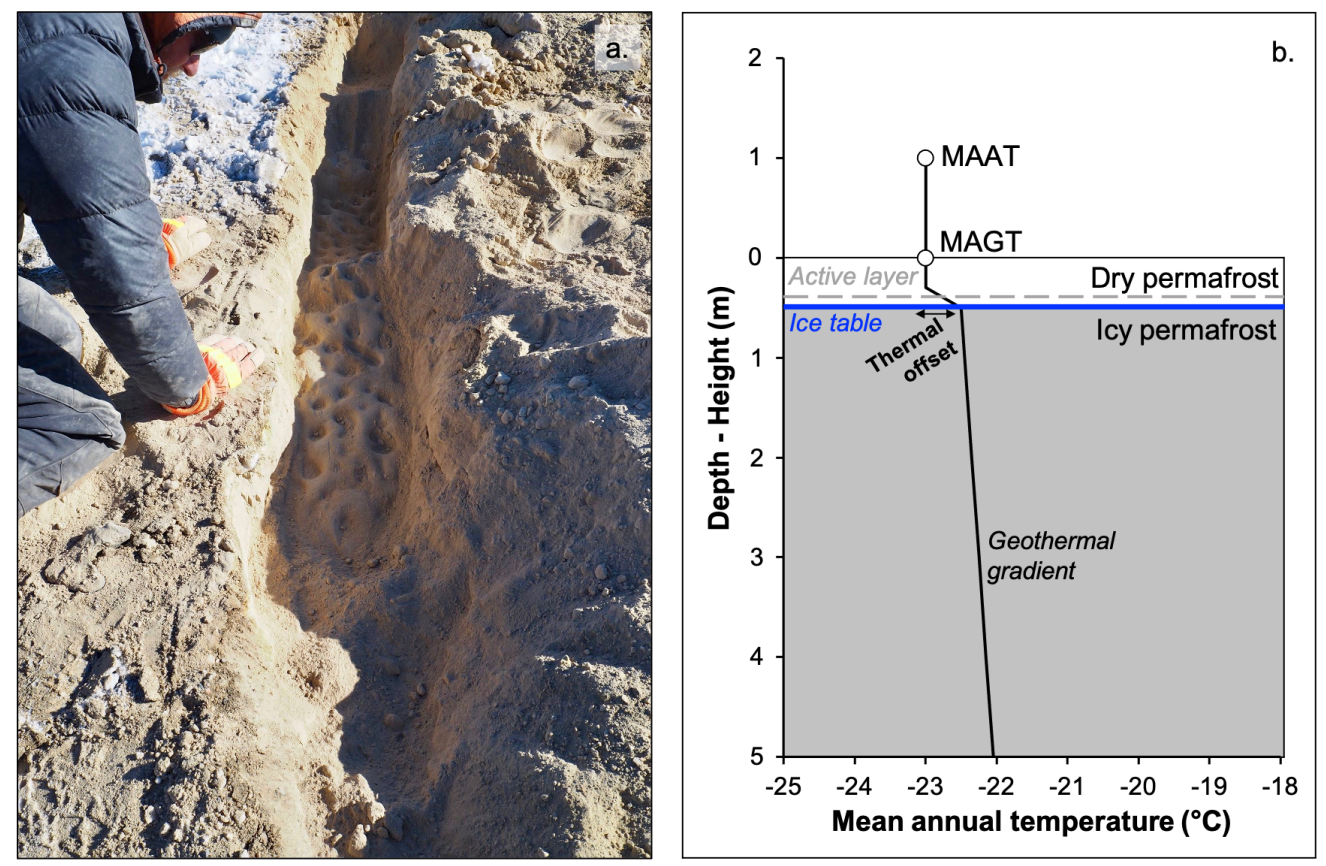

Fig. 2.10 a. Uncovered ice table at Friis Hills, overlain by a $30 \mathrm{~cm}$-thick layer of dry permafrost (photo credit: H. Chorley), b. Schematic mean annual air (MAAT) and ground (MAGT) temperature profile at Friis Hills (adapted from Lacelle et al., 2016). Surface offset between MAAT and MAGT is near $0^{\circ} \mathrm{C}$, but positive thermal offset is observed where ice table depth is $>20 \mathrm{~cm}$, which is the approximate depth of diurnal temperature variation. Ice table marks the transition from dry permafrost to icy permafrost.

In typical periglacial environments, the sediment layer above the ice table that experiences seasonal freezing and thawing is called the active layer (French 2017). In high elevations of the MDV, the active-layer is within the dry permafrost zone $<20 \mathrm{~cm}$ depth (e.g. Hrbáček et al., 2018). In some cases, the active layer is absent altogether where the permafrost doesn't reach $>0{ }^{\circ} \mathrm{C}$ (Bockheim et al., 2007). Thus, although ground surface temperature can be $>0^{\circ} \mathrm{C}$, the term active layer is not relevant in the ultraxerous zone. Permafrost temperatures in the Victoria Land, a region spanning $70^{\circ} 30^{\prime} \mathrm{S}$ to $78^{\circ} 00^{\prime} \mathrm{S}$ which encompasses the MDV, are 
typically between $-14^{\circ} \mathrm{C}$ and $-24^{\circ} \mathrm{C}$; with lowest temperatures occurring in the MDV (Vieira et al., 2010). Measurements of ground temperatures are lacking at Friis Hills, but based on the absence of a surface offset in the upper MDV (Lacelle et al., 2016), the mean annual ground surface temperature (MAGT) should be $\sim-23^{\circ} \mathrm{C}$ (same as MAAT). This can be explained by the fact that unlike Arctic periglacial environments, the MDV surfaces lack vegetation, surface organic layer, snow cover and/or a moist active layer, which typically influence the relationship between air and ground temperatures (Lacelle et al., 2016). Additionally, based on decadal monitoring in a $20 \mathrm{~m}$ deep borehole in Beacon Valley, ground thermal regimes are stable in the MDV (Liu et al., 2018).

\subsection{Modern-day ecology}

The modern terrestrial environment of the MDV is amongst the most inhospitable on Earth. The hyper-arid polar conditions limit the abundance and activity of terrestrial organisms (Hopkins et al., 2009). Respiration, nitrogen mineralization and a substrate-induced responses have been measured under laboratory conditions, while consistent net emissions of $\mathrm{CO}_{2}$ have been measured in situ (Hopkins et al., 2006b). Autochthonous primary production by mosses, lichens, terrestrial cyanobacteria and algae is limited to the low elevations (Friedmann and Ocampo, 1976, Friedmann, 1982, Schwarz et al., 1992, Friedmann et al., 1993, Seppelt and Green, 1998, Pannewitz et al., 2005, Novis et al., 2007). The high elevations lack all types of vascular and cryptogamic vegetation and support exclusively endolithic microbial communities, which grow in the interstitial spaces in fissures rocks, and heterotrophic microbial communities in the sediment (Faucher et al., 2017). The presence of terrestrial heterotrophs can be explained by potential external sources of $\mathrm{C}_{\text {org }}$ and $\mathrm{N}$ such as modern lacustrine cyanobacteria detritus (e.g. Parker et al., 1982, Greenfield, 1997, Elberling et al., 2006, Hopkins et al., 2006a, 2009), marine detritus (Burkins et al., 2000) and paleolake deposits (e.g. Hall et al., 1993, Burkins et al., 2000, Moorhead, 2007, Greenfield et al., 2020). 



\section{Chapter 3}

\section{Organic geochemistry of mid-Miocene permafrost and modern ultraxerous biochemical processes}

As sediments accumulate in periglacial environments, permafrost aggrades incrementally and potentially preserves: (1) sediments, recording geologic conditions; (2) organic material, recording past ecosystems; and (3) ground ice, recording past and present atmospheric and ground conditions (Murton et al., 2017). Permafrost cores dating back to the early Pleistocene have been widely used for paleoenvironmental reconstructions in unglaciated terrain of the Arctic such as northeast Siberia, central and northern Alaska and northwest Canada (e.g. Matsumoto et al., 1995, Sher, 1997, Sher et al., 2005, Lenz et al., 2016, Murton et al., 2015, 2017). In Antarctica, the earliest and most extensive permafrost record is from the Dry Valley Drilling Project (DVDP). From 1971 to 1976, 15 boreholes were drilled in Taylor, Wright and Victoria valleys, as deep as $380 \mathrm{~m}$ (Fig. 3.1; McGinnis, 1981, Torii, 1981). The DVDP cores revealed a highly varied sequence of ice-cemented sands, silts, gravels and diamicts. They provided the first on-land chronology of Antarctica dating back to the Pliocene, using a permafrost proxy (Stuiver et al., 1976). From 1980 to 1984, thirteen additional cores, were drilled in eastern Taylor Valley as part of the Eastern Taylor Valley Drilling Project (ETV) to answer questions that arose following the DVDP (Fig. 3.1; Elston and Bressler, 1981, Elston et al., 1983).

In the 1990s, the COMRAC (Coring for microbial records of Antarctic climate) project investigated organic material and microbial communities preserved in permafrost as indicators of past climates from terrestrial paleoenvironments. Along with sites in Taylor and Miers 
valleys, which dated back to the Pleistocene, cores retrieved from Mount Feather dated back to the late Miocene (Wilson et al., 2002). Following these early efforts, a series of small-scale drilling projects were undertaken throughout the McMurdo Dry Valleys (MDV), mostly in Pliocene to Holocene-age sediments (e.g. VV2010, TV2013, UVP 1-12), but also in Miocene-age sediments such as in Table Mountain (TM97/00). Both the Mount Feather and Table Mountain cores, along with a series of shallow pits and outcrops in the Olympus and Asgard Ranges, showed that the high elevations of the MDV contained a unique terrestrial record preserved in permafrost, which enable paleoenvironmental reconstructions dating back to the mid-Miocene.

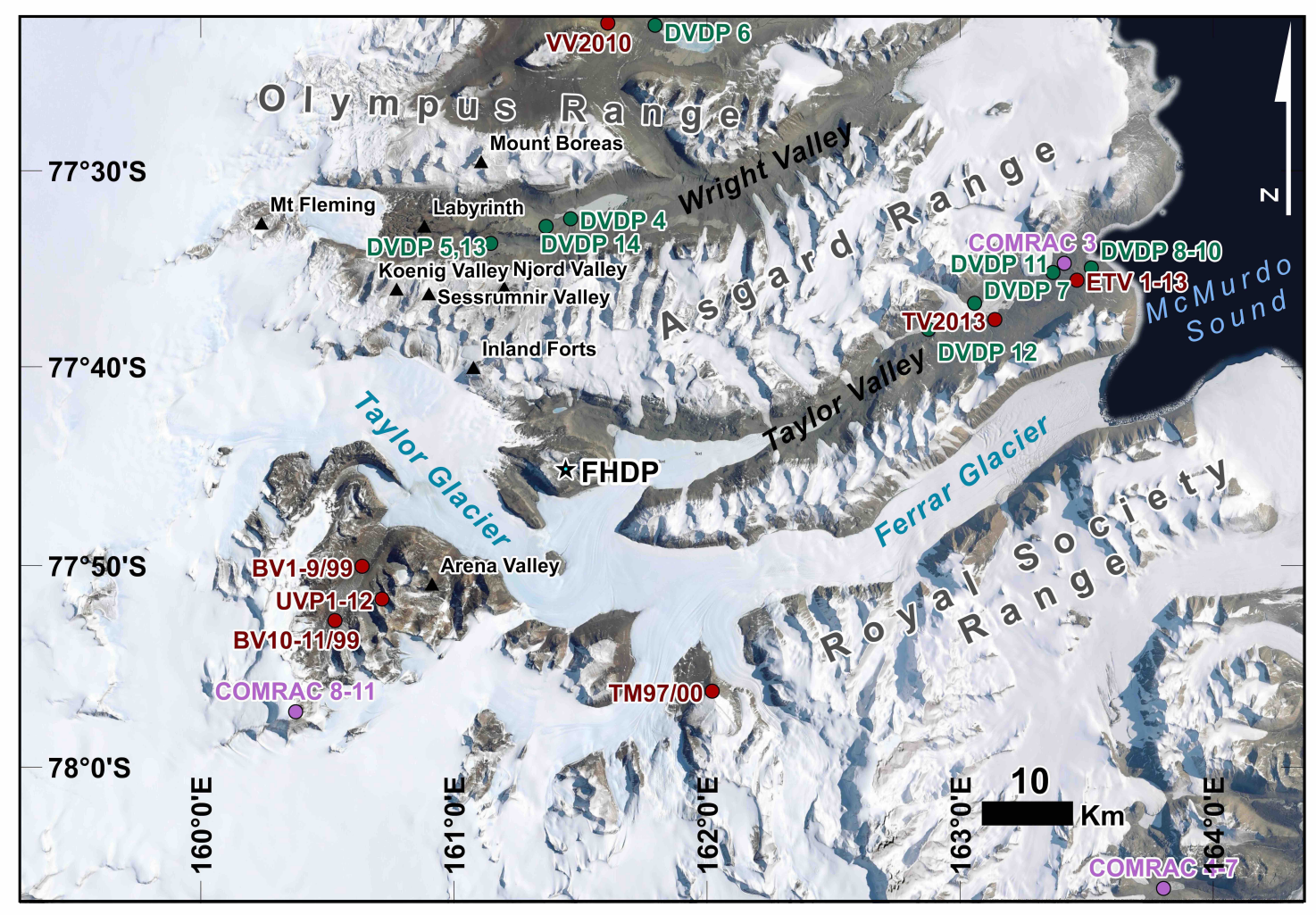

Fig. 3.1 Location of boreholes (circles) in the McMurdo Dry Valleys, Antarctica: DVDP 4-14 drill sites in green (McGinnis, 1981), COMRAC 3-11 drill sites in mauve (Wilson et al., 1996, 2002) and other drill sites in red: BV1-11/99 (e.g. Gilichinsky et al., 2007b); VV2010 (Hagedorn et al., 2010), TV2013 (Toner and Sletten, 2013); ETV 1-13 (Elston and Bressler, 1981, Elston et al., 1983); UVP 1-12 (Lapalme et al., 2017a, Faucher et al., 2017) and TM97/00 (Goff et al., 2002, Dickinson and Rosen, 2003, Dickinson et al., 2012). Shallow pits and outcrops of mid-Miocene age (black triangles; Marchant et al., 1993a, Lewis et al., 2007, 2008, Bockheim and Ackert Jr, 2007). Friis Hills Drilling Project (FHDP) represented with star. 
Surficial deposits at Friis Hills consist of a $\sim 50 \mathrm{~m}$ thick sequence of glacial drifts interbedded with lacustrine sediments, originating from the advance and retreat of a local alpine glacial system connected to the East Antarctic Ice Sheet (EAIS) during the midMiocene. This chapter focuses on the sediment and organic material preserved in core FHDP2C, a $5 \mathrm{~m}$ ice-cemented permafrost core retrieved during the 2016-17 Friis Hills Drilling Project (FHDP). The main objective is to use sediment and organic geochemistry to characterize the mid-Miocene terrestrial paleoenvironment juxtaposed against the modern ultraxerous environment. The ultraxerous environment presents an unprecedented opportunity to document provenance and cycling of organic matter over million-year timescales along with modern processes. Microbial cells dating back to the age of the permafrost have been documented in the Arctic ( $\sim 3 \mathrm{Ma}$; Gilichinsky et al., 2008) and in Antarctica ( $~ 5 \mathrm{Ma}$, COMRAC 8 Mount Feather; Gilichinsky et al., 2007b). As the only lifeform to retain viability over geological timescales, the thawing of mid-Miocene permafrost could reactivate physiological activity of these ancient organisms and expose them to modern ecosystems.

\subsection{Provenance and cycling of organic carbon in the Mc- Murdo Dry Valleys}

Numerous studies describe the presence of microbial metabolic activities in sub-zero temperatures (e.g. Mazur, 1980, Russell, 1990, Finegold, 1996), notably in permafrost at temperatures $>-10^{\circ} \mathrm{C}$, at concentration ranging from $10^{5}$ to $10^{6}$ cells $\mathrm{g}^{-1}$ (Gilichinsky et al., 1995, 2007b, 2008). A number of studies have observed active metabolism from psychrophiles (i.e. extremophile organisms capable of growth and reproduction in low temperatures) under frozen conditions in the Antarctic permafrost of Taylor Valley (e.g. Gilichinsky et al., 2007b, Barrett et al., 2008, Bakermans et al., 2014, Ball and Levy, 2015), Pearse Valley (e.g. Chan-Yam et al., 2019), Miers Valley (e.g. Gilichinsky et al., 2007b, Niederberger et al., 2015b, Vishnivetskaya et al., 2018), Beacon Valley (e.g. Cary et al., 2010) and Garwood Valley (e.g. Elberling et al., 2006, Bate et al., 2008, Fig. 3.1). Ultraxerous environments, such as University and Beacon valleys, are dominated by actinobacterial C-fixers, while subxerous environments, such Taylor and Miers valleys, sustain a more diverse community, dominated by cyanobacteria (Niederberger et al., 2015a). Actinobacteria and cyanobacteria are the most abundant heterotrophic and autotrophic phyla, respectively (e.g. Rego et al., 2019).

Accumulation of organic matter occurs in the MDV despite the limited microbial activity due to the extreme cold and dry climate (Burkins et al., 2000). Soil microbial activity, 
biomass and community diversity depend on the availability of liquid water, temperature, soil $\mathrm{pH}$ and other physical and chemical factors such as conductivity, nitrogen and carbon supply (Dennis et al., 2013). Results of a recent study on microbial communities in Taylor Valley suggest that nutrients (namely nitrogen and carbon) are the main limiting factors for biosynthesis and that water availability alone does not have lasting impacts on microbial communities (Aanderud et al., 2018).

Nitrogen is delivered to the high elevations of the MDV through atmospheric deposition (e.g. Wada et al., 1981, Cary et al., 2010, Michalski et al., 2005). Rates of delivery range from $0.55 \mathrm{mg} \mathrm{NO}_{3}{ }^{-} \mathrm{m}^{-2} \mathrm{yr}^{-1}$ (deposition rates of low accumulation glaciers in the MDV since 1948, based on snow pits; Witherow et al., 2006) to $3.6 \mathrm{mg} \mathrm{NO}_{3}{ }^{-} \mathrm{m}^{-2} \mathrm{yr}^{-1}$ (deposition rate in the University Valley measured over a two-year period 2010-2012; Jackson et al., 2016). Endolithic and hypolithic cyanobacteria also participate in $\mathrm{N}_{2}$ fixation over millions of years, at rates estimated around $0.38 \mathrm{~kg} \mathrm{~N} \mathrm{yr}^{-1}$ in Miers Valley $(11 \mathrm{~km}$ in length and between 1.5 and $2.5 \mathrm{~km}$ wide; Cowan et al., 2011).

Carbon supply and delivery, however, remain enigmatic. Soil organic carbon (SOC) concentrations in bulk sediment typically do not exceed $1.0 \mathrm{mg} \mathrm{g}^{-1}$, especially in the ultraxerous zones (Table 3.1). There are four hypothesized sources of carbon in the ultraxerous soils: (1) legacy deposits of ancient lake sediments; (2) eolian-transported input from higher productivity sites; (3) atmospheric deposition (e.g. Legrand et al., 2013, Antony et al., 2014, Iavorivska et al., 2016); and (4) in situ $\mathrm{CO}_{2}$ fixation (e.g. Matsumoto et al., 1990, Burkins et al., 2000, Elberling et al., 2006).

The concept of ecological legacy has been extensively developed by Burkins et al. (2000, 2001), who suggested that the stable isotope composition of soil organic matter (SOM) in Antarctica was strongly influenced by the sediment record. Their study found that low elevation soils had a stable isotope signature resembling lacustrine sediments and microbial mats, while in higher elevations, the signature resembled that of endolithic communities. They used the natural abundance of $\delta^{13} \mathrm{C}$ and $\delta^{15} \mathrm{~N}$ to identify five isotopic signature fields (Fig. 3.2): marine-derived organic matter (MDOM), lacustrine-derived organic matter (LDOM), endolith-derived organic matter (EDOM), coal and ornithogenic organic matter (OOM). Unlike in the low elevation valleys, where SOM reflects past hydrological changes (i.e. paleolakes, changes in lake extent, ephemeral streams, etc.; e.g. Burkins et al., 2000, 2001, Hopkins et al., 2009), the SOM in the high elevations of the MDV needs to be explained by other processes. Estimates of carbon turnover time in the MDV range from a few decades to about 150 years, suggesting that legacy carbon is a minor contributor to modern carbon cycling (e.g. Barrett et al., 2006, Elberling et al., 2006, Hopkins et al., 2009). 
Table 3.1 Mean or range of SOC, N, C:N, $\delta^{13} \mathrm{C}$ and $\delta^{15} \mathrm{~N}$ concentrations in various sites in the MDV (TV: Taylor Valley, WV: Wright Valley, GV: Garwood Valley, EA: East Antarctica)

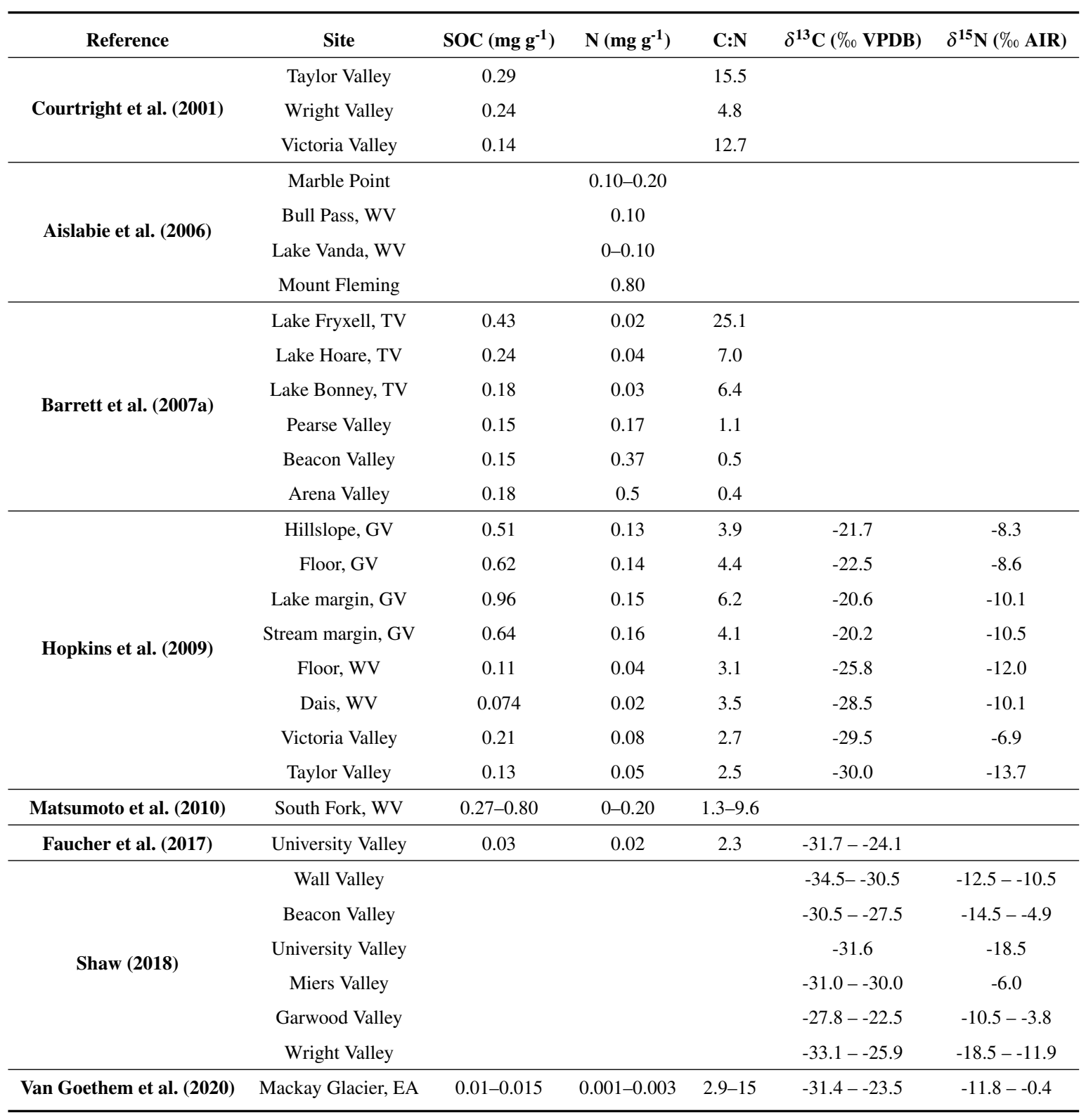




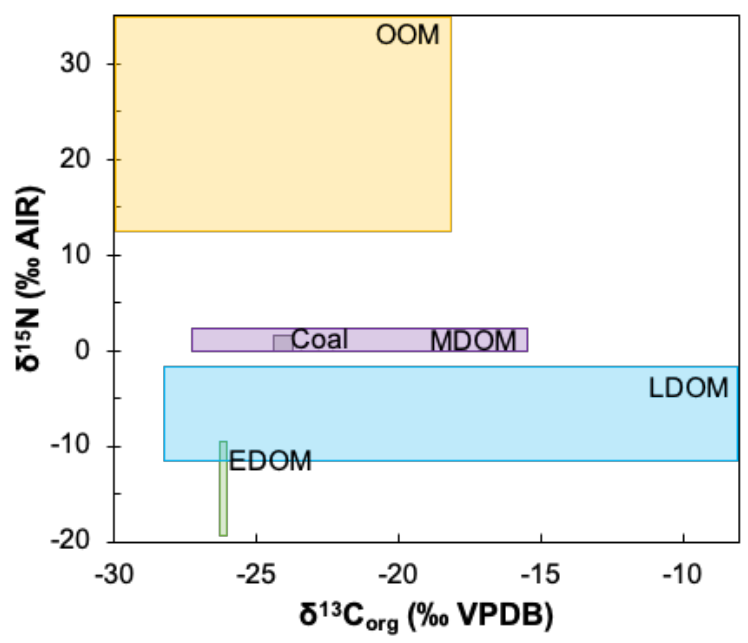

Fig. 3.2 Mean $\delta^{13} \mathrm{C}$ and $\delta^{15} \mathrm{~N}$ for potential soil organic matter sources in the MDV, based on the concept of ecological legacy: marine-derived organic matter (MDOM), lacustrine-derived organic matter (LDOM), endolith-derived organic matter (EDOM), coal and ornithogenic organic matter (OOM). Data from Burkins et al. (2000).

Eolian transport has also been estimated to be an insignificant method of carbon delivery (0.01-7 $\mathrm{g} \mathrm{C} \mathrm{m}^{-2} \mathrm{yr}^{-1}$ ) and relies heavily on the close proximity to lake systems (e.g. Lancaster, 2002, Barrett et al., 2006). The recent discovery of unique, genetically localized microbial communities between valleys also indicates that communities are endemic and that intervalley migrations are negligible (Lee et al., 2012). Atmospheric deposition of organic carbon is estimated $<5 \mathrm{mg} \mathrm{C} \mathrm{m}^{-2} \mathrm{yr}^{-1}$ in Commonwealth Glacier snow, a glacier $\sim 10 \mathrm{~km}$ inland from the Ross Sea in Taylor Valley, and is one of the lowest values measured on Earth (Lyons et al., 2007).

Contemporary sources of carbon sustaining carbon cycling in the MDV remain poorly documented. In situ $\mathrm{CO}_{2}$-fixation through primary productivity seems to be the most consistent source of carbon in ultraxerous zones (e.g. Parsons et al., 2004, Hopkins et al., 2009, Feng et al., 2010), but estimates of carbon fixation are extremely low, ranging from 1-20 $\mathrm{g} \mathrm{C} \mathrm{m}^{-2} \mathrm{yr}^{-1}$ (e.g. Friedmann et al., 1993, Novis et al., 2007, Cary et al., 2010), while the directly measured rate falls below detection limit $\left(\sim 12 \mathrm{nmol} \mathrm{C} \mathrm{cm}{ }^{-3} \mathrm{~h}^{-1}\right.$; Niederberger et al., 2015a). In University Valley (1700 m a.s.1.), microbial activity under ambient conditions was undetectable (Goordial et al., 2016).

A simple way to understand nutrient constraints on biogeochemical processes is to use ecological stoichiometry, particularly $\mathrm{C}: \mathrm{N}$ ratios. Ecological stoichiometry was initially developed in aquatic ecosystems (Redfield Ratio C:N:P = 106:16:1; Redfield, 1958), but has since been applied to terrestrial ecosystems (e.g. Sardans et al., 2012), particularly in 
the MDV to evaluate if conditions are favourable for metabolism of bacteria (e.g. Barrett et al., 2006, Faucher et al., 2017, Faucher, 2017, Aanderud et al., 2018). Recent analyses suggest well-constrained Redfield-like ratios for terrestrial ecosystems, particularly soil $(\mathrm{C}: \mathrm{N}: \mathrm{P}=186: 13: 1)$ and soil microbial biomass $(\mathrm{C}: \mathrm{N}: \mathrm{P}=60: 7: 1$; Cleveland and Liptzin, 2007). Ecological stoichiometry and $\delta^{13} \mathrm{C}$ and $\delta^{15} \mathrm{~N}$ signatures of bulk sediment are used in this thesis to differentiate between mid-Miocene organic matter and modern processes.

\subsection{Methods}

\subsubsection{Core description and sampling}

Lithological descriptions were undertaken in the field and cross-checked on the frozen core prior to sampling (GNS Science National Ice Core Facility, New Zealand). Lithological descriptions followed the same format as Chorley et al., (in review) and were based on definitions established for the Cape Roberts Project and ANDRILL Programme (Hambrey, 1997, McKay et al., 2009) and terrestrial glacial environments (e.g. James and Walker, 1992, van der Meer and Menzies, 2011). The facies attribution was based on lithology, sedimentary structures, texture, clast abundance, deformation features, fossil content, colour and nature of contact with underlying beds. The core was sub-sampled at $2-5 \mathrm{~cm}$ intervals for a total of 105 samples using a Tooline tile cutter with a $2.2 \mathrm{~mm}$ blade and placed into polyethylene bags to thaw. The surface, or dry permafrost layer, was sampled in the field at $5 \mathrm{~cm}$ intervals to the top of the ice table. All sampled were dried at $80^{\circ} \mathrm{C}$ for $24 \mathrm{~h}$ (water was retrieved prior to drying; described in Chapter 4). Munsell colour was determined on dried samples. Each sample was subdivided into subsamples for grain-size, $x$-ray fluorescence (XRF), diatom and macrofragment counts, loss on ignition (LOI), carbon-nitrogen analyses, and for ${ }^{10} \mathrm{Be}_{\text {met }}$ leaching (described in Chapter 5).

\subsubsection{Grain-size and XRF analyses}

The dried samples underwent a grain-size analysis to confirm the qualitative attribution of sedimentological facies. The samples were passed through a $2 \mathrm{~mm}$ sieve and the coarser fraction was excluded from the analysis. Sample pre-treatment consisted of placing a $0.01-1$ $\mathrm{g}$ subsample of sediment (depending on grain-size) in $50 \mathrm{ml}$ centrifuge tubes. Organic material digestion was made by adding $15 \mathrm{ml}$ of $27 \%$ hydrogen peroxide $\left(\mathrm{H}_{2} \mathrm{O}_{2}\right)$, heating up the reaction in a $70^{\circ} \mathrm{C}$ water bath and making sure the sample reached a neutral $\mathrm{pH}$. The 
remaining mineral sediment samples were mixed with a 5\% hexametaphosphate solution to disperse the particles and sonicated for 30 minutes. Duplicates were analyzed for $5 \%$ of the samples to ensure their replicability. A Beckman-Coulter Ls13-320 laser diffraction particle size analyzer (Sedimentology Laboratory, Victoria University of Wellington) was used to determine the grain size of the mineral components of the samples. The instrument measured particle sizes from 0.02 to $2800 \mu \mathrm{m}$ with a precision of approximately $\pm 1 \%$. Grain size results were analyzed using GRADISTAT v.8 (classification shown in Fig. A.1; Blott and Pye, 2001) and ANOVA statistical tests were conducted in MATLAB R2018a(9.4.0.813654).

$\mathrm{XRF}$ analyses were performed to provide information on the environmental processes and provenance at the time of sediment deposition. The samples were placed in $5 \mathrm{ml}$ plastic vials covered with a $4 \mu \mathrm{m}$ polypropylene film. A handheld M-series Vanta Olympus XRF analyzer (50 KV; School of Geography, Environment and Earth Sciences, Victoria University of Wellington), standardized with a series of 8 certified geochemical reference material (U.S. Geological Survey: AGV-2, BHVO-2, COQ-1, SCO-1, SGR-1 and W-2; Geological Society of Japan: JG-2 and JR-2) was used to identify the elemental composition of the different samples. ANOVA statistical tests were conducted in MATLAB R2018a(9.4.0.813654).

\subsubsection{Bulk organic matter and carbonates}

To provide information on changes in paleoenvironments, the LOI method was used on the sediment samples to determine the content of organic matter and carbonates (Heiri et al., 2001). Approximately 1-3 g of each dry sample was placed in a crucible and inserted in a LECO thermo-gravimetric analyzer with an integrated balance to determine the weight loss of the material (model TGA70; Department of Geography, University of Ottawa). Under ambient air conditions, the analyzer reached $105^{\circ} \mathrm{C}$ to ensure the samples were dry, then rose to $550^{\circ} \mathrm{C}$ to combust the $\mathrm{SOM}$ and finally to $950^{\circ} \mathrm{C}$ to combust the carbonates. The mass of each sample was recorded by the TGA70 at each step, once a mass variation of less than $0.1 \%$ was reached. The SOM and carbonates contents were determined using equations 3.1 and 3.2, respectively (Heiri et al., 2001):

$$
\operatorname{SOM}(\%)=\frac{\left(L O I_{105}-L O I_{550}\right)}{L O I_{105}} \cdot 100
$$




$$
\text { Carbonates }(\%)=\frac{\left(L O I_{550}-L O I_{950}\right)}{L O I_{105}} \cdot 1.36 \cdot 100
$$

where $\mathrm{LOI}_{105}$ represents the mass of the sample after being dried at $105^{\circ} \mathrm{C}, \mathrm{LOI}_{550}$ is the mass after being combusted at $550^{\circ} \mathrm{C}$ and $\mathrm{LOI}_{950}$ is the mass after being combusted at $950^{\circ} \mathrm{C}$. In equation 3.2, the constant 1.36 represents the ratio between the molecular weights of $\mathrm{CO}_{3}$ (60) and $\mathrm{CO}_{2}$ (44) (Bengtsson et al., 1986). To ensure replicability of the experiment, $20 \%$ duplicate samples were also analyzed. A Calcium Oxalate standard was added to each sample run to confirm an analytical precision of $\pm 0.1 \%$.

\subsubsection{Soil organic carbon, total nitrogen, $\delta^{13} \mathrm{C}$ and $\delta^{15} \mathrm{~N}$ isotopes and radiocarbon dating}

The concentration of $\mathrm{C}_{\text {org }}$ and $\mathrm{N}$ within each sample was determined using an Elemental VarioEl Cube instrument (Jan Veizer Laboratory, University of Ottawa). The samples were first acidified with $10 \% \mathrm{HCl}$ to remove calcium carbonate and isolate the organic carbon fraction. $100 \mathrm{mg}$ of material was measured into tin capsules, along with $100 \mathrm{mg}$ of tungstic oxide $\left(\mathrm{WO}_{3}\right)$, a combustion catalyst and binder. Calibrated standards of Sulfanilic acid were prepared in a range of weights and run every 40 samples, to ensure instrument precision. Blank standards were also run for calibration. Approximately $20 \%$ of samples were run as duplicates to ensure of the replicability of the experiment. The capsules were flash combusted at $1800^{\circ} \mathrm{C}$ with the addition of oxygen. The resulting gases were carried through the columns of reducing and oxidizing chemicals by helium to obtain $\mathrm{N}_{2}, \mathrm{CO}_{2}, \mathrm{H}_{2} \mathrm{O}$ and $\mathrm{SO}_{2}$. The resulting gases were separated by trap and purge method and measured with a thermoconductivity detector. The analytical precision for the analysis was $\pm 0.1 \%$. Soil organic carbon density $\left(\mathrm{SOC}_{\mathrm{d}}, \mathrm{kg} \mathrm{m}^{-2}\right.$ ) was calculated using the following equation (Zhi et al., 2014):

$$
S O C_{d}=C \cdot B D \cdot t
$$

where $\mathrm{C}$ is the organic carbon concentration $\left(\mathrm{g} \mathrm{kg}^{-1}\right)$, BD is the bulk density $\left(\mathrm{g} \mathrm{cm}^{-3}\right)$ and $\mathrm{t}$ is the thickness of the soil layer (m). 
A DeltaPlus Advantage isotope ratio mass spectrometer (IRMS) coupled with the ConFlo III interface (Jan Veizer Laboratory, University of Ottawa) was used to calculate $\delta^{13} \mathrm{C}$ and $\delta^{15} \mathrm{~N}$ values in bulk sediment. Sample mass was adjusted depending on nitrogen concentration of samples to obtain approximately $100 \mu \mathrm{g}$ of nitrogen per sample. Samples were placed in tin capsules (with tungstic oxide) and flash combusted at $1800^{\circ} \mathrm{C}$. The resulting gases were carried by helium through columns of reducing and oxidizing chemicals and separated through the "purge and trap" method. The results are expressed in $\delta$ notation, which corresponds to the parts per thousand difference of ${ }^{13} \mathrm{C} /{ }^{12} \mathrm{C}$ with respect to the Vienna Pee-Dee Belemnite (VPDB) standard and ${ }^{15} \mathrm{~N} /{ }^{14} \mathrm{~N}$ with respect to the air (AIR) standard. A large error of $\pm 4 \%$ was attributed to the $\delta^{15} \mathrm{~N}$ results due to the possible effects of the $\mathrm{HCl}$ pre-treatment (Kim et al., 2016), but results are still presented to identify relative trends (variation within sample distribution $>4 \%$ ). Multiple comparison analyses were conducted in MATLAB R2018a(9.4.0.813654).

To understand if biogeochemical processes are active at Friis Hills, a single $\sim 2 \mathrm{~g}$ sample of dry permafrost (2-C0-3; $10 \mathrm{~cm}$ depth) was radiocarbon dated (Rafter Radiocarbon Laboratory, GNS Science). The bulk sediment sample $(<300 \mu \mathrm{m})$ was first acid-treated to remove carbonates and then combusted at $900^{\circ} \mathrm{C}$ for 4 hours in an evacuated, sealed quartz tube with cupric oxide and silver wire. The resulting $\mathrm{CO}_{2}$ was graphitized by reduction with hydrogen over iron catalyst, and measured on an accelerator mass spectrometer. Radiocarbon age was corrected to calendar years (cal year BP) using SHCal20 (Hogg et al., 2020). The median calibrated age is reported with the $2 \sigma$ range in Table 3.5.

\subsubsection{Diatoms and macrofragments}

The work described in this section was performed by M. Harper (diatoms) and A. Homes (macrofragments) (2018-2019; School of Geography, Environment and Earth Sciences, Victoria University of Wellington). Their work is included in this thesis to provide a more comprehensive paleoenvironmental interpretation of the FHDP2C core.

A total of 10 samples, at least one from each sedimentary facies, were examined by M. Harper for diatom content. Non-resistant organic matter was removed from the $(\sim 2$ g) sub-samples using hydrogen peroxide. Samples were then sieved with Nylon cloths to isolate the 6-90 $\mu \mathrm{m}$ fraction for diatom analysis. Aliquots of this material were used to estimate abundance per mg. Samples with low diatom counts were concentrated with sodium polytungstate (specific gravity $2.20 \mathrm{~g} \mathrm{~cm}^{-3}$ ) to separate the biogenic silica from the other mineral matter. Some of the remaining material was rinsed and mounted on permanent 
slides using Naphrax ${ }^{\circledR}$ (refractive index 1.65). Assemblage composition was determined by counting and identifying diatom fragments over $\sim 5 \mu$ under a Leitz Diaplan differential interference contrast microscope at $\times 400$ magnification. Population counts were limited to intact valves and significant remains and population analysis was based on counts of genera (generally sufficient for analysis of supraglacial environments; Yallop et al., 2012) because of the difficulty of making the distinction between various mostly extinct species. The $>90$ $\mu \mathrm{m}$ fraction was placed in a petri-dish with enough distilled $\mathrm{H}_{2} \mathrm{O}$ to create a monolayer of material and examined for macrofragments under a dissecting microscope $(\times 6.4-\times 10)$. A random selection of $>100$ plant cuticles from the petri-dish were mounted on microscope slides with glycerine jelly for identification under optical microscope. Plant cuticles were identified and counted by A. Homes to provide additional information on paleoenvironments.

\subsubsection{Chronological control}

The chronostratigraphy of the FHDP cores is based on magnetostratigraphy constrained by radiometric ages of two tephras and is described in H. Chorley's PhD thesis (2020). The tephra found at the bottom of FHDP2C was ${ }^{40} \mathrm{Ar}{ }^{39} \mathrm{Ar}$ dated at $14.4 \mathrm{Ma}$ whereas the top of the core was correlated to magnetozone 1N1 (C5ACn; 14.070 to $13.739 \mathrm{Ma}$ ); thus the $5 \mathrm{~m}$ core spans a ca. 0.4-0.7 Myr period. A complete description of the chronostratigraphy is available in Chorley (2020).

\subsection{Results}

\subsubsection{Sediment description}

The surficial layer of dry permafrost was $35 \mathrm{~cm}$ thick and consisted of light yellowish-brown ( $2.5 \mathrm{Y} 6 / 4)$ very poorly-sorted sandy-mud composed of $31 \%$ clay, $45 \%$ silt and $24 \%$ sand (Fig. 3.3 and Table 3.2). Unit 1 (35-44 cm) consisted of unimodal poorly-sorted muddy-sand with dispersed clasts, and a median grain-size of $150 \mu \mathrm{m}$. It was composed of 5\% clay, $16 \%$ silt and $79 \%$ sand, was light yellowish-brown $(2.5 \mathrm{Y} 6 / 4)$ and displayed mm-scale laminations. Unit $2(44-55 \mathrm{~cm})$ was also a light yellowish-brown muddy-sand but had a very poorly-sorted polymodal grain size distribution of $13 \%$ clay, $32 \%$ silt and 55\% sand (Fig. 3.3 and Table 3.2). Median grain-size within the unit was $81 \mu \mathrm{m}$. Unit $3(55-65 \mathrm{~cm})$ consisted of a polymodal very poorly-sorted sandy-mud, with a median grain-size of $8 \mu \mathrm{m}$. It was composed of $33 \%$ clay, 54\% silt and $13 \%$ sand and was light gray (2.5Y 7/; Table 3.2). Unit 4 (65-264 cm) was 
40 Organic geochemistry of mid-Miocene permafrost and modern biochemical processes

Table 3.2 Grain-size characteristics and Munsell colour of the stratigraphic units in core FHDP2C

\begin{tabular}{ccccccccc}
\hline Unit & Depth (cm) & Munsell (2.5Y) & Clay (\%) & Silt $(\boldsymbol{\%})$ & Sand $(\boldsymbol{\%})$ & Median $(\boldsymbol{\mu m})$ & Sorting & Modality \\
\hline $\mathbf{D P}$ & $0-35$ & $6 / 4$ & 31 & 45 & 24 & 81 & very poor & polymodal \\
\hline $\mathbf{1}$ & $35-44$ & $6 / 4$ & 5 & 16 & 79 & 150 & poor & unimodal \\
\hline $\mathbf{2}$ & $44-55$ & $6 / 4$ & 13 & 32 & 55 & 81 & very poor & polymodal \\
\hline $\mathbf{3}$ & $55-65$ & $7 / 2$ & 33 & 54 & 13 & 8 & very poor & polymodal \\
\hline $\mathbf{4}$ & $65-264$ & $7 / 2$ & 16 & 46 & 38 & 46 & very poor & polymodal \\
\hline $\mathbf{5}$ & $264-350$ & $7 / 2-6 / 3$ & 27 & 57 & 16 & 12 & very poor & polymodal \\
\hline $\mathbf{6}$ & $350-496$ & $5 / 4$ & 8 & 24 & 68 & 145 & very poor & polymodal \\
\hline $\mathbf{7}$ & $496-513$ & $7 / 2$ & 29 & 59 & 12 & 9 & very poor & polymodal \\
\hline
\end{tabular}

a massive diamict with a very poorly-sorted polymodal matrix varying from sandy-mud to muddy-sand (Fig. 3.3 and Table 3.2). Median grain-size within the light gray matrix was 46 $\mu \mathrm{m}$ and was composed of $16 \%$ clay, $46 \%$ silt and $38 \%$ sand. The clasts, consisting mostly of dolerite and some granite, varied in size from $0.2-15 \mathrm{~cm}$ in diameter (Fig. 3.4). Unit $5(264-350 \mathrm{~cm})$ transitioned from a light-gray very poorly-sorted polymodal muddy-sand diamict into a light yellowish-brown poorly-sorted polymodal mud with median grain-size of $12 \mu \mathrm{m}$ composed of $27 \%$ clay, $57 \%$ silt and $16 \%$ sand (Fig. 3.3 and Table 3.2). The upper part of the unit was highly deformed and sheared with rotational structures (Fig. 3.4). Unit 6 $(350-496 \mathrm{~cm})$ was a second diamict with a light olive brown $(2.5 \mathrm{Y} 5 / 4)$ very poorly-sorted polymodal muddy-sand matrix. The matrix was composed of $8 \%$ clay, $24 \%$ silt and $68 \%$ sand and had a median grain-size of $145 \mu \mathrm{m}$ (Fig. 3.3 and Table 3.2). The clasts within this diamict also consisted mainly of dolerite and varied in size from $0.2-8 \mathrm{~cm}$. Unit 7 (496-513 $\mathrm{cm}$ ) was a light gray very poorly-sorted polymodal sandy-mud with dispersed clasts up to 3 $\mathrm{mm}$, with a distribution of $29 \%$ clay, $59 \%$ silt and $12 \%$ and a median grain-size of $9 \mu \mathrm{m}$ (Fig. 3.3 and Table 3.2). The overall average grain-size distribution of the core consisted of $18 \%$ clay, $45 \%$ silt and $37 \%$ sand with a median of $55 \mu \mathrm{m}$, which varied from poorly-sorted to very poorly-sorted. Unit 7 was underlain by a tephra $(513-518 \mathrm{~cm}$ ) dated $\sim 14.4 \mathrm{Ma}$ (Chorley, 2020).

\subsubsection{Sediment XRF geochemistry}

The dry permafrost layer had the highest concentrations of $\mathrm{Mg}$ (avg. $2.9 \times 10^{4} \mathrm{mg} \mathrm{kg}^{-1}$ ), $\mathrm{Al}$ (avg. $9.7 \times 10^{4} \mathrm{mg} \mathrm{kg}^{-1}$ ), Si (avg. $3.3 \times 10^{5} \mathrm{mg} \mathrm{kg}^{-1}$ ) and $\mathrm{K}$ (avg. $1.5 \times 10^{4} \mathrm{mg} \mathrm{kg}^{-1}$ ). Unit 1 contained the lowest concentrations of $\mathrm{Mg}$ (avg. $0.51 \times 10^{4} \mathrm{mg} \mathrm{kg}^{-1}$ ), $\mathrm{Al}$ (avg. $5.2 \times 10^{4}$ $\mathrm{mg} \mathrm{kg}{ }^{-1}$ ), Ti (avg. $0.22 \times 10^{4} \mathrm{mg} \mathrm{kg}^{-1}$ ), Fe (avg. $2.3 \times 10^{4} \mathrm{mg} \mathrm{kg}^{-1}$ ) and $\mathrm{Sr}\left(\right.$ avg. $91 \mathrm{mg} \mathrm{kg}^{-1}$ ), 


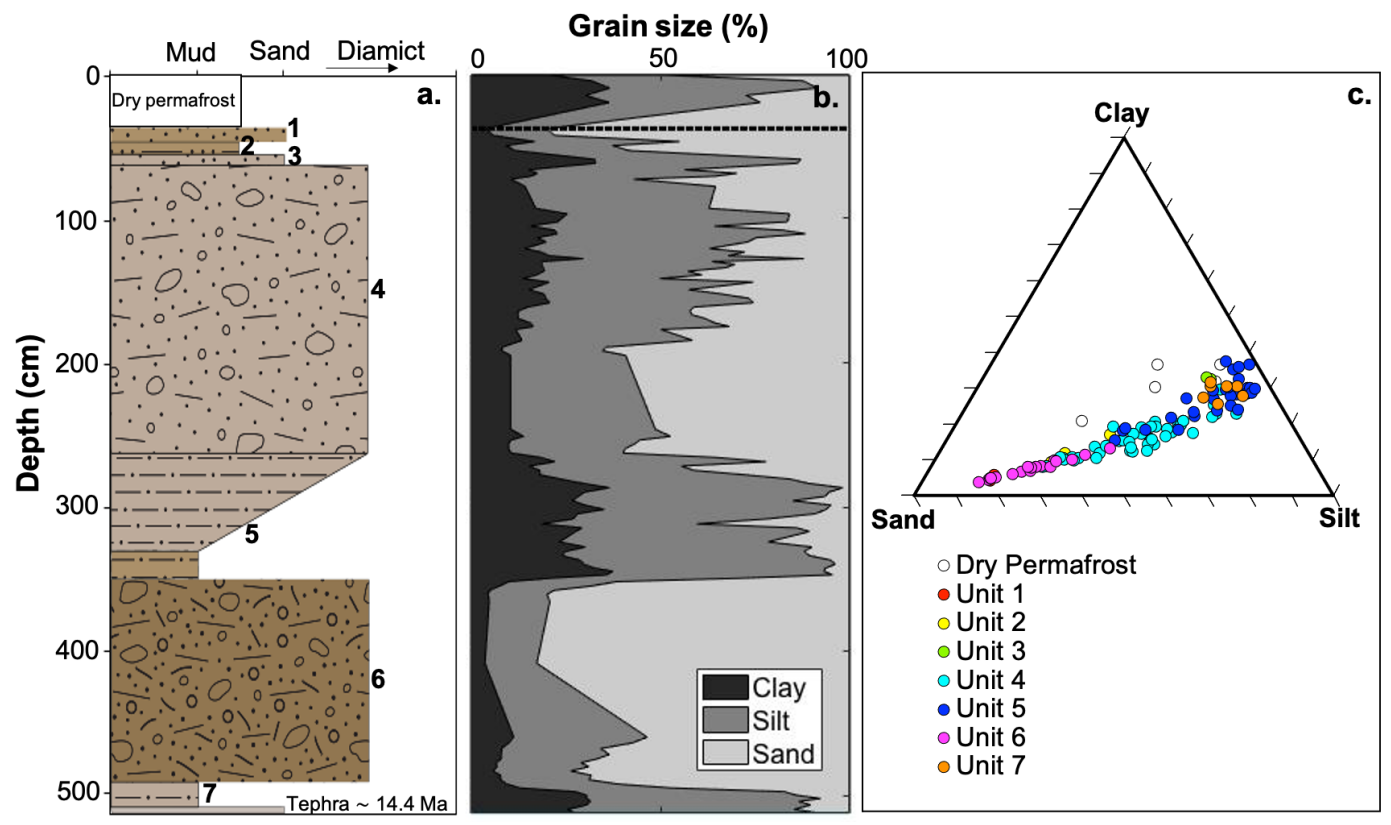

Fig. 3.3 Stratigraphy and grain-size distribution of core FHDP2C. a. sedimentary log of core FHDP2C with stratigraphic units numbered 1 to 7 and associated Munsell colours. b. \% grain size distribution profile. c. ternary plot of grain size distribution based on stratigraphic unit in FHDP2C.

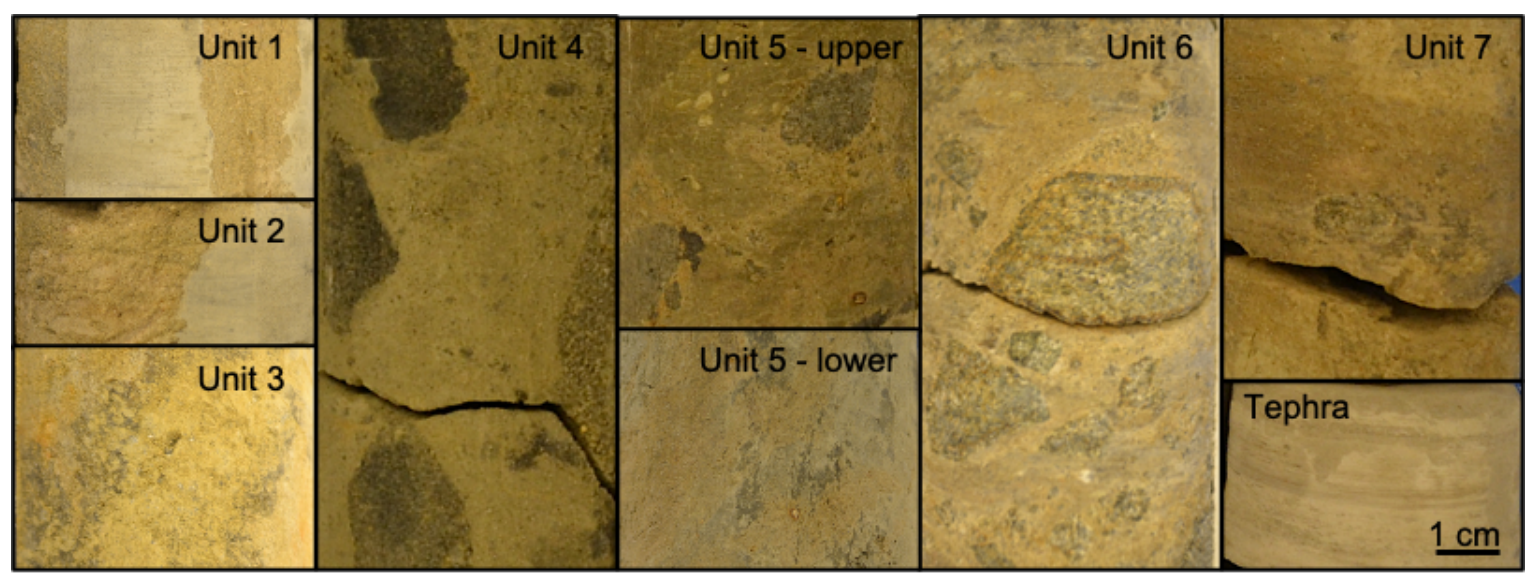

Fig. 3.4 Photos of stratigraphic units $1-7$ and tephra layer in core FHDP2C

and the highest concentrations of $\mathrm{Si}$ (avg. $2.9 \times 10^{5} \mathrm{mg} \mathrm{kg}^{-1}$ ) throughout the ice-cemented core (Fig. 3.5). Units 1 and 2 were found to have statistically similar concentrations of $\mathrm{Al}, \mathrm{Ca}, \mathrm{Fe}, \mathrm{Si}, \mathrm{Sr}$ and $\mathrm{Ti}$ (Appendix Table C.8). $\mathrm{Mg}\left(\right.$ avg. $1.1 \times 10^{4} \mathrm{mg} \mathrm{kg}^{-1}$ ) and $\mathrm{K}($ avg. $0.92 \times 10^{4} \mathrm{mg} \mathrm{kg}^{-1}$ ) were higher in unit 2 than in unit 1 (Fig. 3.5). Unit 3 showed no overlap with unit 1 and only had Ca concentrations overlapping with unit 2 (Appendix Table C.8). It had the highest $\mathrm{Mg}$ (avg. $\left.2.1 \times 10^{4} \mathrm{mg} \mathrm{kg}^{-1}\right), \mathrm{Fe}\left(\operatorname{avg} .6 .1 \times 10^{4} \mathrm{mg} \mathrm{kg}^{-1}\right)$ and $\mathrm{Sr}(\operatorname{avg}$. 
$1.3 \times 10^{2} \mathrm{mg} \mathrm{kg}^{-1}$ ) concentrations throughout the ice-cemented core (Fig. 3.5). Unit 3 had a statistically similar geochemical composition to the lower units 4 (Ca, Mg, $\mathrm{Al}, \mathrm{Si} \mathrm{Sr}, \mathrm{Ti})$, 5 (Mg, Al, Fe, Si, Sr, Ti), 6 (Al, Si, Ti) and 7 (Mg, Al, Fe, Si, Sr; Appendix Table C.8). Unit 4 had the highest concentration of $\mathrm{Ca}\left(3.2 \times 10^{4} \mathrm{mg} \mathrm{kg}^{-1}\right)$ and $\mathrm{Ti}\left(0.38 \times 10^{4} \mathrm{mg} \mathrm{kg}^{-1}\right)$, but intermediate concentration of other elements (Fig. 3.5). Units 5 and 7 were statistically indistinct in all elements and had the highest concentrations of $\mathrm{Al}$ (avg. 7.4 and $7.7 \times 10^{4}$ $\mathrm{mg} \mathrm{kg}^{-1}$, respectively) and $\mathrm{K}$ (avg. $1.3 \times 10^{4} \mathrm{mg} \mathrm{kg}^{-1}$ ) in the ice-cemented core, and lowest concentrations of $\mathrm{Si}$ (avg. 2.4 and $2.3 \times 10^{5} \mathrm{mg} \mathrm{kg}^{-1}$, respectively) and $\mathrm{Ca}$ (avg. $2.0 \times 10^{4} \mathrm{mg}$ $\mathrm{kg}^{-1}$; Table 3.4 and Appendix Table C.8). Unit 6 had overlapping $\mathrm{Ca}$ and Ti compositions to units 5 and 7. It had the lowest $\mathrm{K}$ composition (avg. $0.79 \times 10^{4} \mathrm{mg} \mathrm{kg}^{-1}$; Fig. 3.5).

Using a standard Pearson correlation ( $\mathrm{r}^{2}$ values) on the overall distribution, $\mathrm{Al}$ was found to be moderately positively correlated with $\mathrm{K}\left(\mathrm{r}^{2}=0.52\right)$ and $\mathrm{Fe}\left(\mathrm{r}^{2}=0.63\right)$. Si was found to be moderately negatively correlated with $\mathrm{Al}\left(\mathrm{r}^{2}=-0.70\right), \mathrm{K}\left(\mathrm{r}^{2}=-0.52\right), \mathrm{Fe}\left(\mathrm{r}^{2}=-0.71\right)$ and $\mathrm{Mg}\left(\mathrm{r}^{2}=-0.52\right)$. Moderate positive correlations were also found between $\mathrm{K}$ and $\mathrm{Mg}\left(\mathrm{r}^{2}=\right.$ $0.71)$ and $\mathrm{Ca}$ and $\mathrm{Ti}\left(\mathrm{r}^{2}=0.65\right)$. The strongest correlations were established between $\mathrm{K}$ and $\mathrm{Fe}\left(\mathrm{r}^{2}=0.88\right)$ and $\mathrm{Fe}$ and $\mathrm{Mg}\left(\mathrm{r}^{2}=0.87\right)$ (Table 3.3).

Table 3.3 Pearson correlation ( $\mathrm{r}^{2}$-values) of major elements in core FHDP2C

\begin{tabular}{ccccccc}
\hline & Al & Si & K & Ca & Ti & Fe \\
\hline $\mathbf{A l}$ & & & & & & \\
\hline $\mathbf{S i}$ & $\mathbf{- 0 . 7 0}$ & & & & & \\
\hline $\mathbf{K}$ & $\mathbf{0 . 5 2}$ & $\mathbf{- 0 . 5 2}$ & & & & \\
\hline $\mathbf{C a}$ & 0.35 & 0.29 & -0.02 & & & \\
\hline $\mathbf{T i}$ & 0.06 & 0.00 & -0.13 & $\mathbf{0 . 6 5}$ & & \\
\hline $\mathbf{F e}$ & $\mathbf{0 . 6 3}$ & $\mathbf{- 0 . 7 1}$ & $\mathbf{0 . 8 8}$ & 0.10 & 0.16 & \\
\hline $\mathbf{M g}$ & 0.40 & $\mathbf{- 0 . 5 2}$ & $\mathbf{0 . 7 1}$ & 0.36 & 0.33 & $\mathbf{0 . 8 7}$ \\
\hline
\end{tabular}




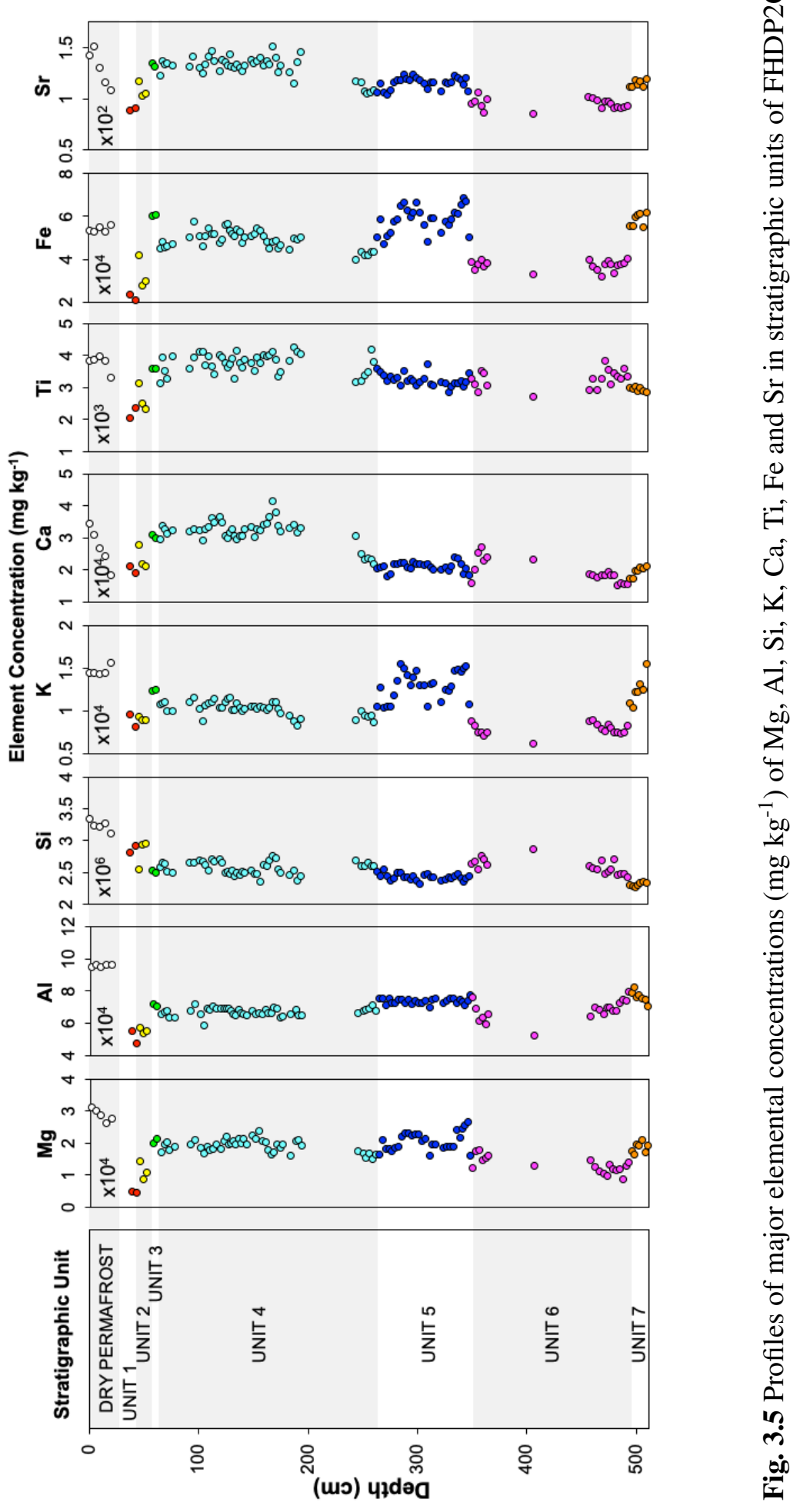




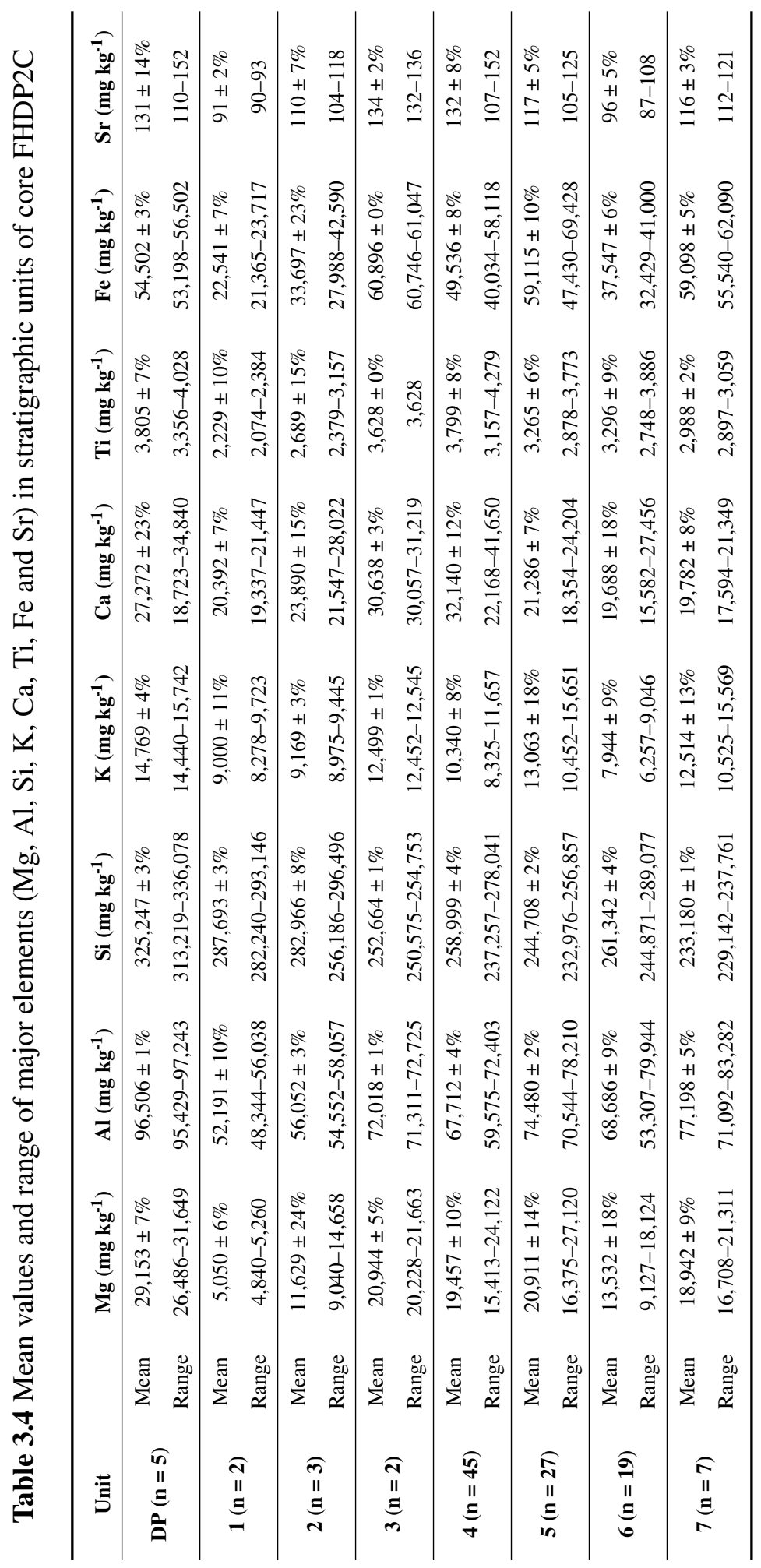




\subsubsection{Organics, carbonates, $\mathrm{C}_{\text {org }}, \delta^{13} \mathrm{C}_{\text {org }}$ and $\delta^{15} \mathrm{~N}$ isotopes}

SOM varied between 0.69 and 5.6\% (avg. $2.4 \pm 1.2 \%$ ) and was highest in the dry permafrost layer (avg. $3.8 \pm 1.6 \%$ ), and in the units 5 (avg. $3.7 \pm 1.5 \%$ ) and 7 (avg. $4.3 \pm 0.4 \%$; Fig. 3.9). The lowest values were found in units 1 (avg. $1.5 \pm 0.2 \%$ ) and 4 (avg. $1.4 \pm 0.2 \%$ ). Carbonates varied between 0.26 and $1.1 \%$ (avg. $0.7 \pm 0.2 \%$ ) and followed similar pattern as SOM: the highest concentrations were found in the dry permafrost layer (avg. $0.8 \pm 0.2 \%$ ) and in the units 5 (avg. $0.8 \pm 0.1 \%$ ) and 7 (avg. $0.9 \pm 0.3 \%$; Fig. 3.8). All other units had concentrations $<0.6 \%$. Soil organic carbon (SOC) values ranged from 0.1 to $1.0 \%$ (avg. $0.2 \pm 0.2 \%)$. Relatively high values were found in the dry permafrost layer and in units 6 and 7. The C:N ratio varied between 6.3 and 86.2 (Fig. 3.9). The large range of C:N values may also partly be attributed to the low concentrations of $\mathrm{N}$ and $\mathrm{C}_{\text {org }}$ nearing the limit of analytical precision (Fig. 3.8e-f). Although duplicate variance was systematically $<0.01 \%$ for $\mathrm{N}$ and $<0.05 \%$ for $\mathrm{C}_{\text {org }}$, $\mathrm{N}$ values ranged from $<0.001$ to $0.08 \%$ and $\mathrm{C}_{\text {org }}$ values ranged from 0.06 to $1.00 \%$, meaning a small analytical error could greatly influence the $\mathrm{C}: \mathrm{N}$ ratio. Therefore, samples with low $\mathrm{C}_{\text {org }}$ and $\mathrm{N}$ need to be interpreted with caution. The dry permafrost layer and stratigraphic unit 7 had ratios near 10 (avg. $10.6 \pm 2.5$ and $11.9 \pm 2.2$. respectively). Units 2, 3 and 4 all had average $C: N$ ratios above 20, while units 1, 5 and 6 had ratios between 10 and 20 (Fig. 3.9). $\delta^{13} \mathrm{C}_{\text {org }}$ values varied between -27.0 and $-19.8 \%$ VPDB (avg. $-24.5 \pm 1.7 \%$ VPDB; Fig. 3.9). The upper three stratigraphic units and the dry permafrost layer averaged between -21.6 and -20.0\% VPDB, while the lower stratigraphic units (4-7) averaged between -25.5 and $-24.5 \%$ VPDB. $\delta^{15} \mathrm{~N}$ values varied between 1.9 and 18.4\%o (avg 9.2 \pm 4.7\% AIR; Fig. 3.9).

Organic matter was moderately correlated with carbonates $\left(r^{2}=0.66\right), C_{o r g}\left(r^{2}=0.35\right)$, $\mathrm{N}\left(\mathrm{r}^{2}=0.42\right)$ and $\delta^{15} \mathrm{~N}\left(\mathrm{r}^{2}=0.39\right.$; Fig. 3.6). No correlation was found between organic matter and $\mathrm{C}: \mathrm{N}$ and $\delta^{13} \mathrm{C}_{\text {org }}$. Carbonates were moderately correlated $\left(\mathrm{r}^{2}=0.40\right)$ with $\mathrm{Si}$ :Al (proxy for biogenic silica), but showed no correlation with other variables (Fig. 3.7). $\mathrm{C}_{\text {org }}$ and $\mathrm{N}$ were highly correlated $\left(\mathrm{r}^{2}=0.91\right)$ and most sample plotted between the Redfield Ratio and the soil ratio. The surficial dry permafrost sample plotted directly on the Redfield Ratio (Redfield 1934). $\mathrm{C}_{\text {org }}$ was not correlated to neither $\mathrm{N}$ nor $\delta^{13} \mathrm{C}_{\text {org }}$ and $\mathrm{N}$ was in turn not correlated to $\delta^{15} \mathrm{~N}$ (Fig. 3.8). 

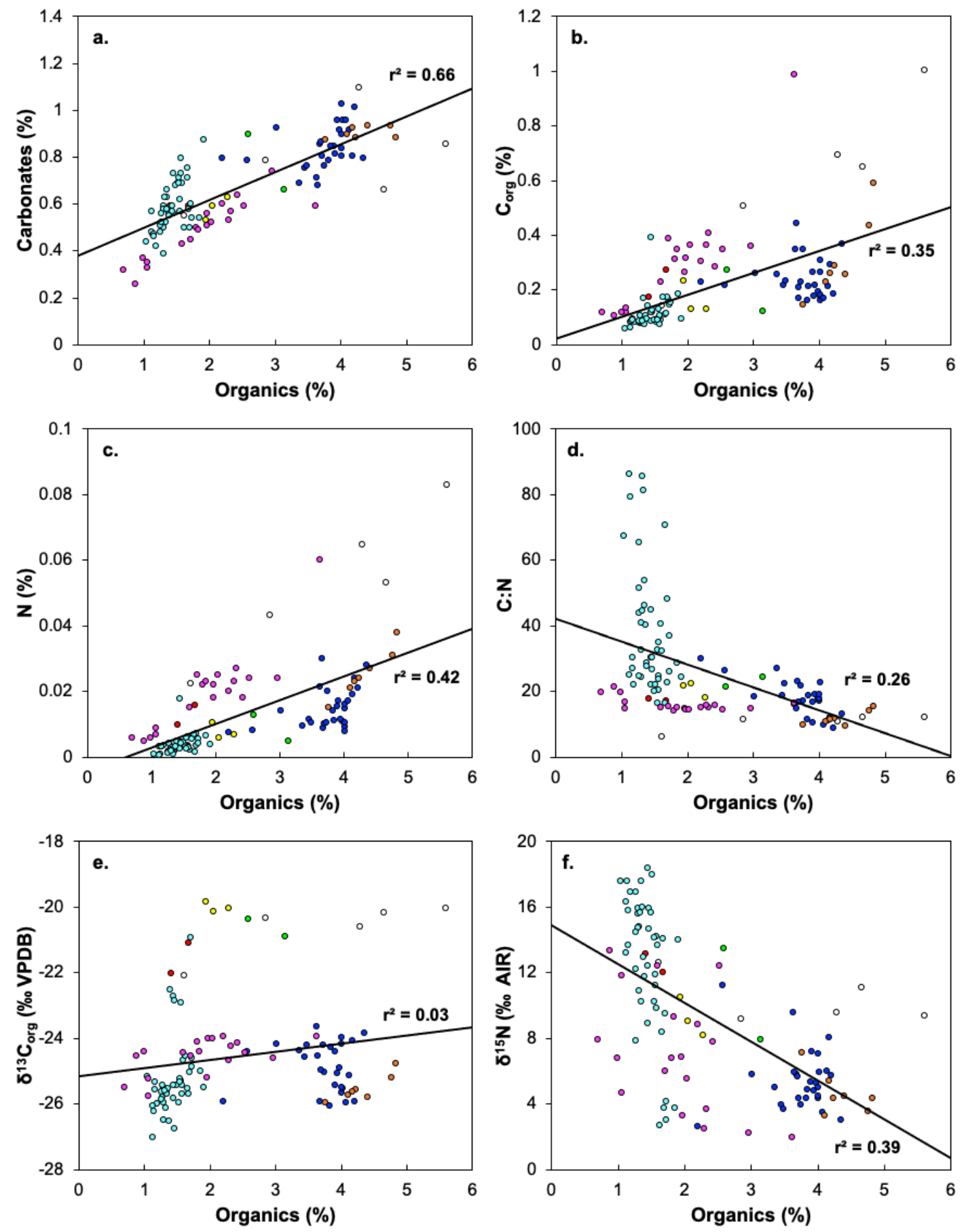

$\circ$ Dry permafrost $\bullet$ Unit $1 \circ$ Unit $2 \circ$ Unit $3 \circ$ Unit $4 \bullet$ Unit $5 \circ$ Unit $6 \circ$ Unit 7

Fig. 3.6 Scatterplots showing relations between organic matter content and a. carbonates, b. $\mathrm{C}_{\text {org }}$, c. $\mathrm{N}$, d. C:N, e. $\delta^{13} \mathrm{C}_{\mathrm{org}}$, and f. $\delta^{15} \mathrm{~N}$ in different FHDP2C stratigraphic units. 

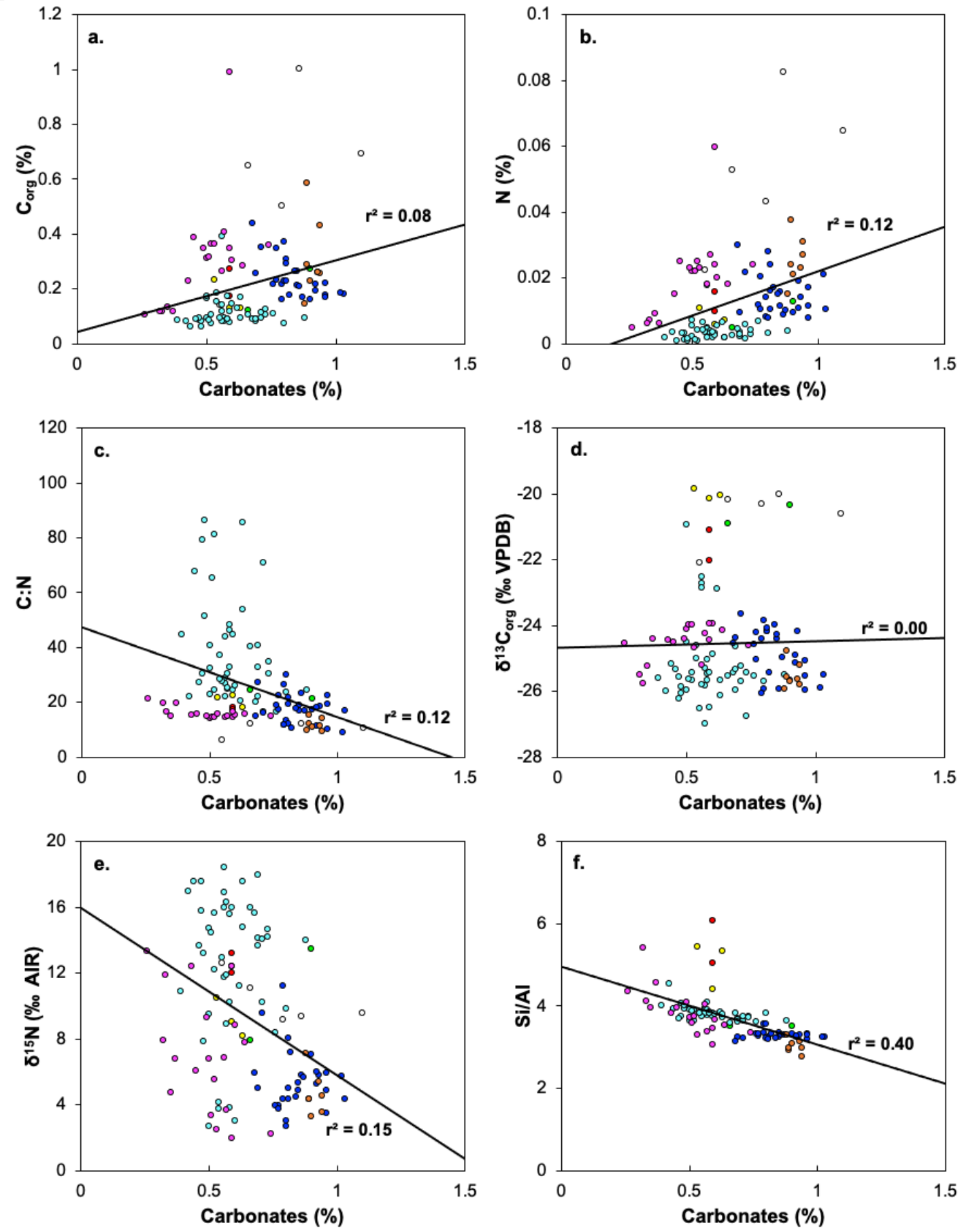

$\circ$ Dry permafrost $\bullet$ Unit $1 \circ$ Unit $2 \circ$ Unit $3 \circ$ Unit $4 \bullet$ Unit $5 \circ$ Unit $6 \circ$ Unit 7

Fig. 3.7 Scatterplots showing relations between carbonates and a. $\mathrm{C}_{\mathrm{org}}$, b. N, c. C:N, d. $\delta^{13} \mathrm{C}_{\text {org }}$, e. $\delta^{15} \mathrm{~N}$ and f. Si/Al in different FHDP2C stratigraphic units. 

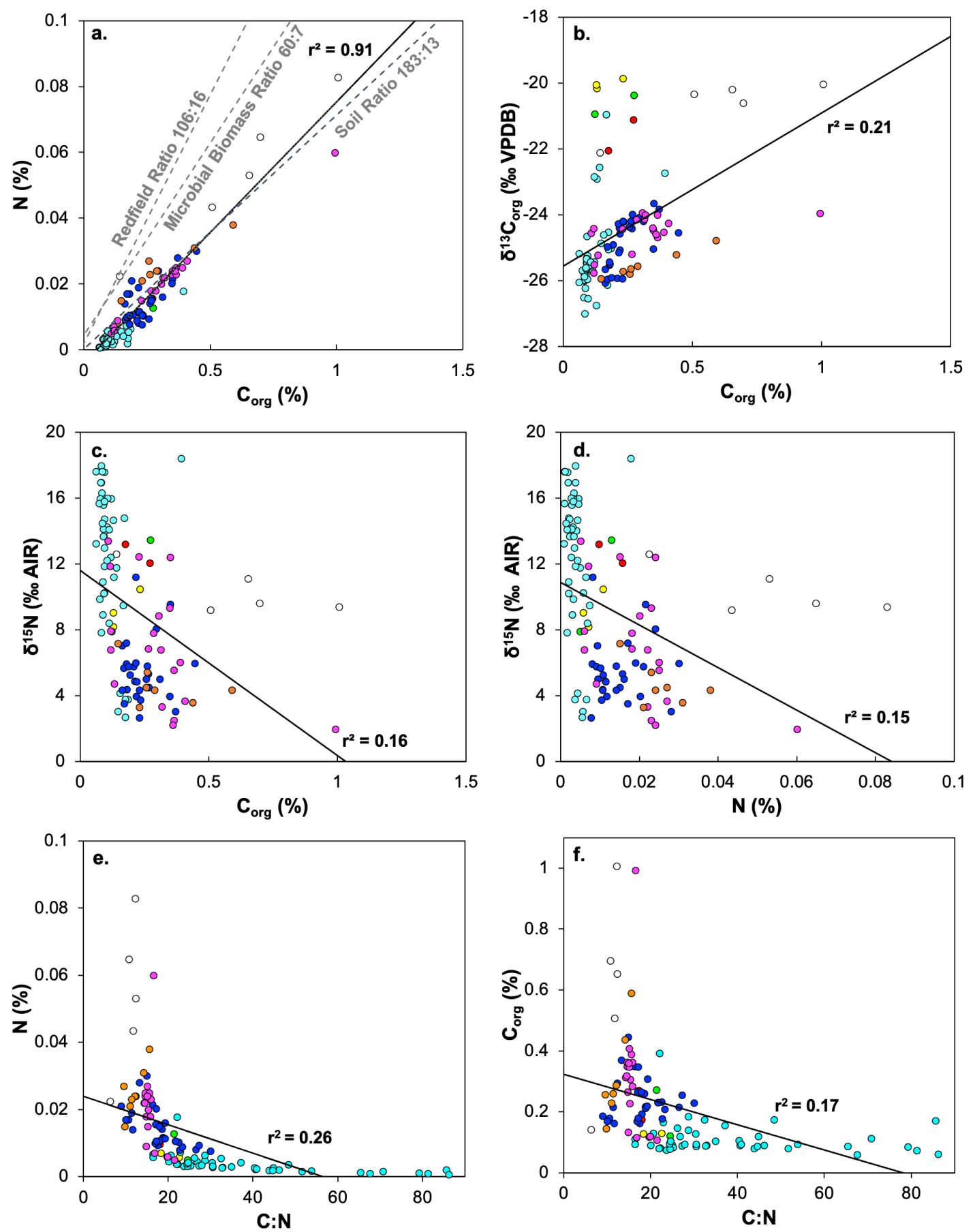

$\circ$ Dry permafrost $\bullet$ Unit $1 \circ$ Unit $2 \circ$ Unit $3 \circ$ Unit $4 \bullet$ Unit $5 \circ$ Unit $6 \circ$ Unit 7

Fig. 3.8 Scatterplots showing relations between a. $\mathrm{C}_{\text {org }}$ and $\mathrm{N}$ and the Redfield Ratio for algal biomass (Redfield, 1934), and the ratio for microbial biomass and soil (Cleveland and Liptzin, 2007), b. $\mathrm{C}_{\text {org }}$ and $\delta^{13} \mathrm{C}_{\text {org }}$, c. $\mathrm{C}_{\text {org }}$ and $\delta^{15} \mathrm{~N}$, d. $\mathrm{N}$ and $\delta^{15} \mathrm{~N}$, e. $\mathrm{N}$ and $\mathrm{C}: \mathrm{N}$ and f. $\mathrm{C}_{\text {org }}$ and $\mathrm{C}: \mathrm{N}$ in different FHDP2C stratigraphic units. 


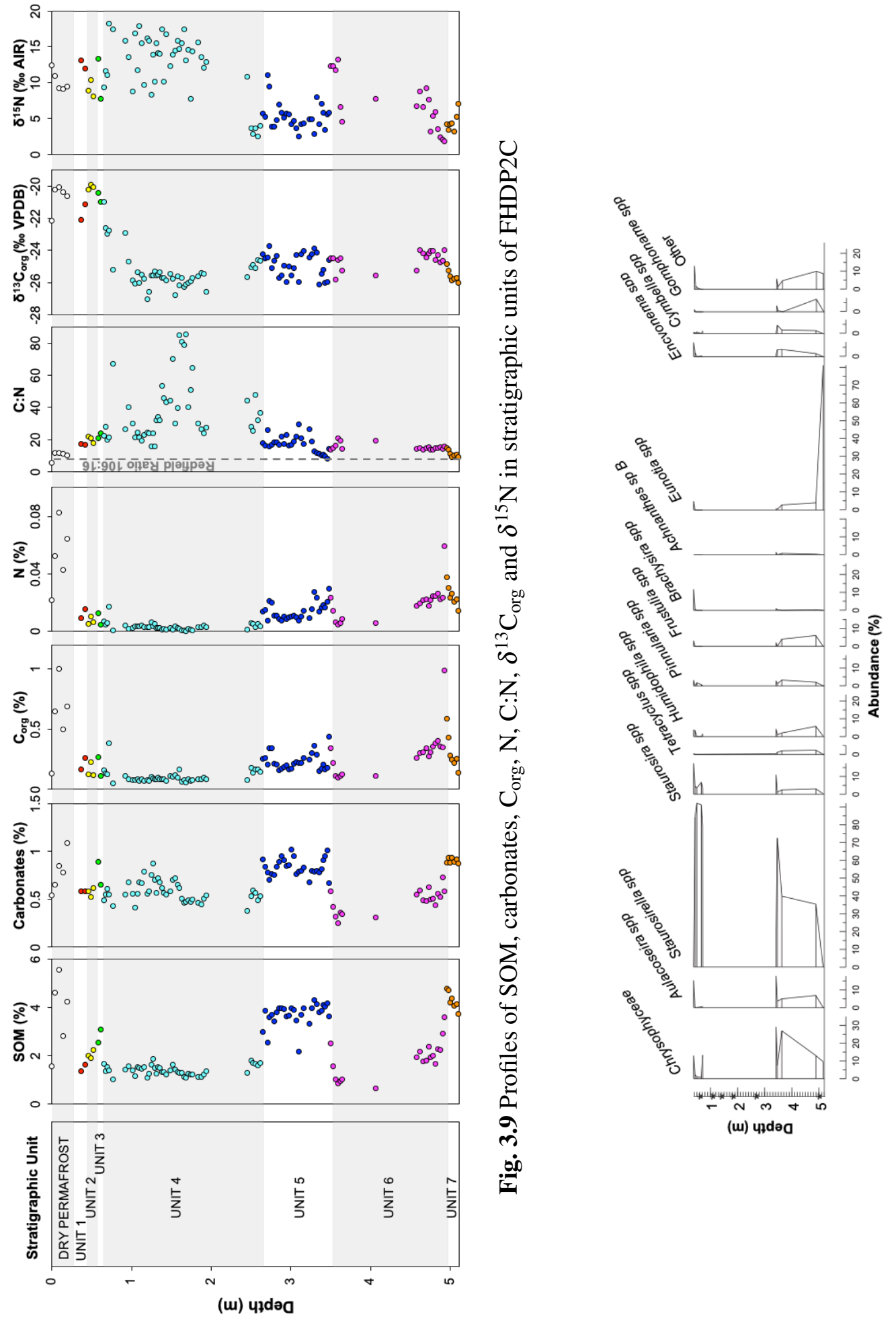

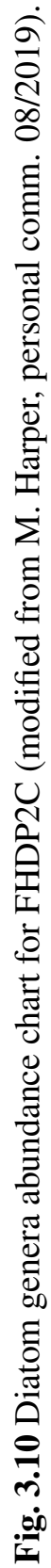




\subsubsection{Radiocarbon dating}

Sample 2-C0-3 yielded a radiocarbon age of 41,749 $\pm 1,736$ years BP and a median calibrated age of 44,957 cal years BP (Table 3.5 and Appendix Fig. F.1). While this age is near the limit of radiocarbon dating, the sample still contained measurable concentrations of radiocarbon meaning the carbon is thousands of years old instead of millions.

Table 3.5 Radiocarbon age from sample of dry permafrost (Appendix Fig. F.1 for calibration curve)

\begin{tabular}{ccccccc}
\hline Sample ID & Depth $(\mathbf{c m})$ & Lab ID & Material & ${ }^{14}$ C year BP & 2 $\sigma$ cal BP & Median cal BP \\
\hline $\mathbf{2 - C 0 - 3}$ & 10 & NZA 70400 & Bulk sediment & $41,749 \pm 1,736$ & $42,364-47,550$ & 44,957 \\
\hline
\end{tabular}

\subsubsection{Diatoms and macrofragments}

The genera Staurosirella and Staurosira (formerly both in the genus Fragilaria) were dominant in FHDP2C, consisting of $54.4 \%$ and $6.4 \%$ of the total diatom assemblage respectively (Fig. 3.10). A small Eunotia species was very abundant in the tephra sample (13.7\% of the total diatom assemblage; Fig. 3.11b). The Aulacoseira (5.7\%), Humidophila (2.5\%), Encyonema (2.4\%), Brachysira (1.9\%), Frustulia (1.7\%), Pinnularia (1.6\%), Gomphonema (1.4\%), Adlafia (1.3\%) and Cymbella (1.2\%) genera were present in diatom-rich samples of the core. Traces of Muelleria, Tetracyclus, Achnanthidium, Fragilariforma, Psammothidium, Nupela, Placoneis, Nitzshia and others were also identified (Appendix Table E.1 for complete count). Unit 4 was devoid of diatoms.

The core contained an assemblage of lichens, liverworts, mosses, dicots, grasses and sedges. Cuticles belonging to the Nothofagaceae family were also observed in most samples. No significant change in plant assemblage was observed throughout the core (Fig. 3.11d). A feather barb was also found in neighbouring core FHDP2A at 1.10-1.15 m depth (Fig. 3.11a).

\subsection{Discussion}

\subsubsection{Sediment provenance}

The polymodal grain-size distribution within core FHDP2C can be attributed to subglacial sediment-mixing processes. If sediments were exclusively the result of crushing and abrasion, 


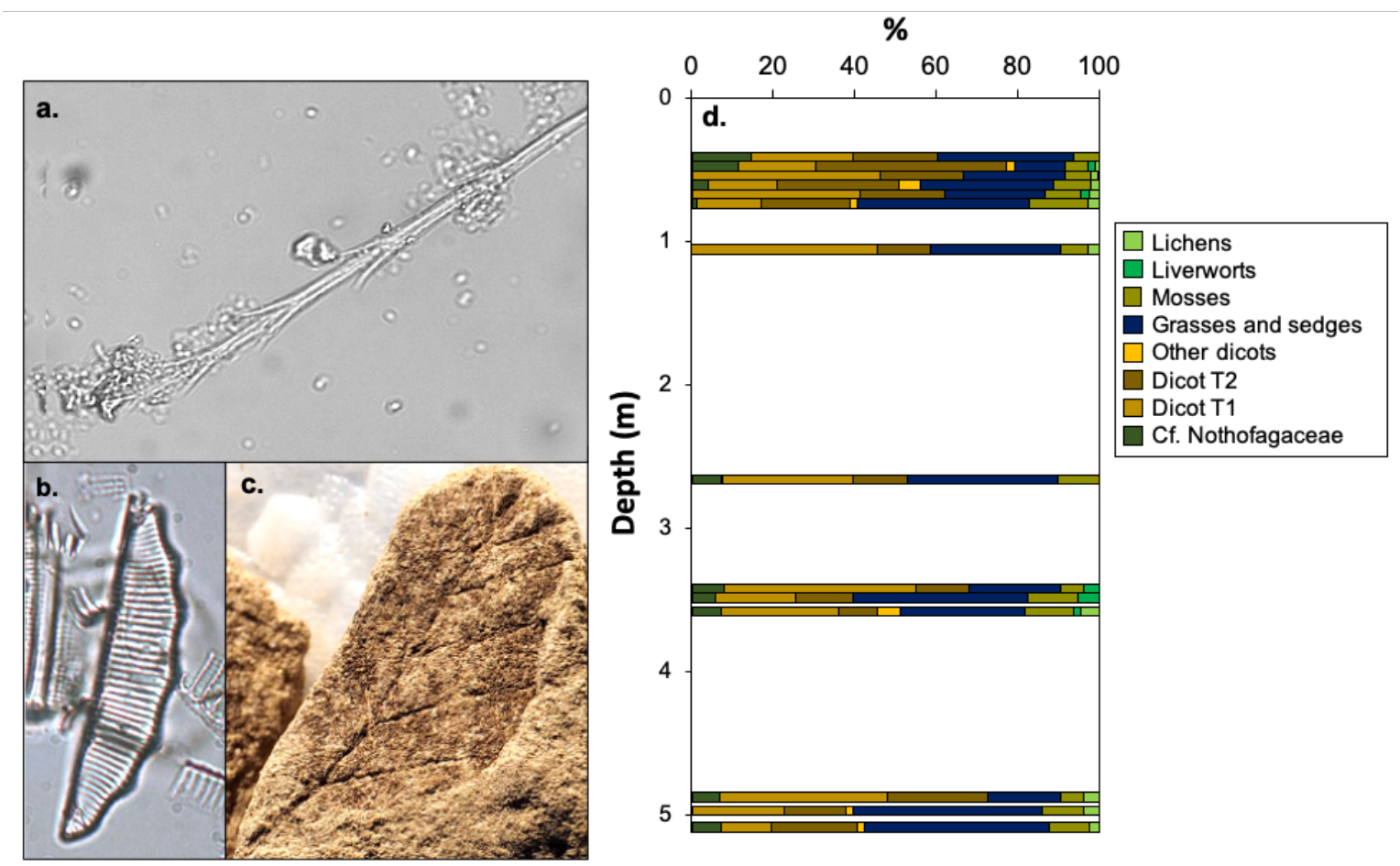

Fig. 3.11 Macrofragments found in FHDP cores. a. feather barb found at 1.10-1.15 $\mathrm{m}$ depth in core FHDP2A (M. Harper, personal comm. 09/2020), b. Eunotia spp. diatom found in tephra layer at base of core FHDP2C (M. Harper personal comm. 11/2018), c. Nothofagus leaf print from Friis Hills (photo credit R. Levy), d. \% types of macrofragments (plants cuticles) observed in samples in FHDP2C (modified from A. Homes, personal comm. 10/2019)

the glacial sediment would be bimodal; with sand being the terminal grade for crushing bedrock, and silt the terminal grade for abrasion of mineral grains (e.g. Haldorsen, 1981, Altuhafi and Baudet, 2011). The increased proportion of clay is the result of mixing processes such as subglacial sediment deformation, subglacial melting and regelation, bed plowing by larger clasts, etc. (e.g. Evans et al., 2006), the additional input of lacustrine sediment and chemical weathering. The dry permafrost layer was richer in sand than the ice-cemented units most likely due to wind erosion (i.e. removal of fines) post-deposition.

The geochemical signature of sediments can be explained by the mixing of five major rock types in the MDV: (1) Ferrar dolerite; (2) McMurdo volcanics basanites; (3) Beacon sandstone; (4) Metasedimentary basement complex; and (5) Granitoids (e.g. Roser and Pyne, 1989, Martin et al., 2015). Due to low concentrations of biogenic silica $(<1 \%$ from microscope estimates), the $\mathrm{SiO}_{2} \mathrm{wt} \%$ was assumed to be lithogenous. Most of FHDP2C units coincided with the Ferrar dolerite signature (Fig. 3.13). At the time of deposition, ice flowed from the west ( $\sim 107^{\circ}$; Lewis and Ashworth, 2015), which is consistent with a Ferrar 
dolerite provenance, since most of the source material in the western portion of Friis Hills also consists of Ferrar dolerite (Fig. 3.12).

Units 1 and 2 had a geochemical signature that was compatible with the Basement complex (Fig. 3.13). The basement crops out to the southeast in the Simmons Basin and on Solitary Rocks, to the north in Pearse Valley, as well as on the eastern portion of Friis Hills (Fig. 3.12). The sediment in units 1 and 2 most likely originated from the eastern portion of Friis Hills, due to the topographic relations (i.e. the other locations are at lower elevations than the units) and the facies of the units (subaqueous debris flows). Conversely, the increased proportion of $\mathrm{SiO}_{2}$ and $\mathrm{Al}_{2} \mathrm{O}_{3}$ in the dry permafrost, indicates a preponderance of more resistant quartz and feldspar minerals than in the parent material (i.e. units 1 and 2), suggesting signs of chemical weathering and diagenesis (e.g. Gibson et al., 1983, Campbell and Claridge, 1987).

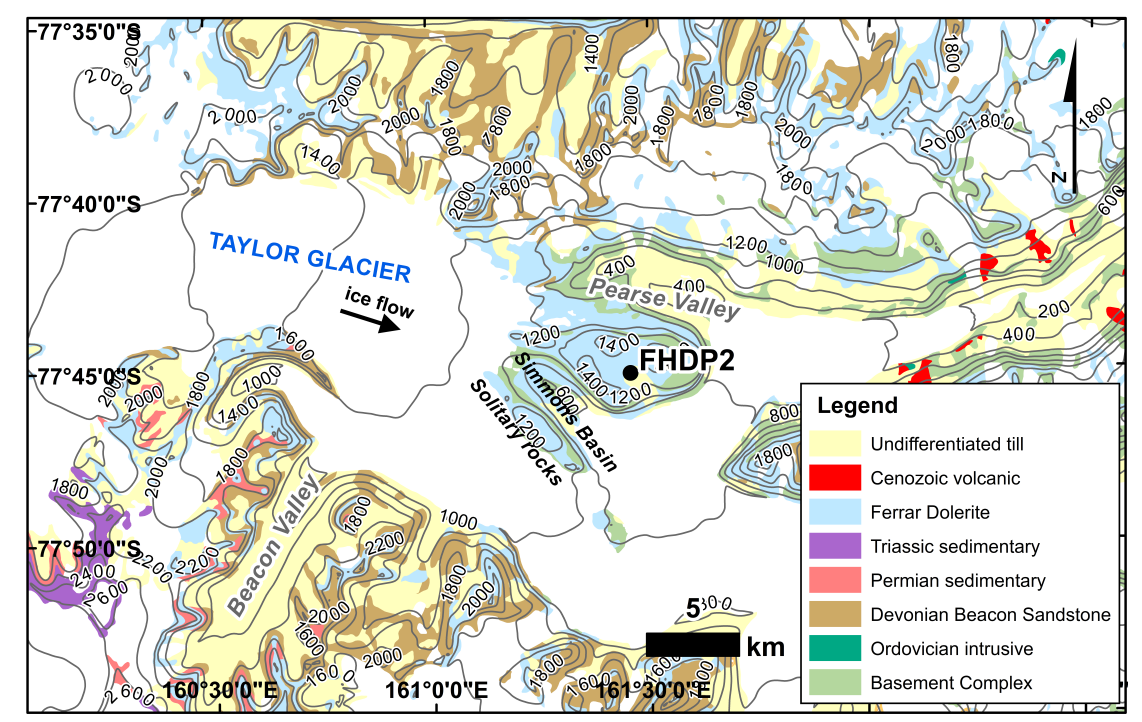

Fig. 3.12 Geological units in the vicinity of Friis Hills (data from GeoMAP v.201907; Cox, Smyth. and the GeoMAP team (2019) with ice flow direction (Lewis and Ashworth, 2015)). Contours at 200 $\mathrm{m}$ intervals.

\subsubsection{Interpretations of stratigraphic units}

Surficial deposits at Friis Hills consisted of a 50 m thick sequence of glacial drifts interbedded with lacustrine sediments, originating from the advance and retreat of a local alpine glacial system connected to the EAIS (Lewis and Ashworth, 2015). Based on magnetostratigraphy constrained by radiometric ages of a tephra, the age of the sediment in FHDP2C lies between 14.4 and $\sim 14 \mathrm{Ma}$ (magnetozone $1 \mathrm{~N} 1, \mathrm{C} 5 \mathrm{ACn} ; 14.070$ to $13.739 \mathrm{Ma}$ ), a period of 

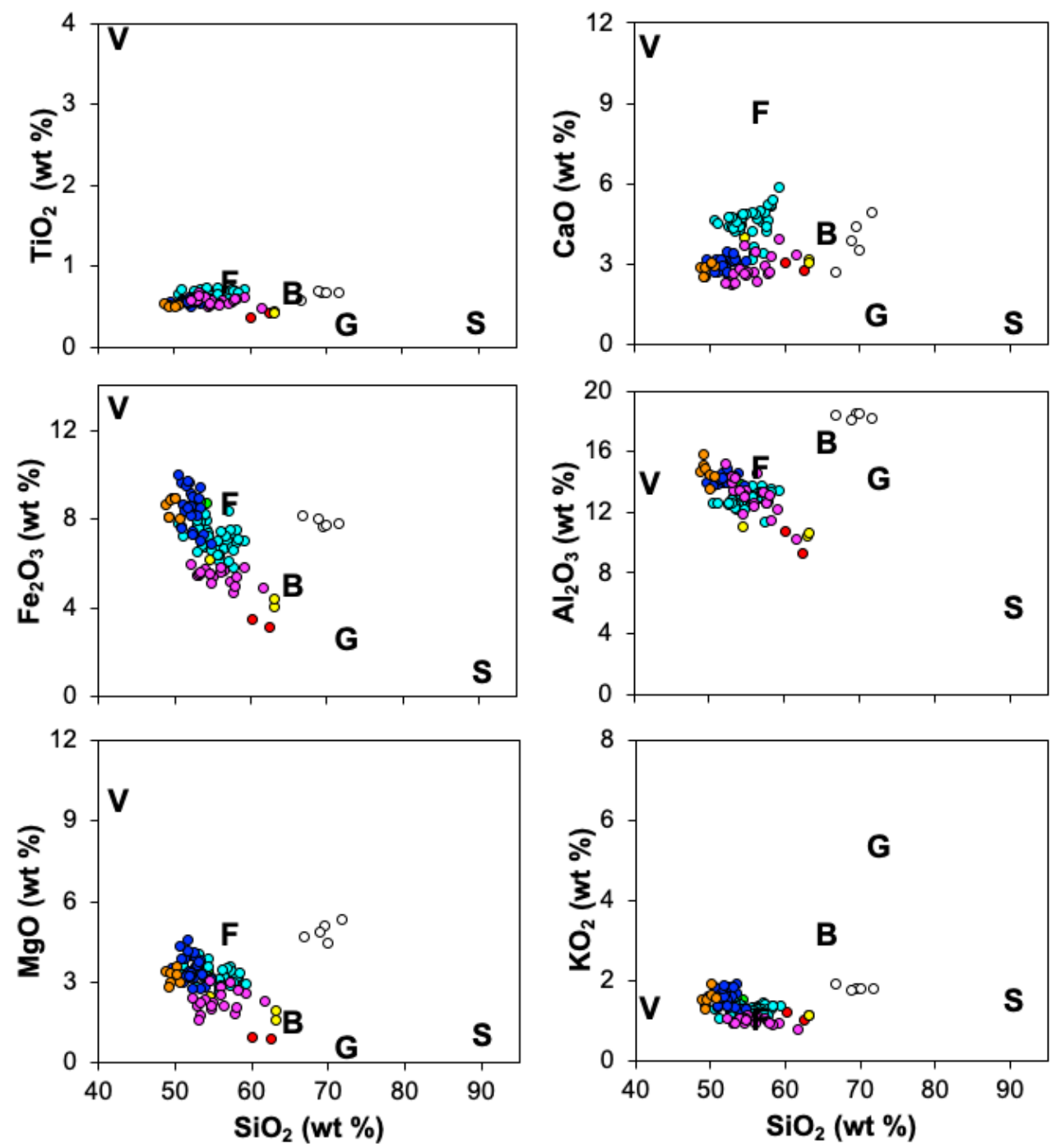

-Unit $1 \circ$ Unit $2 \circ$ Unit $3 \circ$ Unit $4 \bullet$ Unit $5 \circ$ Unit $6 \circ$ Unit $7 \circ$ Dry permafrost

Fig. 3.13 Major elemental oxide diagrams in core FHDP2C. Units displayed in different colours compared to representative composition of major rock types in the McMurdo Dry Valleys B=Basement Complex, F=Ferrar dolerite, $\mathrm{S}=$ Beacon sandstone, $\mathrm{V}=\mathrm{McM}$ urdo volcanics basanite (Roser and Pyne, 1989), $\mathrm{G}=$ Granite (Martin et al., 2015). Center of letter corresponds to average composition.

0.4-0.7 Myr corresponding to the mid-Miocene climate transition (MMCT). Units 5 and 7 were classified as proglacial ponds, units 4 and 6 as subglacial traction tills, and units 1,2 and 3 as subaqueous debris flows. Although the sediment and XRF results showed a succession of glacial facies in FHDP2C, the diatom and macrofossil assemblage showed little variation throughout the core, suggesting the interglacial periods during this interval did not undergo 
major paleoenvironmental shifts and that none of the glacial periods caused a major shift in plant assemblage.

\section{Units 5 and 7: proglacial ponds}

Units 5 and 7 had statistically identical grain-size and XRF elemental compositions (Appendix Table B.4 and C.8) and consisted of lacustrine sediments. They were composed of an average of $58 \%$ silt, $28 \%$ clay and $14 \%$ sand. They had amongst the highest average $\mathrm{C}_{\text {org }}$ and $\mathrm{N}$ (Appendix Fig. D.1) with C:N ratios ratio 10 and 20 (avg. 17.8 and 11.9 respectively), which is indicative of an input of algal biomass (Reiners, 1986). C:N ratios $<10$ suggest a deepwater lacustrine environment dominated by algal signal, while $\mathrm{C}: \mathrm{N}$ ratios between 10 and 20 suggest a higher contribution from vascular plant and shallow, dry or marshy conditions (e.g. Ishiwatari and Uzaki, 1987, Meyers and Ishiwatari, 1993). The $\delta^{13} \mathrm{C}_{\text {org }}$ composition of the bulk organic carbon averaged $-24.8 \%$ in unit 5 and $-25.5 \%$ in unit 7 , which are both indicative of a $\mathrm{C} 3$ plant photosynthetic pathway. The two pond units had a diatom assemblage composed of Staurosirella, (27-79\%) which are tychoplanktic (i.e. mainly live unattached to surface in shallow water), Aulacosiera $(<25 \%)$ which are planktic and Cymbella $(<5 \%)$ which attach to surfaces such as leaves or rocks. Staurosirella are small, reproduce rapidly (e.g. De Angelis et al., 2016) and are typically indicative of shallow waters with low water turnover (Wehr et al., 2015). Poor sorting and polymodal grain-size distribution indicate an important input of terrigenous glacial sediment. The absence of bioturbation, high organic matter content and freshwater diatom assemblage suggest a shallow pond environment with a mixed signal from aquatic and terrestrial plants.

\section{Units 6 and 4: subglacial traction tills}

Units 6 and 4 were both classified as massive matrix-supported diamicts with a very poorlysorted polymodal matrix varying from sandy-mud to muddy-sand. The clasts, consisting mostly of dolerite and minor amounts of granite, varied in size from 0.2 to $15 \mathrm{~cm}$ in diameter and were subangular and striated. The sharp basal contact and structureless nature of these diamicts were associated with subglacial processes (Evans et al., 2006). The lower portion of these units (especially unit 6) displayed signs of ductile deformation with physical mixing of underlying lithologies. The rotational structures, polymodal grain-size distribution and the fine-grained matrix suggest processes of transport in lodgement tills (Evans et al., 2006). Unit 6 comprises sediment from the underlying unit 7, which was interpreted as subglacial deformation associated with a subsequent ice advance, overriding the proglacial 
lacustrine sediment (van der Meer and Menzies, 2011). Units 6 and 4 incorporate the regional paleoenvironmental signal of the tundra that dominated the high elevation of the MDV during the mid-Miocene. Unit 6 had a bulk sediment C:N ratio averaging 16.0 (ranging 14.2 to 21.4), while unit 4 had a $\mathrm{C}: \mathrm{N}$ ratio averaging 38.4 (ranging 16.4 to 86.2 ) respectively. These values correspond to vascular terrestrial plants which typically have C:N ratios $\geq 20$ (e.g. Meyers and Ishiwatari, 1993), and large woody plants which can have C:N ratios $\geq 100$ (e.g. Reiners, 1986). The large range of values in these units may also be attributed to the low concentrations of $\mathrm{N}$ nearing the limit of analytical precision.

\section{Units 1, 2 and 3: subaqueous debris flows}

Units 1, 2 and 3 consist of poorly sorted muddy sand. The lack of structures within these units is compatible with subaqueous cohesive debris flows, such as hyperconcentrated flows (Chorley, 2020). In the glacial context of the site, these debris flows could have originated near the grounding zone, with a river/stream delivering well-sorted sand to a small fluviallacustrine delta (Chorley, 2020). While other units had a Ferrar dolerite signature, these units seemed to be consistent with the basement geochemical signature (Fig. 3.13). The change of sediment provenance in this case would be localized and not related to the glacial drainage system.

\subsubsection{The mid-Miocene tundra environment}

In a glacial setting like the one found at Friis Hills during the mid-Miocene, the organics preserved in glacial units 6 and 4 reflect environmental conditions when the region was icefree. When glaciers advanced in a new period, the plant fragments from the last interglacial period were incorporated in the tills. In the Arctic, this concept has led to misinterpretation of radiocarbon dating, where material much older than glacial deposits were wrongly attributed to glacial advances (e.g. Kennedy et al., 2010, Lacelle et al., 2013b, 2019). Since the diatom and macrofossil assemblage showed little variation throughout the core, the interglacial periods during this interval did not undergo major paleoenvironmental shifts and the organics preserved in core FHDP2C can be interpreted as paleoenvironmental indicators for a $\sim 0.4$ 0.7 Myr period during the MMCT (other than the signature modified from modern processes, see section 3.4.4.).

Plant cuticles from dicots, lichens, mosses, grasses and sedges typical of a polar tundra environment were found throughout the core. The average $\delta^{13} \mathrm{C}_{\mathrm{org}}$ value in the lower section 
of the core was $-25.2 \pm 0.7 \%$. Similar plant assemblage and $\delta^{13} \mathrm{C}_{\text {org }}$ values are found in King George Island (62 23 'S), off the Antarctic Peninsula: lichens (-23.6 $\pm 2.8 \%$ ) , grasses $(-25.6 \pm 1.7 \%)$, mosses $(-25.9 \pm 1.6 \%)$, liverworts $(-26.3 \pm 0.5 \%)$ and algae $(-26.3 \pm 1.2 \%$; Lee et al., 2009). Fragments belonging to the Nothofagaceae (southern beech) family were also observed. The plicate vernation of the Nothofagus leaves suggests deciduousness, which is classically associated with extreme cold climates, and possibly to limited daylight (e.g. McQueen, 1976, Pole, 1994). Deciduous Nothofagus species are widespread in Tierra del Fuego, South America, down to $56^{\circ} \mathrm{S}$; only limited by lack of land (McQueen, 1976). A thermal threshold of 5.5 to $7.5^{\circ} \mathrm{C}$ during the growing season has been set as the lower boundary for tree growth (e.g. Körner, 1998), which is in line with Lewis and Ashworth (2015)'s mean summer air temperature (MSAT) estimate of $\sim 6$ to $7^{\circ} \mathrm{C}$ at Friis Hills. The $\delta^{13} \mathrm{C}_{\text {org }}$ value of terrestrial C3 plants can also be used as a proxy for mean annual precipitation (MAP; e.g. Lee et al., 2005, Diefendorf et al., 2010, Kohn, 2010, Hare et al., 2018) while $\delta^{15} \mathrm{~N}$ provides information on ecosystem organization (e.g. Hobson and Welch, 1992, Skrzypek et al., 2015).

\section{$\delta^{13} \mathrm{C}_{\text {org }}$ of terrestrial $\mathrm{C} 3$ plants as an indicator of mean annual precipitation}

The $\delta^{13} \mathrm{C}_{\text {org }}$ signal of plants depends on the preferential consumption of ${ }^{12} \mathrm{C}$ versus ${ }^{13} \mathrm{C}$ (Farquhar et al., 1980). A highly negative ratio represents a lower ${ }^{13} \mathrm{C}$ intake. There are three biochemical pathways of carbon acquisition used by plants leading to three distinct groups: C3 plants, $\mathrm{C} 4$ plants and CAM plants. The $\delta^{13} \mathrm{C}_{\text {org }}$ composition of the lower section of FHDP2C likely reflects a $\mathrm{C} 3$ photosynthesis pathway since $\mathrm{C} 4$ plants became abundant in grasslands only in the last 7-8 Ma (Cerling et al., 1997) and CAM plants occupy only a small fraction of terrestrial ecosystems, typically in tropical environments (Jacobs et al., 1999). C3 plants exhibit a large range of $\delta^{13} \mathrm{C}_{\text {org }}$ composition (-20 to $-37 \%$ VPDB), generally dependant on physiological responses to aridity (anomalously high $\delta^{13} \mathrm{C}_{\mathrm{org}}$; Tieszen, 1991, Ehleringer and Monson, 1993). Under dry conditions, C3 plants tend to discriminate against ${ }^{13} \mathrm{C}$ to reduce water losses through transpiration (Ehleringer and Monson, 1993). Values above $-25.5 \%$ VPDB are restricted to environments with MAP $<500 \mathrm{~mm} \mathrm{yr}^{-1}$ (Kohn, 2010). This relation, combined with altitude and latitude, can be used to approximate MAP of paleoenvironments dating back millions of years (e.g. Schweizer et al., 2006), using $\delta^{13} \mathrm{C}_{\text {org }}$, which spans the full range of plant growth forms (Kohn, 2010). The equation for $\delta^{13} \mathrm{C}_{\text {org }}$ as a function of MAP is as follows: 


$$
\Delta^{13} C=2.01-1.98 \times 10^{-4} \cdot A+5.88 \cdot \log _{10}(M A P+300)+0.0129 A b s(l)
$$

where $\mathrm{A}$ is altitude (m), MAP is mean annual precipitation $\left(\mathrm{mm} \mathrm{yr}^{-1}\right)$ and 1 is latitude in degrees $\left({ }^{\circ}\right)$ and where:

$$
\Delta^{13} C=\frac{\delta^{13} C_{a t m}-\delta^{13} C_{\text {org }}}{1+\delta^{13} C_{\text {org }} / 1000}
$$

Based on the latest estimates of surface uplift since the early Miocene (100 to $300 \mathrm{~m}$; Stern et al., 2005, Paxman et al., 2019), altitude ranged from 1000 to $1200 \mathrm{~m}$ a.s.l (present-day elevation of $1244 \mathrm{~m}$ a.s.l) and latitude was $77^{\circ}$. The average $\delta^{13} \mathrm{C}_{\text {org }}$ composition (-25.5 \pm $0.7 \%$ VPDB) of samples with a $\mathrm{C}: \mathrm{N}>20$ was used to obtain a complete $\mathrm{C} 3$ signal and corrected using the $\delta^{13} \mathrm{C}_{\text {atm }}$ during the mid-Miocene (-6\% VPDB; Tipple et al., 2010). The resulting MAP ranged from 300 to $850 \mathrm{~mm} \mathrm{yr}^{-1}$ (avg. 500-550 $\mathrm{mm} \mathrm{yr}^{-1}$ ) suggesting that the Friis Hills were semi-arid during the period of sediment deposition $\sim 14-14.4$ Ma.

\section{Implications of $\delta^{15} \mathrm{~N}$ on mid-Miocene ecosystem}

$\delta^{15} \mathrm{~N}$ values from autotrophic sources in the MDV range from -16.6\% (SOM, Battleship Promontory; Burkins et al., 2000) to $6 \%$ (surface mat, Lake Hoare; Wharton Jr et al., 1993). The most depleted $\delta^{15} \mathrm{~N}$ values are associated with cryptoendolithic communities (Burkins et al., 2000), while lacustrine organic matter displays the highest $\delta^{15} \mathrm{~N}$ values (e.g. Wharton Jr et al., 1993, Burkins et al., 2000, Barker et al., 2018). The only exception is found in penguin rookeries where unusually high $\delta^{15} \mathrm{~N}$ have been measured (+28.6-+30.7\%; Wada et al., 1981). This enrichment is associated to the trophic level effect in food web studies (Michener and Lajtha, 2008). Terrestrial species of vascular plants, mosses, lichens and liverworths have $\delta^{15} \mathrm{~N}$ values ranging from -7.9 to $+7.6 \%$ in Falkland $\left(51^{\circ} 76^{\prime} \mathrm{S}\right)$ and Signy $\left(60^{\circ} 71^{\prime} \mathrm{S}\right)$ islands (Bokhorst et al., 2007), and from +1.0 to $+13.6 \%$ (avg. $+5.5 \%$ ) in the Canadian tundra (Tahmasebi et al., 2018).

High trophic levels are characterized by little to no change in $\delta^{13} \mathrm{C}_{\text {org }}$ but increases in $\delta^{15} \mathrm{~N}$ (Fig. 3.14; e.g. Hobson and Welch, 1992). An average $+3.3 \%$ enrichment per trophic level is observed in $\delta^{15} \mathrm{~N}$ in the modern Antarctic Ocean environment (e.g. Wada et al., 1987) and up to $+3.8 \%$ in the High Arctic (Hobson and Welch, 1992). In Taylor Valley, an increase 
ranging from +2 to $+4 \%$ was calculated between trophic levels (Shaw et al., 2018). Thus, the unusually high $\delta^{15} \mathrm{~N}$ in Friis Hills sediment reflects an ecosystem with multiple trophic levels during the mid-Miocene, which could be associated with insects and birds. This claim is supported by the presence of insects fragments (e.g. Lewis and Ashworth, 2015), feather barbs (Fig. 3.11a) and tardigrades fragments within the sediment. Sea birds such as the Antarctic petrel (Thalassoica antarctica), have colonies as far as $200 \mathrm{~km}$ inland in Antarctica (Svarthamaren colony in Queen Maud Land) with an isotopic signature within the range found at Friis Hills (avg. $\delta^{13} \mathrm{C}_{\text {org }}:-25.0 \pm 0.7 \%$ and avg. $\delta^{15} \mathrm{~N}: 9.2 \pm 0.6 \%$; Delord et al., 2020), making the presence of sea birds at Friis Hills plausible during the mid-Miocene. Although other mechanisms of ${ }^{15} \mathrm{~N}$ enrichment such as denitrification cannot be ruled-out the amount of nutrients supplied by birds in polar environments is much larger than any other source (Skrzypek et al., 2015).

The $\delta^{15} \mathrm{~N}$ enrichment at Friis Hills corresponds to $>4$ trophic levels, based on the upper limit of $\delta^{15} \mathrm{~N}$ of C3 plants being around $+10 \%$ (Michener and Lajtha, 2008) and highest recorded value of $\delta^{15} \mathrm{~N}$ in FHDP2C 18.4\% . The error associated with the $\mathrm{HCl}$ pre-treatment systematically decreases the measured $\delta^{15} \mathrm{~N}$ by up to $4 \%$. Therefore, enrichment at Friis Hills represents a minimum estimate (Kim et al., 2016). The $\delta^{15} \mathrm{~N}$ values are similar to those found in fauna of the Antarctic Peninsula (e.g. Dunton, 2001).
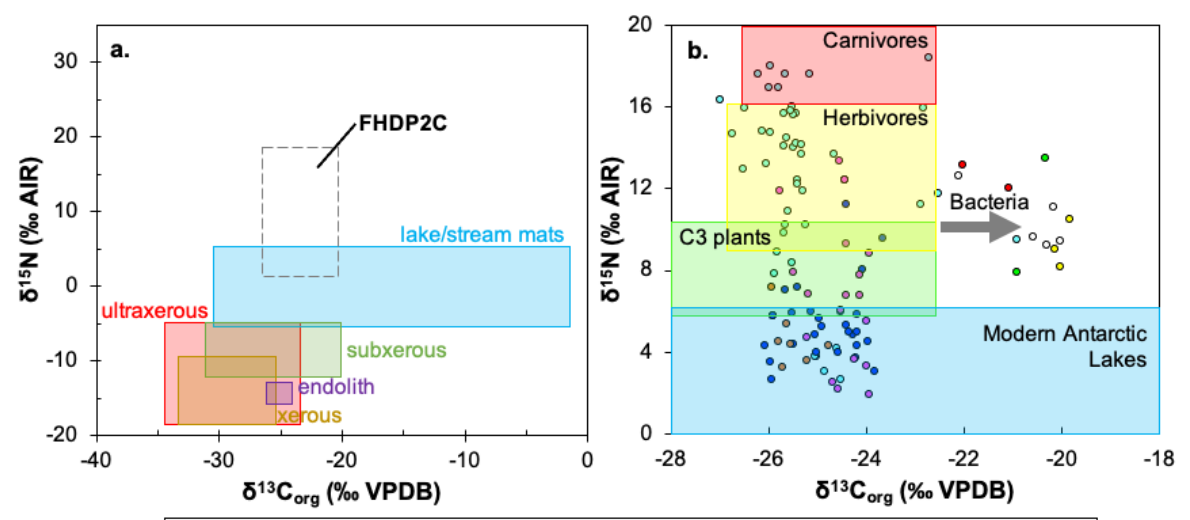

$\circ$ Dry permafrost $\bullet$ Unit $1 \circ$ Unit $2 \circ$ Unit $3 \circ$ Unit $4 \bullet$ Unit $5 \circ$ Unit $6 \circ$ Unit 7

Fig. 3.14 $\delta^{13} \mathrm{C}_{\text {org }}$ and $\delta^{15} \mathrm{~N}$ biplots in bulk sediments. a. $\delta^{13} \mathrm{C}_{\text {org }}$ and $\delta^{15} \mathrm{~N}$ biplot with bulk sediment for ultraxerous environments; Wall, Beacon and University valleys (Faucher et al., 2017, Shaw, 2018), xerous environments; Wright Valley (Hopkins et al., 2009, Shaw, 2018) and, subxerous environments; Miers, Garwood, Taylor and Victoria valleys (Hopkins et al., 2009, Shaw, 2018), lake/stream mats (Lawson et al., 2004, Shaw, 2018) and endolith (Burkins et al., 2000, Hopkins et al., 2009, Shaw, 2018). b. $\delta^{13} \mathrm{C}_{\text {org }}$ and $\delta^{15} \mathrm{~N}$ biplot with signature for $\mathrm{C} 3$ plants-dominated environments (modified from Pearsall (2015), removed other photosynthetic pathways). Modern Antarctic lake signature from Burkins et al. (2000). 


\section{Comparison with modern analogues}

The nearest modern analogue to compare to the mid-Miocene environment at Friis Hills is Taylor Valley. The low elevations of the MDV have a milder climate than modern Friis Hills with summer temperatures $>0{ }^{\circ} \mathrm{C}$ on occasion. This allows for the presence of a lichens, mosses, algae and terrestrial cyanobacteria (e.g. Hopkins et al., 2009), along with the development of more complex ecosystems with multiple trophic levels (Shaw, 2018). However, the climate is too cold and dry to sustain a tundra environment, which results in very low $\delta^{13} \mathrm{C}_{\text {org }}$ and $\delta^{15} \mathrm{~N}$ values and $\mathrm{C}: \mathrm{N}$ ratios inconsistent with biological ratios. Although its position at $77^{\circ} \mathrm{S}$ allows for similarities in terms of daylight and regional climate patterns, the modern subxerous environment of Taylor Valley is a much harsher environment than the mid-Miocene Friis Hills (Table 3.6).

The maritime climatic region of Antarctica includes much of the Antarctic Peninsula (principally the western side) and the nearby islands (King George Island, South Shetland Islands, etc.). It generally receives more precipitation (200-510 $\mathrm{mm} \mathrm{yr}^{-1}$; Bölter and Beyer, 2002) and has milder temperatures with (MSAT $>0{ }^{\circ} \mathrm{C}$; Bölter and Beyer, 2002) than continental Antarctica. It was most likely the last refuge for tundra vegetation in Antarctica before it underwent extinction $~ 5.3 \mathrm{Ma}$ (e.g. Anderson et al., 2011). Vegetation is composed of algae, lichens, mosses, and two species of vascular plants (Deschampsia antarctica and Colobanthus quitensis; Longton, 1967, Bölter et al., 2002, Parnikoza et al., 2011). Soil fauna is limited to nematodes, mites, collemboles, etc., but bird fauna is omnipresent (e.g. Dunton, 2001). As previously stated, similar $\delta^{13} \mathrm{C}_{\text {org }}$ values are found in the $\mathrm{C} 3$ plants of Maritime Antarctica (Lee et al., 2009) and the presence of sea birds in higher trophic levels along with a similar range of $\delta^{15} \mathrm{~N}$ values makes for a good comparison to mid-Miocene Friis Hills ecosystem. However, Maritime Antarctica does not sustain tree species like Nothofagus, implying that it is a colder climate than the Friis Hills during the mid-Miocene.

The cool temperate forest of southern Patagonia ( 46 to $51^{\circ} \mathrm{S},<2000 \mathrm{~m}$ a.s.1.) is dominated by deciduous Nothofagus, and has similar $\delta^{13} \mathrm{C}_{\text {org }}$ values (Peri et al., 2012). However, the region has a MSAT +11 to $+15^{\circ} \mathrm{C}$ and MAP, up to $800 \mathrm{~mm} \mathrm{yr}^{-1}$ (Veblen, 2007), consisting of a milder environment than mid-Miocene Friis Hills. Conversely, the Friis Hills Nothofagus grew in an area covered by a tundra shrub, with low summer temperatures, low precipitation and high wind stress. Their photosynthetic and transpiration rates would have been significantly lower than modern Nothofagus species, as evidenced by the narrow growth rings of the fossil Nothofagus specimens found at Olivers Bluff (Francis and Hill, 1996). The tundra-adapted Nothofagus most likely had a krummholz morphology similar to Salix arctica in the High Arctic (Rees-Owen et al., 2021). Unlike southern Patagonia, the mid-Miocene 
Friis Hills could not sustain a cool temperate forest and was limited to tundra with a single species of dwarf tree.

Carbon and nitrogen of vegetation in the Canadian arctic or in north-west Greenland seem to be more in line with what was found during mid-Miocene at Friis Hills. $\delta^{13} \mathrm{C}_{\text {org }}$ of plant samples in the tundra of Arctic Canada ranges from -27.7 to -24.1 \%o VPDB (avg. -26.1 $\%_{0} \mathrm{VPDB}$ ), and values of $\delta^{15} \mathrm{~N}$ range from +1.0 to $+13.6 \%$ AIR (avg. $+5.5 \%$ AIR; Wooller et al., 2007, Tahmasebi et al., 2018). However, in the low central Arctic $\left(64^{\circ} \mathrm{N}, 400 \mathrm{~m}\right.$ a.s.1), although $\delta^{13} \mathrm{C}_{\text {org }}$ values are comparable to mid-Miocene Friis Hills, the MSAT is higher and precipitation, lower. Alternatively, similar $\delta^{13} \mathrm{C}_{\text {org }}$ values are found in north-west Greenland (Schaeffer et al., 2013), with climatic conditions very similar to estimates from mid-Miocene Friis Hills (MSAT: +4 to $+8^{\circ} \mathrm{C}$ and MAP $<200 \mathrm{~mm} \mathrm{yr}^{-1}$ ). However both the central Canadian arctic and north-west Greenland are beyond the arctic treeline and vegetation is restricted to tundra composed of lichens, mosses, grasses and sedges. The fossil Nothofagus grew in an area covered by a tundra shrub, with low summer temperatures, low precipitation and high wind stress. Their photosynthetic and transpiration rates would have been significantly lower than modern Nothofagus species, as evidenced by the narrow growth rings of the fossil Nothofagus specimens found at Olivers Bluff (Francis and Hill, 1996). The plants most likely had a krummholz morphology similar to Salix arctica in the High Arctic (Rees-Owen et al., 2021).

In a subalpine Canadian sub-arctic site, the Chuck Creek Trail Valley, bulk $\delta^{13} \mathrm{C}_{\text {org }}$ values of $-26 \%$ VPDB and $\delta^{15} \mathrm{~N}$ values of $+13.6 \%$ AIR were encountered $\left(59^{\circ} \mathrm{N}, 1000\right.$ to $1200 \mathrm{~m}$ a.s.l; Verret et al., 2019), with MSAT: $+10.9^{\circ} \mathrm{C}$ and MAP: 500 to $600 \mathrm{~mm} \mathrm{yr}^{-1}$, which is slightly milder and wetter than conditions at Friis Hills during the mid-Miocene. Vegetation in this subalpine tundra consists of grasses and sedges along the valley floor (i.e., Festuca altaica, Carex microchaeta, Hierochloe alpina, Polygonum viviparum) with prostrate deciduous shrubs (mostly birch and willow) occupying the leeward valley walls (Fig. 3.15). This micro-climatic distribution of tundra probably resembles what was found at Friis Hills, which stood several hundred meters above the surrounding topography. The distribution of vegetation was probably spatially variable and dependant on wind patterns, slope, aspect, snow cover and soil drainage.

There appears to be no modern analogue for the mid-Miocene Friis Hills but one can visualize a site in the geographic setting of Taylor Valley with a fauna similar to Maritime Antarctica, deciduous tundra-adapted Nothofagus related to those found in Southern Patagonia, a tundra vegetation comparable to that found in the Arctic with climatic conditions 


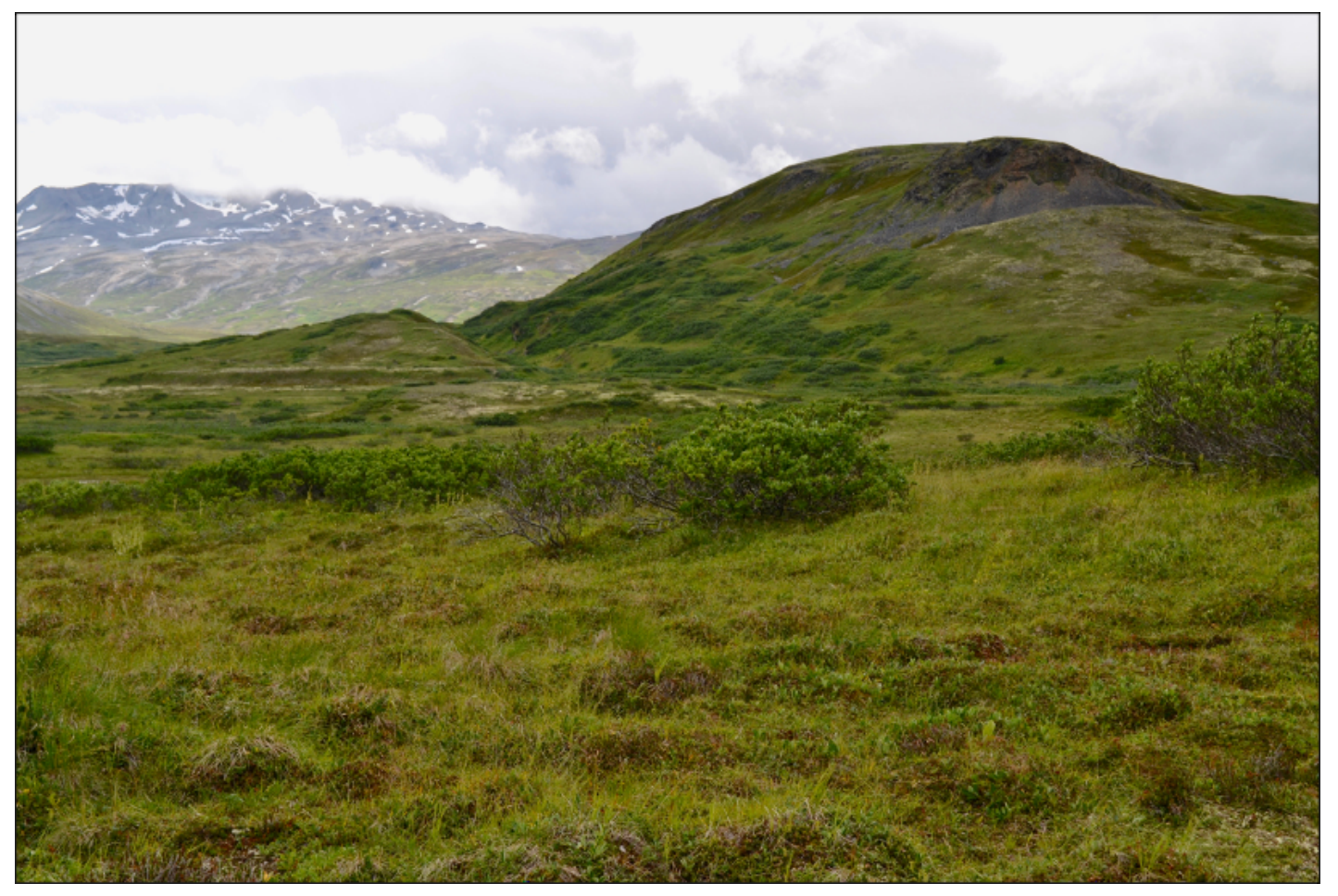

Fig. 3.15 The Chuck Creek Trail Valley in northern British Columbia (Canada), displaying microclimatic distribution of subalpine tundra vegetation as a modern analogue to Friis Hills

analogous to north-west Greenland and a vegetation distribution dependant on microtopography, similar to patterns found in subalpine sub-arctic Canada (Table 3.6). 
62 Organic geochemistry of mid-Miocene permafrost and modern biochemical processes

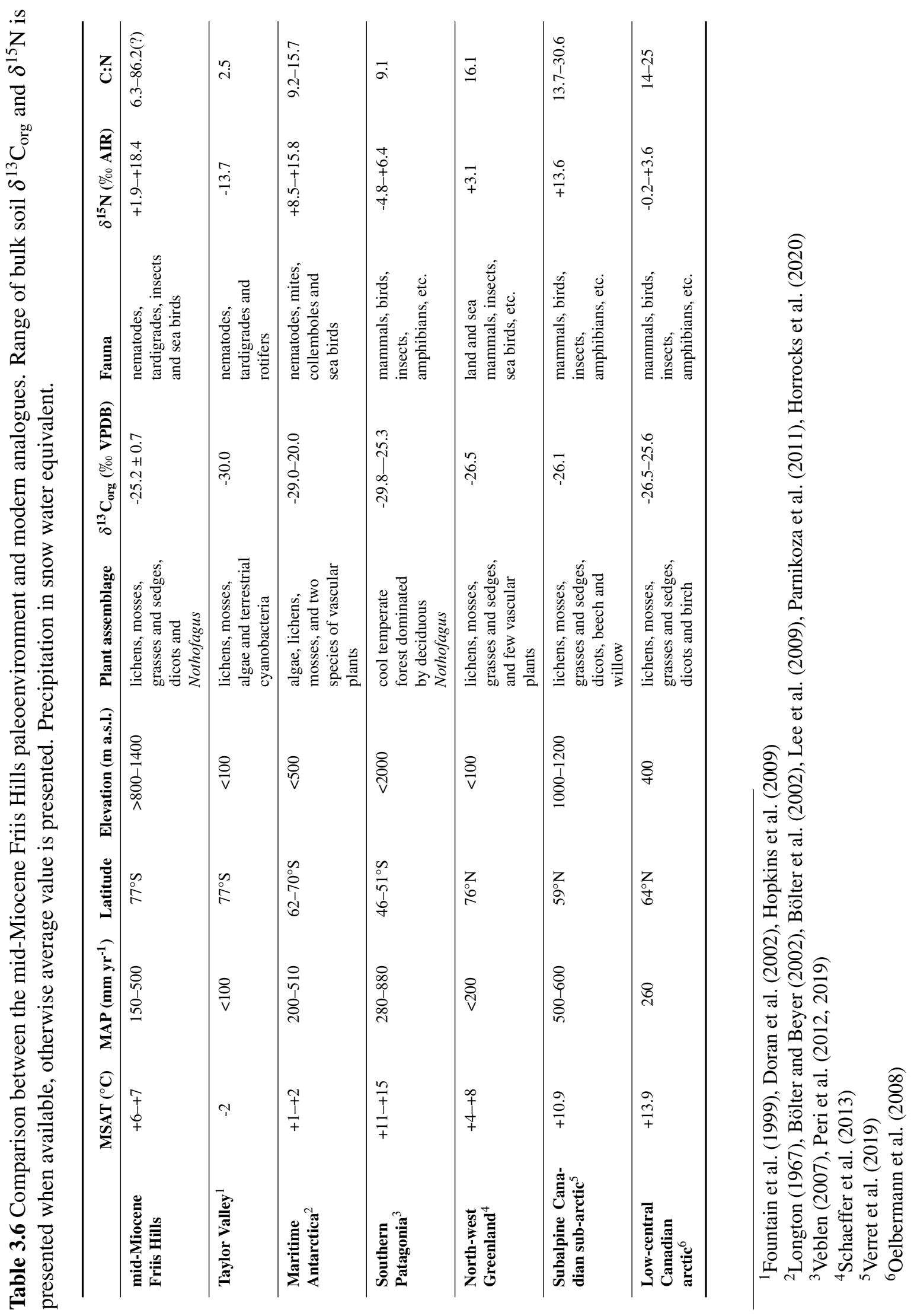




\subsubsection{Provenance and cycling of organic carbon in the near-surface}

The dry permafrost layer had the highest $\mathrm{C}_{\text {org }}$ concentrations in the core, ranging from 1.4 to $10.1 \mathrm{mg} \mathrm{g}^{-1}$ dry soil (avg. $6.0 \pm 0.3 \mathrm{mg} \mathrm{g}^{-1}$ dry soil) and highest $\mathrm{N}$ concentrations in the core, ranging from 0.22 to $0.82 \mathrm{mg} \mathrm{g}^{-1}$ dry soil (avg. $0.53 \pm 0.22 \mathrm{mg} \mathrm{g}^{-1}$ dry soil; Appendix Table D.1). Comparatively, the $C_{\text {org }}$ in the ice-cemented permafrost averaged $2.0 \pm 0.1 \mathrm{mg} \mathrm{g}^{-1}$ dry soil (ranging from 0.6 to $9.9 \mathrm{mg} \mathrm{g}^{-1}$ dry soil; Appendix Table D.1), and $\mathrm{N}$ concentrations ranged from 0.01 to $0.60 \mathrm{mg} \mathrm{g}^{-1}$ dry soil (avg. $0.11 \pm 0.09 \mathrm{mg} \mathrm{g}^{-1}$ dry soil). These values are much higher than those found in other ultraxerous surfaces like University Valley (Faucher et al., 2017) and sites in the Mackay Glacier region (Van Goethem et al., 2020). While the biochemical signature of lower units of the core are compatible with their paleoenvironments, the upper samples $(<1 \mathrm{~m})$ show a clear shift attributable to post-depositional conditions.

Antarctic terrestrial environments harbor the genetic capacity for autotrophic fixation of both carbon and nitrogen (e.g. Hopkins et al., 2006a, Cowan et al., 2011, Niederberger et al., 2015a). What remains unclear is whether these capacities are relic (i.e. legacy footprints), or whether they represent ongoing microbial activity (Cowan et al., 2014).The dry permafrost layer had the lowest $\mathrm{C}: \mathrm{N}$ ratios of the core, ranging from 6.3 to 12.3 (avg 10.6), which corresponds closely to the ratio attributed to microbial biomass ( $\mathrm{C}: \mathrm{N}=60: 7$; Fig. 3.9). The lowest value of 6.3 was found directly at the surface (Fig. 3.9). Biotic influences over biogeochemical cycling in extreme environments such as the MDV can be expressed as the degree at which their biochemical stoichiometry conforms to set ecological ratios (Barrett et al., 2007a). When physical processes are dominant (e.g. physical weathering, aerosol and eolian deposition) and the influences of biota are limited, $\mathrm{C}: \mathrm{N}$ ratios differ from biological ratios (i.e. $\mathrm{C}: \mathrm{N}$ ratios within the signature of organic matter; typically $>4$ ), implying a state of biogeochemical imbalance (e.g. Barrett et al., 2007a, Faucher et al., 2017, Van Goethem et al., 2020). For instance, C:N ratios in the perennially cryotic zone of University Valley were well below ratios associated with biological processes (<1.5; Faucher et al., 2017).

The conformity of surficial dry permafrost sample at Friis Hills to the microbial biomass ratio despite the ongoing atmospheric flux of $\mathrm{NO}_{3}{ }^{-}$(e.g. Witherow et al., 2006, Cary et al., 2010, Jackson et al., 2016) and $\mathrm{C}_{\text {org }}$ (e.g. Lyons et al., 2007) at different rates suggests that the modern environment is regulated by biochemical processes, potentially by nitrifying organisms (i.e. ammonia-oxidizing archaea; Monteiro et al., 2020). Monteiro et al. (2020) found viable microbial communities, although suggesting low turnover of nitrogen, in the ultraxerous zone of the MDV, at higher elevations than Friis Hills (1376 m a.s.l. in Beacon Valley compared to $1244 \mathrm{~m}$ a.s.l. at Friis Hills). Although both autotrophs and heterotrophs within the MDV contribute $\mathrm{N}$ to the system, autotrophs are a source of fixed carbon while 
heterotrophs are a sink. Based on bulk measurements of $\mathrm{C}$ and $\mathrm{N}$, it is impossible to identify the relative ecological roles of autotrophic and heterotrophic communities. However, the radiocarbon date of ca. 40,000 cal years BP at $10 \mathrm{~cm}$ depth suggests that bacterial primary carbon productivity in the dry permafrost may be reactivated over millennial timescales, when climatic conditions or nutrient availability are favourable, and re-establishes biochemical equilibrium between $\mathrm{C}_{\text {org }}$ and $\mathrm{N}$. The surficial sample falls directly on the microbial biomass ratio compared to other dry permafrost samples. This biochemical balance implies that the surface could be reactivated more frequently, where the direct fallout (or other potential external sources) of $\mathrm{NO}_{3}{ }^{-}$and $\mathrm{C}_{\text {org }}$ occurs.

The $\delta^{13} \mathrm{C}_{\text {org }}$ signature of other ultraxerous sites in the MDV have been successfully attributed to the weathering of the Beacon Sandstone, which hosts active endolithic communities (e.g. Friedmann, 1982, Faucher et al., 2017). However, at Friis Hills, the sediment was found to be derived mostly from the neighbouring Ferrar dolerite and Basement complex (Fig. 3.13). The $\delta^{13} \mathrm{C}_{\text {org }}$ signature of mosses and endolithic materials are consistent with that of C3 plants (typically $-25 \%$ to $-30 \%$; Hopkins et al., 2009). On the other hand, bacterial material, which undergoes fractionation with $\mathrm{CO}_{2}$ concentration mechanisms, has an enriched $\delta^{13} \mathrm{C}_{\text {org }}$ signature. At Friis Hills, $\delta^{13} \mathrm{C}_{\text {org }}$ values show a sharp shift within the ice-cemented permafrost, around $1 \mathrm{~m}$, where the average $\delta^{13} \mathrm{C}_{\text {org }}$ changes from $-21.4 \pm 1.4 \%$ to $-25.2 \pm 0.7 \%$ (Fig. 3.9). This shift, irrespective of sediment facies, suggests preferential loss of ${ }^{12} \mathrm{C}$ in $\mathrm{CO}_{2}$ from decomposer respiration which leads to sediment enriched in ${ }^{13} \mathrm{C}$ (Fig. 3.16; Hopkins et al., 2009). The $\delta^{13} \mathrm{C}_{\text {org }}$ signature of the upper section of the core is comparable to that found in other sites in the MDV with active soil respiration (e.g. Garwood Valley; Hopkins et al., 2009). This finding implies that microbial activity extended below the ice table at a time subsequent to the mid-Miocene. The shift in $\delta^{13} \mathrm{C}_{\text {org }}$ likely occurred during a warmer interval when soil respiration depth extended beyond the modern ice table. ${ }^{10} \mathrm{Be}_{\text {met }}$ results (see Chapter 5) suggest a near-saturated active layer extended down to 227 $\mathrm{cm}$ at Friis Hills until $\sim 6.0 \mathrm{Ma}$, thus potentially allowing preferential loss of ${ }^{12} \mathrm{C}$ in the upper section of the core and overprinting the mid-Miocene signature with a ${ }^{13} \mathrm{C}$-enriched signal. During this period, the tundra had likely become extinct from the high elevations of the MDV (e.g. Lewis et al., 2008). With no additional input from C3 plants, the $\delta^{13} \mathrm{C}_{\text {org }}$ signature was overprinted by a bacteria respiration-enriched ${ }^{13} \mathrm{C}$ signal in the upper section of the ice-cemented permafrost. 


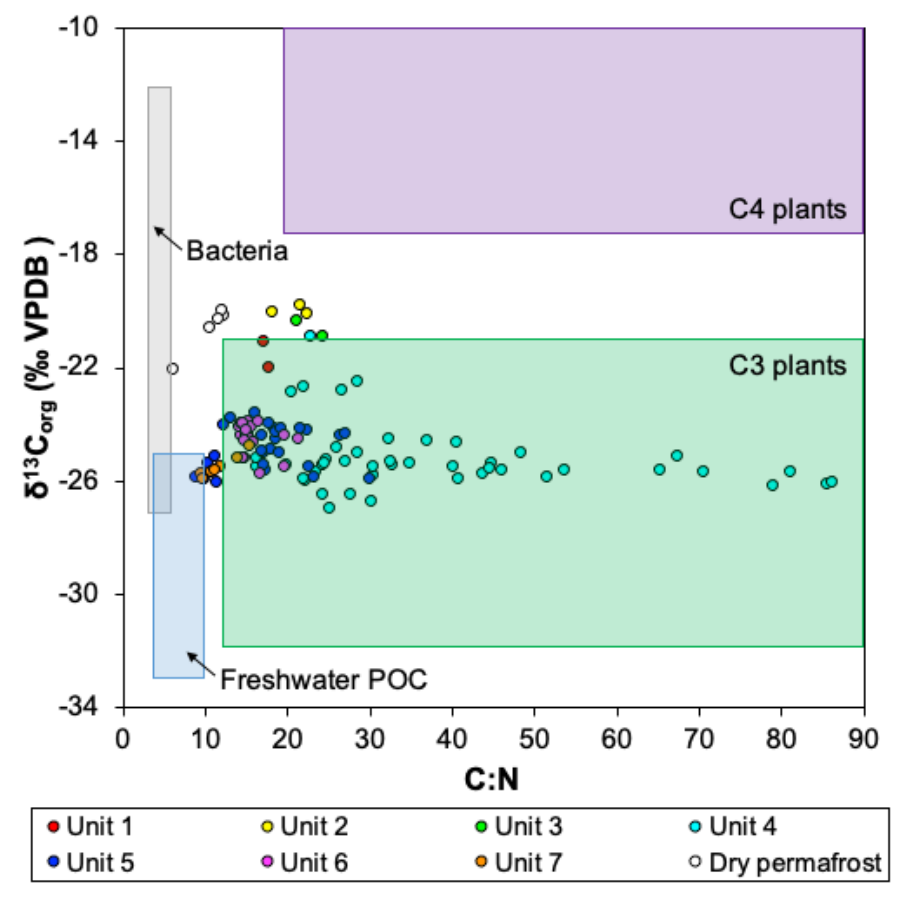

Fig. 3.16 $\delta^{13} \mathrm{C}_{\text {org }}$ and $\mathrm{C}: \mathrm{N}$ in bulk sediment compared to organic matter pools (range of values compiled by Lamb et al. (2006)). Particulate organic carbon (POC) encompasses phytoplankton (e.g. diatoms, dinoflagellates, green algae, euglenoides) and zooplankton.

As demonstrated by the conformity of the dry permafrost layer to biological ratios, the surface pool of organic carbon in the dry permafrost appears to be in equilibrium with contemporary climate and ecosystem (Barrett et al., 2006). The ultraxerous zone of the MDV is periodically regulated by autotrophic organisms, where low rates of metabolism seem to be sufficient to sustain periods of primary productivity over large timescales (millions of years in the case of Friis Hills) and reach a steady-state level of SOC, close to the values measured at Friis Hills. The exposure of the surface for millions of years at Friis Hills allows for an increased carbon stock in the zone affected by microbial activity, above the ice table during significant warm intervals (million-year timescales) and in the dry permafrost (thousand-year timescale). Thus, the calculated $\mathrm{SOC}_{\mathrm{d}}$ below the ice table is greater at Friis Hills than in other ultraxerous sites in the MDV, such as University Valley (dry permafrost was not included in $\mathrm{C}_{\text {org }}$ and $\mathrm{N}$ analyses in University Valley). It reaches $1.3 \mathrm{mg} \mathrm{m}^{-2}$ at $0.5 \mathrm{~m}$ below the ice table while University Valley values reach a maximum of $0.4 \mathrm{mg} \mathrm{m}^{-2}$ at the same depth (Fig. 3.17; Faucher et al., 2017). Below $0.5 \mathrm{~m}$ in the ice-cemented permafrost, the SOC is a legacy of the mid-Miocene period; which averaged $2.0 \pm 0.1 \mathrm{mg} \mathrm{g}^{-1}$ dry soil (ranging from 0.6 to 9.9 $\mathrm{mg} \mathrm{g}^{-1}$ dry soil). 


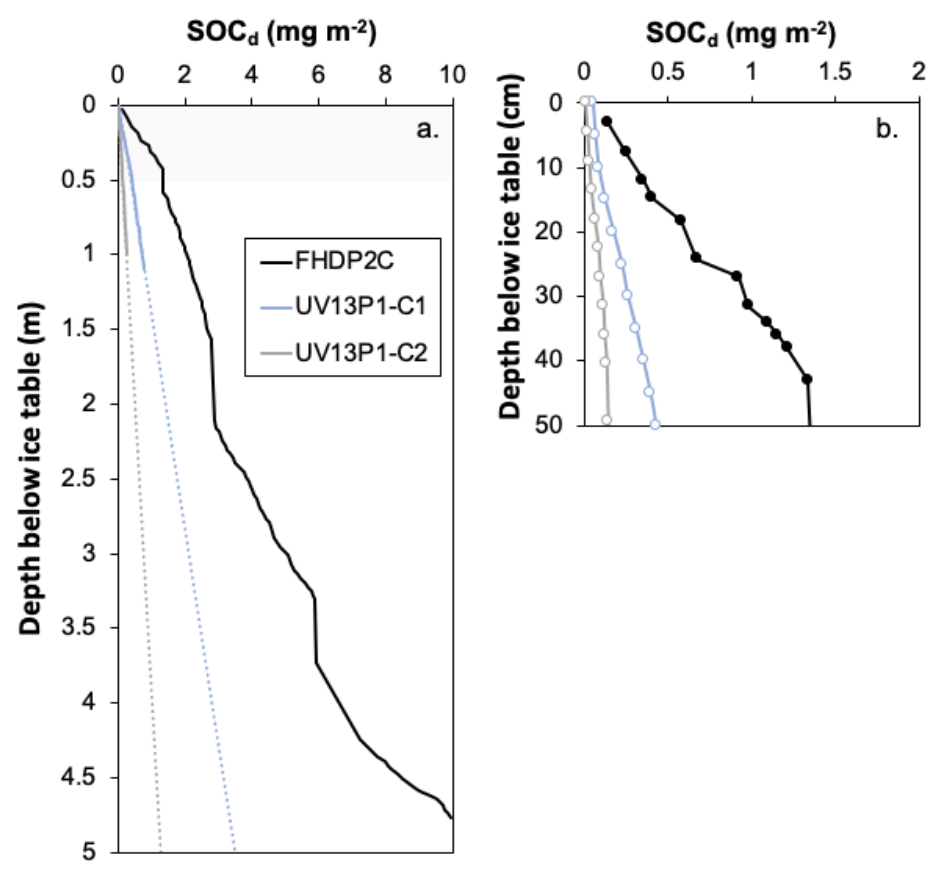

Fig. 3.17 Cumulative soil organic carbon density $\left(\mathrm{SOC}_{\mathrm{d}}\right)$ with depth below the ice table for FHDP2C and two sites in University Valley (UV13P1-C1 and C2; Faucher et al., 2017) a. projected to depth of FHDP2C for comparison (dotted line) and b. upper $50 \mathrm{~cm}$ of ice-cemented permafrost.

\subsection{Conclusion}

The geochemistry of sediments and organics of FHDP2C, which displayed a succession of glacial, glaciolacustrine and subaqueous debris flow facie, has provided important information on the terrestrial environment of the mid-Miocene period ( $14-14.4 \mathrm{Ma})$ :

1. Sediments in FHDP2C were mainly derived from Ferrar dolerite and marginally from the Basement complex.

2. Similar diatom and macrofossil assemblage throughout the core, along with geochemical similarities between the two shallow pond units, suggest that the interglacial periods did not undergo major paleoenvironmental shifts.

3. The SOC below $0.5 \mathrm{~m}$ depth within the ice-cemented permafrost, which is a legacy of the mid-Miocene period, has an average $\delta^{13} \mathrm{C}_{\text {org }}$ of $-25.5 \pm 0.7 \%$ VPDB, indicative of the $\mathrm{C} 3$ plant photosynthetic pathway. This value corresponds to a MAP ranging from 300 to $850 \mathrm{~mm} \mathrm{yr}^{-1}$ (avg. 500-550 $\mathrm{mm}^{-1} \mathrm{yr}$ ). 
4. The unusually high $\delta^{15} \mathrm{~N}$ reflects an ecosystem with numerous trophic levels (up to 3 trophic levels) during the mid-Miocene period.

The upper-meter of the core reflects modern processes:

5. The conformity of dry permafrost samples to biological ratios suggests that the modern environment is regulated by biochemical processes. The current pool of organic carbon in the dry permafrost appears to be in equilibrium with a modern climate and ecosystem.

6. The sharp shift in $\delta^{13} \mathrm{C}_{\text {org }} 0.5 \mathrm{~m}$ below the ice table, suggests microbial activity, likely during a warmer interval when soil respiration depth extended beyond the modern ice table.

7. The calculated $\mathrm{SOC}_{\mathrm{d}}$ is greater at Friis Hills than in other ultraxerous sites in the MDV, because of the exposure to million-year timescales allowing for periods of carbon fixation. 



\section{Chapter 4}

\section{Cryostratigraphy of mid-Miocene permafrost at Friis Hills, upper McMurdo Dry Valleys of Antarctica}

Ground ice is a general term used to define all types of ice contained in frozen ground (Harris et al., 1988). It plays a central role in landscape development of permafrost environments (e.g. Guglielmin, 2012, French, 2017). Most of the existing literature regarding the distribution and origin of ground ice focuses on the Arctic, where periglacial environments are dynamic and extensively monitored (e.g. Zhang et al., 1999, Porter and Opel, 2020). The high-elevations of the McMurdo Dry Valleys (MDV) of Antarctica, known as the stable upland or ultraxerous zone (e.g. Doran et al., 2002, Marchant and Head III, 2007) are thought to have remained frozen under a hyper-arid polar climate since $\sim 13.8 \mathrm{Ma}$ (e.g. Denton et al., 1993, Sugden et al., 1995, Summerfield et al., 1999, Valletta et al., 2015). While sublimation models predict that this subsurface ice should only last a few thousand years (e.g. Hindmarsh et al., 1998, McKay et al., 1998, Schorghofer and Aharonson, 2005, Hagedorn et al., 2007), ground ice is ubiquitous in the MDV in sediments dating back to the Miocene.

Ground ice conditions in the stable uplands remain poorly understood and are expected to be largely absent from the uppermost $1 \mathrm{~m}$ of permafrost (Bockheim et al., 2007). However, ice table depth investigations found that $90 \%$ of the surveyed sites in the stable uplands contained ground ice at shallow depths (ice table depth $<80 \mathrm{~cm}$; Kowalewski et al., 2012, Marinova et al., 2013, Fisher et al., 2016). Numerous shallow cores ( $<6 \mathrm{~m}$ ) in 100,000 to several millions year-old permafrost indicate that ground ice is abundant, often containing ice above pore-saturation, known as excess ice (e.g. Dickinson and Rosen, 2003, Lacelle et al., 
2013a, Lapalme et al., 2017a,b). Ground ice provides a key paleoenvironmental archive of the region (e.g. Sletten et al., 2003, Marchant and Head III, 2007, Levy et al., 2010, Swanger et al., 2010). Besides the burial of glacier ice (e.g. Lacelle et al., 2011, Marchant et al., 2002, Swanger et al., 2010, Swanger, 2017, Swanger et al., 2019), different hypotheses have been advanced to explain the emplacement of ground ice in the permafrost of the upper MDV. For example, in places where ground temperatures remain $<0^{\circ} \mathrm{C}$, ground ice was likely emplaced by vapour-diffusion, whereas in places where ground surface temperatures rise $>0^{\circ} \mathrm{C}$, it was likely emplaced by vapour-diffusion as well as by the freezing of evaporated snowmelt (e.g. Dickinson and Rosen, 2003, Lacelle et al., 2013a, Lapalme et al., 2017a). Therefore, the presence of ground ice and its evolution in the stable uplands is largely affected by late Quaternary processes.

The sediment cores retrieved during the 2016-17 Friis Hills Drilling Project (FHDP) consist of a well-preserved record of Antarctic environmental changes from 14-15 Ma. The objective of this chapter is to understand the origin and evolution of ground ice in a $\sim 50$ m permafrost column over $\sim 15 \mathrm{Myr}$. This objective is accomplished by investigating the cryostratigraphy of the permafrost sediments, including characterizing the cryostructures and determining the ground ice content, as well as major soluble ions and $\delta \mathrm{D}-\delta^{18} \mathrm{O}$ composition of the ground ice. The chapter is separated in two distinct sections: section 4.1 is a review of ground ice and associated processes focusing on the stable uplands of the MDV. The following sections discuss the cryostratigraphy of the FHDP cores by investigating the origin of both near-surface ice and deep ground ice $(>30 \mathrm{~m})$, using the geochemistry of the ice and by modeling the evolution of ground ice content with the REGO vapour-diffusion model.

\subsection{Ground ice and associated processes: a review}

This section focuses on the cases of ground ice in the MDV. In accordance with the terminology defined by Harris et al. (1988), the term ground ice in this chapter refers to ice that forms in-situ, irrespective of the form of occurrence or origin of ground ice but sets apart the cases of buried ice (i.e. ice formed or deposited on the surface and subsequently covered by sediment).

\subsubsection{Heat and moisture transfer processes}

There are five main components in permafrost that affect heat and moisture transfer: sediment, ice, water vapour, liquid water (and its solute load which may affect phase change) and air; 
all of which are free to move within the matrix if appropriate gradients are present (Kane et al., 2001). Conduction is the dominant heat transfer mechanism in permafrost. The main difference between Arctic and Antarctic permafrost regimes is the near absence of free liquid water in Antarctic hyper-arid ground, except the occasional infiltration after snow events (e.g. Friedmann, 1978, Gooseff et al., 2003, Dickinson and Rosen, 2003, Hagedorn et al., 2010, Lacelle et al., 2013a). In the MDV, the majority of water is present as ice and a small fraction as vapour, making vapour-diffusion an important process of moisture transport.

The main factors that influence heat transfer are: (1) phase composition of the ground ice and availability of pore space, which enable vapour-diffusion and/or water advection (i.e. thermal diffusivity); and (2) temperature gradients between the atmosphere and ground (e.g. Boike et al., 2008). Boike et al. (2008) explain the thermal dynamics of permafrost in four different stages: (1) a cold period where temperature is well $<0^{\circ} \mathrm{C}$ and ground water is frozen; (2) a warming period where ground temperature rises; (3) a thawed period where the formation of a thawing front separates frozen and thawed ground, followed by the closing of the zero degree-curtain (e.g. Outcalt et al., 1990, Outcalt and Hinkel, 1996), where surface cooling induces inverse phase change and releases latent heat that opposes the cooling; and (4) the isothermal plateau, where ground temperature remains near $0^{\circ} \mathrm{C}$ for an extended time before the influence of the surface temperature and underlying permafrost make the isothermal plateau disappear and lead back to the cooling stage. In the hyper-arid ground of the MDV, the isothermal plateau is mostly absent because phase change causes minimal release of latent heat. Based on a 1D thermal model compared to decadal observations in Beacon Valley, Liu et al. (2018) concluded that the contribution of latent heat from snowmelt and changes in ice content were negligible. However, surface temperature changes still cause an inversion in soil temperatures around October, which lead to a quasi-isothermal ground well below $0^{\circ} \mathrm{C}$ (Pringle et al., 2003, Hagedorn et al., 2007).

Another particularity of the MDV is the presence of salts which can affect the eutectic point of water (i.e. water may be present in liquid state at temperature $<0^{\circ} \mathrm{C}$ ). For example, surface water has been observed at temperatures $<-4^{\circ} \mathrm{C}$ in small salty hollows (e.g. Campbell and Claridge, 2006). Salt content influences the phase composition of the ground ice and therefore affects the heat and moisture transfer processes.

\subsubsection{Ground ice content and cryofacies}

The amount of ground ice within permafrost varies between ice-rich permafrost, which contains excess ice, and dry permafrost, which contains neither liquid water nor ice (Murton, 
2013). Permafrost can be considered ice-cemented with as little as 5\% moisture content (Campbell et al., 1998b). Ice-rich permafrost typically occurs in frost-susceptible ground, where moisture is abundant such as in the Arctic. On the other hand, dry permafrost, occurs in areas of moisture deficit, such as in the MDV. Ground ice content also depends on a number of factors such as ion concentration, sediment texture and permafrost temperatures (Gilichinsky et al., 2007b).

The amount of ice contained within the ground can be described with three different quantitative parameters: gravimetric water content (GWC), volumetric ice content (VIC) and excess ice (Murton, 2013). GWC is defined as the ratio of the mass of water in a sample to the mass of the dry sample:

$$
G W C(\%)=\frac{m_{\text {water }}}{m_{\text {dry sample }}} \cdot 100
$$

Samples with ice contents below 40-50\% are generally regarded as having low-ice content and those with contents between 50 and $150 \%$ are regarded as having high-ice content (French, 2017). VIC is defined as the ratio of the volume of ice in a sample to the volume of the whole sample:

$$
\operatorname{VIC}(\%)=\frac{v_{\text {ice }}}{v_{\text {total }}} \cdot 100
$$

Saturated grounds have VICs that generally range from 10 to 15\% (Mackay and Black, 1973). Excess ice is the volume of ice that exceeds saturation in the unfrozen sediment in natural conditions (French, 2017). It is defined as the ratio of the volume of supernatant water to the volume of the thawed sample:

$$
\text { Excess ice }(\%)=\frac{v_{\text {water }}}{v_{\text {dry sample }}} \cdot 100
$$

Ground that contains excess ice is described as ice-rich or ice-supersaturated (Murton, 2013, French, 2017). Excess ice content is an indicator of potential volume loss from the thawing of ice-rich grounds. Using VIC, Murton and French (1994) also proposed different cryofacies to classify permafrost according to ground ice content: pure ice $\left(100 \%{ }_{\mathrm{vol}}\right)$, sediment-poor 
ice $\left(\geq 75-100 \%_{\text {vol }}\right)$, sediment-rich ice $\left(\geq 50-75 \%_{\text {vol }}\right)$, ice-rich sediment $(\geq 25-50 \%$ vol $)$ and ice-poor sediment $(<25 \%$ vol $)$.

\subsubsection{Cryostructures and origin of ground ice}

Ground ice structures can be superimposed or inherited (Murton, 2013). Superimposed structures occur during the initial freezing of a homogeneous ground while inherited structures record subsequent variations in the original structure. Mechanical weaknesses and textural inhomogeneities are examples of factors which may cause the development of inherited structures (Murton, 2013). Cryostructures may develop during both freezing and thawing of the ground and may be subsequently altered by changes in temperature gradients and mechanical stresses.

The shape, structure, distribution and proportion of ground ice within frozen ground, which are differentiated and referred to as cryostructures, can provide insight into ground freezing processes (Murton, 2013). The classification proposed by Murton and French (1994), which is extensively used in the Arctic, describes seven different cryostructures (Fig. 4.1): (1) structureless: frozen sediment in which ice is not visible and present within the pores of sand and gravel sediments, consequently lacking structure (also referred to as pore ice or cement ice); (2) lenticular: vertical, horizontal or inclined lens-shaped bodies of ice (the simplest form of segregated ice); (3) layered: vertical, horizontal or inclined, continuous and parallel bands of ice, sediment, or a combination of both; (4) regular reticulate: regular threedimension net-like structure of ice veins; (5) irregular reticulate: irregular three-dimension net-like structure of ice veins; (6) crustal: ice surrounding a rock clast or gravel as a crust or as a rim; and (7) suspended: grains and rocks suspended in ice (also called ataxitic).

\section{Freezing of liquid water}

There are two main types of ice that originate from liquid water: segregated ice and pore ice (Figs 4.1 and 4.2). Segregated ice occurs when water migrates to a freezing front that is either advancing or stable (Mackay, 1983). When near-surface ground temperatures fall $<0^{\circ} \mathrm{C}$ and the freezing front stabilizes, the subsurface water can slowly migrate to the freezing front and form ice (Michel, 2011). If conditions remain stable, ice lenses will continue to grow and become thicker through time (Michel, 1983). If the freezing front is advancing, the formation of ice lenses is limited by the rate of advancement and the rate of water migration to the front (Michel, 2011). This will result in the freezing of the water contained within the sediment 


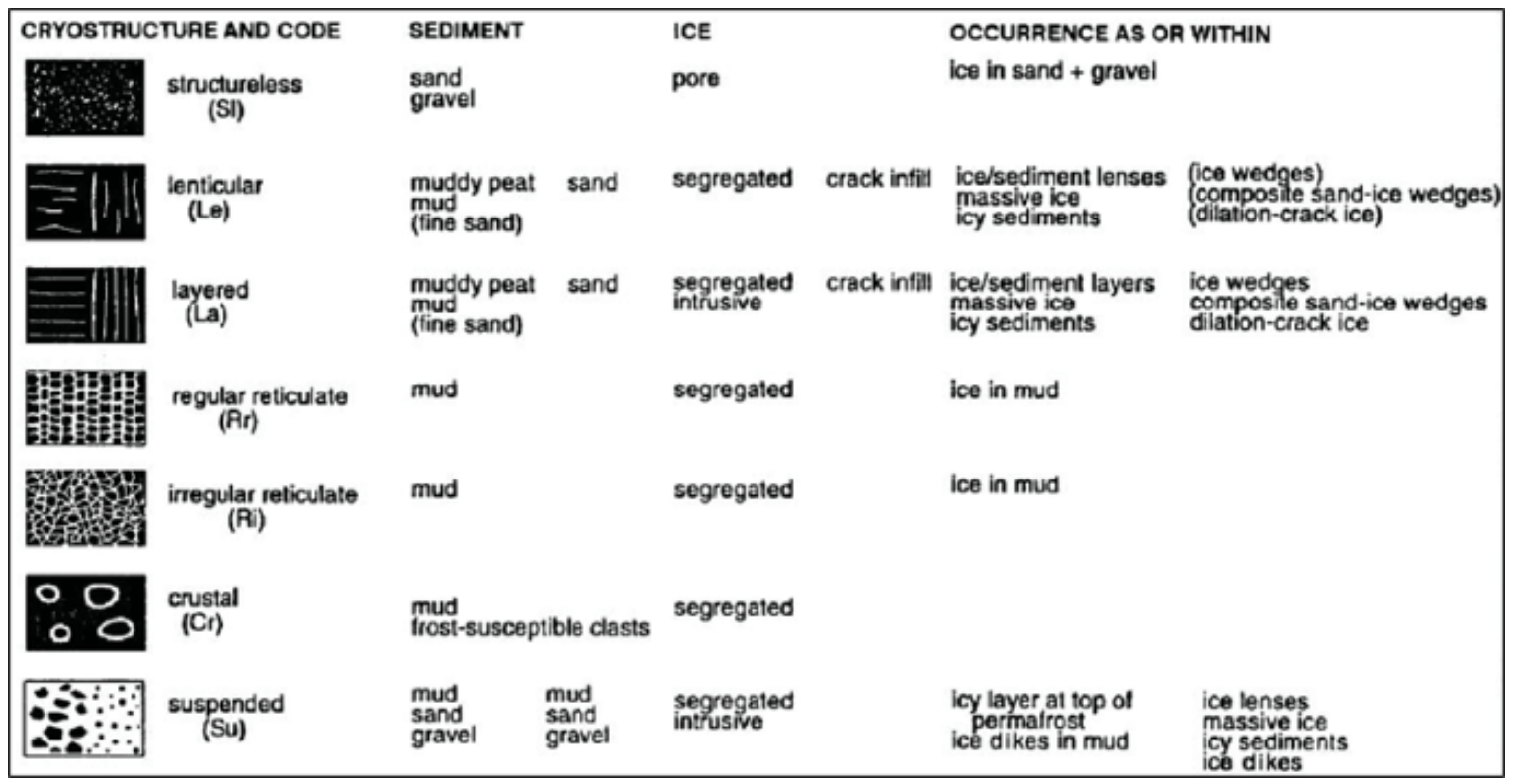

Fig. 4.1 Cryostructure classification by Murton and French (1994)

interstices, or pore ice, or the formation of small ice lenses (Michel, 2011). Boundary conditions greatly impact the styles of freezing resulting in different types and distribution of ground ice (Thomas et al., 2009). In permafrost, two-sided freezing occurs, from the permafrost table upwards and from the surface downwards, resulting in ice segregation at the ice table and near the ground surface, leaving an ice-poor zone between the surface and the ice table (Thomas et al., 2009).

\section{Vapour-diffusion}

Water vapour moves through the ground according to water vapour density: subsurface ice vapour pressure density (VPD) depends solely on temperature while atmospheric VPD is dependent on relative humidity (RH) of the atmosphere (McKay, 2009). If the atmospheric VPD is lower than the VPD at the subsurface ice interface, water vapour will migrate from the ground ice towards the atmosphere. If the gradient is reversed, water vapour will migrate towards the ground ice interface. The redistribution of ground ice in a closed system through vapour-diffusion is considered inherited and creates closed-cavity ice, which is structurally undifferentiable from pore ice (Fig. 4.3). Using the REGO model, Fisher et al. (2016) found that the direction and amplitude of vapour fluxes within the ground was not only dependant on the temperature and RH conditions at the ground surface, but also the depth of diurnal and annual temperature amplitudes within the ground. REGO defines three zones with distinct annual vapour fluxes: Zone 1, which is dominated by diurnal ground temperature cycles and 


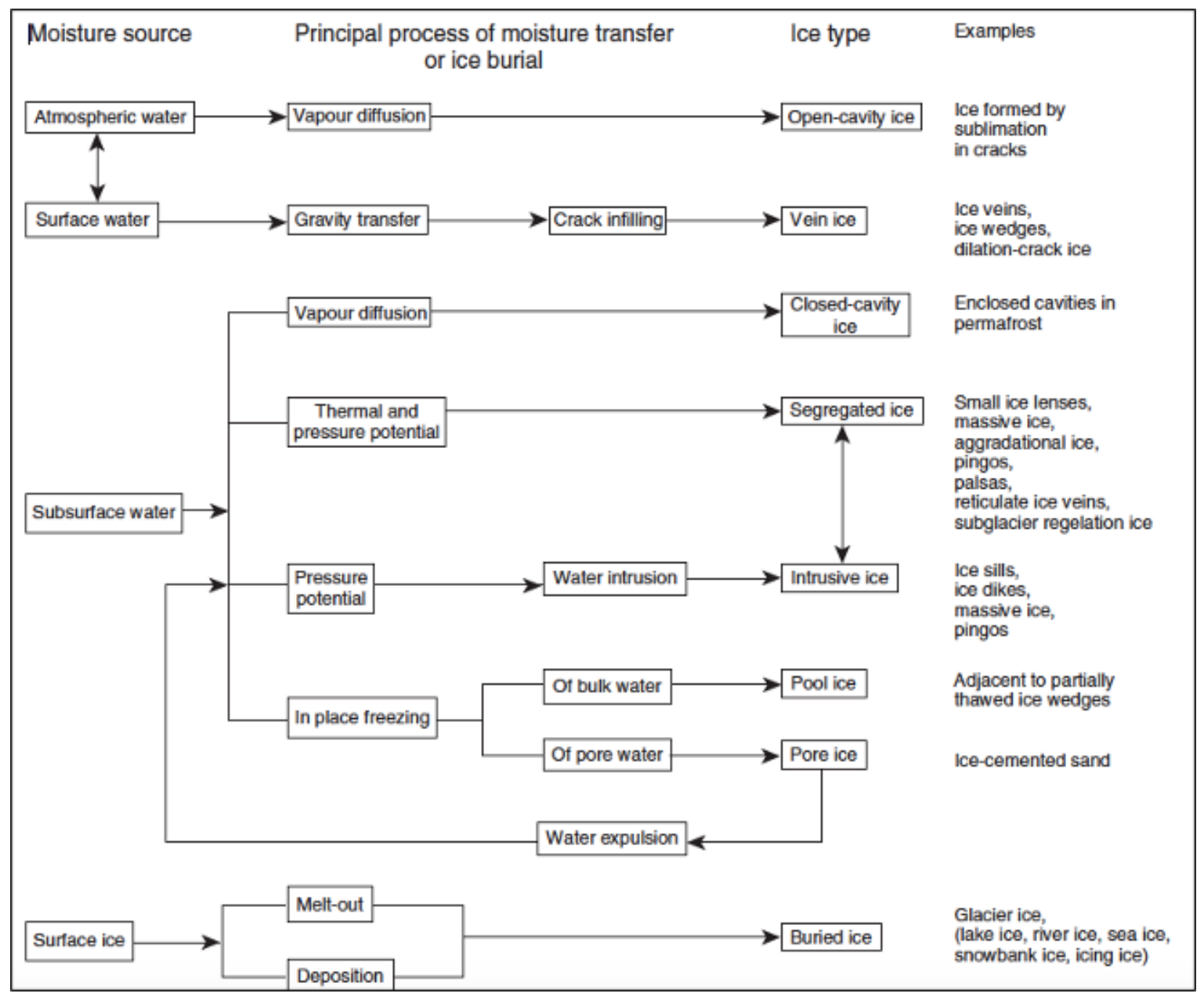

Fig. 4.2 Classification of ground ice based upon the water source (Murton, 2013)

where vapour fluxes are 1 to 2 orders of magnitude higher than the underlying zone, Zone 2 , which is dominated by annual cycles with net downward water vapour transport to the depth of zero annual temperature amplitude (i.e. uppermost 5 to $10 \mathrm{~m}$ ) and Zone 3, which is influenced by upward water fluxes driven by the geothermal gradient that converge to the depth of zero amplitude (Fig. 4.3). Although vapour-diffusion is a slow process, long time scales and stable climatic conditions in the high elevations of the MDV have enabled the ice table depths to reach equilibrium state (Fisher et al., 2016).

\section{Buried ice}

Buried ice is a sub-group of ground ice. There are two types of buried ice: (1) firnified glacier ice and (2) basal ice (Harris and Murton, 2005). Harris and Murton (2005) identified different scenarios where ice burial occurs: (1) sediments are deposited over ice by meltwater, mass 


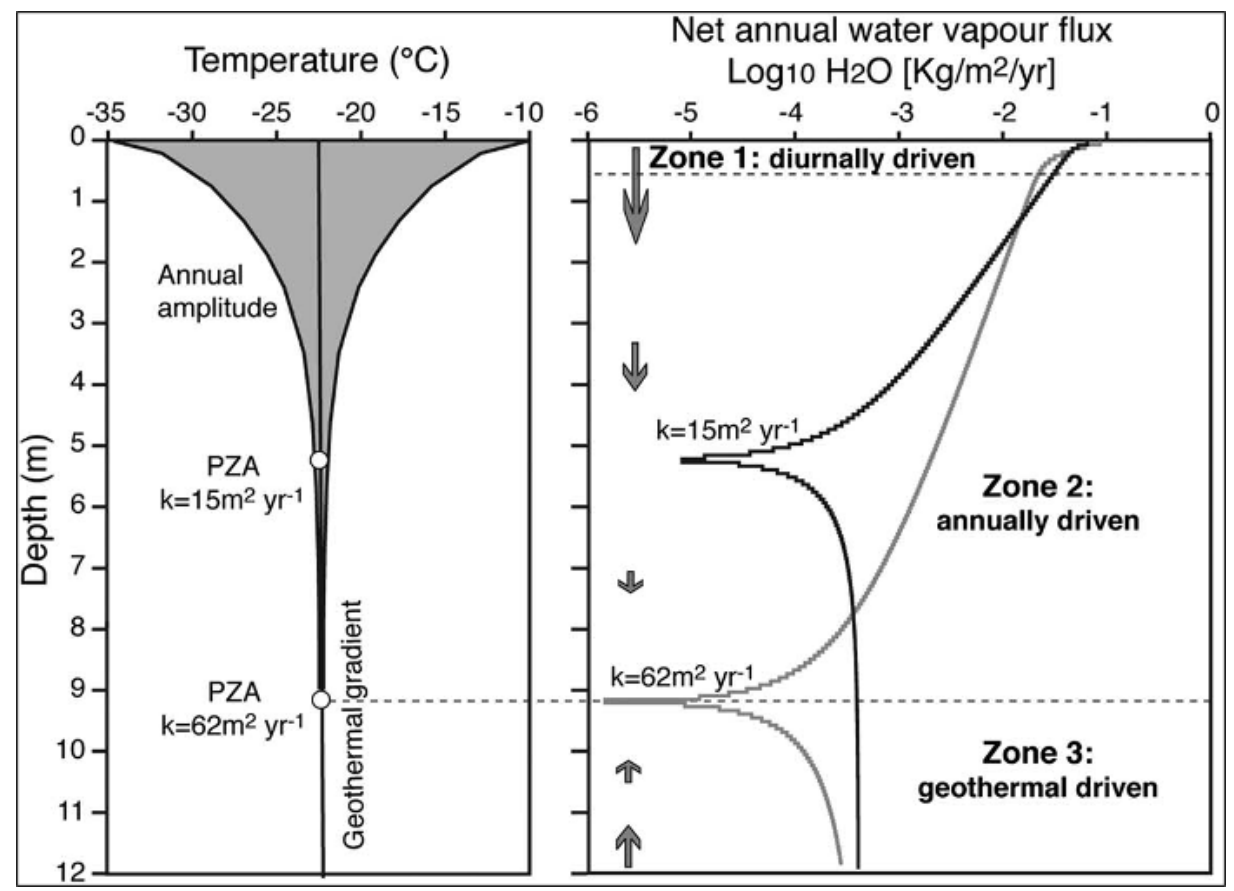

Fig. 4.3 Basic concepts of the REGO model. Modelled vapour flux from diurnal and annual temperature cycles and distribution of ground ice in the ground with varying thermal diffusivities $(\mathrm{k})$ and with a constant geothermal gradient (Fisher et al., 2016). (PZA: point of nearly zero thermal amplitude)

movement, lacustrine or aeolian processes; (2) sediments with basal ice get exposed through melting and create an insulating blanket over the remaining ice; and (3) glacial thrusting and shearing emplaces sediment over ice (Fig. 4.2). In all cases, if the glacier margin lies within the permafrost zone and the debris cover is thicker than the permafrost table, the massive ice can be preserved within the permafrost indefinitely. This has been observed in multiple locations in the Arctic, particularly in the Canadian Arctic, where ice from the Laurentide Ice Sheet and other Pleistocene glaciers have been preserved for thousands of years (e.g. French and Harry, 1990, Sharpe, 1992, Dredge et al., 1999, St-Onge and McMartin, 1999, Dyke and Savelle, 2000, Murton et al., 2005, Kokelj et al., 2017, Lacelle et al., 2018, Coulombe et al., 2019) and in northwestern Siberia, where ice from the Barents-Kara Ice Sheet has been preserved for 80 to 90 kyr (e.g. Kaplanskaya and Tarnogradskiy, 1986, Astakhov and Isayeva, 1988, Svendsen et al., 2004).

\subsubsection{Timing of ground ice formation}

Determining the age of ground ice within permafrost is important to understand its genesis and its role as a paleoenvironmental proxy (e.g. Lacelle and Vasil'chuk, 2013). Previous 
studies have attempted to derive an age for ground ice using material enclosed within the ice and the stratigraphic context (e.g. French and Shur, 2010). However, depending on the genesis of ground ice (superimposed or inherited), interpreting ground ice geochemical results from permafrost can be quite complex. The rate of accumulation of the sediment is not necessarily constant or continuous and infiltration may cause the stable water isotopic record to be missing or replaced with more contemporary water (Stuiver et al., 1976, 1981). This may occur when temperatures are not sufficiently low to enable permafrost formation or because post-depositional melting erased the record (Stuiver et al., 1976). This can also happen through the slow redistribution of ice through vapour-diffusion (Fisher et al., 2016).

Direct ground ice dating using cosmogenic radionuclides and radioisotopes is a growing method in cryostratigraphy (e.g. Nolte et al., 2005). However, applications are still limited. ${ }^{14} \mathrm{C}$ has an age limit of $\sim 50 \mathrm{kyr}$ and requires the presence of $\mathrm{CO}_{2}$ gas bubbles (e.g. Moorman et al., 1996), organic fragments, or dissolved organic carbon within the ice (e.g. Lachniet et al., 2012). ${ }^{36} \mathrm{Cl}$ has an age limit of $\sim 3 \mathrm{Ma}$ (Marchant et al., 2002) and still requires a good understanding of permafrost history for interpretation (e.g. Gilichinsky et al., 2007a, Blinov et al., 2009). Used in groundwater geochemistry, ${ }^{129} \mathrm{I}$ is a radioisotope that has a half-life of $\sim 15.7 \mathrm{Ma}$ and is therefore widely used to date ancient water (e.g. Herod et al., 2013). However, large volumes of water (> 1 L) are required for the analysis, which is often impossible to retrieve in permafrost cores. Chapter 5 suggests a new approach to dating ground ice using ${ }^{10} \mathrm{Be}_{\text {met }}$ as a tracer for water infiltration. The following sub-sections discuss how stable water isotopes and soluble ions within the ice can be used to infer the origin and timing of ground ice.

\section{Isotope geochemistry of ground ice}

Isotope geochemistry has proven efficient in understanding the origin and age of ground ice in both Arctic (e.g. Burn, 1997, Lorrain and Demeur, 1985, Mackay and Dallimore, 1992, Lacelle et al., 2004, 2009, Murton et al., 2004, 2005) and Antarctic (e.g. Dickinson and Rosen, 2003, Hagedorn et al., 2010, Lacelle et al., 2013a, Lapalme et al., 2017a) permafrost. It can be used to understand: (1) the water source (atmospheric, surface or groundwater) and genesis of ground ice; (2) the timing of ground ice formation; and (3) the identification of microbial activity in the ice (Lacelle and Vasil'chuk, 2013). Isotope fractionations, which occur during phase changes (i.e. freezing, condensation, absorption), provide a unique signature to water preserved in permafrost (Lacelle and Vasil'chuk, 2013). 
Stable water isotopes and fractionation processes Given that there is a total of two stable isotopes of hydrogen ( $\mathrm{H}$ and $\mathrm{D})$ and three isotopes of oxygen $\left({ }^{16} \mathrm{O},{ }^{17} \mathrm{O}\right.$ and $\left.{ }^{18} \mathrm{O}\right)$ in nature, a total of nine different water molecules, or isotopologues, exist. These isotopologues differ not only in mass, ranging from a mass of 18 for $\mathrm{H}_{2}{ }^{16} \mathrm{O}$ to a mass of 22 for $\mathrm{D}_{2}{ }^{18} \mathrm{O}$, but also in physical and thermodynamic properties (Criss, 1999). Isotopic fractionation refers to the partioning of water into parts that have different isotopic ratios. More massive isotopes are referred as heavy isotopes $\left({ }^{18} \mathrm{O}\right.$ and $\left.\mathrm{D}\right)$ and less massive isotopes, as light isotopes $\left({ }^{16} \mathrm{O}\right.$ and $\mathrm{H}$ ). Following fractionation, one part is enriched in the heavy isotopes and the other is depleted. The fractionation factor is referred to $\alpha$. For example, when water freezes under equilibrium conditions, it undergoes a Rayleigh-type fractionation, which is expressed by the following equation:

$$
R=R_{0} f^{\left(\alpha_{i}-w-1\right)}+\left(\alpha_{i-w}-1\right)
$$

where $\mathrm{R}$ is the isotope ratio of ${ }^{18} \mathrm{O} /{ }^{16} \mathrm{O}$ or $\mathrm{D} / \mathrm{H}, \alpha_{\mathrm{i}-\mathrm{w}}$ is the equilibrium isotope fractionation factor between water and ice and $\mathrm{f}$ is the residual fraction of water during freezing. The first ice to form will be enriched in ${ }^{18} \mathrm{O}$ and $\mathrm{D}$ (Lacelle, 2011). As freezing continues, the residual water becomes depleted in ${ }^{18} \mathrm{O}$ and $\mathrm{D}$, therefore the subsequent ice becomes progressively depleted in ${ }^{18} \mathrm{O}$ and D. Jouzel and Souchez (1982) also established that the initial isotopic composition of the water has an impact on the isotope composition of ice during freezing, estimated with the following equation:

$$
\alpha_{\delta O}=\frac{\alpha_{i-w} \cdot\left(\alpha_{i-w}-1\right) \cdot(1000+\delta O)}{1000}+1
$$

where $\delta \mathrm{O}$ is the initial isotopic composition of water. Other factors like the freezing rate, boundary-layer thickness and isotope diffusion also influence isotope fractionation kinetics (Lacelle, 2011). On the contrary, when water evaporates, lighter isotopes preferentially go from the liquid phase to the vapour phase. It is an unidirectional kinetic process, meaning that under $\mathrm{RH}<100 \%$, there is no backwards isotopic exchange between the departing vapour and remaining water (Criss, 1999). In conditions where the RH and isotopic composition of water vapour are known and constant over time, the isotopic composition of a water body can be explained by an open system Rayleigh distillation: 


$$
d \ln R_{w}=\left(\frac{1}{\alpha_{\text {evap }}}-1\right) d \ln f
$$

where $R_{w}$ is the isotope ratio of meltwater, $\alpha_{\text {evap }}$ is the fractionation coefficient during evaporation and $f$ is the fraction of remaining water (Criss, 1999). Isotope effects during non-equilibrium evaporation have been explored theoretically and experimentally. RH has an impact on progressive isotopic enrichment during evaporation (Fig. 4.4). The Craig and Gordon (1965) model for quantifying evaporation comprises a combination of equilibrium and kinetic fractionation effects.

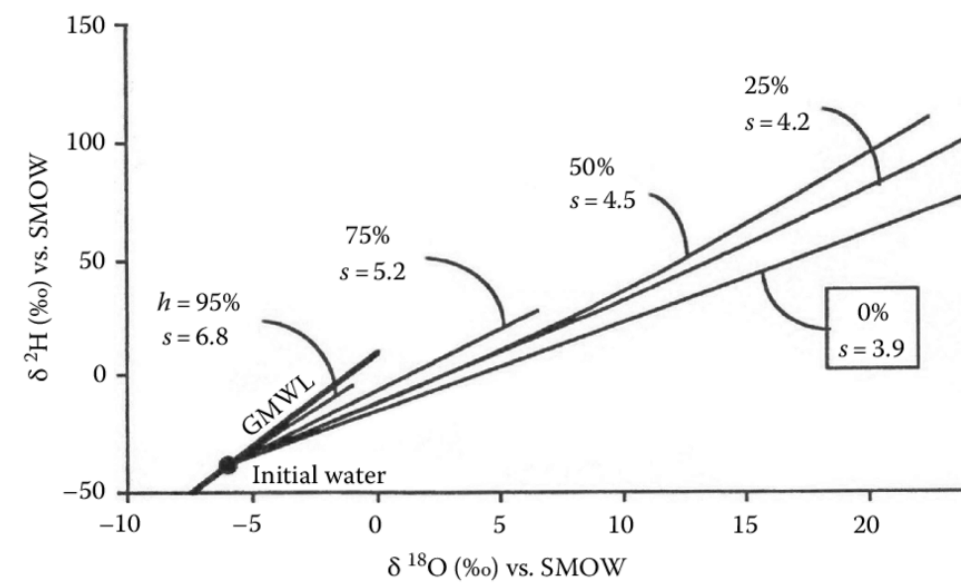

Fig. 4.4 Isotopic enrichment in evaporating water and the effects of humidity. Global meteoric water line (GMWL) in bold (Gonfiantini, 1986)

Isotopic evaporation trends can also be strongly modified by changes in salt concentrations (Sofer and Gat, 1972, 1975). This effect is known as the isotope salt effect and is denoted by $\Gamma$ :

$$
\Gamma=\frac{{\frac{R_{l}}{R_{v}}}^{\text {purewater }}}{{\frac{R_{l}}{R_{v}}}^{\text {saltsolution }}}=\frac{\alpha_{1-v}^{\text {purewater }}}{\alpha_{1-v}^{\text {saltsolution }}}
$$

where $\alpha$ is the isotope equilibrium fractionation factor between solution and vapour (Horita et al., 1993).

Global meteoric water line, local meteoric water line, and $\delta \mathrm{D}, \delta^{18} \mathrm{O}$ and D-excess in meteoric water Craig (1961) established that the global $\delta \mathrm{D}$ and $\delta^{18} \mathrm{O}$ compositions in 
precipitation were highly correlated, with a regression slope of 8 , which corresponds to the global meteoric water line (GMWL):

$$
\delta D=8 \delta^{18} O+10
$$

The slope value of the GMWL provides an approximation for the ratio of the equilibrium fractionation factors between water and vapour for $\delta \mathrm{D}$ and $\delta^{18} \mathrm{O}$ (Lacelle, 2011):

$$
S=\frac{\ln \left(\alpha D_{w-v}\right)}{\ln \left(\alpha^{18} O_{w-v}\right)}
$$

where $\alpha_{\mathrm{w}-\mathrm{v}}$ is the equilibrium isotope fractionation factor between water and vapour. The $\mathrm{y}$-intercept value is $+10 \%$ and corresponds to $d$, known as deuterium excess or D-excess (Dansgaard, 1964).

This value $\mathrm{D}$-excess of $+10 \%$ implies that on a global scale, standardized by the Vienna Standard Mean Ocean Water (VSMOW), kinetic evaporation from the oceanic waters occurs (Lacelle, 2011). This produces water vapour that is isotopically depleted from parent water, but still above the GMWL. Subsequent condensation then results in an enrichment in D, shifted by approximately $10 \%$, which corresponds to D-excess. The values of D-excess in precipitation are therefore related to the changes in temperature and $\mathrm{RH}$ which influence the evaporation process (Merlivat and Coantic, 1975). The value of the slope between D-excess and $\delta \mathrm{D}$ can be approximated with the following equation:

$$
S_{D-\text { excess }-D}=\frac{\ln \left(\alpha D_{w-v}\right)-8 \ln \left(\alpha^{18} O_{w-v}\right)}{\ln \left(\alpha D_{w-v}\right)}
$$

Based on this equation, the regression slope value between D-excess and D in meteoric waters should be approximately 0.04 (for values at $20^{\circ} \mathrm{C}$ ), represented by near horizontal line in a D-Excess- $\delta$ D plot (Lacelle, 2011). Although the GMWL is a good approximation of the isotopic composition of precipitation, locally, air temperature, proximity to moisture sources and trajectories of weather systems over land masses alter the regression slope values of meteoric water lines (Lacelle, 2011). Taken into consideration, these factors define the local meteoric water line (LMWL; Lacelle, 2011). In the lower elevations of the MDV, Gooseff 
et al. (2006) derived the LMWL using precipitation and surface snow and established the following equation: $\delta \mathrm{D}=7.7 \delta^{18} \mathrm{O}-8.7, \mathrm{r}^{2}=0.99$. Lacelle et al. (2011) found a slightly higher regression slope $\left(\delta \mathrm{D}=7.9 \delta^{18} \mathrm{O}+0.8 ; \mathrm{r}^{2}=0.97\right)$ for University Valley (1700 m a.s.1.). Since terrestrial water and ice are derived from precipitation, the modern LMWL, which requires a good understanding of regional hydrology, provides a baseline with which to compare the isotopic composition of ground ice.

Stable water isotope hydrology of the McMurdo Dry Valleys The main source of precipitation in the MDV is snow sourced from the Ross Embayment during the ice-free summer months (Fountain et al., 2010). Therefore, in the MDV, alpine glaciers are depleted in heavy isotopes inland from the coast. This trend can be observed in both Taylor Valley glaciers and Taylor Dome (Fountain et al., 2006). Matsubaya et al. (1979) conducted an extensive study on glaciers and lakes in Southern Victoria Land. They found alpine glaciers and meltwater isotopic values ranging between -210 and $-260 \%$ for $\delta \mathrm{D}$ and between -26 and $-34 \%$ for $\delta^{18} \mathrm{O}$. Taylor Glacier was found to have a lower isotopic ratio $\left(\delta \mathrm{D}=-330 \%\right.$ and $\delta^{18} \mathrm{O}=$ $-42.5 \%$ ) than other alpine glaciers in the area, resembling the isotopic signature of inland snow and ice. In the 1990s, Taylor Dome was drilled to a depth of $554 \mathrm{~m}$, corresponding to an age of $150 \mathrm{kyr}$ (Steig et al., 2000, Grootes et al., 2001). Stable isotope conditions correlated with air temperature fluctuations: $\delta^{18} \mathrm{O}:-37$ to $-40 \%$ during the warmer intervals (MIS 5, 3 and the early Holocene) and -43 to $-45 \%$ during colder intervals (MIS 6,4 and 2; Steig et al., 2000).

Gooseff et al. (2006) categorized the hydrology of the MDV into the following components: (1) glacial snow pack, (2) glacier ice, (3) intermittent valley-bottom snow, (4) stream flow, (5) hyporheic water and (6) lake water. Processes enabling interactions among these storages include: meltwater production (e.g. Von Guerard et al., 1995, Conovitz et al., 1998), snow and ice sublimation, stream and lake water evaporation (e.g. Chinn, 1993, Miller and Aiken, 1996, Bomblies et al., 2001, Lorrain et al., 2002), stream discharge (McKnight and Andrews, 1993), and hyporheic exchange (e.g. Runkel et al., 1998, McKnight et al., 1999, Gooseff et al., 2002, 2003). Using samples collected from 1993 to 2002 within the Taylor Valley hydrologic basin, Gooseff et al. (2006) compared $\delta \mathrm{D}$ and $\delta^{18} \mathrm{O}$ data in (1) fresh snow, (2) snow pits, (3) glacier ice and (4) streams to the GMWL (Fig. 4.5). As established by Craig (1961), they found that all hydrological compartments plotted on a slope less than 8 , generally below the GMWL. Snow pit and glacier ice plotted along a similar slope (7.99 and 7.75 respectively), stream water isotopic values plotted on a slightly lower slope (7.28) while fresh snow was best described by a much lower slope (6.41), possibly attributed to the sublimation fractionation (Gooseff et al., 2006). Stable isotopes from the glacier ice were 
significantly more depleted than stream and lakes samples. Streams were in turn, significantly more enriched than lakes (Gooseff et al., 2006). Isotopic composition of surface waters is initially dictated mostly by meteoric water, but surface evaporation results in a significant enrichment in $\delta \mathrm{D}$ and $\delta^{18} \mathrm{O}$ which plots to the right of the LMWL (Criss, 1999). Amongst the different saline lakes studied, Don Juan Pond, in Wright Valley, was found to have the most enriched isotope signature. The near-surface pore ice studied in the MDV also has an evaporative signature which plots right of the LMWL (e.g. Dickinson and Rosen, 2003, Hagedorn et al., 2010, Lacelle et al., 2013a, ; Fig. 4.6).

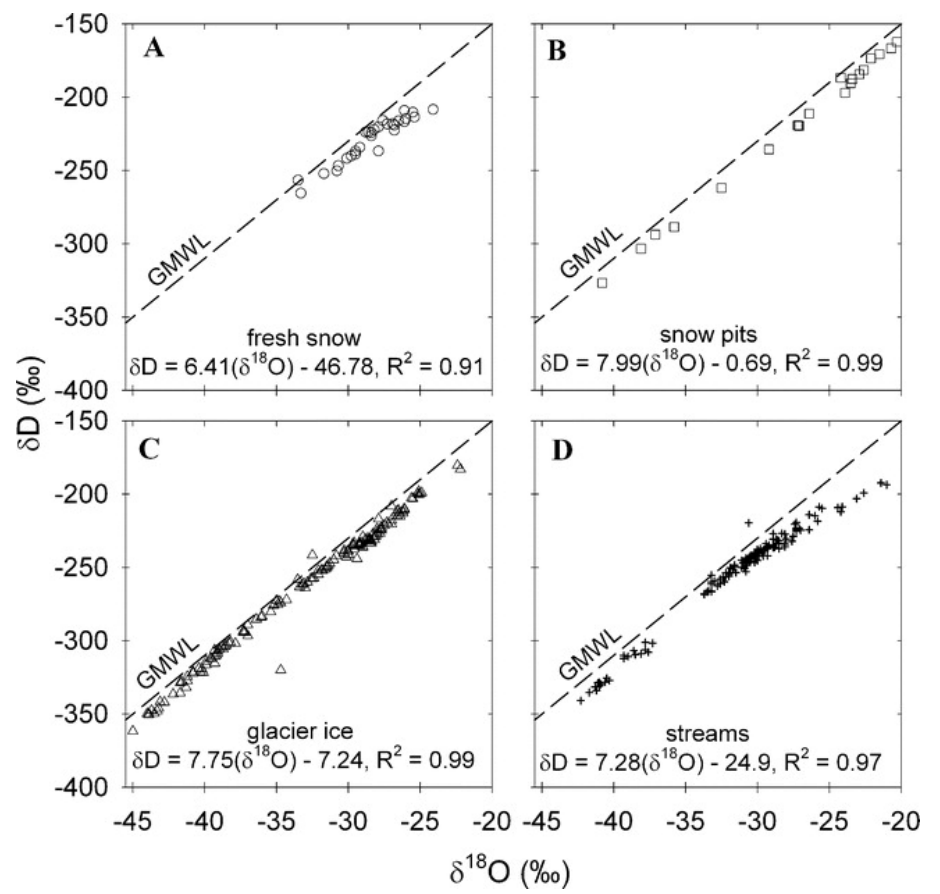

Fig. 4.5 Stable isotope data collected from Taylor Valley from December 1993 to January 1994 for a. fresh snow; b. snow pits; c. glacier ice; and d. stream water (Gooseff et al., 2006).

Interpreting $\delta \mathrm{D}, \delta^{18} \mathrm{O}$ and $\mathrm{D}$-excess values in ground ice The method of comparing the value of the regression slope between the stable water isotopes $\left(\mathrm{S} \delta \mathrm{D}-\delta^{18} \mathrm{O}\right)$ and the GMWL or the LMWL has been widely used since the mid-1970s to study the origin of ground ice (Lacelle, 2011). When water condenses from vapour to snow (or ice), its isotopic composition plots along the LMWL (Lacelle et al., 2013a, Lacelle and Vasil' chuk, 2013). However, when water experiences slow freezing, its isotopic composition generally plots along a regression line with a slope between 3.0 and 7.0, depending on the initial isotopic composition of the water and the freezing rate (Jouzel and Souchez, 1982, Lacelle, 2011, Lacelle et al., 2013a, Lacelle and Vasil'chuk, 2013). Assuming a meteoric origin of ice, the intercept point with 


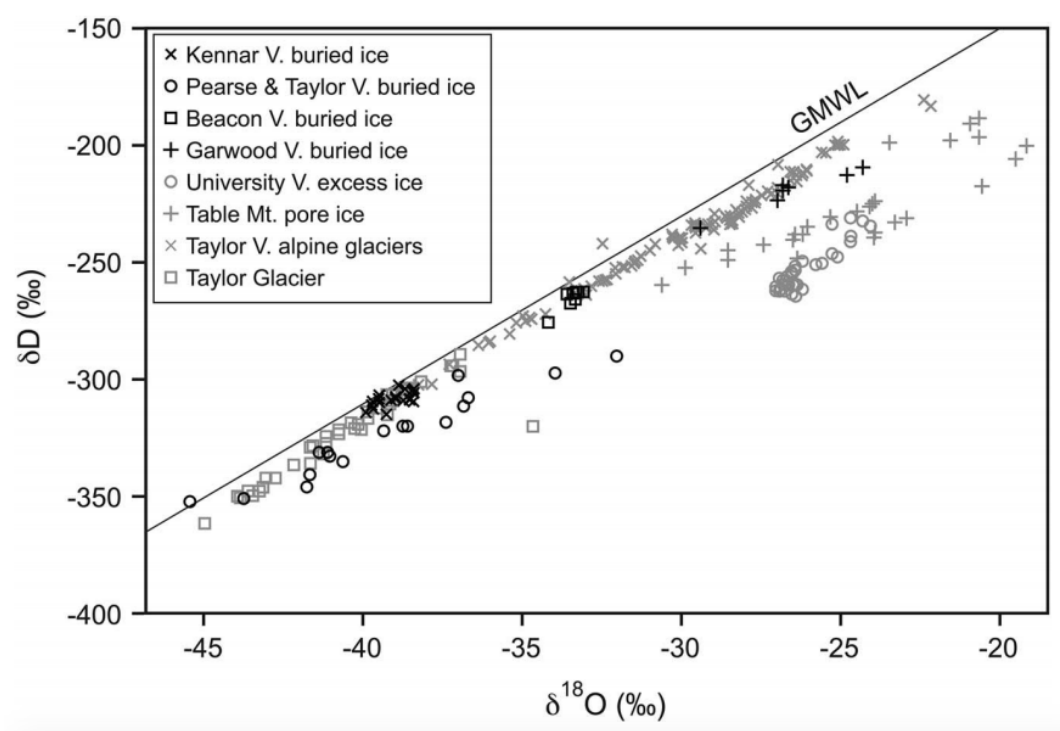

Fig. 4.6 Stable isotope composition for selected buried ice, excess ice, pore ice and glacier ice in the MDV, compiled by Swanger (2017). Taylor Glacier and Taylor Valley alpine glaciers (Gooseff et al., 2006), Beacon Valley buried ice (Sugden et al., 1995), University Valley excess ice (Lacelle et al., 2013a), Table Mountain ground ice (Dickinson and Rosen, 2003), Pearse and Taylor valleys buried ice (Swanger et al., 2010), Garwood Valley (Pollard et al., 2002), Kennar Valley (Swanger, 2017)

the regression slope and the LMWL would indicate its initial meteoric isotopic composition (Hagedorn et al., 2010). Sublimating ice would also plot along a regression slope between 4.0 and 6.0, with low D-excess values (e.g. Stichler et al., 2001, Sokratov and Golubev, 2009, Lacelle et al., 2011, 2013a).

More recently, the D-excess value and its relation to $\delta \mathrm{D}$ has also been used to infer freezing conditions and types of ground ice (e.g. Meyer et al., 2002, Gooseff et al., 2006, Stenni et al., 2007, Raffi and Stenni, 2011, Lacelle, 2011). Unlike $\delta \mathrm{D}$ and $\delta^{18} \mathrm{O}$, variations of D-excess reflect changes in the source of moisture (e.g. Fisher et al., 2004, Jouzel et al., 2007, Stenni et al., 2010). Depleted D-excess values suggest that evaporation fractionation has occurred, which influences the ratio of $\mathrm{O}$ isotopes over $\mathrm{H}$ isotopes (Gooseff et al., 2006). Therefore, the relation between D-excess and $\delta \mathrm{D}$ (and $\delta^{18} \mathrm{O}$ ) in meteoric precipitation are distributed in a horizontal band with a predicted value slope of 0.04 and with a variability associated with seasonal conditions (Lacelle, 2011). A negative relation between D-excess and $\delta \mathrm{D}$ would be suggestive of ice formed by the freezing of liquid water, since freezing of water results in progressive depletion of $\delta \mathrm{D}$ (Lacelle, 2011). 


\section{Soluble ions in ground ice}

Soluble salts are very important indicators of past and present weathering conditions in Antarctica (Campbell and Claridge, 1987). They have also been used as an indicator of relative soil age (Bockheim, 1979, 1982, 1990, Everett, 1971, Pastor and Bockheim, 1980). The hyper-arid conditions of the MDV allow for the preservation of these salts within the soil over millions of years (Bockheim, 1983, Hall et al., 1993, Marchant et al., 1994). In fact, contemporary inputs of material and energy are minimal, adding to the importance of the legacy of past climatic events (Bockheim et al., 2008). Reworking of these salt deposits can be indicators of past lacustrine events (e.g. Field, 1975, Morikawa et al., 1975, Bockheim et al., 2008, Barrett et al., 2010, Toner et al., 2013) and past ice sheet advances (Toner et al., 2013). Vertical migration of water through the ground can also result in remobilization of salts and produce enriched horizons (e.g. Gibson et al., 1983, Dickinson and Rosen, 2003, Wentworth et al., 2005). Although salt composition varies greatly from site to site, the salts in the MDV consist largely of chlorides, nitrates and sulphates anions, and of sodium, potassium, calcium, and magnesium cations (Campbell and Claridge, 1987, Table 4.1).

The proposed sources of salts include marine sea-spray aerosols (Claridge and Campbell, 1968, Keys and Williams, 1981), marine incursions (Nakai et al., 1975), hydrothermal processes (Takamatsu et al., 1993), oxidized nitrogen and sulfur compounds deposited on the East Antarctic Ice Sheet (EAIS; Bao et al., 2000, Claridge and Campbell, 1968, Michalski et al., 2005), chemical weathering (Linkletter, 1971, Claridge and Campbell, 1977, Keys, 1980) and atmospheric fallout (e.g. Takamatsu et al., 1988, Jackson et al., 2016). A combination of sources is likely, followed by subsequent reworking through aeolian processes (Lyons et al., 2003, Fortner et al., 2005, Witherow et al., 2006) and leaching (Wilson, 1979, Keys, 1980, Hagedorn et al., 2010) over million-year timescales.

Salts that are deposited through precipitation of snow and dry fallout become concentrated because of the hyper-arid environment in which evaporation/sublimation exceeds precipitation (Marchant and Head III, 2007, Jackson et al., 2016). As a general rule, salt concentrations in soils are dependent on the proximity of the source. Chloride salts are more dominant near the coast, due to the influence of $\mathrm{Cl}^{-}$-rich marine sea-spray aerosols, whereas sulfate and nitrate salts, derived from $\mathrm{NO}_{3}{ }^{-}$and $\mathrm{SO}_{4}{ }^{2-}$ sulfur compounds in the upper atmosphere (Bao et al., 2000, Michalski et al., 2005), above the EAIS and transported by katabatic winds (Fountain et al., 2010), dominate near the Polar Plateau (Claridge and Campbell, 1968, Keys and Williams, 1981). In an extensive study in Taylor Valley soils, Toner et al. (2013) found that near McMurdo Sound, $\mathrm{SO}_{4}{ }^{2-} / \mathrm{Cl}^{-}$and $\mathrm{NO}_{3}{ }^{-} / \mathrm{Cl}^{-}$ratios were closer to the seawater signature and increased with distance inland. Chemical weathering may 
Table 4.1 Ion composition of permafrost sediments and ice in the MDV

\begin{tabular}{lllllllll}
\hline & & \multicolumn{5}{c}{ Ion Concentration $\left(\mathbf{m m o l ~ k g}^{-1}\right)$} \\
\hline Site & $\begin{array}{l}\text { Distance } \\
\text { inland }(\mathbf{k m})\end{array}$ & $\begin{array}{l}\text { Sediment } \\
\text { age }\end{array}$ & $\mathbf{C a}^{2+}$ & $\mathbf{M g}^{2+}+\mathbf{K}^{+}$ & $\mathbf{N a}^{+}$ & $\mathbf{C l}^{-}$ & $\mathbf{S O}_{\mathbf{4}}{ }^{2-}$ & $\mathbf{N O}^{{ }^{-}}$ \\
\hline $\begin{array}{l}\text { Taylor Valley } \\
\text { COMRAC 3 }\end{array}$ & $<5$ & $\begin{array}{l}\text { Holo- } \\
\text { Pliocene }\end{array}$ & $0.4-0.6$ & $0.8-2.0$ & $13.1-14.7$ & $5.0-6.0$ & $7.8-10.6$ & - \\
\hline $\begin{array}{l}\text { Taylor Valley } \\
\text { TV2013 }\end{array}$ & $\sim 10$ & $\begin{array}{l}\text { Holo- } \\
\text { Pliocene }\end{array}$ & $0.3-2.5$ & $1.0-1.7$ & $1.0-9.0$ & $1.0-10.0$ & $0.1-0.4$ & $0.01-0.09$ \\
\hline $\begin{array}{l}\text { Miers Valley } \\
\text { COMRAC 4 4 }\end{array}$ & $\sim 25$ & $\begin{array}{l}\text { Holo- } \\
\text { Pliocene }\end{array}$ & $1.2-2.0$ & $0.6-0.8$ & $3.3-6.7$ & $2.0-3.0$ & $2.2-5.0$ & - \\
\hline $\begin{array}{l}\text { Table Mountain } \\
\text { TM00 }\end{array}$ & $\sim 40$ & Miocene & $4.3-157$ & $0.17-16.9$ & $1.5-36.2$ & $17.7-218$ & $0.01-2.4$ & $4.1-169$ \\
\hline $\begin{array}{l}\text { Low Beacon Valley }>40 \\
\text { BV1-9/99 }\end{array}$ & Miocene & $66.0-98.0$ & $14.2-17.8$ & $34.5-47.9$ & $5.5-54.0$ & $12.2-17.8$ & $179-339$ \\
\hline $\begin{array}{l}\text { Mid-Beacon Valley }>40 \\
\text { BV10-11/99 }\end{array}$ & Miocene & $6.2-36.0$ & $1.0-14.2$ & $6.2-34.2$ & $1.3-17.2$ & $5.2-17.8$ & $23.4-107$ \\
\hline
\end{tabular}

also lead to increased $\mathrm{SO}_{4}{ }^{2-}$ concentrations (Kelly and Zumberge, 1961, Bao and Marchant, 2006). Salt distribution is also influenced by other factors like soil age, leaching, soil texture, calcite/gypsum dissolution, cation exchange and past glacial and lacustrine events (Toner and Sletten, 2013, Toner et al., 2013).

Interpreting soluble ions in ground ice Soluble ions provide additional information on the processes leading to the formation of ground ice (Lacelle and Vasil'chuk, 2013). Buried surface glacial ice has low dissolved ion concentrations whereas ice formed by the freezing of liquid water has higher ion concentrations, due to the dissolution of soluble ions in ground water (Lacelle and Vasil'chuk, 2013). Ground ice originating from vapour-diffusion also has low soluble ion concentration (Lacelle et al., 2013b). In a marine setting, the ice would display a similar ionic facies to seawater ( $\mathrm{Na}$ :Cl ratio of 1:1; Lacelle and Vasil'chuk, 2013). Fritz et al. (2011) successfully distinguished ground ice originating from glacial meltwater to sea water on the coast of Hershel Island, Canada. A number of studies have also successfully identified the origin of ground ice by coupling $\delta \mathrm{D}$ and $\delta^{18} \mathrm{O}$ ratios with ionic concentrations and ratios. Slagoda et al. (2012) characterized the origin of ice wedges and complex massive ice bodies in the Yamal Peninsula, Russia, and Lacelle et al. (2013a), in University Valley, differentiated between ice originating from freezing of liquid water and vapour-diffusion.

\footnotetext{
${ }^{1}$ Data retrieved from Gilichinsky et al. (2007b); water extractions

${ }^{2}$ Data retrieved from Toner and Sletten (2013); thawed pore ice

${ }^{3}$ Data from W. Dickinson (personal comm. 10/2018); thawed pore ice
} 


\subsubsection{Distribution of ground ice in the McMurdo Dry Valleys}

The earliest and most extensive database for permafrost and ground ice in the MDV is the Dry Valleys Drilling Project (DVDP), where ground ice was found to depths of $320 \mathrm{~m}$ in Taylor Valley (Stuiver et al., 1976). The Coring for microbial records of Antarctic climate (COMRAC) boreholes (5-20 m) from Taylor Valley (COMRAC 3; $50 \mathrm{~m}$ a.s.1.), Miers Valley (COMRAC 4-7; $190 \mathrm{~m}$ a.s.1.), Mount Feather (COMRAC 8-11; $2570 \mathrm{~m}$ a.s.l.) and Beacon Valley (1/99-11/99; $1270 \mathrm{~m}$ a.s.1.) were all ice-cemented and had GWC comparable to the Arctic (25-50\%) immediately below the dry permafrost layer (e.g. Friedmann et al., 1996, Wilson et al., 1996, 2002, Sletten et al., 2003, Gilichinsky et al., 2007b, Fig. 4.7).

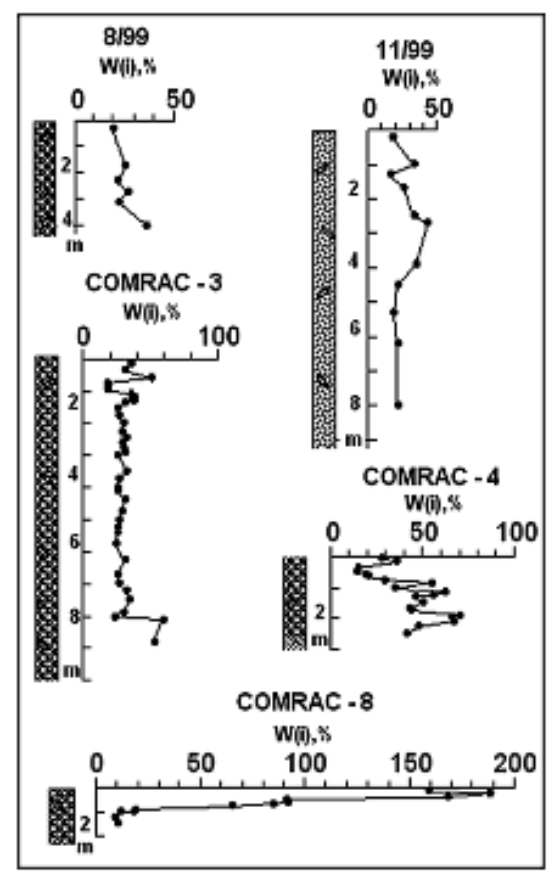

Fig. 4.7 Gravimetric water content (in wt\%) in COMRAC permafrost cores surveyed in the 1990s from Taylor Valley (COMRAC-3), Miers Valley (COMRAC-4), Mount Feather (COMRAC-8) and Beacon Valley (8/99 and 11/99; Gilichinsky et al., 2007b)

Between 1990 and 1999, 350 surficial sites from locations with different climatic conditions and ranges of land surface ages were investigated throughout the MDV (Balks et al., 1995, Campbell et al., 1994, 1997, 1998a,b, Campbell, 2003, Campbell and Claridge, 2006) Most of these sites were dug within the dry permafrost. Campbell and Claridge (2006) found that GWC averaged around 40\% in coastal sites (Marble Point and Scott Base), 34\% at higher elevations (Beacon Heights) and from 0.5 to $5 \%$ in inland sites (Vanda, Convoy Range and New Mountain; Fig. 4.8). 


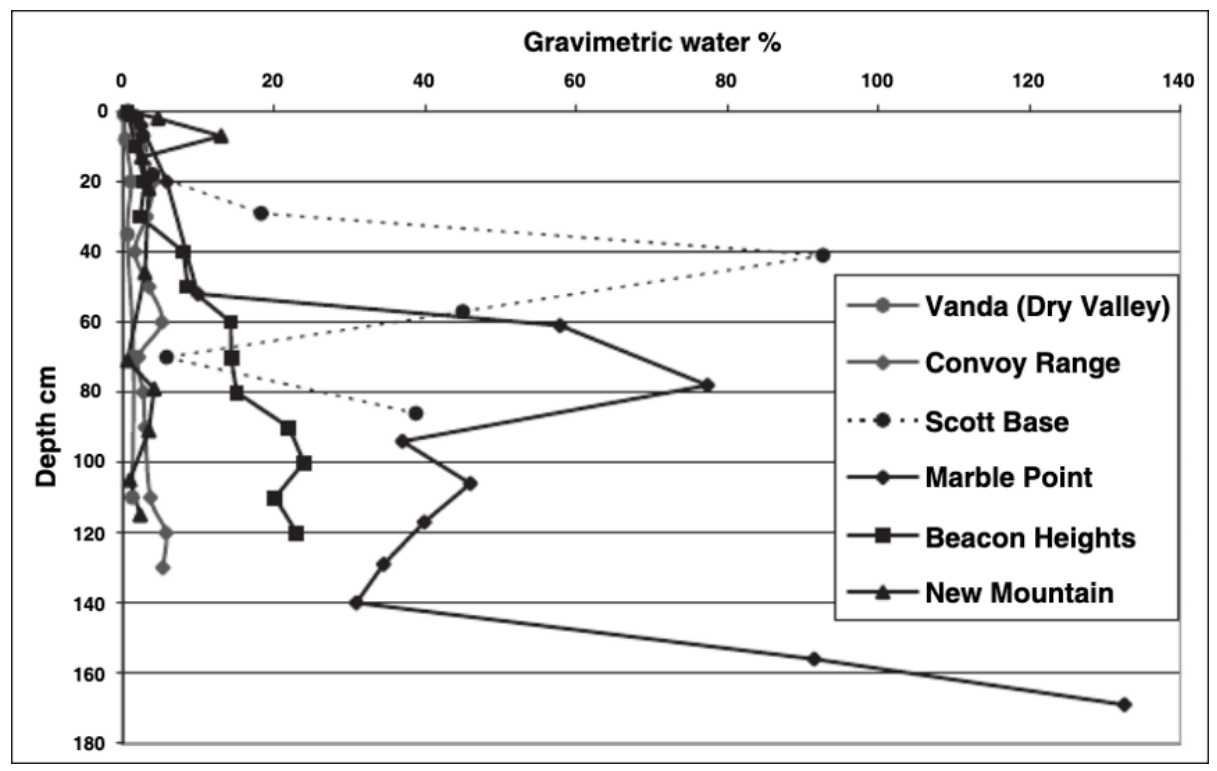

Fig. 4.8 Gravimetric water content for selected surficial sites in the MDV (Campbell and Claridge, 2006)

Based on these surveys, Bockheim et al. (2007) compiled a ground ice distribution map in the MDV and estimated that 55\% of the surface area of the MDV consists of icy permafrost, $43 \%$ consists of dry permafrost and the remaining $2 \%$ consists of massive ice (Fig 4.9). While more than 800 sites to depths of $1.5 \mathrm{~m}$ were surveyed, most of the sites ( $>70 \%)$ considered in the study were situated in coastal and low-elevations regions of the MDV (Campbell and Claridge, 2006). Since those surveys, numerous case studies in high elevations (> $1000 \mathrm{~m}$ a.s.l.) of the MDV (Lacelle et al., 2013a, Lapalme et al., 2017a) have observed icy permafrost or massive ice in zones identified as dry permafrost, suggesting that ground ice has been underestimated in the high-elevations of the MDV (Fig. 4.9). Investigations by Kowalewski et al. (2012) and Marinova et al. (2013) in high-elevation of the MDV concluded that $90 \%$ of the surveyed areas contained icy permafrost at shallow depths $(<80 \mathrm{~cm})$, which conflicts with the idea that ground ice is largely absent from the high-elevations of the MDV.

Near surface ice (pore and lenticular) in Beacon Valley (Marchant et al., 2002), Table Mountain (Dickinson and Rosen, 2003), Victoria Valley (Hagedorn et al., 2010) and Taylor Valley (Toner and Sletten, 2013) has a high concentration of ions and an evaporative isotopic signature (Table 4.2). The presence of this ice is attributed to the percolation of snowmelt, which underwent significant evaporative loss. Cores from University Valley (e.g. Lacelle et al., 2013a, Lapalme et al., 2017a) contain excess ice that was likely emplaced by a combination of vapour-diffusion as well as the freezing of evaporated snowmelt (Table 4.2). 


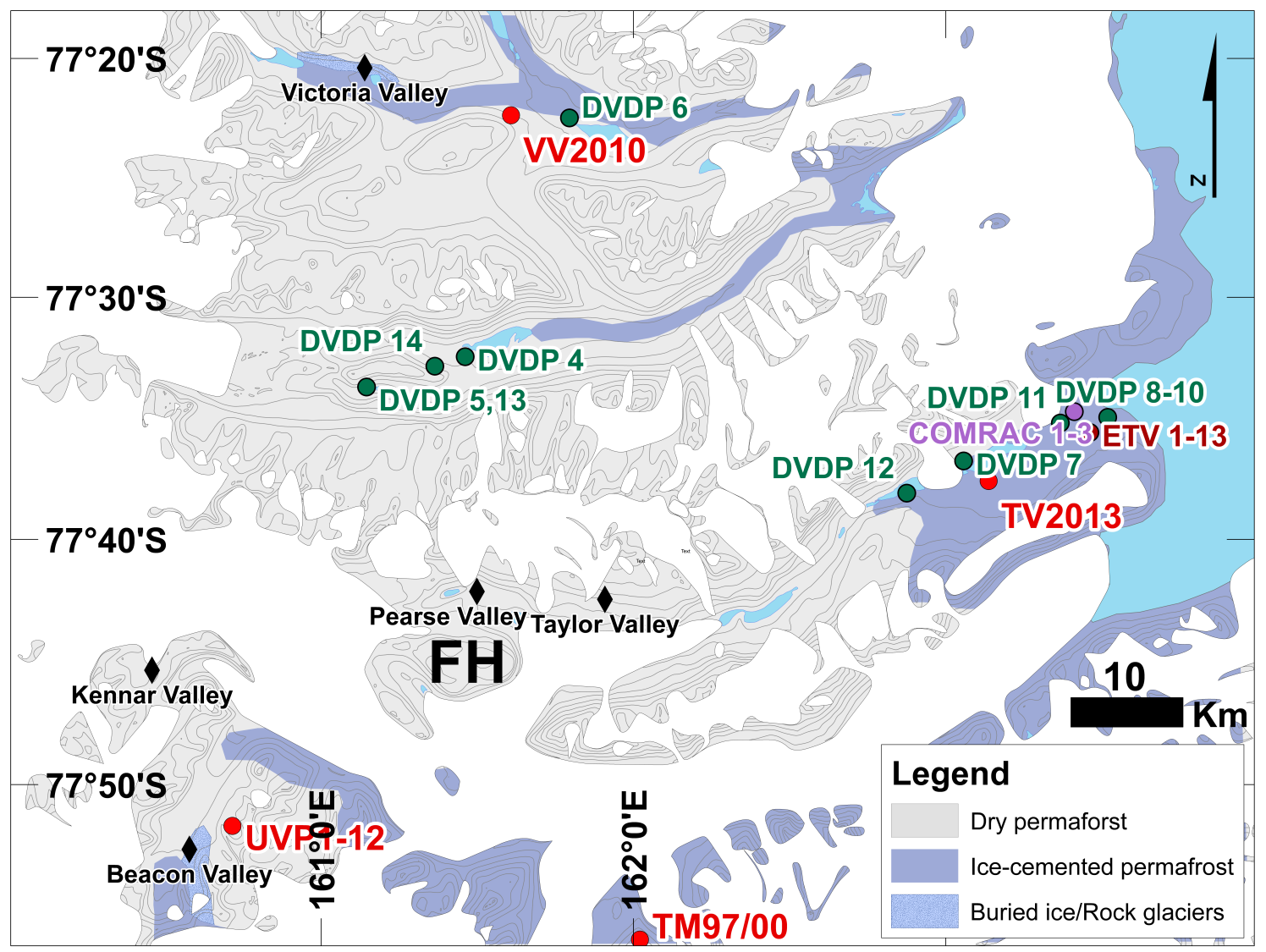

Fig. 4.9 Predicted distribution of ground ice (modified from Bockheim et al., 2007) compared to locations of drilled boreholes in icy permafrost (circles) and Friis Hills (the current study; FH) in the MDV, Antarctica. DVDP 4-14 drill sites in green (McGinnis, 1981), COMRAC 1-11 drill sites in mauve (Wilson et al., 1996, 2002), other drill sites in red: VV2010 (Hagedorn et al., 2010), TV2013 (Toner and Sletten, 2013), ETV 1-13 (Elston and Bressler, 1981, Elston et al., 1983), UVP 1-12 (Lapalme et al., 2017a, Faucher et al., 2017) and TM97/00 (Goff et al., 2002, Dickinson and Rosen, 2003, Dickinson et al., 2012). Drilling sites in buried ice/rock glaciers marked as black diamonds: Kennar Valley (Swanger, 2017), Taylor Valley (Hassinger and Mayewski, 1983, Swanger et al., 2010), Pearse Valley (Hassinger and Mayewski, 1983, Swanger et al., 2019), Beacon Valley (e.g. Sugden et al., 1995), Victoria Valley (e.g. Hagedorn et al., 2007, Bannister et al., 2019) 


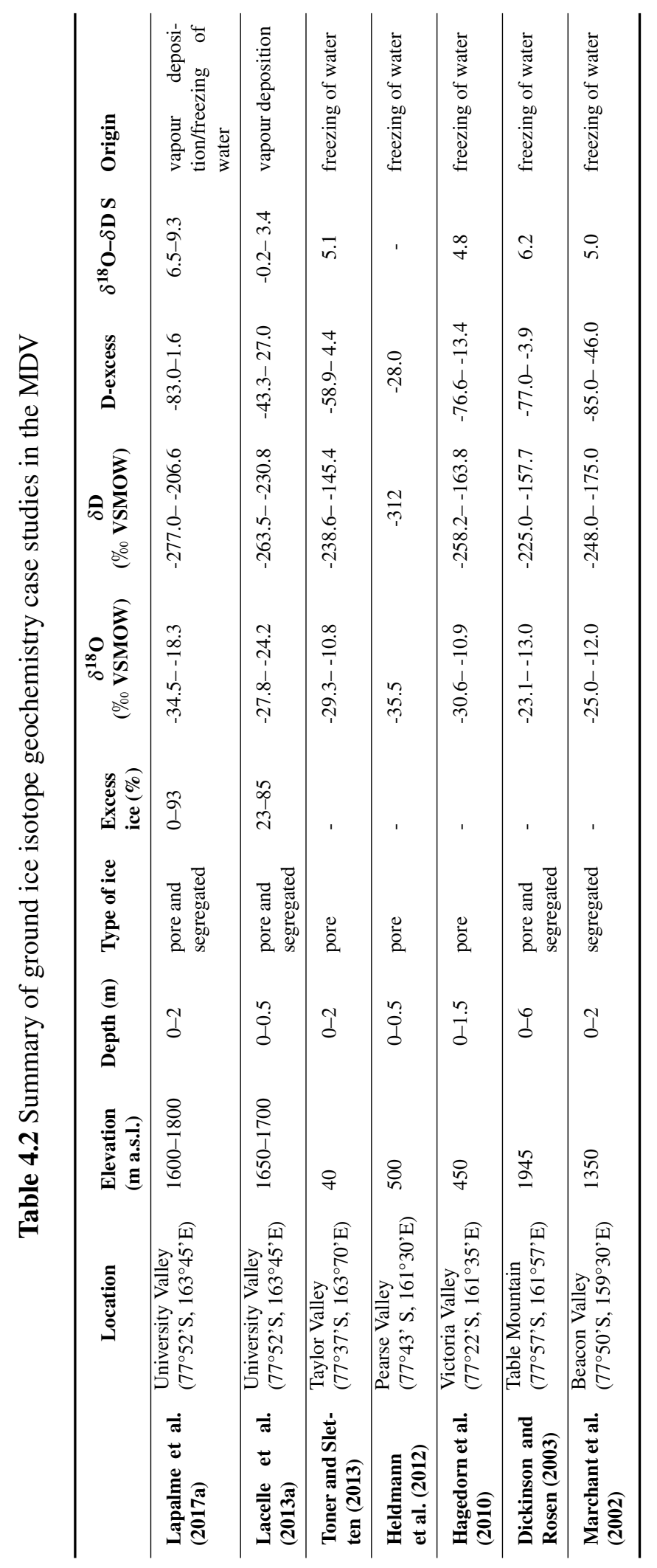




\subsection{Methods}

\subsubsection{Water extraction}

The sub-sampling of the permafrost cores was based on the sedimentological facies. The lacustrine and glaciofluvial deposits were sampled at high resolution $(<1 \mathrm{~m}$ interval) whereas the diamict sections were sampled at $1 \mathrm{~m}$ interval. Ice-rich layers were also sampled. The FHDP2C core $(0.35-5.18 \mathrm{~m})$ was selected for detailed analyses because of its high ground ice content and was sub-sampled at 2 to $5 \mathrm{~cm}$ intervals. The cores were sub-sampled using a tile cutter with a $2.2 \mathrm{~mm}$ blade and placed into polyethylene bags. A total of 168 samples were retrieved from FHDP1A (0.86 to $7.24 \mathrm{~m}$ and 15.15 to $33.60 \mathrm{~m}$ ), FHDP1B (14.59 to $16.33 \mathrm{~m}$ ), FHDP2A (0.61 to $7.05 \mathrm{~m}$ and 10.40 to $17.83 \mathrm{~m}$ ) and FHDP3A (15.02 to 50.48 $\mathrm{m})$ and 105 samples from FHDP2C. All samples were thawed, transferred into pre-weighed graduated polypropylene tubes and, once the sediment settled, the volume of supernatant water and of sediment were recorded. The tubes were then centrifuged to extract the water within the sediment. The water was decanted into vials for subsequent geochemical analyses. Only 33 samples of the 273 contained sufficient meltwater for geochemical analyses; 28 samples were from the uppermost $2 \mathrm{~m}$ and five samples were retrieved from 35 to $45 \mathrm{~m}$ depth in FHDP3A. Once the water was extracted, the sediments were then dried at $85^{\circ} \mathrm{C}$ for $48 \mathrm{~h}$ and the mass of the dried sample recorded.

Ground ice content was assessed by determining the excess ice, GWC and VIC using equations 4.1 to 4.3. Excess ice content is defined as the volume of ice in the sediments exceeding the total pore volume that the sediments could contain under natural unfrozen conditions. The GWC was determined from the mass of the water and dry mass of the sediments. The VIC was determined from the total volume of water, including interstitial water, and the total volume of the sample.

\subsubsection{Stable water isotopes}

The stable water isotopes $\left(\delta^{18} \mathrm{O}\right.$ and $\left.\delta \mathrm{D}\right)$ of the melted ground ice samples were analyzed with a Los Gatos Research Triple Isotope Water Analyzer (TIWA-45-EP), using Off-Axis Integrated Cavity Output Spectroscopy laser absorption technology (Department of Geography, University of Ottawa). This method directly measured ${ }^{18} \mathrm{O} /{ }^{16} \mathrm{O},{ }^{17} \mathrm{O} /{ }^{16} \mathrm{O}$ and $\mathrm{D} / \mathrm{H}$ ratios (Berman et al., 2013). Using a graduated pipette, $1 \mathrm{ml}$ of water sample was placed in $2 \mathrm{ml}$ scintillation vials. Seven measurements were taken with a CTC Analytics LC-PAL 
auto-injector and the mean of the four last measurements were retrieved to obtain one highthroughput result (Berman et al., 2013). A set of three standards calibrated to the VSMOW were added to the analysis to ensure precision. Additionally, duplicates of $20 \%$ of samples were analyzed to test the replicability of the experiment. The $\delta$-notation was used to express the results in reference to VSMOW. The relation between $\delta^{18} \mathrm{O}$ and $\delta \mathrm{D}$ was plotted against the LMWL of $\delta \mathrm{D}=7.9 \delta^{18} \mathrm{O}+0.8$ (Lacelle et al., 2011). Analytical replicability for $\delta^{18} \mathrm{O}$ and $\delta \mathrm{D}$ was $\pm 0.3 \%$ and $\pm 1 \%$, respectively. The $\mathrm{D}$-excess was calculated using the equation of Dansgaard (1964) derived from equation 4.8:

$$
D-\text { excess }=\delta D-8 \times \delta^{18} O
$$

\subsubsection{Soluble ion}

Melted ground ice samples were also analyzed directly for major cations $\left(\mathrm{Ca}^{2+}, \mathrm{Mg}^{2+}, \mathrm{Sr}^{2+}\right.$, $\left.\mathrm{Na}^{+}, \mathrm{K}^{+}, \mathrm{Fe}^{+}\right)$and anions $\left(\mathrm{Cl}^{-}, \mathrm{SO}_{4}{ }^{2-}, \mathrm{NO}_{3}{ }^{-}\right)$. The method used in this chapter, in contrast to the method used to obtain total soluble salt content in dry permafrost, where distilled water is added to dry sediment, provides the actual concentration of soluble ions in the sample (e.g. Lacelle et al., 2013a, Toner et al., 2013). Two sets of samples were prepared, one for cation analysis, and the other for anion analysis. To approximate the concentration of ions, the electrical conductivity of the samples was measured with a handheld conductometer. Using a graduated pipette, $0.1 \mathrm{ml}$ of sample was mixed with $10 \mathrm{ml}$ of Milli-Q to obtain a solution with a concentration of ions within the analytical range of the instrument. The samples undergoing cation analysis were first acidified with ultra-pure $\mathrm{HNO}_{3}$ acid to obtain a $\mathrm{pH}$ of 2. The cation analysis was conducted using a Varian Vista-Pro Inductively Coupled Plasma Atomic Emission Spectrometer (ICP-AES) while the anion analysis was done by ion chromatography using a Dionex-100 (Geochemistry Laboratory, University of Ottawa). To compare samples with different ice contents, the measured concentrations were normalized using the following equation:

$$
\text { Corrected } C_{\text {ions }}=\frac{\text { Measured } C_{\text {ions }} \times m_{\text {water }}}{m_{\text {sediment }}}
$$

The charge balance error was calculated by first converting the measured ppm values to their charge milliequivalent in meq $\mathrm{L}^{-1}$ and by subsequently comparing the positive and 
negative charge. A median charge balance error of $-3.5 \%$ was calculated for the near-surface samples, and a charge balance error of $+8.26 \%$ for the deep samples, suggesting that dissolved inorganic carbon, such as $\mathrm{HCO}_{3}{ }^{-}$and $\mathrm{CO}_{3}{ }^{2-}$, were not major missing ions.

\subsubsection{The REGO model}

\section{Lacelle and D. Fisher created the WATERREGO and REGO models and generated model outputs.}

The REGO model is a dynamical 1D water vapour transport model which can be applied to icy and dry sediment. It includes both diffusion (Fick) and advection fluxes (Darcy flow), along with phase changes (Fisher, 2005, Fisher et al., 2016). The diffusive water flux component is dependant on the thermophysical properties of the sediment, while the direction of vapour-diffusion is dependent on the vapour density gradient in the column similar to other models (e.g. Hindmarsh et al., 1998, Hagedorn et al., 2007, Kowalewski et al., 2011, Liu et al., 2015). What sets REGO apart from these models is the coupling of diurnal and annual ground temperature cycles and their diminishing effects from the surface down, as well as the effect of the geothermal gradient in the opposite direction. REGO progressively reduces porosity as ice accumulates in the ground. However, porosity is never zero as tensile stress induces cracks, allowing vapour to move though the ground matrix over time (Fisher et al., 2016). The WATEREGO model is a time-varying 1D liquid water transport model. Similarly to REGO, it also includes both diffusive and advective transport driven by stress fields (dependant on thermophysical characteristics of soil such as dry porosity, density, tortuosity and thermal diffusivity) in the ground, along with phase changes (Lacelle et al., 2013a). It is also coupled with temperature cycles and the geothermal gradient. The model allows the assessment of unfrozen water content in icy permafrost, the direction and speed at which the water is transported and the depths where it accumulates or is removed (Lacelle et al., 2013a).

The evolution of an initial ground ice profile in the $50 \mathrm{~m}$ sediment sequence was assessed using the REGO model and its WATERREGO subroutine (Fisher et al., 2019, 2020). The model allows for evolving residual unfrozen water (including its chemistry and its freezingpoint temperature, under changing soil temperature and water-ice phase) to migrate in the icy soils by diffusive and advective transport driven by stress fields over diurnal and seasonal temperature cycles. The modelling also takes into account the effect of Van der Waals (VdW) forces that are effective at moving unfrozen water in the uppermost $1 \mathrm{~m}$. The model uses a modified Rempel-type equation to determine the fraction of residual volume of water in 
freezing soils. However, during the freezing of water at a given temperature decrement, ions are concentrated in the residual water and the new ionic concentration can produce a freezing-point temperature that may be lower than the surrounding soil temperature. This produces an instability in the equation that would force the ground ice to completely melt, but REGO limits the amount of ground ice that can melt based on a heat energy exchange (see eq. (12) in Fisher et al. (2019)). The model then combines the results of many possible values of parameters related to soil types, thermal properties and temperature cycles and uses them to make ensemble averages of bulk water speeds, their derivatives with depth and the unfrozen water content at different time steps. The model was intended to produce ensemble average profiles that could be compared to the average profiles of a large suite of boreholes in permafrost in varying terrain (10 or more). In the case of Friis Hills, the number of boreholes is small and they are close together, but the modelling results are informative. The model inputs are listed in Appendix Table G.1 and are representative of the environmental conditions at Friis Hills.

\subsection{Results}

\subsubsection{Cryostratigraphy and ground ice content}

The moisture content in the surficial dry permafrost was lowest at the surface $\left(3 \%_{\mathrm{vol}}\right)$ and increased towards the ice table where it reached $10 \%$ vol. The amounts of ground ice in the icy permafrost were consistent between the five cores and showed a general decrease with depth (Fig. 4.10). Ground ice content was highest in the uppermost $1 \mathrm{~m}$ where it averaged $29 \%_{\mathrm{vol}}$, classifying this interval as ice-rich sediments (Figs 4.10 and 4.11). Ice lenses 0.2 to $3.0 \mathrm{~cm}$ thick were also observed in this interval (Fig. $4.12 \mathrm{a}-\mathrm{e}$ ). The VIC progressively decreased between 1 and $5 \mathrm{~m}$ (from $\sim 23$ to $10 \%$ vol ) and the cryofacies changed to ice-poor sediment (Figs 4.10 and 4.11). Between 5 and $20 \mathrm{~m}$, the VIC was lowest and had values comparable to the surface layer of dry permafrost ( 2 to $10 \%$ vol $)$. The VIC increased in the 20 to $30 \mathrm{~m}$ depth interval, averaging $\sim 13 \%$ vol. Below $30 \mathrm{~m}$, the VIC continued to increased, averaging 16 to $21 \%$ vol and two ice lenses ( 2 and $15 \mathrm{~cm}$-thick) were found in FHDP3A at 37 and $43 \mathrm{~m}$ depth, respectively, in massive diamictites (Figs 4.10 and 4.12f). Ground ice was found in all sedimentological facies, although there was a slight positive correlation between ice content and clay-silt content (Fig. 4.10 e-f). 


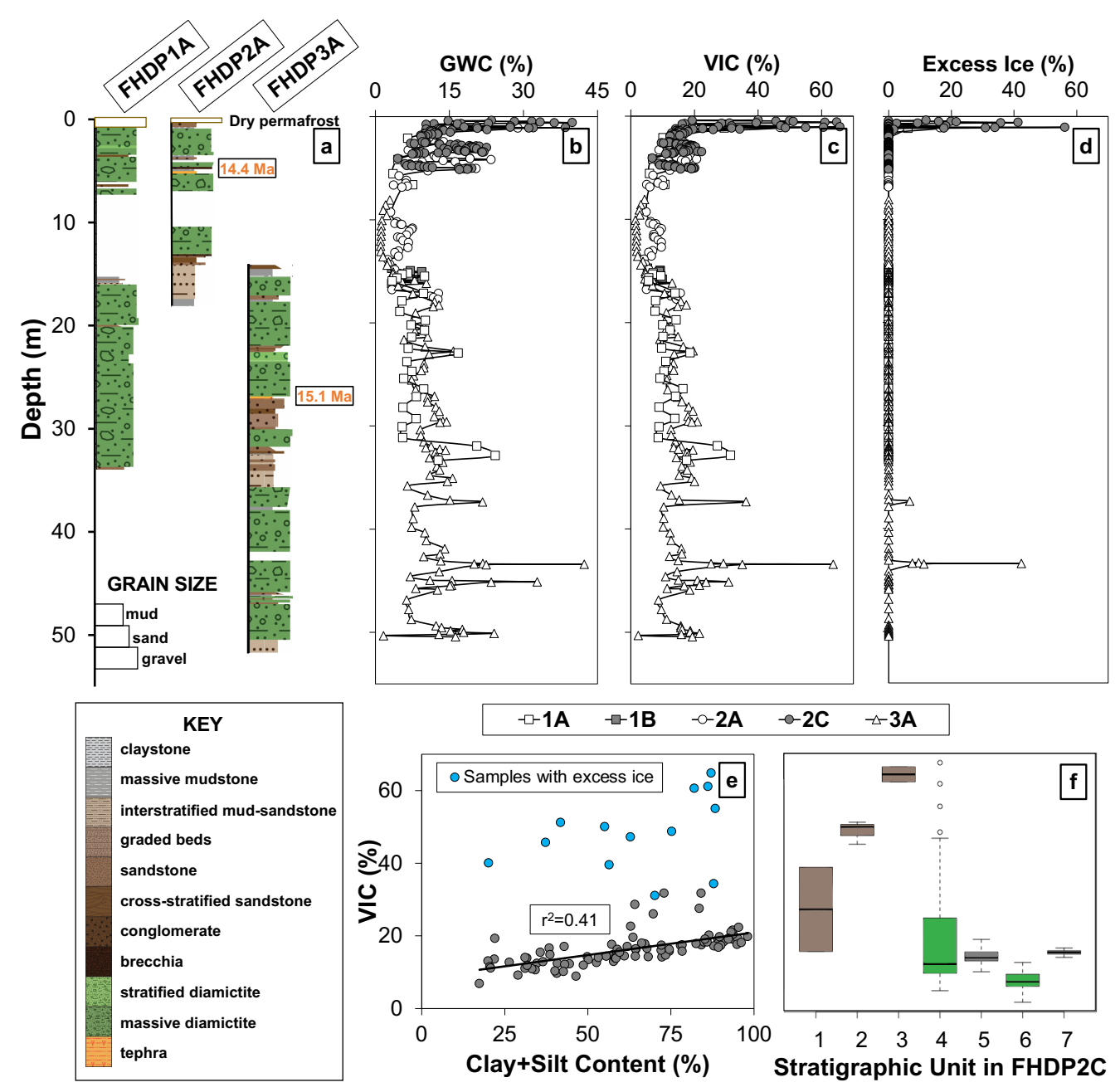

Fig. 4.10 Relation between stratigraphy and ground ice content at Friis Hills. a. General stratigraphy of Friis Hills Drilling Project (FHDP) cores FHDP1A, 2A and 3A with tephra ages provided by Chorley (2020). b.-d. Gravimetric water content (GWC), volumetric ice content (VIC) and excess ice content, respectively in the five FHDP cores. e. Relation between VIC and clay + silt content in FHDP2C. f. Boxplots of the VIC for the various stratigraphic units in FHDP2C.

\subsubsection{Geochemistry of ground ice}

The uppermost $1.5 \mathrm{~m}$ of the Friis Hills cores had a $\mathrm{Na}-\mathrm{Cl}$ geochemical facies and the sum of ions per sample ranged from 3.9 to $14.3 \mathrm{mg} \mathrm{g}^{-1}$ dry soils, averaging $8.8 \pm 2.5 \mathrm{mg} \mathrm{g}^{-1}$ dry soils. Concentrations of individual anions varied between 258 and $6,031 \mathrm{mg} \mathrm{kg}^{-1}$ dry soils; with $\mathrm{Cl}^{-}>\mathrm{SO}_{4}{ }^{2-}>\mathrm{NO}_{3}{ }^{-}$. Concentrations of the individual cations varied between 13 and 


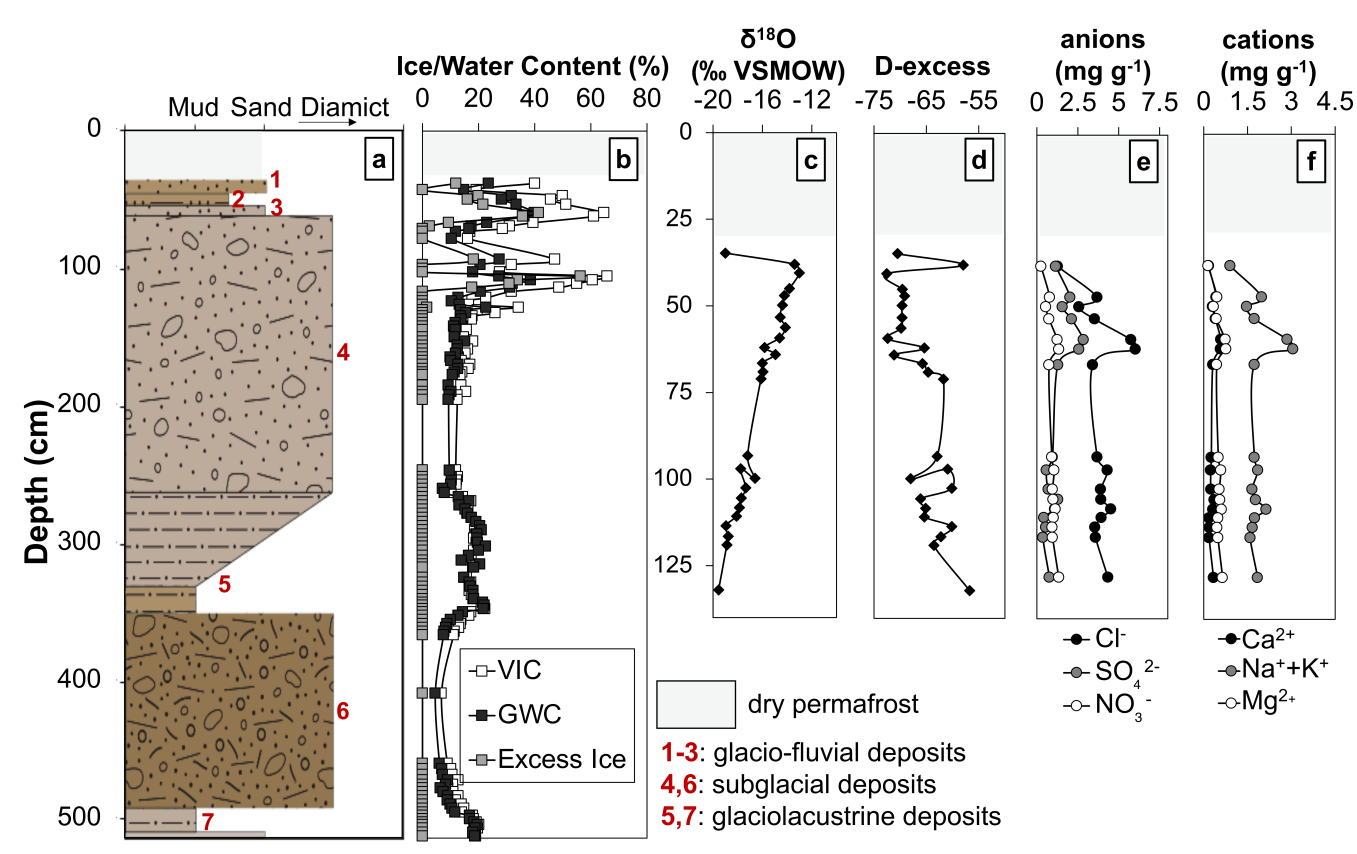

Fig. 4.11 Sedimentary, ground ice, $\delta^{18} \mathrm{O}$ and D-excess and major ion profiles in core FHDP2C. a. Lithological facies (described in Chapter 3) including Munsell colours of each unit. b. Ground ice content (volumetric ice content (VIC), gravimetric water content (GWC) and excess ice content). c. $\delta^{18} \mathrm{O}$ composition of ground ice. d. D-excess composition of ground ice. e. Dissolved anions $\left(\mathrm{Cl}^{-}\right.$, $\left.\mathrm{SO}_{4}{ }^{2+}, \mathrm{NO}_{3}{ }^{-}\right)$. f. Dissolved cations $\left(\mathrm{Ca}^{2+}, \mathrm{Na}^{+}, \mathrm{K}^{+}, \mathrm{Mg}^{2+}\right)$. Note: analyses of stable water isotopes and soluble ions was only possible in the uppermost $1.25 \mathrm{~m}$, where sufficient meltwater could be recovered. VSMOW $=$ Vienna Standard Mean Ocean Water.

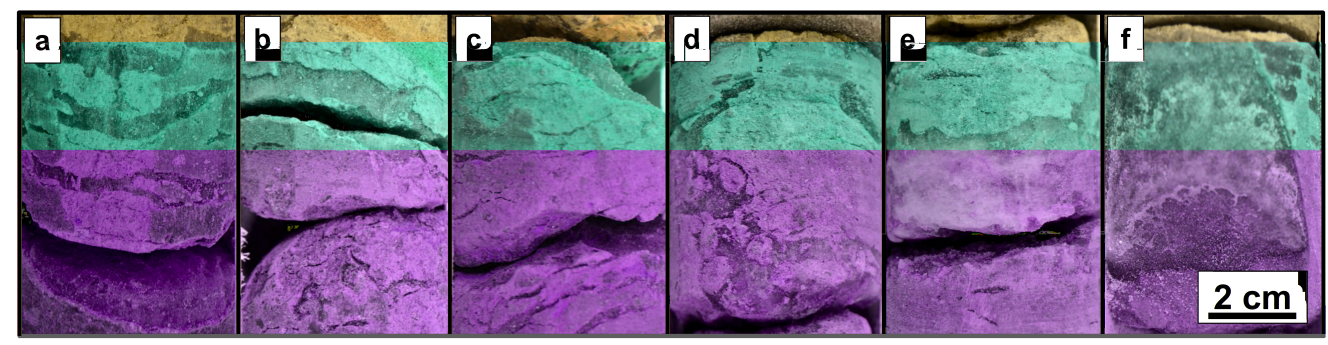

Fig. 4.12 Examples of lenticular cryostructures in Friis Hills sediments. a.-e. Within the upper $1 \mathrm{~m}$ of icy permafrost in core FHDP2C. f. At $43 \mathrm{~m}$ depth in core FHDP3A (section of the $15 \mathrm{~cm}$-thick ice lens).

$2,998 \mathrm{mg} \mathrm{kg}^{-1}$ dry soils; with $\mathrm{Na}^{+}>\mathrm{Mg}^{2+}>\mathrm{Ca}^{2+}>\mathrm{K}^{+}$(Figs 4.11 and 4.14). The ion content generally increased with depth, with maximum content at $60 \mathrm{~cm}$ and at $110 \mathrm{~cm}$ depth (Fig. 4.11). The molar ratios $\mathrm{Na} / \mathrm{Cl}, \mathrm{Ca} / \mathrm{Cl}, \mathrm{Mg} / \mathrm{Cl}, \mathrm{SO}_{4} / \mathrm{Cl}$ and $\mathrm{NO}_{3} / \mathrm{Cl}$ averaged $0.74 \pm 0.11,0.07$ $\pm 0.02,0.19 \pm 0.01,0.13 \pm 0.08,0.14 \pm 0.02$, respectively. All molar ratios showed a general 
decrease with depth, except for $\mathrm{Mg} / \mathrm{Cl}$ and $\mathrm{NO}_{3} / \mathrm{Cl}$ which increased with depth. In FHDP3A (15.02 to $50.48 \mathrm{~m}$ ), samples from ground ice below $30 \mathrm{~m}$ had a $\mathrm{Ca}-\mathrm{SO}_{4}$ geochemical facies and a much lower total ionic concentration, where the sum of ions ranged from 0.3 to $0.5 \mathrm{mg}$ $\mathrm{g}^{-1}$ dry soils, averaging $0.3 \pm 0.1 \mathrm{mg} \mathrm{g}^{-1}$ dry soils. Concentrations of anions varied between 0.6 and $171.2 \mathrm{mg} \mathrm{kg}^{-1}$ dry soils: $\mathrm{SO}_{4}{ }^{2-}>\mathrm{Cl}^{-}>\mathrm{NO}_{3}{ }^{-}$(Fig. 4.14). Concentrations of the major cations varied between 2.9 and $71.6 \mathrm{mg} \mathrm{kg}^{-1}$ dry soils: $\mathrm{Ca}^{2+}>\mathrm{Na}^{+}>\mathrm{Mg}^{2+}>\mathrm{K}^{+}$(Fig. 4.14). The molar ratios below $30 \mathrm{~m}$ depth were all significantly higher than in the uppermost $1.5 \mathrm{~m}$, except for $\mathrm{NO}_{3} / \mathrm{Cl}$, which was near 0 due to the low content of $\mathrm{NO}_{3}$.

The $\delta^{18} \mathrm{O}$ values of the ice lenses and pore ice found within the uppermost $1 \mathrm{~m}$ ranged between -19.8 and $-12.8 \%$ (avg. $=-16.2 \pm 1.8 \%$ ) and showed a general decrease with depth (Fig. 4.11). In Figure 4.13, the samples were distributed along a regression slope of $6.1\left(\mathrm{r}^{2}=0.89\right)$ and plotted below the MDV LMWL of 7.9. The D-excess values ranged between -73.0 and $-52.9 \%$ (avg. $=-65.6 \pm-4.3 \%$; Fig. 4.13). Due to low ice content in the 1 to $30 \mathrm{~m}$ intervals of core, no samples could be retrieved for $\delta \mathrm{D}-\delta^{18} \mathrm{O}$ analysis. The ice lenses below $30 \mathrm{~m}$ in core FHDP3A had the lowest $\delta^{18} \mathrm{O}$ values, ranging between -35.8 and $-32.6 \%$ (average $-34.6 \pm 1.2 \%$; Fig. 4.13). These samples plotted on the LMWL with D-excess values between 2.4 and $8.7 \%$ (average $6.9 \pm 2.6 \%$ ).
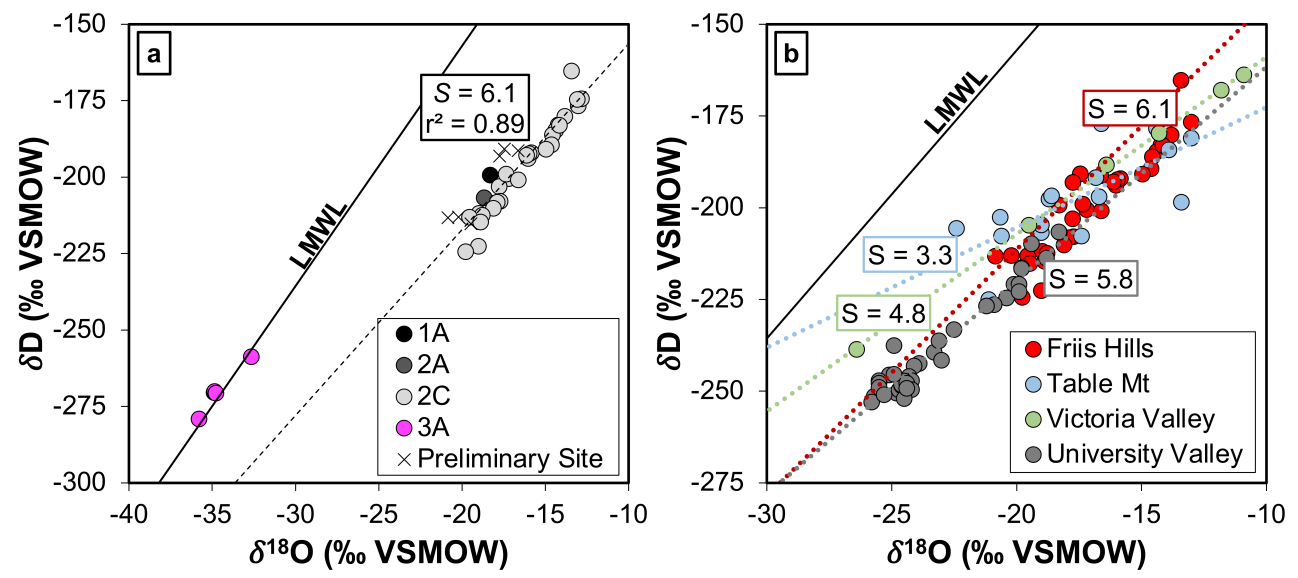

Fig. 4.13 $\delta \mathrm{D}-\delta^{18} \mathrm{O}$ of ground ice at Friis Hills compared to other sites in the McMurdo Dry Valleys. a. $\delta \mathrm{D}-\delta^{18} \mathrm{O}$ scatter plot of ground ice in the various cores at Friis Hills. b. $\delta \mathrm{D}-\delta^{18} \mathrm{O}$ of ground ice in core FHDP2C compared with other sites in the McMurdo Dry Valleys: Table Mountain (1945 m a.s.l.; Dickinson and Rosen, 2003), Victoria Valley (450 m a.s.l.; Hagedorn et al., 2010) and University Valley (1600-1800 m a.s.l.; Lapalme et al., 2017a). The local meteoric water line is shown for comparison purposes (LMWL: $\delta \mathrm{D}=7.9 \delta^{18} \mathrm{O}+0.8$; Lacelle et al. (2011)). 
The $\delta^{18} \mathrm{O}$ and $\delta \mathrm{D}$ composition in samples in the uppermost $1 \mathrm{~m}$ were negatively correlated with $\mathrm{Cl}^{-}$and $\mathrm{NO}_{3}{ }^{-}$and positively correlated with $\mathrm{SO}_{4}{ }^{2-}\left(\mathrm{r}^{2}>0.8\right)$. In deep FHDP3A samples, a negative correlation was established with $\mathrm{NO}_{3}{ }^{-}\left(\mathrm{r}^{2}>0.8\right)$ and a positive correlation with $\mathrm{SO}_{4}{ }^{2-}\left(\mathrm{r}^{2}>0.6\right)$. No correlation was found between $\delta^{18} \mathrm{O}$ and $\delta \mathrm{D}$ and $\mathrm{Cl}^{-}$(Fig. 4.15)

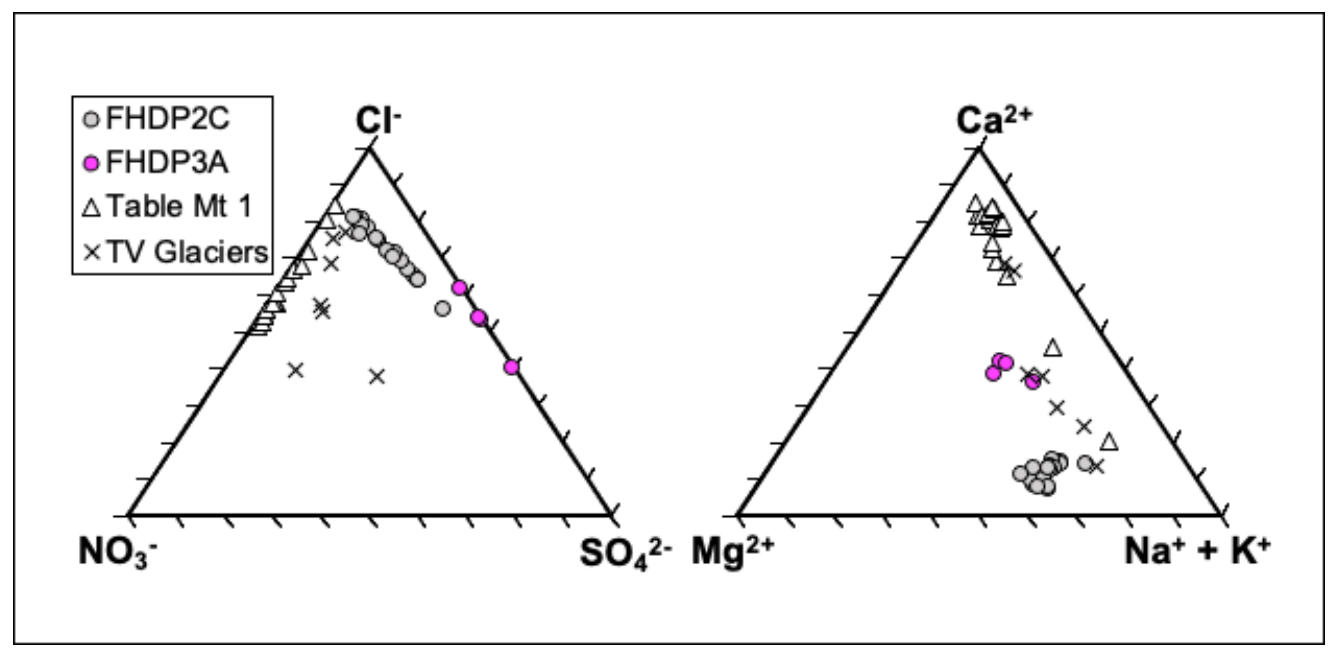

Fig. 4.14 Tertiary graph of equivalent fractions of major anions and cations within ground ice samples of FHDP compared to ground ice samples retrieved at Table Mountain (Dickinson and Rosen, 2003) and glacier ice samples retrieved in lower Taylor Valley glaciers (Lyons et al., 1998). 

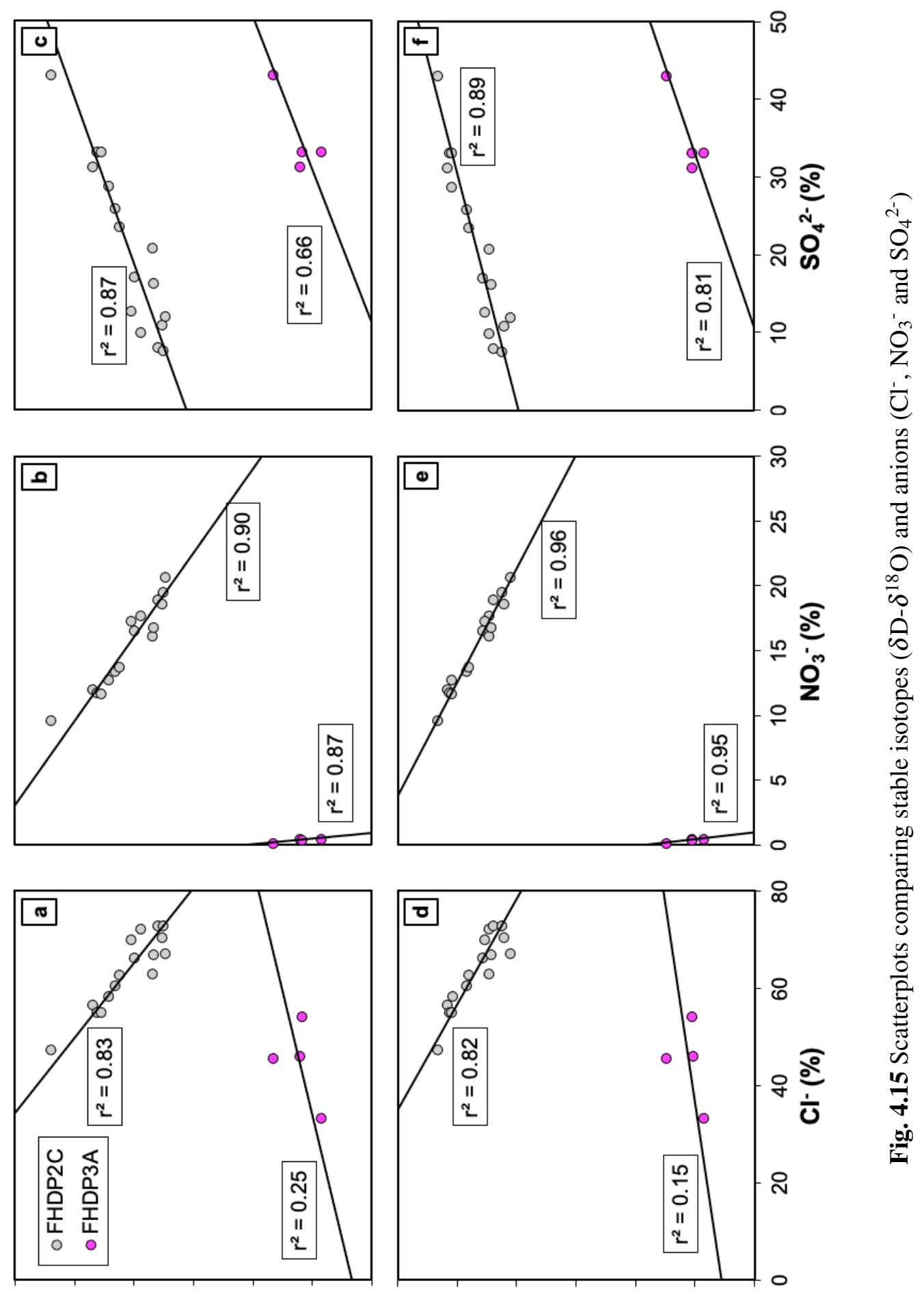

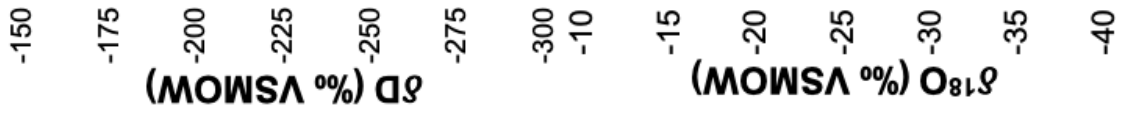




\subsection{Discussion}

The Friis Hills cores showed four cryostratigraphic units that were independent of sediment types: (1) surficial dry permafrost (0 to $30 \mathrm{~cm})$; (2) ice-rich to ice-poor permafrost $(0.3$ to $5.0 \mathrm{~m}$ ); (3) near-dry permafrost (5 to $20 \mathrm{~m}$ ); and (4) ice-poor to ice-rich permafrost with distinct thin ice layers $\left(20\right.$ to $50 \mathrm{~m}$ ). The geochemistry and $\delta \mathrm{D}-\delta^{18} \mathrm{O}$ composition also showed contrasting values between the uppermost ice-rich permafrost and the two ice lenses $>30 \mathrm{~m}$ depth. The ground ice in the uppermost $1 \mathrm{~m}$ was characterized by $\mathrm{NaCl}$ geochemical facies, high solute load (3.9-14.3 $\mathrm{mg} \mathrm{g}^{-1}$ dry soil) and $\delta^{18} \mathrm{O}$ values $(-19.8$ to $-12.8 \%$ ) as well as a $\delta \mathrm{D}-\delta^{18} \mathrm{O}$ regression slope of 6.1 , which is lower than the LMWL. The 2 and 15 cm-thick ice lenses $>30 \mathrm{~m}$ were characterized by $\mathrm{CaSO}_{4}$ geochemical facies, lower solute load (0.3-0.5 mg g ${ }^{-1}$ dry soil) and $\delta^{18} \mathrm{O}$ values (-35.8 to $\left.-32.6 \%\right)$ as well as a $\delta \mathrm{D}-\delta^{18} \mathrm{O}$ distributed along the LMWL. Below, the cryostratigraphy of the Friis Hills cores is discussed by comparing the results to those from other sites in the stable uplands zone. To elucidate dominant processes that shaped ground ice conditions at Friis Hills, the evolution of ground ice content was modelled using REGO.

\subsubsection{Origin of ground ice in the upper $1 \mathrm{~m}$}

Most studies on ground ice in the MDV have been restricted to shallow $(<6 \mathrm{~m})$ permafrost cores (e.g. Dickinson and Rosen, 2003, Hagedorn et al., 2010, Lacelle et al., 2013a, Lapalme et al., 2017a, Swanger, 2017). Excluding the burial of glacier ice, two origins for this ground ice have been proposed: (1) vapour-deposited ice and (2) ice formed from the freezing of evaporated snowmelt (e.g. Dickinson and Rosen, 2003, Hagedorn et al., 2010, Lacelle et al., 2013a, Lapalme et al., 2017a). Vapour-deposited ground ice is characterized by: (1) a maximum ice content at the ice table that subsequently gradually decreases with depth; (2) $\delta^{18} \mathrm{O}$ and D-excess profiles that both decrease with depth and; (3) $\delta \mathrm{D}-\delta^{18} \mathrm{O}$ slope values similar to the LMWL but shifted below it due to low D-excess (in the -48 to $-27 \%$ range). By contrast, the freezing of evaporated snowmelt is generally characterized by: (1) variable ground ice content profiles; (2) decreasing $\delta^{18} \mathrm{O}$ but increasing D-excess profiles with depth; and (3) $\delta \mathrm{D}-\delta^{18} \mathrm{O}$ slopes lower than the LMWL with very low D-excess (mostly in the -83 to $-46 \%$ range).

The ground ice samples in the uppermost $1 \mathrm{~m}$ of Friis Hills had $\delta \mathrm{D}-\delta^{18} \mathrm{O}$ and D-excess compositions that are consistent with the freezing of evaporated snowmelt. The $\delta \mathrm{D}-\delta^{18} \mathrm{O}$ and D-excess of ground ice in the uppermost $1 \mathrm{~m}$ were enriched in ${ }^{18} \mathrm{O}$ by $\sim 10 \%$ with 
D-excess being $\sim 60-70 \%$ lower compared to the isotopic composition of snow and glacial ice in Taylor Valley glacier and snow (e.g. Gooseff et al., 2006). However, the $\delta \mathrm{D}-\delta^{18} \mathrm{O}$ and D-excess of ground ice was in the range of ground ice from Table Mountain (1945 $\mathrm{m}$ a.s.1.) and Victoria Valley (450 $\mathrm{m}$ a.s.1.). Ground ice in the seasonally cryotic zone of University Valley (1600-1800 m a.s.l.) has slightly lower $\delta \mathrm{D}-\delta^{18} \mathrm{O}$ values, but the $\mathrm{D}$-excess and $\delta \mathrm{D}-\delta^{18} \mathrm{O}$ slope values are in the same range as those in Friis Hills (Figs 4.13 and 4.16). Therefore, similar to Table Mountain, Victoria Valley and University Valley, the isotopic composition of ground ice in the uppermost $1 \mathrm{~m}$ at Friis Hills was probably affected by two distinct processes: (1) infiltration and partial evaporation of snowmelt through the surficial dry permafrost and (2) its subsequent freezing at the ice table and underlying icy permafrost soils.
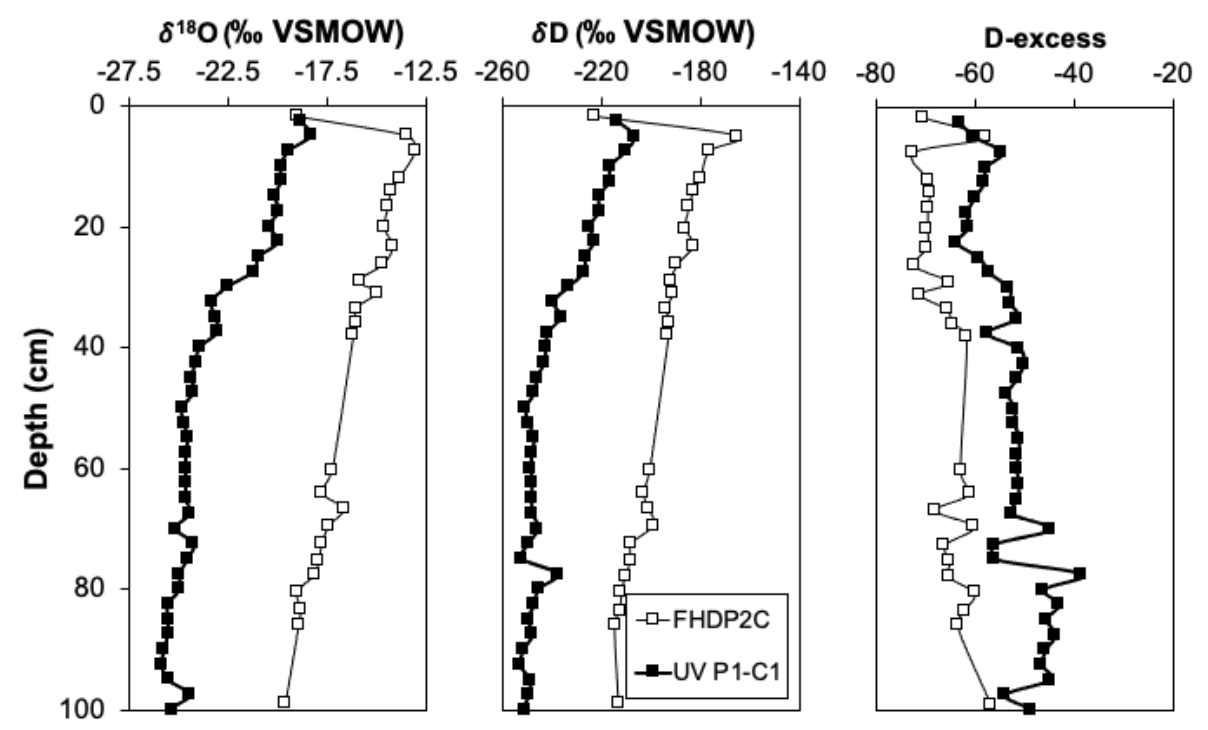

Fig. 4.16 Comparison between $\delta^{18} \mathrm{O}, \delta \mathrm{D}$ and $\mathrm{D}$-excess profiles within the first meter of icy permafrost (ice table at $0 \mathrm{~cm}$ ) in University Valley (UV) site P1-C1 (Lapalme et al., 2017a) and FHDP2C

The composition of $\delta^{18} \mathrm{O}$ and D-excess in the uppermost $1 \mathrm{~m}$ at Friis Hills was modelled using the Craig et al. (1963) and Craig (1965) models for isotopic exchange of evaporating water with ambient soil moisture as well as the isotope salt effect correction of Sofer and Gat (1975). The model predicts the evolution of evaporating meteoric water in the dry sandy soils during the summer season when the dry soil temperature is at or above the eutectic of the pore water (Appendix Table H.1). At FHDP2, the ice table depth is $35 \mathrm{~cm}$ and, according to the ice table depth and ground surface humidity relation (Fisher et al., 2016), the ground surface humidity is estimated at $93 \%$ and the soil relative humidity ranges from $90 \%$ to $95 \%$. 
The initial $\delta^{18} \mathrm{O}$ composition of snow was set at $-35 \%$ (although it does not significantly influence the steady-state isotopic value). The soil water vapour was assumed to be in the -26 to $-30 \%$ range (similar to those used for University Valley; Lapalme et al., 2017a). The initial soluble ion concentration was set at $10 \%$ of seawater salinity, as measured just under the ice table (even if the average in the uppermost $1 \mathrm{~m}$ of icy permafrost is $47 \%$ of seawater salinity). In the modelling scenarios, the $\delta^{18} \mathrm{O}$ of soil water approached a steady-state value that was dependant on the $\delta^{18} \mathrm{O}$ of soil vapour and humidity (Fig. 4.17). The modelled $\delta^{18} \mathrm{O}$ composition of infiltrating snowmelt required in order to match the range of $\delta^{18} \mathrm{O}$ values measured near the ice table $(-13.4 \%)$ was reached by using a soil RH of $90-95 \%$ and a $\delta^{18} \mathrm{O}$ soil vapour of -26 to $-28 \%$ after $>10 \%$ of the water had evaporated, after which $\delta^{18} \mathrm{O}$ residual water reached a steady-state value (Fig. 4.17). The evaporated snowmelt in the dry soil lag with $\delta^{18} \mathrm{O}$ composition that evolved from -35 to $-13 \%$ then set the initial $\delta^{18} \mathrm{O}$ composition of water that will begin to freeze at and below the ice table to develop the icy permafrost.

Freezing of the partially evaporated snowmelt at the ice table and deeper in the icy permafrost imparts a progressively more depleted (in ${ }^{18} \mathrm{O}$ ) signature in the residual water (and a corresponding increase in D-excess) due to the preferential incorporation of the heavier isotopes in the ice following a Rayleigh-type isotope fractionation, with the extent of fractionation being dependent on the freezing rate and thickness of the boundary layer (Lacelle et al., 2011). Considering that the $\delta \mathrm{D}-\delta^{18} \mathrm{O}$ composition of the ground ice at Friis Hills and its profile in the uppermost $1 \mathrm{~m}$ is very similar to other sites in the stable upland zone where ground ice formed from the infiltration and freezing of evaporated snowmelt (Fig. 4.13), suggests that the environmental conditions between the sites are similar and that the ground ice in the near-surface permafrost is dynamic and responding to changes in environmental conditions.

This challenges the assumption that Friis Hills has remained frozen since 13.8 Myr with no infiltration of meteoric water in the sediments (Valletta et al., 2015). Similar to the other locations in the stable uplands, there probably have been short periods when the ground surface temperatures rose above freezing, even for just a few hours. For example, wet sediments were observed to depths of $25-30 \mathrm{~cm}$ following snow fall in University Valley (Lacelle et al., 2016). With appropriate snow cover, sufficient snowmelt was able to infiltrate the dry sediments and reach the ice table at Friis Hills (e.g. Dickinson et al., 2012, Lacelle et al., 2016). Van der Waals forces around soil particles, which are very sensitive to temperature and most effective near the surface, produce a pressure gradient that moves liquid water towards the cold front of the ice table (Fisher et al., 2019). Periodic supplies of small volumes of snowmelt are therefore enough to recharge ground ice near the ice table. 


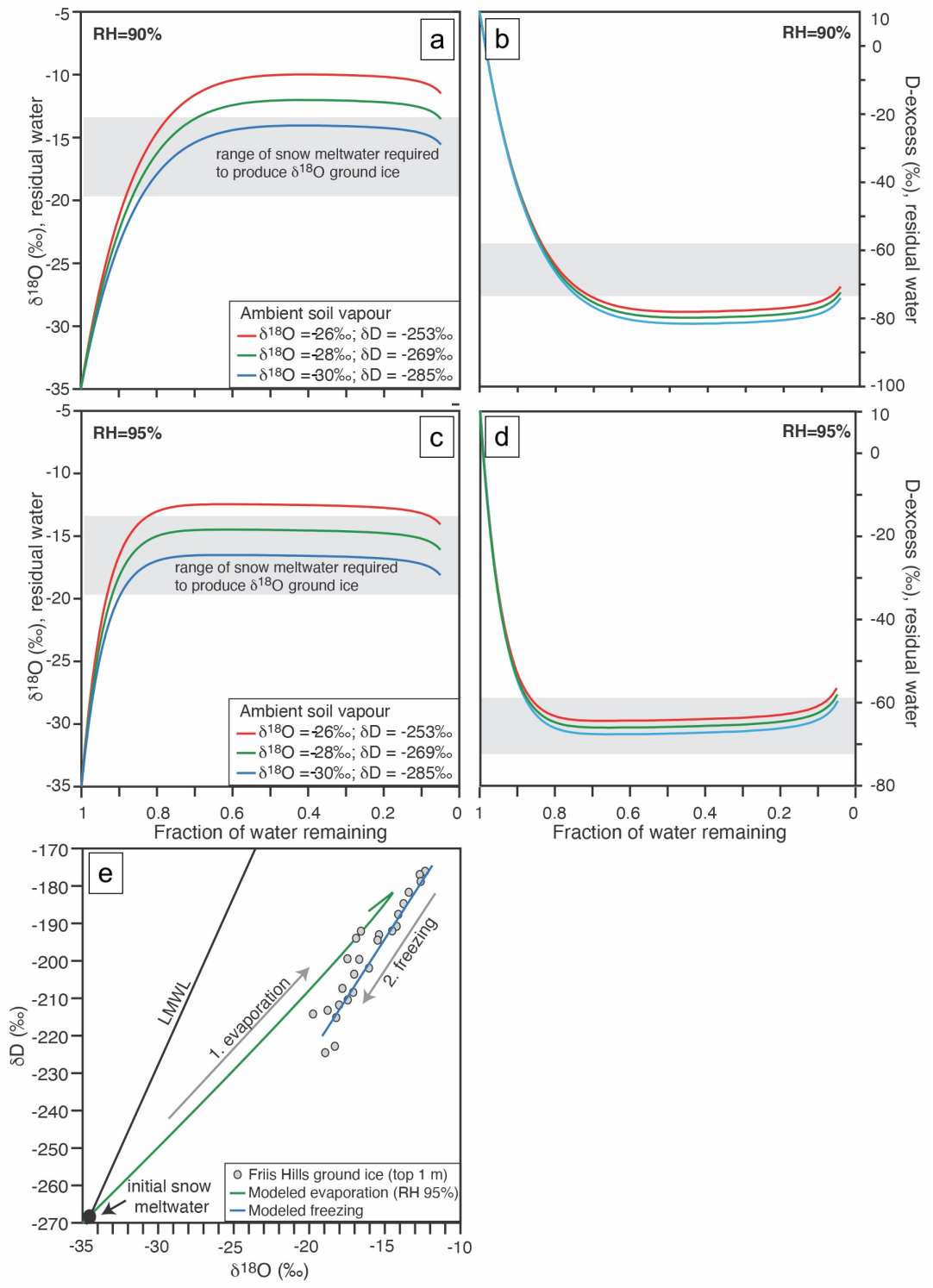

Fig. 4.17 Modelling the evaporation effect on the isotopic evolution of snowmelt and resulting nearsurface ice. Evolution of (a. \& c.) $\delta^{18} \mathrm{O}$ and (b. \& d.) D-excess for two scenarios of relative humidity (RH) (a. \& b.) of $90 \%$ and (c. \& d.) $95 \%$ for a range of soil water vapour values using a combination of the Craig et al. (1963) and Craig (1965) models for isotope exchange of evaporating water with ambient soil moisture and the isotope salt effect correction of Sofer and Gat (1975). e. At the end of the evaporative evolution, the liquid water $\delta^{18} \mathrm{O}$ and $\delta \mathrm{D}$ are used to determine the first formed ice isotopic composition at the ice table. Note: for example, the liquid water's $\delta^{18} \mathrm{O}$ at the ice table is $\sim-15 \%$, so the first ice formed at the ice table would be $\sim-12 \%$ and would progressively decrease with depth following the freezing of the residual water. (LMWL $=$ local meteoric water line) 


\subsubsection{Origin of ground ice at 35-50 m depth}

At Friis Hills, the 2 and $15 \mathrm{~cm}$ thick ice lenses found at 37 and $43 \mathrm{~m}$ depths, respectively, in FHDP3A had lower solute loads (average $=0.3 \pm 0.1 \mathrm{mg} \mathrm{g}^{-1}$ ) and were characterized by a $\mathrm{CaSO}_{4}$ geochemical facies, a eutectic point of $-0.02^{\circ} \mathrm{C}, \delta^{18} \mathrm{O}$ values of $-34.6 \pm 1.2 \%$ and a $\delta \mathrm{D}-\delta^{18} \mathrm{O}$ regression slope value similar to the LMWL (Fig. 4.13a). With the exception of a solute load that was $\sim 400$ times greater than in precipitation (assuming a $0.74 \mathrm{mg} \mathrm{kg}^{-1}$ baseline; Taylor Glacier fresh snow $500 \mathrm{~m}$ a.s.1.; Lyons et al., 2003), the $\delta^{18} \mathrm{O}$ composition, $\delta \mathrm{D}-\delta^{18} \mathrm{O}$ slope value and geochemical facies of the deep ground ice are comparable to those of snow and glacial ice located $\sim 20-30 \mathrm{~km}$ towards the Ross Sea in the mixed intermediate zone (e.g. lower Taylor Glacier and Canada Glacier; Gooseff et al., 2006).

Based on these characteristics, it is tempting to associate the deep ice lenses with buried glacier ice or snow deposited during the mid-Miocene. However, this origin would not explain the solute load in the ice nor the lenticular cryostructure, which are two characteristics generally associated with intra-sedimental ice (i.e. segregated, injection, intrusive ice; e.g. Coulombe et al., 2019, and references therein). In theory, intra-sedimental ice should have a $\delta \mathrm{D}-\delta^{18} \mathrm{O}$ slope value lower than the LMWL, but there are some instances where the $\delta \mathrm{D}-\delta^{18} \mathrm{O}$ measurements of this type of ice show a meteoric origin. For example, seasonal ice layers in a pingo near Tuktuyaktuk (Mackay, 1990) and reticulate ice in marine clays in the Eureka lowlands (Roy, 2019) had $\delta \mathrm{D}-\delta^{18} \mathrm{O}$ slope values near the GMWL. The reason why the intra-sedimental ice had a $\delta \mathrm{D}-\delta^{18} \mathrm{O}$ slope near the GMWL, which is similar to the FHDP3A ice lenses, relates to sampling and melting the entire ice layer, thus preserving the isotopic mass balance and removing the effect of freezing on $\delta \mathrm{D}$ and $\delta^{18} \mathrm{O}$ within the ice lens.

The ice lenses preserved a GMWL signature, this suggests that the water from which the deep ice layers formed did not experience evaporation, which in turn would have enriched the $\delta \mathrm{D}$ and $\delta^{18} \mathrm{O}$ composition prior to freezing and shifted their $\delta \mathrm{D}-\delta^{18} \mathrm{O}$ composition below the LMWL. This implies that the site probably had an active layer with near-saturated soils, as commonly found today in high Arctic permafrost regions, and not a dry permafrost lag. Therefore, the FHDP3A ice lenses likely originated from the freezing of meteoric water following the deposition of the sediments $\sim 15.0 \mathrm{Ma}$ and probably consist of segregated ice. However, without dating the ice lenses directly, it is not possible to infer whether the ice is synchronous to the period of sediment deposition $\sim 14-15 \mathrm{Ma}$, when a tundra ecosystem occupied the region, or during the colder mid-Miocene climate transition (MMCT). In Chapter $5,{ }^{10} \mathrm{Be}_{\text {met }}$ is used as a tracer to constrain the timing of water infiltration in the deep permafrost. 


\subsubsection{Mid-Miocene paleotemperature reconstruction}

Ice wedges, and more recently pore ice, with $\delta^{18} \mathrm{O}$ compositions that preserve a meteoric signature are sometimes used as paleotemperature proxies (e.g. Schwamborn et al., 2006, Porter and Opel, 2020). In a similar fashion, the average $\delta^{18} \mathrm{O}$ composition of the deep ice lenses $(-34.6 \pm 1.2 \%$ ), which probably formed from the freezing of meteoric water, can be compared to the $150 \mathrm{kyr}$ record at Taylor Dome (2,365 $\mathrm{m}$ a.s.l. and $80 \mathrm{~km}$ inland) in order to constrain air temperatures during the Miocene Climatic Optimum (MCO)-MMCT. The $\delta^{18} \mathrm{O}$ of the ice lenses is $2-3 \%$ higher than recorded during warm intervals over the past $150 \mathrm{kyr}$ (i.e. early Holocene and MIS5e, which were $1-3^{\circ} \mathrm{C}$ warmer than today in Antarctica; Grootes et al., 2001, Jouzel et al., 2007). Based on the $\delta^{18} \mathrm{O}$-temperature relation $\left(\mathrm{dT} / \mathrm{d} \delta^{18} \mathrm{O}=2.1 \pm 0.2 \mathrm{~K} / \% 0\right)$, this would imply that temperatures at Friis Hills were $5-9{ }^{\circ} \mathrm{C}$ warmer during the mid-Miocene. However, comparison of late Quaternary climate to the mid-Miocene climate must account for different environmental factors, such as changes in $\delta^{18} \mathrm{O}$ of seawater, seasonality of precipitation, distance from coast, site elevation and $\delta^{18} \mathrm{O}$-temperature relation.

Based on the $\delta^{18} \mathrm{O}$ of benthic foraminifera, the $\delta^{18} \mathrm{O}$ of the Southern Ocean during the mid-Miocene was $1.0 \%$ lower than today (Billups and Schrag, 2002). In the MDV, the $\delta^{18} \mathrm{O}$ composition of shallow ice cores on glaciers decrease as a function of distance from the coast, and the data fit the following equation: $\mathrm{y}=-0.1528 \mathrm{x}-28.38$ (where $\mathrm{x}=$ distance in $\mathrm{km} ; \mathrm{r}^{2}=0.89$; Gooseff et al., 2006). The modern $\delta^{18} \mathrm{O}$-elevation relation in Antarctica fits a slope of $-0.68 \%$ per $100 \mathrm{~m}$ (Wang et al., 2009). However, the relation is largely temperature dependent, as shown in Greenland, where the $\delta^{18} \mathrm{O}$-elevation relation decreases to $-0.62 \pm$ 0.03\% per $100 \mathrm{~m}$ (Dahl-Jensen et al., 2013).

If the $\delta^{18} \mathrm{O}$ of ice layers is corrected for changes in $\delta^{18} \mathrm{O}$ of seawater $(-1.0 \%)$ for the latest palaeogeographical conditions of Friis Hills, $\sim 30 \mathrm{~km}$ closer to the coast due to higher sea level (present-day location of Lake Bonney, $+4.5 \%$ distance from coast; Lyons et al., 2005) with little elevation change since the mid-Miocene $(0 \%)$, the $\delta^{18} \mathrm{O}$ composition of the ice would increase by $\sim 3.5 \%$ and suggest that the mean annual air temperature (MAAT) during the late stage of the mid-Miocene was $\sim 7^{\circ} \mathrm{C}$ warmer than today. If the same corrections are kept for both $\delta^{18} \mathrm{O}$ of seawater and distance from coast, but $300 \mathrm{~m}$ of uplift since the late Miocene is applied ( $\sim 2 \%$ uplift; e.g. Wilch et al., 1993), the $\delta^{18} \mathrm{O}$ composition of the ice would increase by $\sim 5.5 \%$. This would suggest that the MAAT during the late stage of the mid-Miocene was $\sim 11-12^{\circ} \mathrm{C}$ warmer than today, corresponding to a MAAT of between $-16^{\circ} \mathrm{C}$ and $-11^{\circ} \mathrm{C}$ (in the range of that of present-day high Arctic Canada). However, this comparison must be taken with caution, as the various $\delta^{18} \mathrm{O}$ empirical relations cannot 
be directly transferred to other climate periods because their calibration assumes similar distributions of precipitation, moisture source and trajectory (i.e. unchanged atmospheric circulation; Sturm et al., 2010). The MCO and MMCT were periods characterized by changes in deep-ocean circulation and associated meridional heat transfer, therefore most probably affecting moisture source and precipitation (e.g. Herold et al., 2012).

\subsubsection{A model for ground ice content evolution since the mid-Miocene}

Previous discussion sections have shown that the ground ice in the near-surface is derived from the freezing of evaporated snowmelt and its migration into the icy permafrost, whereas the ground ice in the deep icy permafrost is interpreted to be derived from the freezing of meteoric water. However, the presence of near-dry permafrost across 5 to $20 \mathrm{~m}$ depth is enigmatic, as both freezing of evaporated snowmelt and vapour diffusion are expected to incorporate ice in accumulating dry sediment (e.g. Fisher et al., 2016). For example, even if the infiltration, migration and freezing of evaporated snowmelt is ignored, the slow process of vapour-deposited ice is expected to fill the pore space of sediments with ice within a few hundred years (e.g. Lacelle et al., 2013a). Through the $~ 14$ Myr of exposure time at Friis Hills, it is possible that the superimposed ice, which refers to the initial emplacement of ice, evolved to inherited ice, which developed from subsequent variations in the initial structure caused by the thermal and stress fields in the icy permafrost. Such redistribution was inferred by Fisher et al. (2019), where the ground ice content profile was predicted to evolve over the Holocene due to the migration of residual unfrozen water in the permafrost under thermal and stress fields. This process results in the development of ice-rich and ice-poor zones at distinct depths determined by the thermal diffusivity of the icy permafrost, with the change in ice content determined by evolved time. 


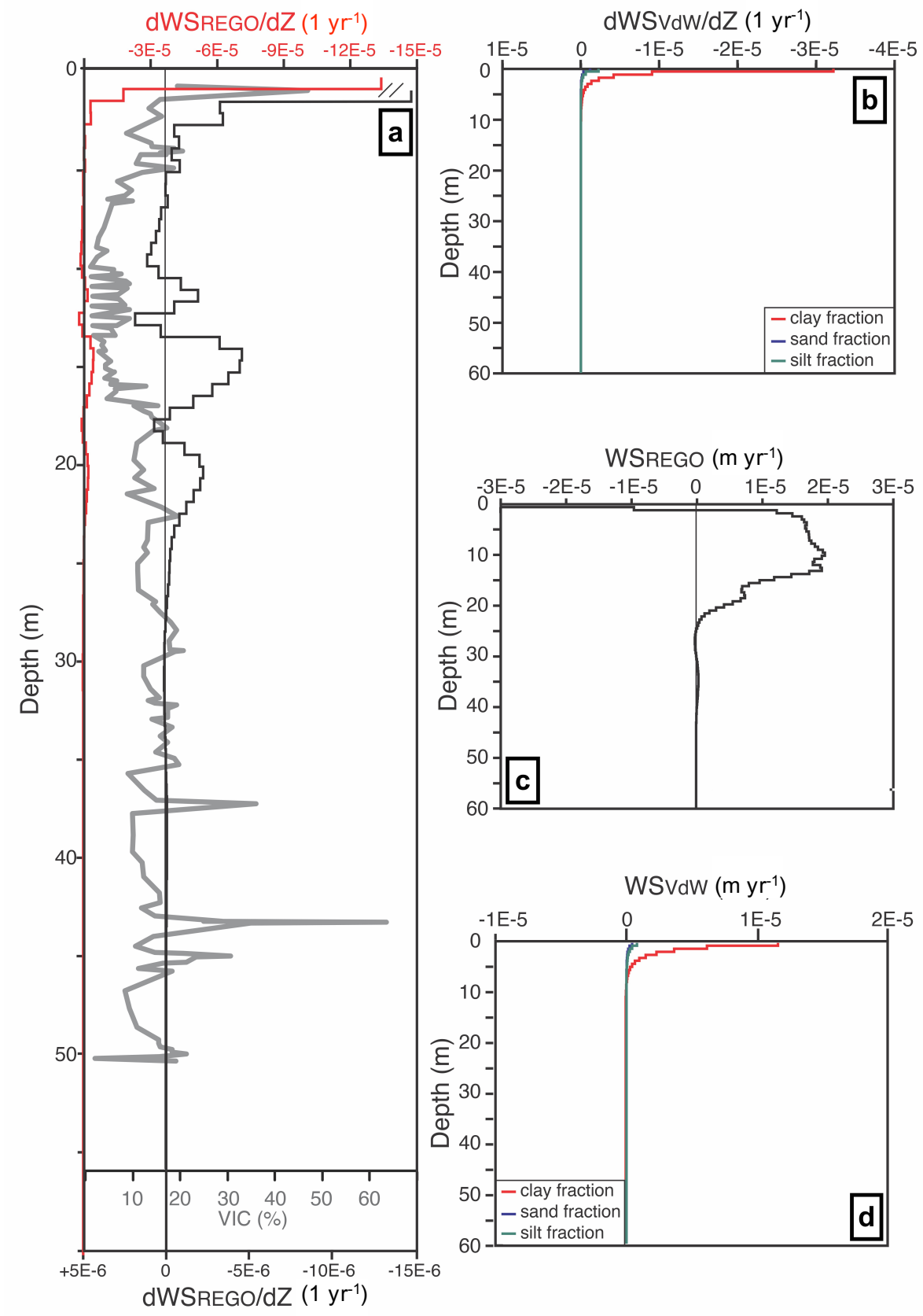

Fig. 4.18 Comparison of ground ice content profile at Friis Hills with the REGO model. a. The depth derivative of the REGO forces residual water speeds (dWS) plotted in relation to volumetric ice content (VIC) with depth in Friis Hills cores (grey line). Note that because of the enhanced effect of Van der Waals (VdW) forces in the upper $1 \mathrm{~m}$, the depth derivative of the REGO forces within the top $1 \mathrm{~m}$ is shown by the red curve and that below is shown by the black curve (both with their separate $\mathrm{x}$-axes). $\mathrm{b}$. The depth derivative of the water speeds of $\mathrm{VdW}$ forces $\left(\mathrm{dWS}_{\mathrm{VdW}}\right)$ for different grain sizes. c. The ensemble annual average water speed caused by stresses in the icy soils (WS REGO) and by d. the VdW forces (WS VdW), respectively. Negative values of the depth derivative of water speed show zones of ice accumulation, while positive values show zones of ice removal. The soil used was the Fujinomori soil (Watanabe and Mizoguchi, 2002) and the migrating water started as 1/10th concentration seawater (Appendix Table G.1). Fujinomori soil has a clay, silt and sand composition similar to the Friis Hills cores. 
In this research, the REGO model is used with the WATERREGO subroutine to assess how an initial ground ice profile in a $60 \mathrm{~m}$ icy permafrost column would evolve over time under diurnal and seasonal thermal variations using values of input parameters that are representative of the environmental conditions at Friis Hills (Appendix Table G.1). The modelling indicates that the diurnal stress cycles affect the uppermost $30-50 \mathrm{~cm}$ and the seasonal stress cycles extends to a depth of $\sim 22 \mathrm{~m}$. This is slightly below the depth of zero thermal amplitude, because stress in a rigid frozen soil can propagate further than the temperature waves that cause them. The diurnal and seasonal thermal regime and associated $\mathrm{VdW}$ and rheological forces on the transport of residual water lead to the evolution of ice-rich zones near the surface of permafrost and at 3 and $5 \mathrm{~m}$, as observed in the Friis Hills (Fig. 4.18). Because of the effectiveness of $\mathrm{VdW}$ forces at moving unfrozen water, the uppermost $1 \mathrm{~m}$ of icy permafrost is a fast-responding zone. This could explain why the results from different sites in the MDV have similar ground ice and $\delta^{18} \mathrm{O}$ profiles, as they can quickly respond to changing environmental conditions (Fig. 4.16). From $\sim 5$ to $15 \mathrm{~m}$ depths, the seasonal cycles and rheological forces remove ice (wet removal process), with the unfrozen water being transported and frozen above or below these depths. This matches fairly well the observed near-dry permafrost at 5 to $20 \mathrm{~m}$ depth. The depth difference can be attributed to the simplified stratigraphy in the model (single sediment type and not multi-layered), which would affect the values of the thermal diffusivity. Below the effects of the stresses caused by decaying thermal amplitude $(\sim 22 \mathrm{~m})$, the wet removal process has no effect, and the emplaced ground ice is only very slowly modified by upward migration of unfrozen water along the geothermal gradient. The two ice lenses at 37 and $45 \mathrm{~m}$ depths occur below the depth of zero thermal and stress amplitudes and would not be modified by the seasonal temperature and stress fields that induce the downwards migration of unfrozen water.

Rate of ice accumulation in the $50 \mathrm{~m}$ Friis Hills cores over 14 Myr was calculated from the total volume of water, bulk density and thickness of samples. The calculation indicates an ice accumulation rate of $0.0004 \mathrm{~mm} \mathrm{yr}^{-1}$, which is about 1 to 2 orders of magnitude less than estimated at University Valley (Fig. 4.19). However, the very low rate of ice accumulation at Friis Hills was expected and fits with the decreasing ice accumulation rates over the period of accumulation. According to Fisher et al. (2019), ground ice accumulation rate decreases following some e-folding function following decrease in porosity as ice accumulates. 


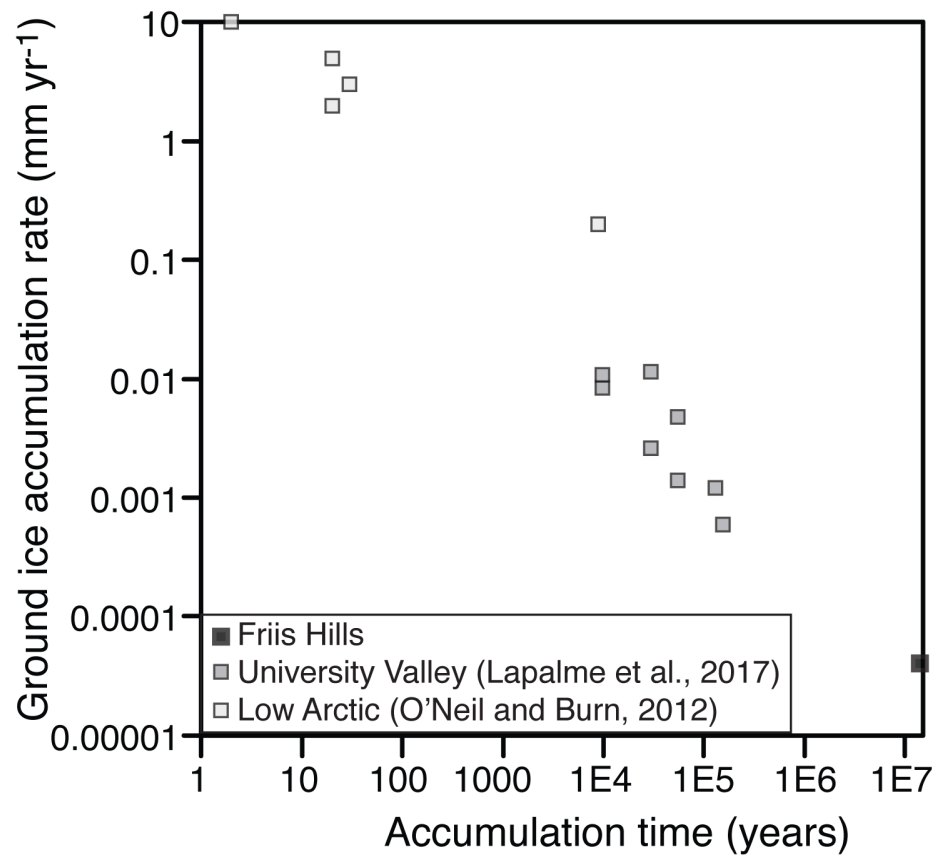

Fig. 4.19 Relation between accumulation time and ground ice accumulation rate in Friis Hills compared to University Valley (Lapalme et al., 2017a) and a site in the Low Arctic (O'Neill and Burn, 2012, and references therein)

\subsection{Conclusion}

Based on the results presented in this study, the following conclusions can be drawn regarding the cryostratigraphy of Friis Hills and the origin of the ground ice:

1. The Friis Hills cores showed four cryostratigraphic units that are independent of sediment types: (1) surficial dry permafrost (0 to $30 \mathrm{~cm}$ ); (2) ice-rich to ice-poor permafrost ( 0.3 to $5.0 \mathrm{~m}$ ); (3) near-dry permafrost ( 5 to $20 \mathrm{~m}$ ); and (4) ice-poor to ice-rich permafrost with distinct thin ice layers (20 to $50 \mathrm{~m}$ ).

2. The ground ice in the uppermost $1 \mathrm{~m}$ is characterized by a $\mathrm{NaCl}$ geochemical facies, high solute loads (3.9 to $14.3 \mathrm{mg} \mathrm{g}^{-1}$ dry soil) and $\delta^{18} \mathrm{O}$ values (-19.8 to $-12.8 \%$ ) and a $\delta \mathrm{D}-\delta^{18} \mathrm{O}$ regression slope of 6.1 , plotting below the LMWL. This indicates that the near-surface ground ice in the ice-rich to ice-poor permafrost ( 0.3 to $5.0 \mathrm{~m}$ ) was formed from the freezing of evaporated snowmelt. This process occurs on a regional scale in the MDV. 
3. The near-dry permafrost across 5 to $20 \mathrm{~m}$ depths originates from the redistribution of unfrozen water through rheological forces driven by seasonal thermal and stress fields. This allows for the ground ice content to be slowly removed across that depth over 14 Myr.

4. The ground ice at $>30 \mathrm{~m}$ depth is characterized by $\mathrm{CaSO}_{4}$ geochemical facies, lower solute loads ( 0.3 to $0.5 \mathrm{mg} \mathrm{g}^{-1}$ dry soil) and $\delta^{18} \mathrm{O}$ values $(-35.8$ to $-32.6 \%)$ and $\delta \mathrm{D}$ $\delta^{18} \mathrm{O}$ distributed along the LMWL. These ice lenses probably formed from the freezing of meteoric groundwater, as shown by their lenticular structure and high salt load in comparison to meteoric water, although a buried snow/ice origin is possible.

5. The deep ice lenses and their meteoric signatures suggest a near-saturated active layer following sediment deposition during the mid-Miocene, similar to modern high Arctic sites, where evaporation in the active layer is limited. Temperature reconstruction based on the corrected $\delta^{18} \mathrm{O}$ value of the deep ground ice and changes in paleogeography suggest that the MAAT during the mid-Miocene was $\sim 7-12^{\circ} \mathrm{C}$ warmer at Friis Hills. 



\section{Chapter 5}

\section{Meteoric Beryllium-10 in mid-Miocene permafrost and polar aridity in East Antarctica}

The upper elevations of the McMurdo Dry Valleys (MDV), known as the stable upland or ultraxerous zone (Doran et al., 2002, Marchant and Head III, 2007) are thought to have remained unglaciated under a hyper-arid polar climate since $\sim 12.5 \mathrm{Ma}$ (e.g. Denton et al., 1993, Sugden et al., 1995, Summerfield et al., 1999, Valletta et al., 2015). Ground ice and meteoric Beryllium-10 $\left({ }^{10} \mathrm{Be}_{\mathrm{met}}\right)$ profiles in permafrost soils from this region have therefore the potential to record the onset of polar aridity and the response of the East Antarctic Ice Sheet (EAIS) to warm periods of the late Miocene and Pliocene. ${ }^{10} \mathrm{Be}_{\text {met }}$ is formed in the upper atmosphere by cosmic rays spallation of oxygen, producing ${ }^{10} \mathrm{BeO}$ and ${ }^{10} \mathrm{Be}(\mathrm{OH})_{2}$ which binds itself to atmospheric aerosols and is transferred to the surface by wet or dry deposition (Lal and Peters, 1967, McHargue and Damon, 1991). Through continued deposition, ${ }^{10} \mathrm{Be}_{\text {met }}$ accumulates at the surface and the high reactivity of hydrolyzed ${ }^{10} \mathrm{Be}_{\text {met }}$ at most natural $\mathrm{pH}$ levels $(\mathrm{pH}>4)$ ensures that ${ }^{10} \mathrm{Be}_{\text {met }}$ nuclides adsorb easily onto fine soil particles. The presence of ${ }^{10} \mathrm{Be}_{\text {met }}$ in ultraxerous permafrost is significant because ${ }^{10} \mathrm{Be}_{\text {met }}$ enters the soil profile attached to fine particles from the surface.Through the downward percolation of water, translocation and illuviation processes transport clays through an open-pore network until they fall out of traction because of blocked pathways or reduced flow.

Early numerical modeling suggested that the uppermost tens of meters of permafrost soils in the upper MDV should be largely deprived of ground ice due to its sublimation under 
hyper-arid climate (Hindmarsh et al., 1998, McKay et al., 1998, Schorghofer and Aharonson, 2005, Hagedorn et al., 2007). However, recent studies documented the widespread presence of ice-cemented permafrost soils that was inferred to have formed through infiltration and freezing of evaporated snowmelt (Dickinson and Rosen, 2003, Hagedorn et al., 2010, Lacelle et al., 2013a, Lapalme et al., 2017a). These contrasting views, concerning polar aridity, are also observed in ${ }^{10} \mathrm{Be}_{\text {met }}$ measurements from Miocene-age ultraxerous permafrost soils. Dickinson et al. (2012) found significant ${ }^{10} \mathrm{Be}_{\text {met }}$ concentrations down to at least $4.5 \mathrm{~m}$ at Table Mountain, suggesting infiltration of liquid water and clay illuviation during a warm period well after 12.5 Ma. Conversely, Valletta et al. (2015) suggested persistent polar aridity following the deposition of sediment between $14-17.5$ Ma at Friis Hills, based on ${ }^{10} \mathrm{Be}_{\text {met }}$ concentrations below the analytical blank range within $60 \mathrm{~cm}$ of depth.

This chapter reports new ${ }^{10} \mathrm{Be}_{\text {met }}$ measurements from mid-Miocene permafrost in the upper MDV (Friis Hills and Table Mountain) with the objective of capturing the timing of the onset of permanent polar aridity (i.e. little to no liquid water). The results are used to constrain the timing and extent of water infiltration in permafrost sediments since the mid-Miocene. This has major implications for Antarctic paleoclimate through the Neogene.

\subsection{Principles of the ${ }^{10} \mathrm{Be}_{\text {met }}$ tracer}

Beryllium-10 $\left({ }^{10} \mathrm{Be}\right)$ is a radioactive isotope of Beryllium (half-life: $1.36 \mathrm{Myr}$; Nishiizumi et al., 2007) that is absent from natural materials unless exposed to cosmic radiation (Lal, 1991). There are two different types of ${ }^{10} \mathrm{Be}$ : (1) in situ and (2) meteoric. In-situ ${ }^{10} \mathrm{Be}$ is produced within minerals on the ground surface. ${ }^{10} \mathrm{Be}_{\mathrm{met}}$ is formed in the upper atmosphere by cosmic rays spallation of oxygen, producing ${ }^{10} \mathrm{BeO}$ and ${ }^{10} \mathrm{Be}(\mathrm{OH})_{2}$, which in turn attach to atmospheric aerosols (primarily sulfates) and are brought to Earth's surface through wet precipitation (i.e. meteoric, rain or snow) or dry deposition (dust) (e.g. Lal and Peters, 1967, Tuniz et al., 1983, Nishiizumi et al., 1984, McHargue and Damon, 1991, Gosse and Phillips, 2001, Fig. 5.1).

Unlike in-situ ${ }^{10} \mathrm{Be},{ }^{10} \mathrm{Be}_{\text {met }}$ is rapidly homogenized in the atmosphere within 1 to 2 years, making altitudinal scaling calibrations unnecessary (Raisbeck et al., 1981, Heikkilä et al., 2013). Additionally, the high reactivity of hydrolyzed ${ }^{10} \mathrm{Be}_{\text {met }}$ at most natural $\mathrm{pH}$ levels $\left(\mathrm{pH}>4\right.$ ) ensures that when ${ }^{10} \mathrm{Be}_{\text {met }}$ nuclides reach the surface, they absorb easily onto fine soil particles (Fig. 5.1). The affinity of ${ }^{10} \mathrm{Be}_{\text {met }}$ for clay, along with the predictability of atmospheric flux of ${ }^{10} \mathrm{Be}_{\text {met }}$, make it a suitable environmental tracer with applications such as quantifying erosion rates (e.g. Brown et al., 1992, Willenbring and von Blanckenburg, 2010) 
or tracing continental sedimentation in deep marine authigenic minerals and ferromanganese deposits (e.g. von Blanckenburg et al., 1996, 2012, 2015, Willenbring and von Blanckenburg, 2010, von Blanckenburg and Bouchez, 2014). More recently, ${ }^{10} \mathrm{Be}_{\text {met }}$ has also been used to calculate soil residence times, subglacial processes and interglacial surface exposure (Graly et al., 2018), as well as movement of water through soil profile (e.g. Dickinson et al., 2012, Valletta et al., 2015). Extensive details of the physical and chemical behaviour of Beryllium in the environment are beyond the scope of this thesis but have been the central subject of other works (e.g. Vesely et al., 2002, Taylor et al., 2003, Boschi, 2016).

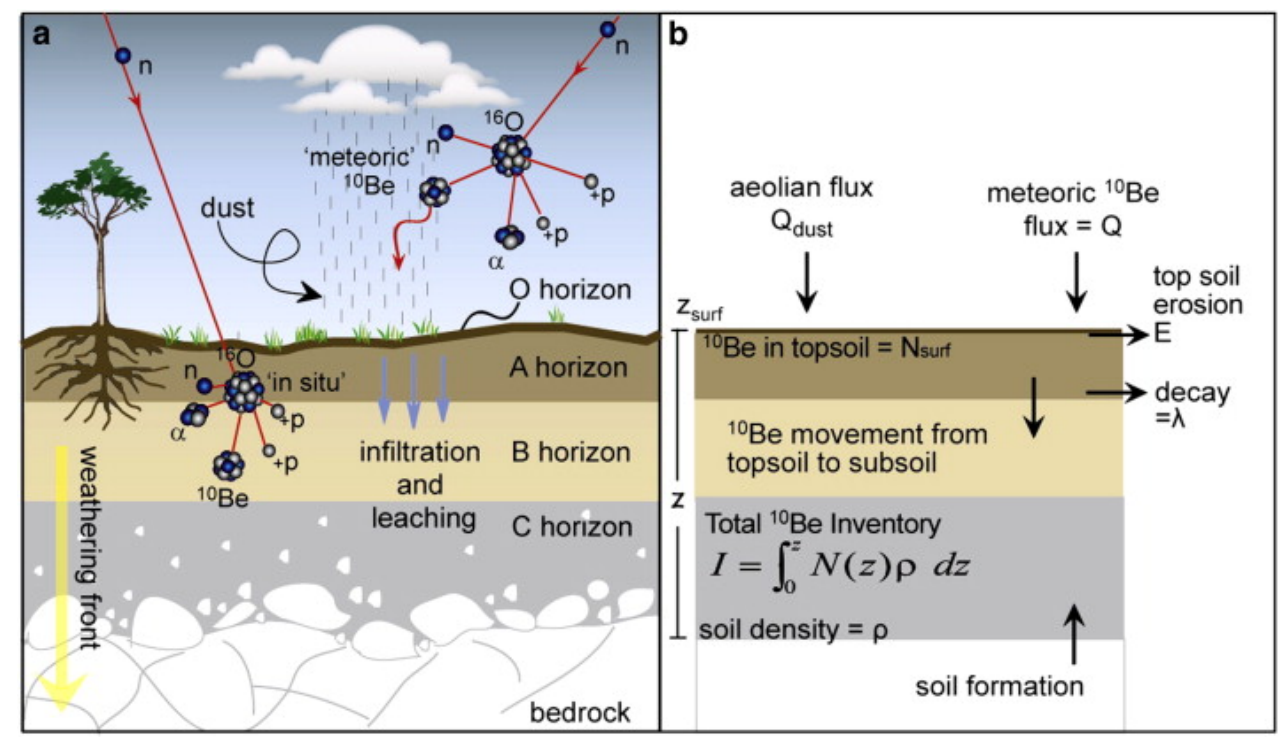

Fig. 5.1 ${ }^{10} \mathrm{Be}_{\text {met }}$ in soil profiles. a. Schematic diagram of incorporation of ${ }^{10} \mathrm{Be}_{\text {met }}$ in soil profiles. b. Definition of variables in equation 5.3 (Willenbring and von Blanckenburg, 2010)

\subsubsection{Quantifying the atmospheric flux of ${ }^{10} \mathrm{Be}_{\text {met }}$ in the McMurdo Dry Valleys}

The flux of ${ }^{10} \mathrm{Be}_{\text {met }}$ that reaches the Earth's surface is a function of both changes in atmospheric production and delivery of those nuclides to the surface (Willenbring and von Blanckenburg, 2010). The production rate varies mostly based on changes in intensity and orientation of the Earth's geomagnetic field, which produces a predictable latitudinal variation (e.g. Lal and Peters, 1967, Masarik and Beer, 1999, 2009, Dunai, 2001, Darvill, 2013, Fig. 5.2). At high latitudes, the Earth's magnetic field lines are sub-perpendicular to cosmic rays, resulting in limited deflection and allowing more cosmic rays to reach the surface. The delivery of ${ }^{10} \mathrm{Be}_{\text {met }}$ is also influenced by climatic factors like atmospheric circulation. Fluxes 
are greatest in mid latitudes where precipitation and tropospheric-stratospheric mixing are greatest (Heikkilä et al., 2013). The global average flux of ${ }^{10} \mathrm{Be}_{\text {met }}$ to the Earth's surface is $5.8 \times 10^{5}$ at g$^{-1} \mathrm{~cm}^{-1} \mathrm{yr}^{-1}$ (Masarik and Beer, 1999, Field et al., 2006, Heikkilä, 2007).

In the MDV, the main sources of ${ }^{10} \mathrm{Be}_{\text {met }}$ are dry fallout, snow and wind remobilization of soils, which together represent the ${ }^{10} \mathrm{Be}_{\text {met }}$ flux at ground surface (Steig et al., 1995).

$$
Q_{\text {total }}=Q_{\text {meteoric }}+Q_{\text {dust }}
$$

Steig et al. $(1995,1996,2000)$ measured ${ }^{10} \mathrm{Be}_{\text {met }}$ accumulation rates in Taylor Dome ice cores of $1.3 \times 10^{5}$ at $\mathrm{g}^{-1} \mathrm{yr}^{-1}: \sim 0.3 \times 10^{5}$ at $\mathrm{g}^{-1} \mathrm{yr}^{-1}$ deposited by snow and $\sim 1.0 \times 10^{5}$ at $\mathrm{g}^{-1} \mathrm{yr}^{-1}$ deposited from dry fallout. More recent estimations by Lal (2007) attribute $<10 \%$ of ${ }^{10} \mathrm{Be}_{\text {met }}$ to dust transport in Vostok and Taylor Dome cores, even during peak dust epochs. Taylor Dome is an active accumulation area. Consequently, directly using this flux for other areas of the MDV has proven to be an overestimate due to removal of ${ }^{10} \mathrm{Be}_{\text {met }}$ by decay or remobilization (e.g. Graham et al., 2002, Schiller et al., 2009, Dickinson et al., 2012). The flux of ${ }^{10} \mathrm{Be}_{\text {met }}$ is therefore dependant on location and topography. Schiller (2007) noted that Wright Valley receives most of its ${ }^{10} \mathrm{Be}_{\text {met }}$ from wind-blown dust and a small fraction by snowfall. Trinh-Le (2017) added that because of the presence of a glacier, University Valley gets an additional ${ }^{10} \mathrm{Be}_{\text {met }}$ input from wind-blown snow. Dickinson et al. (2012) found a

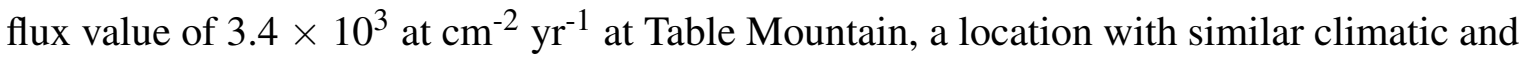
erosional conditions to Friis Hills.

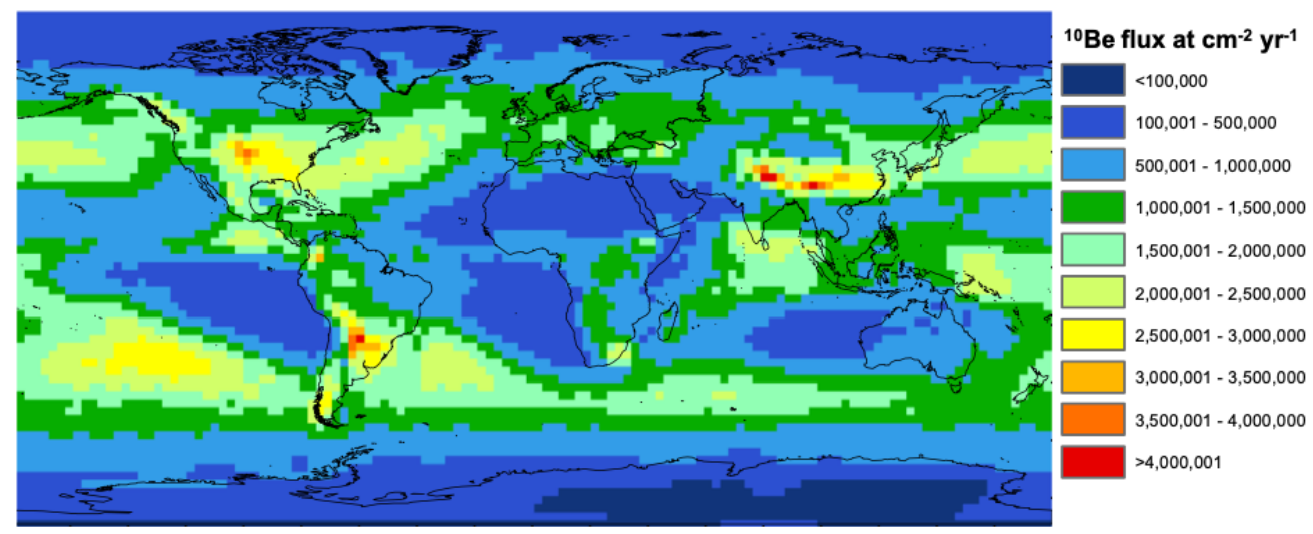

Fig. 5.2 Distribution of modern ${ }^{10} \mathrm{Be}_{\text {met }}$ atmospheric flux (Heikkilä and Von Blanckenburg, 2015) 


\subsection{2 ${ }^{10} \mathrm{Be}_{\text {met }}$ distribution with depth}

Although ${ }^{10} \mathrm{Be}_{\text {met }}$ accumulates at the surface, it can migrate into the ground through infiltration and clay illuviation (Willenbring and von Blanckenburg, 2010). Considering a constant flux of ${ }^{10} \mathrm{Be}_{\text {met }}$ at the surface, Brown et al. (1992) suggested using the following equation to model the downward redistribution of the nuclide:

$$
N(z)=N_{\text {surface }} e^{-z k}
$$

where $\mathrm{N}(\mathrm{z})$ is the ${ }^{10} \mathrm{Be}_{\text {met }}$ concentration (at $\mathrm{g}^{-1}$ ) at depth $\mathrm{z}(\mathrm{cm}), \mathrm{N}_{\text {surface }}$ is the surface concentration of ${ }^{10} \mathrm{Be}_{\text {met }}$ concentration $\left(\mathrm{at} \mathrm{g}^{-1}\right)$ and $\mathrm{k}$ is an absorption coefficient $\left(\mathrm{cm}^{-1}\right)$ that describes the decrease of nuclide with depth (Willenbring and von Blanckenburg, 2010). The coefficient $\mathrm{k}$ describes the shape of the ${ }^{10} \mathrm{Be}_{\text {met }}$ distribution within a homogeneous soil profile with constant subsurface density. In zones of constant soil production, concentration of ${ }^{10} \mathrm{Be}_{\text {met }}$ would decrease exponentially with increasing depth (Brown et al., 1992), with peaks in clay-rich horizons (e.g. Pavich et al., 1986). ${ }^{10} \mathrm{Be}_{\text {met }}$ can also accumulate on ice and snow and infiltrate soil columns in subsequent melts (e.g. Finkel and Nishiizumi, 1997, Schiller et al., 2014). Recycling of previously exposed material, for example in till deposits, may also lead to enriched values at depth (Balco, 2004).

\subsubsection{Erosion rates and soil ages from inventory of ${ }^{10} \mathrm{Be}_{\text {met }}$}

${ }^{10} \mathrm{Be}_{\text {met }}$ inventories within soil profiles can be used to determine rates of soil production and erosion along with soil age, or the time it was first exposed to the surface (Willenbring and von Blanckenburg, 2010). The inventory, I $\left(\mathrm{at} \mathrm{cm}^{-2}\right)$ can be calculated using the following equation:

$$
I=\int_{0}^{z} N(z) \rho d z
$$

where $\mathrm{z}$ is the depth to the bottom of the soil column, $\mathrm{N}(\mathrm{z})$ is the concentration of ${ }^{10} \mathrm{Be}_{\text {met }}$ atoms at depth $\left(\right.$ at $\left.\mathrm{g}^{-1}\right), \mathrm{z}(\mathrm{cm})$ and $\rho$ the soil density $\left(\mathrm{g} \mathrm{cm}^{-3}\right)$. By assuming that the flux of ${ }^{10} \mathrm{Be}_{\text {met }}, \mathrm{Q}(\mathrm{t})\left(\right.$ at $\left.\mathrm{cm}^{-2} \mathrm{yr}^{-1}\right)$ is known at a given site and fluctuates with time, then the ${ }^{10} \mathrm{Be}_{\text {met }}$ 
inventory is related to the soil age, $\mathrm{t}$, the erosion rate, $\varepsilon$, and radioactive decay through the following equation (Willenbring and von Blanckenburg, 2010):

$$
\frac{d}{d t} I(t)=-\lambda I(t)-N_{\text {surf }}(t) \rho \varepsilon(t)+Q(t)
$$

where $\lambda$ is the radioactive decay of ${ }^{10} \mathrm{Be}, \varepsilon(\mathrm{t})$ is the erosion rate of the surface $\left(\mathrm{cm} \mathrm{yr}^{-1}\right)$, which can vary over time, and $\mathrm{N}_{\text {surf }}$ is the ${ }^{10} \mathrm{Be}_{\text {met }}$ concentration at the surface (at $\mathrm{g}^{-1}$ ). When assuming that the flux fluctuates around a nearby mean value, $Q(t)=(Q)$ and that the surface is not eroding, $\varepsilon(\mathrm{t})=0$, the integration of the previous equation yields:

$$
I=\frac{Q}{\lambda}\left(1-e^{-\lambda t}\right)
$$

which allows estimation of the age of very stable soils (Willenbring and von Blanckenburg, 2010). In a setting where erosion is known and steady, $\varepsilon(\mathrm{t})=\varepsilon$ and the integration of equation 5.3 yields:

$$
I=\frac{\left(Q-\varepsilon \rho N_{\text {surf }}\right)\left(1-e^{\lambda t}\right)}{\lambda}
$$

The age of soil for various plausible erosion rates can be calculated with (Willenbring and von Blanckenburg, 2010):

$$
t=\frac{-\ln \left(1-\frac{I \lambda}{Q-\varepsilon \rho N_{\text {surf }}}\right)}{\lambda}
$$

again, where I is the depth-integrated inventory of ${ }^{10} \mathrm{Be}_{\text {met }}\left(\right.$ at $\left.\mathrm{cm}^{-2}\right), \mathrm{N}_{\text {surf }}$ is the the ${ }^{10} \mathrm{Be}_{\text {met }}$ concentration at the surface (at $\mathrm{g}^{-1}$ ), $\mathrm{Q}$ is the local flux of ${ }^{10} \mathrm{Be}_{\text {met }}\left(\right.$ at $\mathrm{cm}^{-2} \mathrm{yr}^{-1}$ ), $\varepsilon$ is the erosion rate $\left(\mathrm{cm} \mathrm{yr}^{-1}\right)$ and $\rho$, the soil density $\left(\mathrm{g} \mathrm{cm}^{-3}\right)$. Going back to equation 5.6, at steady state condition $(\mathrm{t} \rightarrow \infty)$, then I varies according to the following equation (Brown et al., 1988): 


$$
I=\frac{Q-\varepsilon \rho N_{\text {surf }}}{\lambda}
$$

If one assumes: (1) exponential decrease in concentration with depth, (2) constant inventory over time $(\mathrm{d} / \mathrm{dt}=0),(3) \mathrm{k} » \lambda$ (i.e. $\lambda$ becomes insignificant, see equation 20 Willenbring and von Blanckenburg (2010)) and (4) steady state using a single surface measurement, the following equation can be used (Willenbring and von Blanckenburg, 2010):

$$
N_{\text {surf }}=\frac{Q}{\rho \varepsilon}
$$

\section{Denudation (or erosion) rates in the McMurdo Dry Valleys estimated by cosmogenic radionuclide abundance}

Cosmogenic nuclides (CNs; for example: ${ }^{10} \mathrm{Be},{ }^{26} \mathrm{Al},{ }^{21} \mathrm{Ne},{ }^{3} \mathrm{He}$, and ${ }^{36} \mathrm{Cl}$ ), which accumulate at the Earth's surface, are useful proxies to determine exposure ages of surface rocks and deposits over time scales that range from thousands to millions of years. The dependence of CNs production rates as a function of shielding depths also make it possible to estimate erosion rates of Earth's surface from CNs. Erosion rates are essential to understand landscape development (Lal, 1991) and have been extensively documented in Antarctica (Fig. 5.3). Although current erosion rates in Antarctica are amongst the lowest in the world because of hyper-arid polar climate, low erosion rates can drastically increase the calculated ages of ancient surfaces, such as those present in the MDV (e.g. Margerison et al., 2005). Erosion reduces the apparent age of surfaces dated by CNs. It is therefore very important to use precise erosion rates in the MDV to obtain realistic results. Most investigations of CNs in the MDV establish a steady-state degradation of bedrock and regolith of $\sim 0.01-3.00 \mathrm{~m} \mathrm{Ma}^{-1}$ (Tables 5.1 and 5.2). 
118 Meteoric Beryllium-10 in mid-Miocene permafrost and polar aridity in East Antarctica

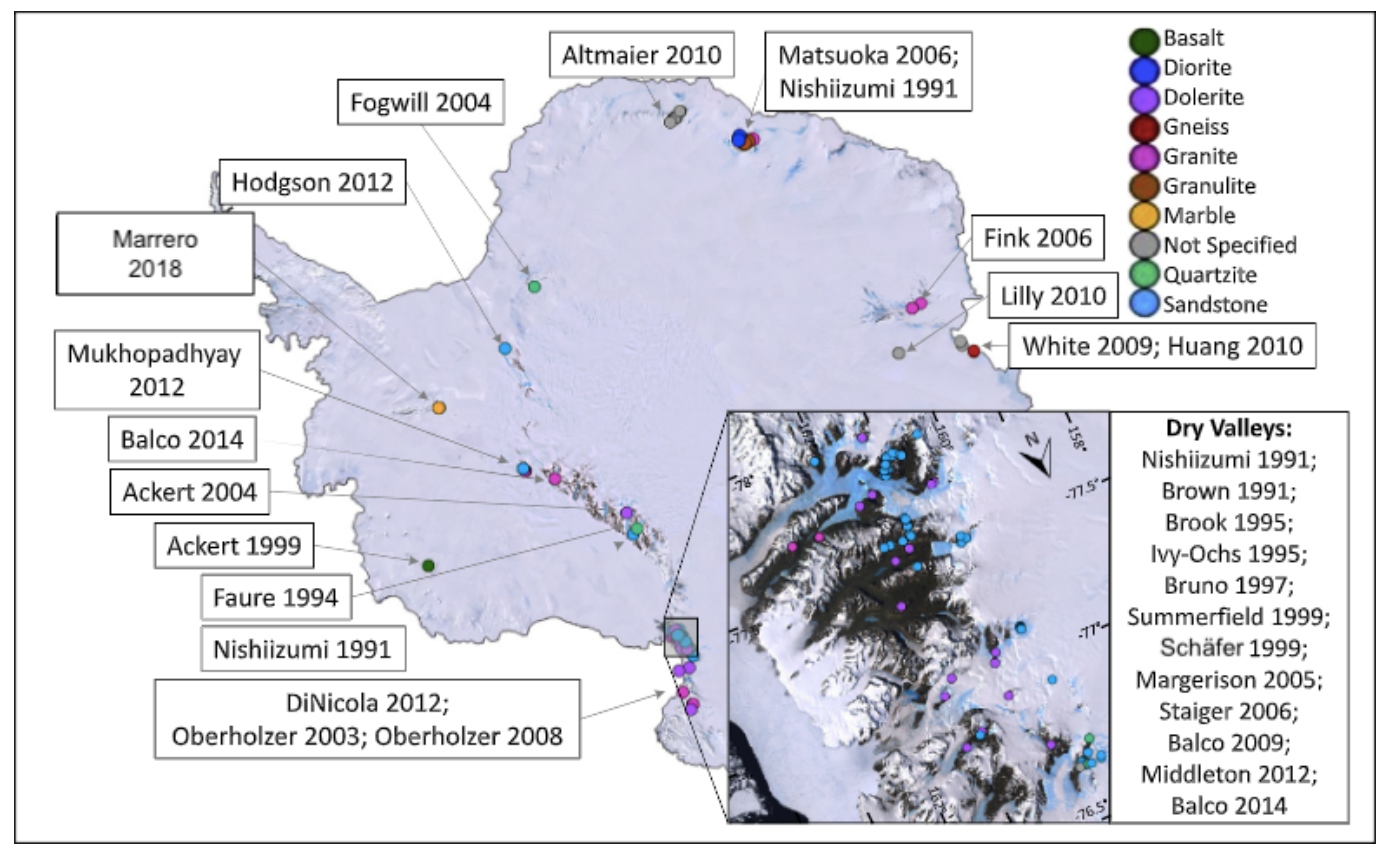

Fig. 5.3 Locations of all Antarctic cosmogenic nuclide-derived erosion rate studies prior to 2015, compiled by Marrero et al. (2018). Analyses distribution as follows: ${ }^{10} \mathrm{Be}(32 \%),{ }^{26} \mathrm{Al}(24 \%),{ }^{21} \mathrm{Ne}$ $(26 \%),{ }^{3} \mathrm{He}(15 \%)$, and ${ }^{36} \mathrm{Cl}(3 \%$, basalts only) 
Table 5.1 Erosion or denudation rates based on bedrock and boulder samples in different locations of the McMurdo Dry Valleys

\begin{tabular}{|c|c|c|c|c|}
\hline Reference & Location & Material & $\min -\max \varepsilon\left(\mathbf{m ~ M a}^{-1}\right)$ & CNs \\
\hline \multirow{5}{*}{ Nishiizumi et al. (1991) } & Allan Hills & & $0.24-0.85$ & \multirow{5}{*}{${ }^{10} \mathrm{Be} \&{ }^{26} \mathrm{Al}$} \\
\hline & $\left(76.7^{\circ} \mathrm{S} 159.6^{\circ} \mathrm{E}\right)$ & Sandstone & & \\
\hline & $\begin{array}{l}\text { Tillite Glacier } \\
\left(839^{\circ} \mathrm{S} 1663^{\circ} \mathrm{F}\right)\end{array}$ & & $<0.11-0.21$ & \\
\hline & $(83.95166 .3 \mathrm{E})$ & & & \\
\hline & $\begin{array}{c}\text { Wright Valley } \\
\left(77.6^{\circ} \mathrm{S} 161.3^{\circ} \mathrm{E}\right)\end{array}$ & \multicolumn{2}{|r|}{$0.54-1.31$} & \\
\hline Ivy-Ochs et al. (1995) & $\begin{array}{c}\text { Table Mountain } \\
\left(78.0^{\circ} \mathrm{S} 162.0^{\circ} \mathrm{E}\right)\end{array}$ & Sandstone \& Granite & $0.005-0.70$ & ${ }^{10} \mathrm{Be} \&{ }^{26} \mathrm{Al}$ \\
\hline Brook et al. (1995) & $\begin{array}{l}\text { Mount Fleming } \\
\left(77^{\circ} 6^{\circ} \mathrm{S} 160.1^{\circ} \mathrm{E}\right)\end{array}$ & Sandstone & $0.06-0.13$ & ${ }^{10} \mathrm{Be} \&{ }^{26} \mathrm{Al}$ \\
\hline \multirow[t]{2}{*}{ Summerfield et al. (1999) } & $\begin{array}{c}\text { Arena Valley } \\
\left(77.8^{\circ} \mathrm{S} 160.9^{\circ} \mathrm{E}\right)\end{array}$ & Sandstone & $0.26-0.60$ & \multirow[t]{2}{*}{${ }^{21} \mathrm{Ne}$} \\
\hline & $\begin{array}{l}\text { Mount Fleming } \\
\left(77^{\circ} 6^{\circ} \mathrm{S} 160.1^{\circ} \mathrm{E}\right)\end{array}$ & & $<0.16$ & \\
\hline \multirow{8}{*}{ Schäfer et al. (1999) } & $\begin{array}{l}\text { Mount Fleming } \\
\left(77.6^{\circ} \mathrm{S} 160.1^{\circ} \mathrm{E}\right)\end{array}$ & & $0.06-0.12$ & \multirow{8}{*}{${ }^{21} \mathrm{Ne}$} \\
\hline & $\begin{array}{c}\text { Friis Hills } \\
\left(77.8^{\circ} \mathrm{S} 161.5^{\circ} \mathrm{E}\right)\end{array}$ & Dolerite & 0.19 & \\
\hline & $\begin{array}{l}\text { Insel Mountain } \\
\left(77.4^{\circ} \mathrm{S} 161.5^{\circ} \mathrm{E}\right)\end{array}$ & & $0.08-0.10$ & \\
\hline & $\begin{array}{c}\text { Labyrinth } \\
\left(77.6^{\circ} \mathrm{S} 160.8^{\circ} \mathrm{E}\right)\end{array}$ & & $0.25-0.36$ & \\
\hline & $\begin{array}{c}\text { Dais } \\
\left(77.6^{\circ} \mathrm{S} 161.3^{\circ} \mathrm{E}\right)\end{array}$ & & $0.13-0.14$ & \\
\hline & $\begin{array}{c}\text { Pandora Spire } \\
\left(77.8^{\circ} \mathrm{S} 161.2^{\circ} \mathrm{E}\right)\end{array}$ & & 0.25 & \\
\hline & $\begin{array}{l}\text { Mount Feather } \\
\left(78.0^{\circ} \mathrm{S} 160.4^{\circ} \mathrm{E}\right)\end{array}$ & Sandstone \& Dolerite & $0.10-0.25$ & \\
\hline & $\begin{array}{l}\text { Table Mountain } \\
\left(78.0^{\circ} \mathrm{S} 162.0^{\circ} \mathrm{E}\right)\end{array}$ & Sandstone & $0.11-0.14$ & \\
\hline \multirow[t]{2}{*}{ Margerison et al. (2005) } & $\begin{array}{l}\text { Mackay Nunataks } \\
\left(\sim 77.1^{\circ} \mathrm{S} 160.4^{\circ} \mathrm{E}\right)\end{array}$ & Dolerite & $0.11-0.27$ & \multirow[t]{2}{*}{${ }^{3} \mathrm{He}$} \\
\hline & $\begin{array}{c}\text { Coombs Hills } \\
\left(76.9^{\circ} \mathrm{S} 160.0^{\circ} \mathrm{E}\right)\end{array}$ & & $0.03-0.06$ & \\
\hline \multirow[t]{2}{*}{ Balco and Shuster (2009) } & $\begin{array}{c}\text { Arena Valley } \\
\left(77.9^{\circ} \mathrm{S} 160.9^{\circ} \mathrm{E}\right)\end{array}$ & Sandstone & $0.4-2.2$ & \multirow[t]{2}{*}{${ }^{10} \mathrm{Be} \&{ }^{26} \mathrm{Al}$} \\
\hline & $\begin{array}{c}\text { East Groin } \\
\left(77.4^{\circ} \mathrm{S} 162.2^{\circ} \mathrm{E}\right)\end{array}$ & & $0.6-1.2$ & \\
\hline Middleton et al. (2012) & $\begin{array}{l}\text { Sessrumnir Valley } \\
\left(77.6^{\circ} \mathrm{S} 160.5^{\circ} \mathrm{E}\right)\end{array}$ & Sandstone & $0.06-0.23$ & ${ }^{21} \mathrm{Ne} \&{ }^{10} \mathrm{Be}$ \\
\hline \multirow[t]{2}{*}{ Balco et al. (2014) } & $\begin{array}{c}\text { Mount DeWitt } \\
\left(77.2^{\circ} \mathrm{S} 159.8^{\circ} \mathrm{E}\right)\end{array}$ & Sandstone & $0.5-1.7$ & \multirow[t]{2}{*}{${ }^{21} \mathrm{Ne} \&{ }^{10} \mathrm{Be} \&{ }^{26} \mathrm{Al}$} \\
\hline & $\begin{array}{c}\text { East Groin } \\
\left(77.4^{\circ} \mathrm{S} 162.2^{\circ} \mathrm{E}\right)\end{array}$ & & $0.2-1.7$ & \\
\hline
\end{tabular}


120 Meteoric Beryllium-10 in mid-Miocene permafrost and polar aridity in East Antarctica

Table 5.2 Erosion or denudation rates based on regolith in different locations of the McMurdo Dry Valleys

\begin{tabular}{|c|c|c|c|c|}
\hline Reference & Location & Material & $\min -m a x \varepsilon\left(\mathrm{m} \mathrm{Ma}^{-1}\right)$ & CNs \\
\hline Brook et al. (1995) & $\begin{array}{c}\text { Arena Valley } \\
\left(77.8^{\circ} \mathrm{S} 160.9^{\circ} \mathrm{E}\right)\end{array}$ & Glacial Drift & $0.05-0.26$ & ${ }^{10} \mathrm{Be} \&{ }^{26} \mathrm{Al}$ \\
\hline Staiger et al. (2006) & $\begin{array}{c}\text { Vernier Valley } \\
\left(78.0^{\circ} \mathrm{S} 161.2^{\circ} \mathrm{E}\right)\end{array}$ & Glacial Drift & $0.02-1.08$ & ${ }^{21} \mathrm{Ne}$ \\
\hline Putkonen et al. (2008) & $\begin{array}{c}\text { Arena Valley } \\
\left(77.8^{\circ} \mathrm{S} 161.0^{\circ} \mathrm{E}\right)\end{array}$ & Landslide & 2.1 & ${ }^{10} \mathrm{Be} \&{ }^{26} \mathrm{Al}$ \\
\hline Schiller et al. (2009) & $\begin{array}{c}\text { Wright Valley } \\
\left(77.5^{\circ} \mathrm{S} 162.4^{\circ} \mathrm{E}\right)\end{array}$ & Soil Profile & $2.0-3.0$ & ${ }^{10} \mathrm{Be}_{\text {met }}$ \\
\hline Morgan et al. (2011) & $\begin{array}{c}\text { Arena Valley } \\
\left(77.8^{\circ} \mathrm{S} 160.9^{\circ} \mathrm{E}\right) \\
\text { Beacon Valley } \\
\left(77.8^{\circ} \mathrm{S} 160.7^{\circ} \mathrm{E}\right)\end{array}$ & Glacial Drift & $0.4-1.2$ & ${ }^{10} \mathrm{Be} \&{ }^{26} \mathrm{Al}$ \\
\hline Dickinson et al. (2012) & $\begin{array}{l}\text { Table Mountain } \\
\left(78.0^{\circ} \mathrm{S} 162.0^{\circ} \mathrm{E}\right)\end{array}$ & Debris flow \& Glacial Drift & $0.37-1.2$ & ${ }^{10} \mathrm{Be}_{\text {met }}$ \\
\hline
\end{tabular}

\subsection{4 ${ }^{10} \mathrm{Be}_{\text {met }}$ case studies in the McMurdo Dry Valleys and implica- tions of leaching method}

Dickinson et al. (2012) first questioned the persistent aridity of the high elevations of the MDV (e.g. Marchant et al., 1996, Sugden et al., 1995), after observing illuviated clays in thin sections of sediments belonging to the Sirius Group on Table Mountain. Illuviated clays are well documented in temperate and semi-arid environments and typically require the downward percolation of liquid water through sediment or soil profiles (e.g. Buurman et al., 1998, Veldkamp, 1999). To test if the high elevations of the MDV had in fact remained arid since 12.5 Ma, Dickinson et al. (2012) proposed using ${ }^{10} \mathrm{Be}_{\text {met }}$ as a tracer of water infiltration. Concentrations of ${ }^{10} \mathrm{Be}_{\text {met }}$ were measured to depths of $4.5 \mathrm{~m}$ in icy permafrost of Table Mountain, varying from $2.9 \times 10^{8}$ at $\mathrm{g}^{-1}$ at the surface to $1.7 \times 10^{5}$ at $\mathrm{g}^{-1}$ at $4.5 \mathrm{~m}$ in TM1 and from $5.2 \times 10^{7}$ at $\mathrm{g}^{-1}$ at the surface to $5.1 \times 10^{3}$ at $\mathrm{g}^{-1}$ at $3 \mathrm{~m}$ in TM4 (Fig 5.4; Dickinson et al., 2012). Their study calculated a minimum closure age at Table Mountain of $6 \mathrm{Ma}$ (i.e. time at which the study site became permanently frozen and closed to the input of water).

The study of ${ }^{10} \mathrm{Be}_{\text {met }}$ at Table Mountain by Dickinson et al. (2012) along with other early ${ }^{10} \mathrm{Be}_{\text {met }}$ investigations in the MDV (e.g. Graham et al., 2002, Schiller, 2007, Schiller et al., 2009) used an aggressive leaching method to extract ${ }^{10} \mathrm{Be}_{\text {met }}$ from the sediment. This method used $6 \mathrm{M} \mathrm{HCl}$ for $1 \mathrm{~h}$ at $100^{\circ} \mathrm{C}$ (Graham et al., 2001, Ditchburn and Graham, 2002) and was criticized because of the possibility of liberating in situ ${ }^{10} \mathrm{Be}$ via partial decomposition of clay minerals (Valletta et al., 2015). Although Dickinson et al. (2012) estimated the concentration of in situ ${ }^{10} \mathrm{Be}$ to be $<1 \%$ of the ${ }^{10} \mathrm{Be}_{\text {met }}$ fractions, the great age of the Table Mountain sediments, like most sediments in the MDV, allow for millions of years of in situ ${ }^{10} \mathrm{Be}$ accumulation, which could cause significant contamination (Valletta et al., 2015). After 
correcting for in situ ${ }^{10} \mathrm{Be}$ contamination in Table Mountain samples, Valletta et al. (2015) used Wittmann et al. (2012)'s mild leaching method consisting of $0.5 \mathrm{M} \mathrm{HCl}$ for $24 \mathrm{~h}$ at room temperature followed by $1 \mathrm{M}$ hydroxylamine hydrochloride for $4 \mathrm{~h}$ in an $80^{\circ} \mathrm{C}$ ultrasonic bath. They measured concentrations of $1.5 \times 10^{7}$ at $\mathrm{g}^{-1}$ at the surface, but it dropped two orders of magnitude $\left(3.1 \times 10^{5}\right.$ at $\left.\mathrm{g}^{-1}\right)$ in concentration, at $20 \mathrm{~cm}$ depth. At $60 \mathrm{~cm}$ depth, concentrations fell below the blank range $\left(<3.0 \times 10^{4}\right.$ at $\mathrm{g}^{-1} ;$ Fig 5.4). With the assumption that the Friis Hills sediments have remained a closed system, their study concluded that the lack of ${ }^{10} \mathrm{Be}_{\text {met }}$ at $60 \mathrm{~cm}$ depth could be associated with a minimum closing age of 11.0-17.5 Ma, supporting persistent polar aridity following sediment emplacement between 14-17.5 Ma. In other words, this finding implies that the Friis Hills have undergone aridification around $14 \mathrm{Ma}$ ago and that the sediments have remained untouched by meteoric water since then (Valletta et al., 2015).

Trinh-Le (2017) measured ${ }^{10} \mathrm{Be}_{\text {met }}$ concentrations using the mild method in three cores up to depths of $55 \mathrm{~cm}$ in University Valley, where sediments have been dated back $200 \mathrm{ka}$ (optically stimulated luminescence age of sediment). Concentrations varied from $2.17 \times 10^{9}$ to $2.23 \times 10^{7}$ at $\mathrm{g}^{-1}$ (Fig. 5.4). The three sampled cores had higher ${ }^{10} \mathrm{Be}_{\text {met }}$ concentration near the surface, followed by an abrupt decrease in concentration by one or two order of magnitude immediately below the surface, which then remained fairly constant with depth. Concentrations at the surface were also orders of magnitude higher than at other sites (i.e. Wright Valley, Table Mountain) with no evidence of wind erosion. This suggests that University Valley could be a catchment area for ${ }^{10} \mathrm{Be}_{\text {met }}$ in the MDV and that the amount of liquid water has been insufficient to translocate ${ }^{10} \mathrm{Be}_{\text {met }}$ into the sediment column for the last 200 kyr (Trinh-Le, 2017).

\subsection{Methods}

In December 2014, two $60 \mathrm{~cm}$ cores (FA and C2) and one $20 \mathrm{~cm}$ core (C1) were retrieved from a preliminary ${ }^{10} \mathrm{Be}_{\text {met }}$ survey at Friis Hills. A total of 40 additional samples were selected from cores of the 2016 Friis Hills Drilling Project (FHDP2C and FHDP3A). The samples selected were as follows: 5 samples from the dry permafrost layer at FHDP2C $(5 \mathrm{~cm}$ intervals), 6 samples from the first meter of icy permafrost at FHDP2C ( $20 \mathrm{~cm}$ intervals), 8 samples from meter 1 to 5 of icy permafrost FHDP2C (50 cm intervals), 3 samples at meter 37 of FHDP3A (above, within and below an ice lens), 7 samples at meter 43 of FHDP3A ( 2 above, 4 within and 1 below a $15 \mathrm{~cm}$ thick body of ice). Samples were also selected from two Table Mountain cores (TM01-1 and TM97): 2 samples from the dry permafrost 


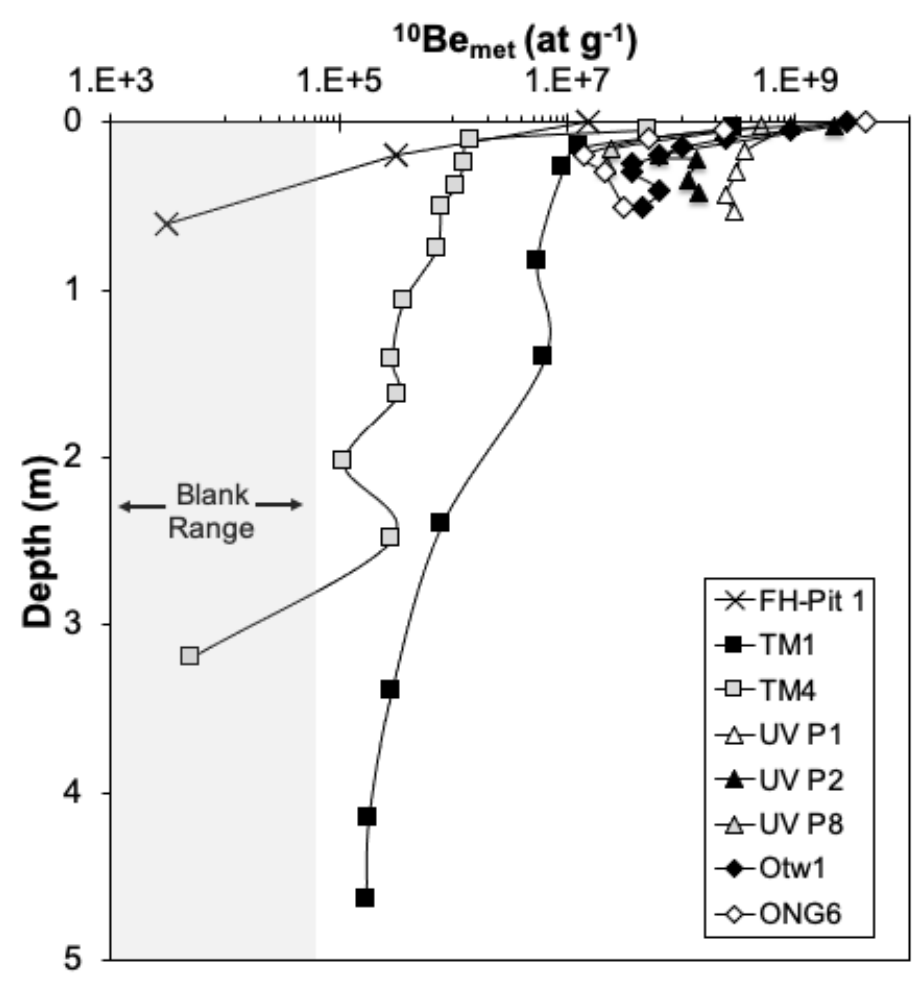

Fig. 5.4 ${ }^{10} \mathrm{Be}_{\text {met }}$ concentration (at $\mathrm{g}^{-1}$ ) for different sites in the MDV: Table Mountain (TM1 and TM4; Dickinson et al., 2012), University Valley (UV P1, P2 and P8; Trinh-Le, 2017), Otway Massif and Ong Valley (Otw1 and ONG6; pers. comm. Dickinson 11/20, from R. Delisle student report 2012); and Friis Hills (FH-Pit 1; Valletta et al., 2015)

layer at TM01 (20 cm intervals), 8 samples from meter 1 to 8 of icy permafrost at Table Mountain (1 m intervals) from both TM01-1 and TM97 and 1 duplicate. Sediment samples were manually dry-sieved to $45-90 \mu \mathrm{m}$ and precisely weighed between 0.75 and $1.00 \mathrm{~g}$ into $50 \mathrm{ml}$ centrifuge tubes before undergoing the sequential extraction procedure.

\subsubsection{Sequential ${ }^{10} \mathrm{Be}_{\text {met }}$ extraction, column chemistry, precipitation, oxydation and target packing}

The method used in this thesis follows the Wittmann et al. (2012) method (adapted from Tessier et al., 1979, Bourlès et al., 1989, Guelke-Stelling and von Blanckenburg, 2012). Amorphous oxide-bound Beryllium ( $\mathrm{Be}_{\mathrm{am}-\mathrm{ox}}$ ) was first extracted by adding $10 \mathrm{ml}$ of $0.5 \mathrm{M}$ $\mathrm{HCl}$ and gently shaking at room temperature for $24 \mathrm{~h}$. The crystalline oxide-bound Beryllium $\left(\mathrm{B}_{\text {ex-ox }}\right)$ was secondly extracted by adding $10 \mathrm{ml}$ of $1 \mathrm{M}$ hydroxylamine-hydrochloride solution 
(in $1 \mathrm{M} \mathrm{HCl}$ ) and placing the samples in an ultrasonic bath at $80^{\circ} \mathrm{C}$ for $4 \mathrm{~h}$, shaking occasionally. Hydroxylamine-hydrochloride was removed by a series of $10 \mathrm{ml}$ concentrated $\mathrm{HNO}_{3}$ and 10 $\mathrm{ml} 30 \% \mathrm{H}_{2} \mathrm{O}_{2}$ washes. The solution was dried down and dissolved in $10 \mathrm{ml} 3 \mathrm{M} \mathrm{HNO}_{3}$. A $0.5 \mathrm{ml}$ sub-sample was retrieved for aliquots of major and minor element analysis and for ${ }^{9} \mathrm{Be}$ measurement. A ${ }^{9} \mathrm{Be}$ carrier solution of $0.8 \mathrm{~g}$ (375 ppm in $3 \mathrm{M} \mathrm{HNO}_{3}$ ) was added to the solution, which then went through Fe columns ( 2 ml Biorad $1 \times 8$ 100-200 mesh resin in 15 $\mathrm{ml}$ Eichrom columns) and Be columns (5 ml Biorad AG50-X8 200-400 mesh cation resin in $15 \mathrm{ml}$ Eichrom columns). Samples were evaporated, then taken up in in $5 \mathrm{ml} 1 \mathrm{M} \mathrm{HNO}_{3}$.

To precipitate $\mathrm{Be}(\mathrm{OH})_{2}, 0.550 \mathrm{ml}$ of concentrated $(25 \%) \mathrm{NH}_{4} \mathrm{OH}$ was added to the samples to reach a $\mathrm{pH}$ of $\sim 9$. The samples were centrifuged, decanted and the precipitates were redissolved in $5 \mathrm{ml} 1 \mathrm{M} \mathrm{HNO}_{3}$. This step was repeated a second time and a final 3 $\mathrm{ml}$ milliQ $\mathrm{H}_{2} \mathrm{O}$ wash was performed to remove ammonia from the $\mathrm{Be}(\mathrm{OH})_{2}$ precipitates. The $\mathrm{Be}(\mathrm{OH})_{2}$ precipitates were then dissolved in $0.3 \mathrm{ml}$ of $5 \mathrm{M} \mathrm{HNO}_{3}$, transferred to quartz crucibles and dried down at $120^{\circ} \mathrm{C}$. The samples were subsequently calcined for 1 to 2 minutes over open flame to form BeO. Niobium $(\sim 0.3 \mathrm{mg})$ was incorporated to form a homogeneous powder. The powder was then transferred into AMS aluminum targets.

\subsubsection{AMS measurement and sample calibration}

Samples from preliminary cores FA, C1 and C2 were measured on the $500 \mathrm{kV}$ AMS (TANDY, ETH Zürich, 2018) while FHDP2C, FHDP3A, TM01 and TM97 samples were measured on the $300 \mathrm{kV}$ AMS (MILEA, ETH Zürich, 2019). The samples were normalized using the 2007S and S2010N standards (Nishiizumi et al., 2007). The concentration of ${ }^{10} \mathrm{Be}_{\text {met }}\left(\mathrm{at} \mathrm{g}^{-1}\right)$ per samples was determined with the following equation:

$$
C^{10} B e_{\text {met }}=\frac{\left(\frac{N_{0} \cdot m_{9_{B e}}}{M_{9_{\text {Bearrier }}}}\right)\left(\frac{{ }^{10} \text { Be }}{{ }^{9} \text { Bet }}\right)_{\text {measured }}-{ }^{10} B e_{\text {met }} \text { blank }}{m_{\text {sample }}}
$$

where $\left({ }^{10} \mathrm{Be}_{\text {met }} /{ }^{9} \mathrm{Be}\right)_{\text {measured }}$ is the ratio of ${ }^{10} \mathrm{Be}_{\text {met }}$ to ${ }^{9} \mathrm{Be}$ measured directly from the sample, $\mathrm{N}_{0}$ is Avogadro's number $\left(6.022 \times 10^{23} \mathrm{~mol}^{-1}\right), \mathrm{m}_{9} \mathrm{Be}$ carrier is the mass of ${ }^{9} \mathrm{Be}$ in the added carrier solution $(\mathrm{g}), \mathrm{M}_{9} \mathrm{Be}$ is the molar mass of ${ }^{9} \mathrm{Be}\left(\mathrm{g} \mathrm{mol}^{-1}\right),{ }^{10} \mathrm{Be}_{\text {met }}$ blank is the number of ${ }^{9} \mathrm{Be}$ atoms added by the carrier solution multiplied by the average ${ }^{10} \mathrm{Be} /{ }^{9} \mathrm{Be}$ ratio measured in laboratory blank samples. 
To ensure that ${ }^{10} \mathrm{Be}_{\text {met }}$ measurements were independent of grain-size distribution (e.g. Wittmann et al., 2012), the stable isotope ${ }^{9} \mathrm{Be}$ was measured on the aliquot retrieved in section 5.2.1. on an Agilent Microwave Plasma-Atomic Emission Spectrometry (MP-AES) instrument model 4210 (University of Canterbury, School of Physical and Chemical Sciences). Concentrations in ppm were measured with a standard error of $\pm 15 \%$.

\subsubsection{Calculation of closures ages using paleo-surface concentrations of ${ }^{10} \mathrm{Be}_{\text {met }}$}

Closure age (t), or the time when ${ }^{10} \mathrm{Be}_{\text {met }}$ stopped infiltrating the ground and was sealed-off in the sediment profile can be calculated using ${ }^{10} \mathrm{Be}_{\text {met }}$ concentrations at depth (Fig. 5.5). The regional proximity of Friis Hills and Table Mountain allows two important assumptions for calculating closure ages of the sediment profiles: (1) the flux of ${ }^{10} \mathrm{Be}_{\text {met }}$ is comparable at both sites and (2) ${ }^{10} \mathrm{Be}_{\text {met }}$ stopped migrating in the soil profiles at the same time (i.e. the closure age is synchronous). These assumptions enable the calculation of erosion rates at the two different sites. Dickinson et al. (2012) established that closure ages (yr) could be calculated using paleo-surface ${ }^{10} \mathrm{Be}_{\text {met }}$ concentration through the following equation:

$$
t=\frac{-\ln \frac{N_{\text {paleo }}}{N_{\text {modern }}}}{\lambda}
$$

where $\mathrm{N}_{\text {paleo }}$ is the paleo-surface concentration of ${ }^{10} \mathrm{Be}_{\text {met }}$ (at $\mathrm{g}^{-1}$ ) and $\mathrm{N}_{\text {modern }}$ is the modern surface concentration of ${ }^{10} \mathrm{Be}_{\text {met }}\left(\right.$ at $\left.\mathrm{g}^{-1}\right)$.

$\mathrm{N}_{\text {paleo }}$ can be projected by fitting an exponential equation:

$$
N_{\text {paleo }}=a e^{b E}
$$

where $\mathrm{a}$ and $\mathrm{b}$ are regression constants and $\mathrm{E}$ is a length measurement (multiplied by time) of the erosion rate $\varepsilon$ described by the following equation:

$$
\varepsilon=\frac{Q}{\rho N_{\text {modern }}}
$$




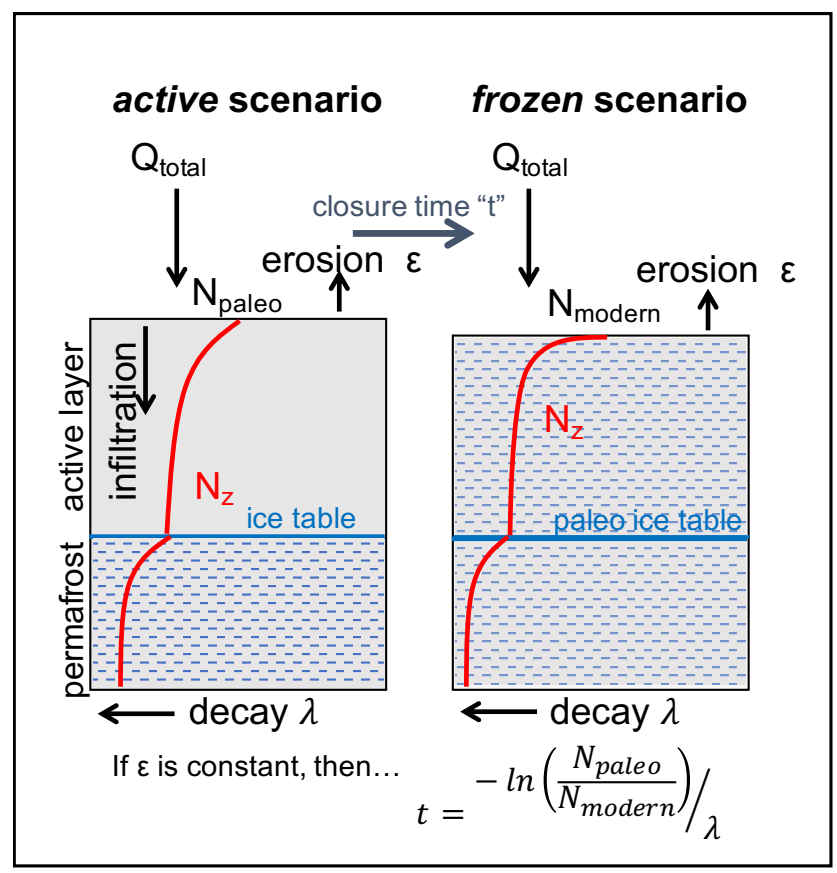

Fig. 5.5 Schematic representation of a ${ }^{10} \mathrm{Be}_{\text {met }}$ ground profile. The active scenario, where ${ }^{10} \mathrm{Be}_{\mathrm{met}}$ infiltration occurs is compared to the frozen scenario where ${ }^{10} \mathrm{Be}_{\text {met }}$ accumulates at the surface. Closure age represents the time since the system has been sealed-off from infiltration

where $\mathrm{Q}$ is the local flux of ${ }^{10} \mathrm{Be}_{\text {met }}\left(\right.$ at $\left.\mathrm{cm}^{-2} \mathrm{yr}^{-1}\right), \rho$ is the soil density $\left(\mathrm{g} \mathrm{cm}^{-3}\right)$ and $\mathrm{N}_{\text {modern }}$ is the ${ }^{10} \mathrm{Be}_{\text {met }}$ concentration at the surface $\left(\right.$ at $\left.\mathrm{g}^{-1}\right)$. By assuming that the closure age $(\mathrm{t})$ was the same throughout the MDV, then:

$$
\frac{N_{\text {paleoFH }}}{N_{\text {modernFH }}}=\frac{N_{\text {paleoTM }}}{N_{\text {modernTM }}}
$$

Additionally, by assuming that $\mathrm{Q}$ is the same for both sites, that erosion is lock-stepped (i.e. erosion is set for that time step), and reorganizing all variables (Dickinson et al., 2012):

$$
E_{T M}=\frac{\rho_{F H} N_{\text {modernFH }}}{\rho_{T M} N_{\text {modernTM }}} E_{F H}
$$

and 


$$
E_{F H}=\frac{\ln \frac{a_{F H} N_{\text {modernTM }}}{a_{T M} N_{\text {modernFH }}}}{b_{F H}-b_{T M} \frac{\rho_{F H} N_{\text {modernFH }}}{\rho_{T M} N_{\text {modern } T M}}}
$$

$\mathrm{E}_{\mathrm{FH}}$ and $\mathrm{E}_{\mathrm{TM}}$ can then be used to calculate erosion-corrected minimum closure age using equations 5.11 and 5.12 .

\subsection{Results}

\subsubsection{Testing for grain-size dependency}

Concentrations of ${ }^{9} \mathrm{Be}$ measured independently on the MP-AES varied between $9.6 \times 10^{16}$ and $3.0 \times 10^{17}$ at $\mathrm{g}^{-1}$. When normalized to ${ }^{9} \mathrm{Be},{ }^{10} \mathrm{Be}_{\text {met }}$ values have been found to be highly correlated to non-normalized ${ }^{10} \mathrm{Be}_{\text {met }}$ values, implying that the reported ${ }^{10} \mathrm{Be}_{\text {met }}$ concentrations are not grain-size dependant (e.g. Wittmann et al., 2012). As such, the depth profiles represent true changes in ${ }^{10} \mathrm{Be}_{\text {met }}$ and are not influenced by changes in grain size down the core.

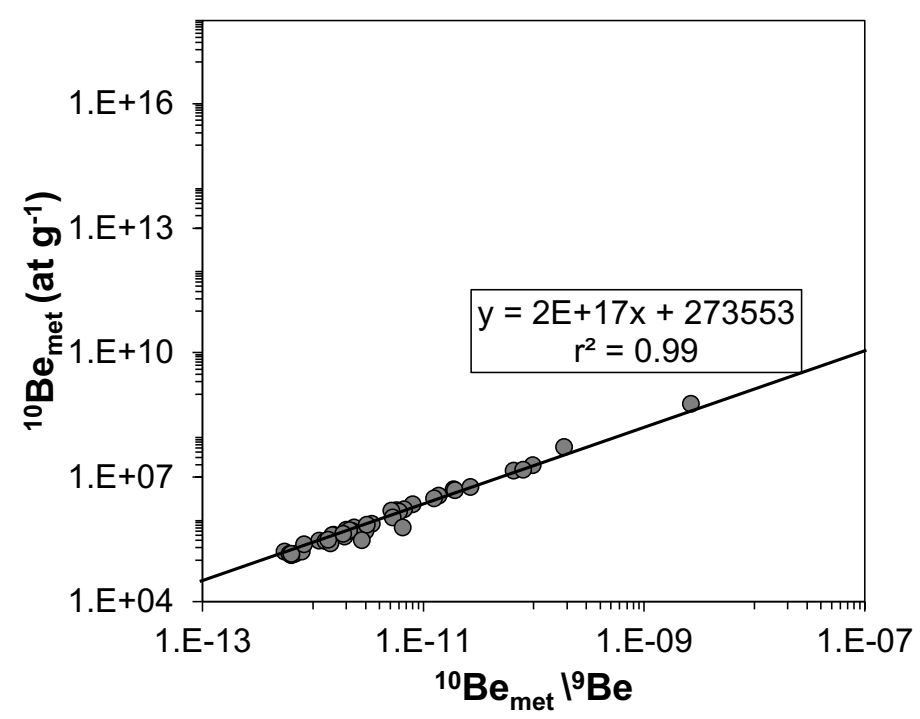

Fig. 5.6 ${ }^{10} \mathrm{Be}_{\text {met }}$ and ${ }^{10} \mathrm{Be}_{\text {met }} /{ }^{9} \mathrm{Be}$ biplot. Note: here, ${ }^{9} \mathrm{Be}$ is measured independently on a MP-AES 


\subsection{2 ${ }^{10} \mathrm{Be}_{\text {met }}$ distribution with depth}

Friis Hills cores C2, FA and FHDP2C displayed similar trends with depth, dropping an order of magnitude within the first $5 \mathrm{~cm}$ (Fig. 5.7a, Tables 5.3 and 5.4). Surface concentrations of ${ }^{10} \mathrm{Be}_{\text {met }}$ varied between $5.37 \times 10^{7}$ and $2.15 \times 10^{8}$ at $\mathrm{g}^{-1}$. Concentrations dropped to between $1.19 \times 10^{6}$ and $2.24 \times 10^{6}$ at $\mathrm{g}^{-1}$ at $60 \mathrm{~cm}$. Table Mountain (TM01) surface samples also showed a similar trend with a surface value of $5.85 \times 10^{8}$ at $\mathrm{g}^{-1}$ and dropping to $1.97 \times 10^{7}$ at $\mathrm{g}^{-1}$ at $27 \mathrm{~cm}$. In core $\mathrm{C} 1$, concentrations remained within the same order of magnitude within the first $20 \mathrm{~cm}$ : varying from $8.9 \times 10^{5}$ to $2.0 \times 10^{5}$ at $\mathrm{g}^{-1}$.

The ${ }^{10} \mathrm{Be}_{\text {met }}$ profiles at Friis Hills and Table Mountain both followed statistically similar trends. Concentrations of ${ }^{10} \mathrm{Be}_{\text {met }}$ were highest at the surface, averaging $1.09 \times 10^{8}$ at $\mathrm{g}^{-1}$ and $5.85 \times 10^{8}$ at $\mathrm{g}^{-1}$, respectively. Below the surface, concentrations decreased by one to two orders of magnitude and remained above the analytical blank range throughout all depths (Fig. 5.7b). Lower samples (down to $10 \mathrm{~m}$ ) reached a steady state value varying between 2.92 and $6.15 \times 10^{5}$ at g $^{-1}$ (avg. $4.57 \times 10^{5}$ at $\mathrm{g}^{-1}$; Fig. 5.7b and Table 5.4) in FHDP2C and between $3.04 \times 10^{5}$ and $1.07 \times 10^{6}$ at $^{-1}$ (avg. $6.11 \times 10^{5}$ at $\mathrm{g}^{-1} 1$; Fig. 5.7b and Table 5.4) in TM01-97. Deep ${ }^{10} \mathrm{Be}_{\text {met }}$ concentrations (35 to $45 \mathrm{~m}$ depth) varied between 1.33 and $4.31 \times 10^{5}$ at $^{-1}$ (avg. $2.10 \times 10^{5}$ at $\mathrm{g}^{-1}$; Fig. 5.7b and Table 5.4). 

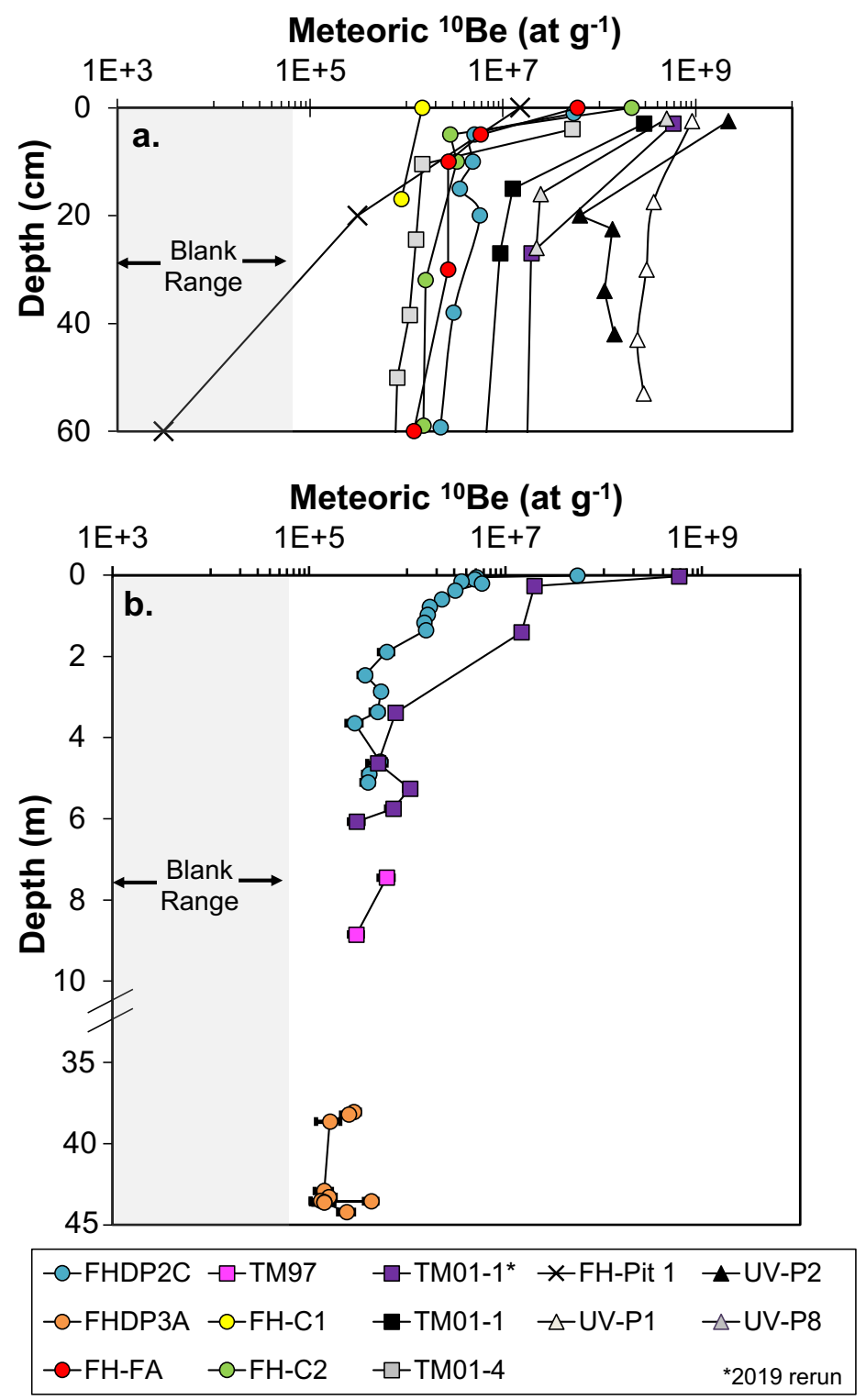

Fig. 5.7 ${ }^{10} \mathrm{Be}_{\text {met }}$ concentrations measured in both shallow and deep upper MDV sites. a. ${ }^{10} \mathrm{Be}_{\mathrm{met}}$ concentrations measured at shallow depths in Friis Hills cores and Table Mountain core TM01 reruns, compared to Table Mountain (Dickinson et al., 2012), University Valley (Trinh-Le, 2017) and Friis Hills Pit 1 (Valletta et al., 2015), b. ${ }^{10} \mathrm{Be}_{\text {met }}$ concentrations measured in both shallow and deep upper MDV sites. FHDP2C and FHDP3A from Friis Hills and TM01 and TM97 from Table Mountain. 
Table 5.3 Concentrations of ${ }^{10} \mathrm{Be}_{\text {met }}$ measured by Trinh-Le (2017) in preliminary sites at Friis Hills

\begin{tabular}{|c|c|c|c|c|c|}
\hline Sample ID & Depth (cm) & ${ }^{10} \mathrm{Be} /{ }^{9} \mathrm{Be}\left(10^{-12}\right)$ & Error $(\%)$ & ${ }^{10} \mathrm{Be}_{\text {met }}\left(\right.$ at g $\left.^{-1}\right)$ & ${ }^{10} \mathrm{Be}_{\mathrm{met}}$ Error (at $\left.\mathrm{g}^{-1}\right)$ \\
\hline \multicolumn{6}{|c|}{ FRIIS HILLS (FA) } \\
\hline FA-0 & 0 & 2.027 & 2.4 & $5.92 \times 10^{7}$ & $1.40 \times 10^{6}$ \\
\hline FA-5 & 5 & 0.199 & 7.5 & $5.85 \times 10^{6}$ & $4.41 \times 10^{5}$ \\
\hline FA-10 & 10 & 0.093 & 6.9 & $2.71 \times 10^{6}$ & $1.87 \times 10^{5}$ \\
\hline FA-30 & 30 & 0.093 & 9.9 & $2.70 \times 10^{6}$ & $2.67 \times 10^{5}$ \\
\hline FA-60 & 60 & 0.041 & 15.3 & $1.19 \times 10^{6}$ & $1.83 \times 10^{5}$ \\
\hline \multicolumn{6}{|c|}{ FRIIS HILLS (C2) } \\
\hline $\mathrm{C} 2-0$ & 0 & 7.344 & 2.0 & $2.15 \times 10^{8}$ & $4.30 \times 10^{6}$ \\
\hline $\mathrm{C} 2-5$ & 5 & 0.096 & 11.3 & $2.83 \times 10^{6}$ & $3.21 \times 10^{5}$ \\
\hline $\mathrm{C} 2-10$ & 10 & 0.114 & 10.0 & $3.33 \times 10^{6}$ & $3.32 \times 10^{5}$ \\
\hline $\mathrm{C} 2-32$ & 32 & 0.054 & 12.6 & $1.58 \times 10^{6}$ & $1.98 \times 10^{5}$ \\
\hline $\mathrm{C} 2-59$ & 59 & 0.051 & 20.6 & $1.50 \times 10^{6}$ & $3.09 \times 10^{5}$ \\
\hline \multicolumn{6}{|c|}{ FRIIS HILLS (C1) } \\
\hline $\mathrm{C} 1-0$ & 0 & 0.049 & 13.4 & $1.45 \times 10^{6}$ & $1.95 \times 10^{5}$ \\
\hline $\mathrm{C} 1-17$ & 17 & 0.030 & 27.7 & $8.85 \times 10^{5}$ & $2.45 \times 10^{5}$ \\
\hline \multicolumn{6}{|c|}{ LAB BLANKS } \\
\hline Blank & - & 0.003 & 57.7 & - & - \\
\hline
\end{tabular}


130 Meteoric Beryllium-10 in mid-Miocene permafrost and polar aridity in East Antarctica

Table 5.4 Measured and calculated values of ${ }^{10} \mathrm{Be}_{\text {met }}$ (Note: ${ }^{\mathrm{A}-\mathrm{D}}$ indicates which blank is associated to which sample and $*$ indicates 2019 reruns)

\begin{tabular}{|c|c|c|c|c|c|}
\hline Sample ID & Depth $(\mathbf{c m})$ & ${ }^{10} \mathrm{Be} /{ }^{9} \mathrm{Be}\left(10^{-12}\right)$ & Error $(\%)$ & ${ }^{10} \mathbf{B e}_{\text {met }}\left(\right.$ at $\left.\mathbf{g}^{-1}\right)$ & ${ }^{10} \mathbf{B e}_{\text {met }} \operatorname{Error}\left(\right.$ at $\left.\mathrm{g}^{-1}\right)$ \\
\hline \multicolumn{6}{|c|}{ FRIIS HILLS (FHDP2C) } \\
\hline $2-\mathrm{C} 0-1^{\mathrm{A}}$ & 1 & 2.294 & 1.5 & $5.37 \times 10^{7}$ & $8.07 \times 10^{5}$ \\
\hline $2-\mathrm{C} 0-2^{\mathrm{A}}$ & 5 & 0.200 & 3.5 & $5.05 \times 10^{6}$ & $1.76 \times 10^{5}$ \\
\hline $2-\mathrm{C} 0-3^{\mathrm{A}}$ & 10 & 0.209 & 3.6 & $4.85 \times 10^{6}$ & $1.76 \times 10^{5}$ \\
\hline $2-\mathrm{C} 0-4^{\mathrm{A}}$ & 15 & 0.157 & 3.9 & $3.55 \times 10^{6}$ & $1.44 \times 10^{5}$ \\
\hline $2-\mathrm{C} 0-5^{\mathrm{A}}$ & 20 & 0.258 & 3.3 & $5.74 \times 10^{6}$ & $1.90 \times 10^{5}$ \\
\hline $2 \mathrm{C}-\mathrm{C} 1-2^{\mathrm{A}}$ & 38 & 0.125 & 4.8 & $3.07 \times 10^{6}$ & $1.50 \times 10^{5}$ \\
\hline $2 \mathrm{C}-\mathrm{C} 1-10^{\mathrm{A}}$ & 59.5 & 0.085 & 6.1 & $2.24 \times 10^{6}$ & $1.37 \times 10^{5}$ \\
\hline $2 \mathrm{C}-\mathrm{C} 1-18^{\mathrm{A}}$ & 78 & 0.070 & 5.6 & $1.70 \times 10^{6}$ & $9.68 \times 10^{4}$ \\
\hline $2 \mathrm{C}-\mathrm{C} 1-22^{\mathrm{A}}$ & 97 & 0.062 & 7.8 & $1.61 \times 10^{6}$ & $1.27 \times 10^{5}$ \\
\hline $2 \mathrm{C}-\mathrm{C} 1-29^{\mathrm{A}}$ & 116.5 & 0.067 & 5.9 & $1.49 \times 10^{6}$ & $8.95 \times 10^{4}$ \\
\hline $2 \mathrm{C}-\mathrm{C} 2-8^{\mathrm{A}}$ & 135.5 & 0.052 & 8.1 & $1.54 \times 10^{6}$ & $1.27 \times 10^{5}$ \\
\hline $2 \mathrm{C}-\mathrm{C} 2-26^{\mathrm{B}}$ & 189.5 & 0.024 & 15.9 & $6.16 \times 10^{5}$ & $1.02 \times 10^{5}$ \\
\hline $2 \mathrm{C}-\mathrm{C} 3-3^{\mathrm{B}}$ & 246 & 0.020 & 12.7 & $3.72 \times 10^{5}$ & $5.05 \times 10^{4}$ \\
\hline $2 \mathrm{C}-\mathrm{C} 3-16^{\mathrm{B}}$ & 286.5 & 0.019 & 11.5 & $5.41 \times 10^{5}$ & $6.50 \times 10^{4}$ \\
\hline $2 \mathrm{C}-\mathrm{C} 4-9^{\mathrm{B}}$ & 336.5 & 0.023 & 14.4 & $5.00 \times 10^{5}$ & $7.60 \times 10^{4}$ \\
\hline $2 \mathrm{C}-\mathrm{C} 4-20^{\mathrm{B}}$ & 364.5 & 0.011 & 15.8 & $2.92 \times 10^{5}$ & $5.00 \times 10^{4}$ \\
\hline $2 \mathrm{C}-\mathrm{C} 5-2^{\mathrm{B}}$ & 459 & 0.024 & 13.4 & $5.29 \times 10^{5}$ & $7.42 \times 10^{4}$ \\
\hline $2 \mathrm{C}-\mathrm{C} 5-11^{\mathrm{B}}$ & 490 & 0.017 & 12.1 & $4.10 \times 10^{5}$ & $5.29 \times 10^{4}$ \\
\hline $2 \mathrm{C}-\mathrm{C} 5-20^{\mathrm{B}}$ & 510.5 & 0.016 & 13.0 & $3.99 \times 10^{5}$ & $5.53 \times 10^{4}$ \\
\hline \multicolumn{6}{|c|}{ FRIIS HILLS (FHDP3A) } \\
\hline $3 \mathrm{~A}-\mathrm{C} 27-1^{\mathrm{B}}$ & 3717.5 & 0.014 & 13.7 & $2.87 \times 10^{5}$ & $4.29 \times 10^{4}$ \\
\hline $3 \mathrm{~A}-\mathrm{C} 27-2^{\mathrm{B}}$ & 3736.5 & 0.013 & 15.3 & $2.55 \times 10^{5}$ & $4.31 \times 10^{4}$ \\
\hline $3 \mathrm{~A}-\mathrm{C} 28-1^{\mathrm{B}}$ & 3785.5 & 0.007 & 23.8 & $1.63 \times 10^{5}$ & $4.49 \times 10^{4}$ \\
\hline $3 \mathrm{~A}-\mathrm{C} 33-1^{\mathrm{C}}$ & 4265.5 & 0.008 & 16.5 & $1.43 \times 10^{5}$ & $2.77 \times 10^{4}$ \\
\hline $3 \mathrm{~A}-\mathrm{C} 33-2^{\mathrm{C}}$ & 4307 & 0.009 & 15.1 & $1.60 \times 10^{5}$ & $2.79 \times 10^{4}$ \\
\hline $3 \mathrm{~A}-\mathrm{C} 33-3^{\mathrm{C}}$ & 4333.75 & 0.008 & 18.1 & $1.33 \times 10^{5}$ & $2.86 \times 10^{4}$ \\
\hline $3 \mathrm{~A}-\mathrm{C} 33-4^{\mathrm{C}}$ & 4337 & 0.021 & 14.8 & $4.31 \times 10^{5}$ & $6.74 \times 10^{4}$ \\
\hline $3 \mathrm{~A}-\mathrm{C} 33-5^{\mathrm{C}}$ & 4341.5 & 0.007 & 22.4 & $1.43 \times 10^{5}$ & $3.78 \times 10^{4}$ \\
\hline $3 \mathrm{~A}-\mathrm{C} 33-6^{\mathrm{C}}$ & 4344.5 & 0.008 & 18.3 & $1.42 \times 10^{5}$ & $3.07 \times 10^{4}$ \\
\hline $3 \mathrm{~A}-\mathrm{C} 34-1^{\mathrm{C}}$ & 4411.5 & 0.010 & 16.8 & $2.42 \times 10^{5}$ & $4.49 \times 10^{4}$ \\
\hline \multicolumn{6}{|c|}{ TABLE MOUNTAIN (TM01/TM97) } \\
\hline TM01-S1 ${ }^{\mathrm{C}} *$ & 3 & 22.667 & 1.5 & $5.85 \times 10^{8}$ & $8.77 \times 10^{6}$ \\
\hline TM01-S2 ${ }^{\mathrm{C}} *$ & 27 & 0.856 & 2.3 & $1.97 \times 10^{7}$ & $4.49 \times 10^{5}$ \\
\hline TM01-9C* & 140.5 & 0.545 & 2.9 & $1.45 \times 10^{7}$ & $4.24 \times 10^{5}$ \\
\hline TM01-25 ${ }^{\mathrm{C} *}$ & 339 & 0.033 & 10.7 & $7.59 \times 10^{5}$ & $8.38 \times 10^{4}$ \\
\hline TM01-37 $*$ & 463.5 & 0.023 & 20.9 & $5.04 \times 10^{5}$ & $1.11 \times 10^{5}$ \\
\hline TM01-42D & 525.5 & 0.041 & 13.0 & $1.07 \times 10^{6}$ & $1.42 \times 10^{5}$ \\
\hline TM01-44 ${ }^{\mathrm{D}}$ & 575 & 0.028 & 15.2 & $7.21 \times 10^{5}$ & $1.14 \times 10^{5}$ \\
\hline TM01-48 & 607 & 0.014 & 15.6 & $3.07 \times 10^{5}$ & $5.20 \times 10^{4}$ \\
\hline TM97-7B-1 ${ }^{\mathrm{D}}$ & 745 & 0.030 & 16.4 & $6.18 \times 10^{5}$ & $1.06 \times 10^{5}$ \\
\hline TM97-7B-2 & 885 & 0.015 & 14.4 & $3.04 \times 10^{5}$ & $4.76 \times 10^{4}$ \\
\hline \multicolumn{6}{|c|}{ LAB BLANKS } \\
\hline Blank $1^{\mathrm{A}}$ & - & 0.008 & 18.2 & - & - \\
\hline Blank $2^{\mathrm{B}}$ & - & 0.004 & 30.1 & - & - \\
\hline Blank $3^{\mathrm{C}}$ & - & 0.001 & 53.9 & - & - \\
\hline Blank $4^{\mathrm{D}}$ & - & 0.003 & 37.8 & - & - \\
\hline
\end{tabular}




\subsection{Discussion}

\subsubsection{Correction of Table Mountain samples and implications of leach- ing methods}

The study of ${ }^{10} \mathrm{Be}_{\text {met }}$ at Table Mountain by Dickinson et al. (2012) along with other early ${ }^{10} \mathrm{Be}_{\text {met }}$ investigations in the MDV (Graham et al., 2002, Schiller, 2007, Schiller et al., 2009) used an aggressive leaching method to extract ${ }^{10} \mathrm{Be}_{\text {met }}$ from the sediment $(6 \mathrm{M} \mathrm{HCl}$ for $1 \mathrm{~h}$ at $100^{\circ} \mathrm{C}$; Graham et al., 2001, Ditchburn and Graham, 2002). As previously discussed, this method was criticized because of the possibility of liberating in-situ ${ }^{10} \mathrm{Be}$ via partial decomposition of clay minerals (Valletta et al., 2015). After correcting for in-situ ${ }^{10} \mathrm{Be}$ contamination in Table Mountain samples, Valletta et al. (2015) suggested using Wittmann et al. (2012)'s mild leaching method $(0.5 \mathrm{M} \mathrm{HCl}$ for $24 \mathrm{~h}$ at room temperature $+1 \mathrm{M}$ hydroxylamine hydrochloride for $4 \mathrm{~h}$ in an $80^{\circ} \mathrm{C}$ ultrasonic bath). This leaching protocol has shown to fully remove ${ }^{10} \mathrm{Be}_{\text {met }}$ and to release minimal in-situ ${ }^{10} \mathrm{Be}$ (Wittmann et al., 2012).

To test the possible contamination from the aggressive leaching method, five TM01 samples were duplicated using the mild leaching method. ${ }^{10} \mathrm{Be}_{\text {met }}$ concentrations were found to be between 1.50 and 1.66 (avg. 1.57) times higher using the mild leaching method than the values obtained using the aggressive method by Dickinson et al. (2012). Therefore, the concerns raised by Valletta et al. (2015) about the aggressive leaching method and the possible contamination from in-situ ${ }^{10} \mathrm{Be}$ in Table Mountain samples, which would have increased the measured ${ }^{10} \mathrm{Be}_{\text {met }}$ concentrations, were found to be minimal. The discrepancy found from the method testing could be due to a combination of two main causes: (1) the leaching process and/or (2) the AMS measurement and sample calibration. The TM01 samples were originally analyzed at the AMS facility at GNS Science, New Zealand and calibrated with the National Institute of Standards and Technology (NIST) standard SRM 4325 (Nishiizumi et al., 2007, Zondervan et al., 2007, Dickinson et al., 2012). The different AMS facilities used for each study along with natural variation could only explain up to $10 \%$ difference (Jull et al., 2015). Therefore, the larger (50 to 66\%) difference points towards another explanation. The aggressive $\mathrm{HCl}$ leach did not include a step to leach the $\mathrm{Be}_{\mathrm{ex} \text {-ox }}$ fraction (see section 5.2.1). Wittmann et al. (2012) calculated that 47 to $74 \%$ of the total ${ }^{10} \mathrm{Be}_{\text {met }}$ in their samples was located in the $\mathrm{Be}_{\mathrm{am}-\mathrm{ox}}$ fraction, and 20 to $45 \%$ was located in the $\mathrm{Be}_{\mathrm{ex}-\mathrm{ox}}$ fraction. This could therefore explain how the original Table Mountain samples had lower concentrations of ${ }^{10} \mathrm{Be}_{\text {met }}$. However, the risks of contamination using the aggressive method may not fully be ruled out and to limit uncertainty, using the Wittmann et al. (2012) method for all subsequent ${ }^{10} \mathrm{Be}_{\text {met }}$ leaching is recommended. Considering the offsets were 
consistent through all samples, since the leaches came from the same parent material and were within the same grain-size range, the offset was applied as a correction factor to all TM01 samples (Table 5.5).

Table 5.5 Duplicate samples in TM01 show ${ }^{10} \mathrm{Be}_{\text {met }}$ concentrations measured by aggressive and mild leaching methods. (*data from (Dickinson et al., 2012)

\begin{tabular}{|c|c|c|c|c|c|c|c|}
\hline Original ID* & Sample ID & Depth (cm) & $\begin{array}{c}{ }^{10} \mathrm{Be}_{\mathrm{met}}\left(\mathrm{at}^{-1}\right) \\
\text { aggressive leach* }\end{array}$ & $\begin{array}{c}{ }^{10} \mathrm{Be}_{\text {met }}\left(\text { at }^{-1}{ }^{-1}\right) \\
\text { mild leach }\end{array}$ & Offset & $\begin{array}{c}\text { Corrected } \\
{ }^{10} \mathrm{Be}_{\text {met }}\left(a^{-1} \mathrm{~g}^{-1}\right)\end{array}$ & Error \\
\hline R27476 & TM01-S1 & 3 & $2.90 \mathrm{E}+08$ & $5.85 \mathrm{E}+08$ & 1.50 & $4.56 \mathrm{E}+08$ & $8.77 \mathrm{E}+06$ \\
\hline R27477 & - & 15 & $1.26 \mathrm{E}+07$ & - & - & $1.98 \mathrm{E}+07$ & - \\
\hline R27478 & TM01-S2 & 27 & $9.33 \mathrm{E}+06$ & $1.97 \mathrm{E}+07$ & 1.53 & $1.47 \mathrm{E}+07$ & $4.49 \mathrm{E}+05$ \\
\hline R27479 & - & 82.75 & $5.42 \mathrm{E}+06$ & - & - & $8.53 \mathrm{E}+06$ & - \\
\hline R27541 & TM01-9 & 140.5 & $6.38 \mathrm{E}+06$ & $1.45 \mathrm{E}+07$ & 1.56 & $1.00 \mathrm{E}+07$ & $4.24 \mathrm{E}+05$ \\
\hline R27542 & - & 239.5 & $7.98 \mathrm{E}+05$ & - & - & $1.26 \mathrm{E}+06$ & - \\
\hline R27543 & TM01-25 & 339 & $2.87 \mathrm{E}+05$ & $7.59 \mathrm{E}+05$ & 1.62 & $4.52 \mathrm{E}+05$ & $8.38 \mathrm{E}+04$ \\
\hline R27480 & - & 415.3 & $1.81 \mathrm{E}+05$ & - & - & $2.85 \mathrm{E}+05$ & - \\
\hline R27544 & TM01-37 & 463.5 & $1.73 E+05$ & $5.04 \mathrm{E}+05$ & 1.66 & $2.72 \mathrm{E}+05$ & $1.11 \mathrm{E}+05$ \\
\hline
\end{tabular}

\subsubsection{Modelling ${ }^{10} \mathrm{Be}_{\text {met }}$ distribution with depth}

Both sites had similar ${ }^{10} \mathrm{Be}_{\text {met }}$ concentration profiles, which, excluding deep samples from FHDP3A, were analysed and treated through log-transform. The data distribution was best represented by a segmented model with linear function for the upper samples and a constant (intercept only) function for the lower samples (Fig. 5.8). The distribution was separated into three distinct groups (upper, lower and deep) with segmentation (i.e. data split) at 227 $\mathrm{cm}$ for FHDP2C and $349 \mathrm{~cm}$ for TM01-97 between the upper and lower groups. Samples within the upper group followed equation $\mathrm{y}=5.03 \mathrm{E}+6 \mathrm{e}^{-1.08 \mathrm{E}-2 \mathrm{x}}\left(\mathrm{r}^{2}=0.915\right)$ in FHDP2C and $\mathrm{y}=2.50 \mathrm{E}+7 \mathrm{e}^{-1.16 \mathrm{E}-2 \mathrm{x}}\left(\mathrm{r}^{2}=0.932\right)$ in TM01-97. Samples within the lower group reached a steady state value of $4.26 \times 10^{5}$ at $\mathrm{g}^{-1}$ in FHDP2C and $4.45 \times 10^{5}$ at $\mathrm{g}^{-1}$ in TM01-TM97. Deep samples below $35 \mathrm{~m}$ were found to be statistically different than the low samples of FHDP2C ( $\mathrm{p}$-value < 0.05 ), varying between 1.33 and $4.31 \times 10^{5}$ at $\mathrm{g}^{-1}$ (avg. $2.10 \times 10^{5}$ at $^{-1}$ ).

\subsubsection{Calculation of closure ages}

Modeling of ${ }^{10} \mathrm{Be}_{\text {met }}$ distribution in the profiles can determine when ${ }^{10} \mathrm{Be}_{\text {met }}$ stopped infiltrating the sediment and was closed-off from the surface. The proximity of Friis Hills and Table Mountain and the similar cryostratigraphic profiles allowed two important assumptions for modeling closure ages in the permafrost: (1) the flux of ${ }^{10} \mathrm{Be}_{\text {met }}$ was the same; (2) the 


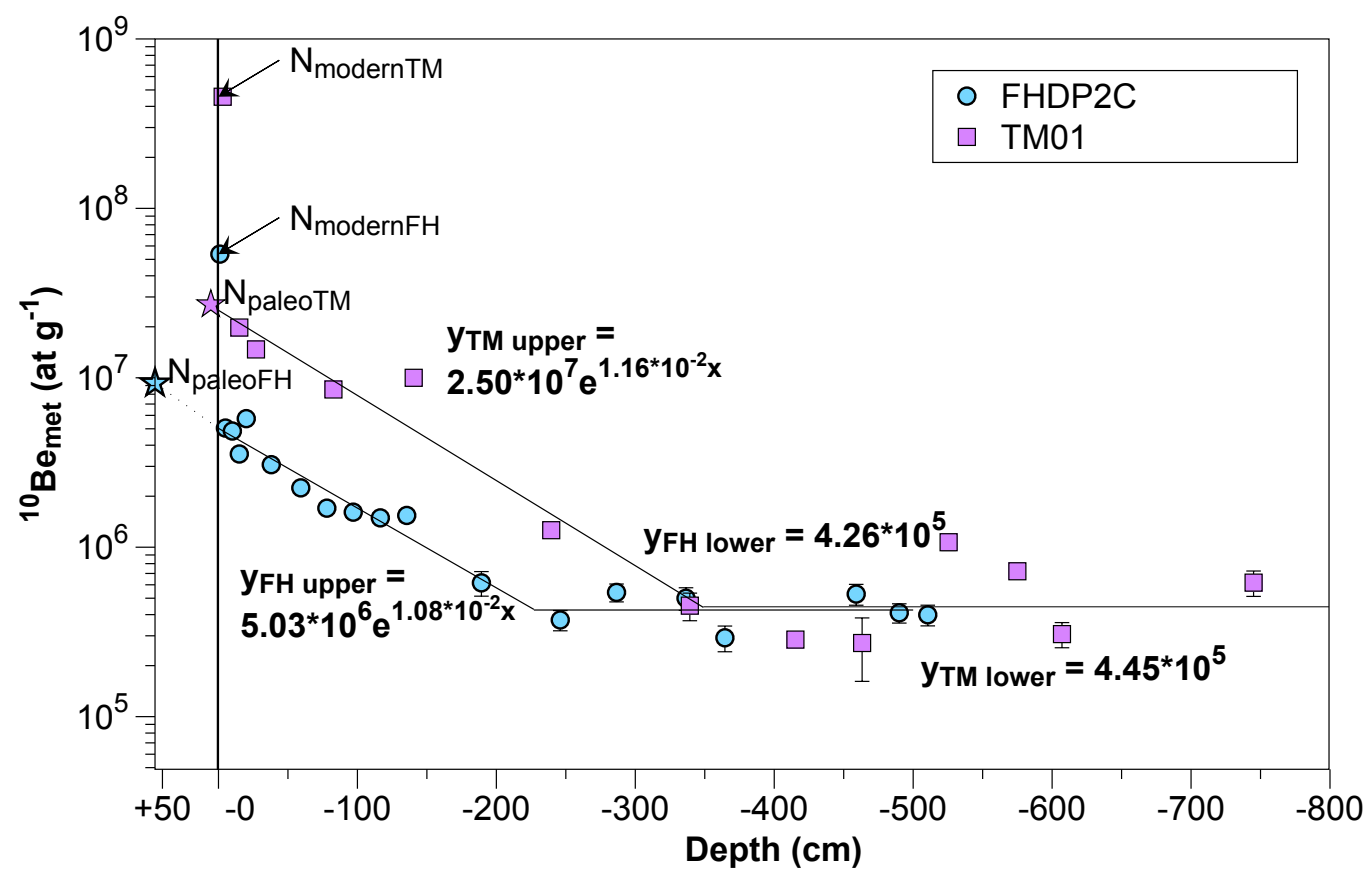

Fig. 5.8 Exponential regression equations for measured ${ }^{10} \mathrm{Be}_{\text {met }}$ concentrations of FHDP2C and TM01-1 and TM97 in sub-surface profiles for upper and lower sample groups. Segmentation at 227 $\mathrm{cm}$ in Friis Hills samples and $349 \mathrm{~cm}$ in Table Mountain samples.

closure age was synchronous; and (3) erosion rates were lock-stepped. Closure ages were calculated using paleo-surface ${ }^{10} \mathrm{Be}_{\text {met }}$ concentrations, which were first erosion-corrected (described in section 5.2.4). Assuming synchronous closure ages in the upper groups, ${ }^{10} \mathrm{Be}_{\text {met }}$ concentrations yielded erosion rate of $0.011 \mathrm{~m} \mathrm{Ma}^{-1}$ for TM01-97 ( $\left.\mathrm{E}_{\mathrm{TM}}\right)$ and $0.095 \mathrm{~m} \mathrm{Ma}^{-1}$ for FHDP2C ( $\left.\mathrm{E}_{\mathrm{FH}}\right)$ (Table 5.6). These results are within regolith erosion rates in the MDV (0.02 and $3.0 \mathrm{~m} \mathrm{Ma}^{-1}$; Table 5.2). This suggests that the erosion-correction required for modeling closure ages is realistic. The closure age for the upper group at Friis Hills and Table Mountain calculated from the erosion-corrected $\mathrm{N}_{\text {paleo }}$ was $6.0 \pm 0.5 \mathrm{Ma}$ (Table 5.6).

Since the lower groups followed a linear regression where $b=0$ and the upper profile overprinted the lower profile, fitting an exponential equation to solve for $\mathrm{N}_{\text {paleo }}$ was not possible for the lower groups. The most realistic way to estimate $\mathrm{N}_{\text {paleo }}$ for the lower groups was to use the b-value from the upper groups and the same lock-stepped erosion rates. Closure age was then approximated using equation 5.11, which assumes that $\mathrm{N}_{\text {modern }}$ has not changed since closure. However, the closure age would increase if more ${ }^{10} \mathrm{Be}_{\text {met }}$ was retained at the surface, had the climate been wetter in the past (e.g. Field et al., 2006). Based on the $\delta^{13} \mathrm{C}$ signal of $\mathrm{C} 3$ plants (-25.5 $\pm 0.7 \%$ VPDB; see Chapter 3), mean annual precipitation of 300 to $850 \mathrm{~mm} \mathrm{yr}^{-1}$ (avg. 500-550 $\mathrm{mm} \mathrm{yr}^{-1}$ ) was estimated for Friis Hills during the 
mid-Miocene. Using a modern analogue for surface ${ }^{10} \mathrm{Be}_{\text {met }}$ concentration with similar $\delta^{13} \mathrm{C}$ values, like Northern Sweden $\left(\delta^{13} \mathrm{C}=-26 \%\right.$, ${ }^{10} \mathrm{Be}_{\text {met }}=2.0 \times 10^{8}$ at $\mathrm{g}^{-1}$; Ebert et al., 2012, Jelinski, 2014), ${ }^{10} \mathrm{Be}_{\text {met }}$ surface concentrations could have been approximately 4 times higher. The decay required to obtain current ${ }^{10} \mathrm{Be}_{\text {met }}$ concentrations can be modelled using the maximum $\mathrm{N}_{\text {modern. }}$. This age represents an estimate of maximum closure age for the lower group (assuming lock-stepped erosion). A maximum closure age of $\sim 12.0 \mathrm{Ma}$ for FHDP2C and $\sim 16.0 \mathrm{Ma}$ for TM01-97 for the lower section of the cores was calculated. However, these ages need to be treated with caution as they only represent a broad estimate of time required for ${ }^{10} \mathrm{Be}_{\text {met }}$ concentrations in the $10^{8}$ at ${ }^{-1}$ range to decay to $10^{5}$ at $\mathrm{g}^{-1}$. Similarly, using the average ${ }^{10} \mathrm{Be}_{\text {met }}$ concentration for the deep samples as $\mathrm{N}_{\text {paleo }}$, the closure age at 40 m depth at Friis Hills was 14.0 Ma.

Table 5.6 Calculated erosion rates and closure ages for TM01-97 and FHDP2C (* Data from Dickinson et al. (2012)

\begin{tabular}{ccc}
\hline Parameters & TM01-97 & FHDP2C \\
\hline Sediment density $(\rho)\left[\mathrm{g} \mathrm{cm}^{-3}\right]$ & $1.20^{*}$ & 1.23 \\
\hline $\mathrm{N}_{\text {modern }}\left[\mathrm{at}^{-1}\right]$ & $(4.56 \pm 0.08) \mathrm{E}+8$ & $(5.37 \pm 0.08) \mathrm{E}+7$ \\
\hline \multicolumn{3}{c}{ UPPER GROUP } \\
\hline Regression constants \\
\hline $\mathrm{a}$ & $(2.5 \pm 0.6) \mathrm{E}+7$ & $(5.0 \pm 0.5) \mathrm{E}+6$ \\
\hline $\mathrm{b}$ & $(-1.2 \pm 0.2) \mathrm{E}-2$ & $(-1.1 \pm 0.1) \mathrm{E}-2$ \\
\hline Closure Age (erosion-corrected) & $6.8 \pm 3.5$ \\
\hline Vertical Erosion $\left[\mathrm{cm}^{-}\right.$ & $1.1 \pm 0.7$ \\
\hline Erosion Rate $\left[\mathrm{cm} \mathrm{Ma}^{-1}\right]$ & $(6.3 \pm 3.8) \mathrm{E}+2$ & $(6.3 \pm 3.8) \mathrm{E}+2$ \\
\hline${ }^{10} \mathrm{Be}_{\text {met }}$ flux $(\mathrm{Q})$ in soil $\left[\mathrm{at} \mathrm{cm}{ }^{-2} \mathrm{a}^{-1}\right]$ & $6.0 \pm 0.5$ & $6.0 \pm 0.6$ \\
\hline Closure Age $(\mathrm{Ma})$ &
\end{tabular}

\subsubsection{Timing of water percolation and onset of polar aridity}

The ${ }^{10} \mathrm{Be}_{\text {met }}$ profiles and their decay curves suggest two active periods, when water infiltration was possible: the upper sections, which closed-off $6.0 \pm 0.5 \mathrm{Ma}$ at $227 \mathrm{~cm}$ for FHDP2C and $349 \mathrm{~cm}$ for TM01-97, and the lower sections, which closed-off during the mid-Miocene. In the permafrost sediment column, ${ }^{10} \mathrm{Be}_{\text {met }}$ can be transported by: (1) mechanical transport of ${ }^{10} \mathrm{Be}_{\text {met }}$ absorbed to clays, which translocate by percolating water; or (2) solution transport of ${ }^{10} \mathrm{Be}_{\text {met }}$ soil with $\mathrm{pH}<4$. The latter is unlikely considering that typical modern soil $\mathrm{pH}$ are between 7.5 and 9.5 in the MDV with the lowest values of 5 to 6 found in highly nitric soils (Campbell and Claridge, 1987, Campbell et al., 1998a). Although major volcanic eruptions 
can decrease $\mathrm{pH}$ of snowmelt to 3.5-4.5 for periods of 1 to 10 years (Koerner and Fisher, 1982, Delmas et al., 1985), they must occur in close proximity to the site for substantial accumulation of acidic fallout and would still not lower $\mathrm{pH}$ below ${ }^{10} \mathrm{Be}$ solubility threshold.

Therefore, the presence of ${ }^{10} \mathrm{Be}_{\text {met }}$ below the surface reflects a time when translocation of clays was possible in a warmer and wetter climate, likely similar to those in modern high Arctic, which allows the translocation of fine particles and requires enough water to percolate through the active layer and into the permafrost soils. The closure ages associated with

${ }^{10} \mathrm{Be}_{\text {met }}$ concentrations in the lower sections of FHDP2C and TM01-97 and in deep Friis Hills samples imply that the infiltration of water happened more or less simultaneously with the deposition of the sediment (i.e. syngenetic ground ice; see Chapter 4). As sedimentation occurred during the mid-Miocene (see Chapter 3), permafrost was aggrading with minimal lag time. However, the upper section, which has a minimum closure age of $6.0 \pm 0.5 \mathrm{Ma}$ challenges the idea that the upper MDV remained frozen under hyper-arid climate since the middle Miocene climate transition (MMCT) and supports the hypothesis that the Miocene has undergone sustained cooling with onset of polar aridity between 7 and 5.4 Ma (Herbert et al., 2016). However, it is impossible to infer if conditions favorable to water infiltration prevailed throughout all the late Miocene period and ended 6.0 Ma or a single warm period punctuated the late Miocene and ended 6.0 Ma.

\subsubsection{Paleo-active layer depth and climate at Friis Hills during the late Miocene (6.0 Ma)}

The segmentation between the upper and lower groups occurred at $227 \mathrm{~cm}$ in FHDP2C and $349 \mathrm{~cm}$ in TM01-97, meaning that when water last infiltrated these sites (6.0 Ma), the maximum active layer depth was $355 \mathrm{~cm}$ at Table Mountain $(6.8 \mathrm{~cm}$ vertical erosion; Table 5.6) and $284 \mathrm{~cm}$ (57 cm vertical erosion; Table 5.6) at Friis Hills. By inputting the paleo-active layer depth for Friis Hills into PERICLIMv.1.0 (Table 5.7; Uxa et al., 2020), a model that derives paleo-air temperature characteristics through inverse solution of the Stefan (1891) equation, a mean annual air temperature (MAAT) ranging from -12 to $-7^{\circ} \mathrm{C}$ is obtained compared to the modern MAAT of $-22.7 \pm 1.3^{\circ} \mathrm{C}$ (Fountain and Doran, 2016). The model also yielded a mean summer air temperature (MSAT) ranging from 6 to $12^{\circ} \mathrm{C}$. These active layer depths and modelled air temperature are comparable to modern analogues in high- and mid-Arctic areas such as west Greenland (e.g. Van Tatenhove and Olesen, 1994).

The modelled MAAT and MSAT are in line with other proxies, which also challenge the persistent aridity of the MDV through the Neogene. Based on lipid biomarkers of the Sirius 
Group in Olivers Bluff (850 km south of the MDV), Rees-Owen et al. (2018) established that through the Neogene, Antarctic MSAT was $\sim 5^{\circ} \mathrm{C}$, which is significantly higher than present and allowed a low diversity plant community to exist. Based on magnetic minerals and organic geochemical records in core DVDP-11 (Taylor Valley), Ohneiser et al. (2020) also suggested a MSAT of $\sim 5^{\circ} \mathrm{C}$. They established that a transition to cooler conditions in Taylor Valley occurred between 4.1 and 2.6 Ma (Ohneiser et al., 2020). Longer-term temperature records throughout the Neogene suggest that continental summer temperatures ranged between 4 and $12{ }^{\circ} \mathrm{C}$ (Prebble et al., 2006, Warny et al., 2009) and that tundra vegetation persisted on the Antarctic Peninsula until 5.3 Ma (Anderson et al., 2011). However, it is important to note that using active layer depth as a proxy for MAAT and MSAT does not consider other parameters that can affect ground thermal properties such as snow, vegetation, slope orientation and angle, drainage, etc. The modelled MAAT and MAST, therefore, need to be treated with caution.

Table 5.7 Values of parameters used in PERICLIMv1.0 model

\begin{tabular}{cc}
\hline Input Parameters & Values \\
\hline Thaw depth $(\mathrm{m})$ & 2.84 \\
\hline Thawed ground thermal conductivity $\left(\mathrm{W} \mathrm{m}^{-1} \mathrm{~K}^{-1}\right)$ & $2.0-2.5^{1}$ \\
\hline Volumetric ground moisture content & $0.2-0.4$ \\
\hline Thawing n-factor & 2.5 \\
\hline Annual air temperature amplitude $\left({ }^{\circ} \mathrm{C}\right)$ & $35-40^{2}$ \\
\hline Period of air temperature oscillations $(\mathrm{d})$ & 365 \\
\hline
\end{tabular}

\subsubsection{The not so frozen Dry Valleys: late Quaternary processes}

In Chapter 4, it was established through isotope geochemistry, that the near-surface ground ice in in the upper MDV is formed through freezing of evaporated snowmelt, a process which occurs on a regional scale in the MDV (Dickinson and Rosen, 2003, Hagedorn et al., 2010, Lacelle et al., 2013a, Lapalme et al., 2017a). Emplacement of ground ice in the upper MDV sediment has therefore been occurring well after the closure age of 6.0 Ma. Throughout the MDV, ${ }^{10} \mathrm{Be}_{\text {met }}$ concentrations decrease by one or two orders of magnitude immediately below the surface (Figs 5.4 and 5.7) and suggest that the amount of liquid water has been insufficient to translocate ${ }^{10} \mathrm{Be}_{\text {met }}$ for at least $2.97 \mathrm{Ma}$ (reviewed age of Hart Ash; Schiller et al., 2009, 2019). It is therefore likely that the water present in the upper MDV under modern conditions is limited to thin liquid films.

\footnotetext{
${ }^{1}$ retrieved from Andersland and Anderson (1978) for sandy sediments

${ }^{2}$ retrieved from Fountain and Doran (2016)
} 
Climatic conditions under which the translocation of ${ }^{10} \mathrm{Be}_{\text {met }}$ occurs are poorly defined, especially in hyper-arid environments and depend on factors such as precipitation, time and pore structure of the ground. Using ${ }^{10} \mathrm{Be}_{\text {met }}$ as a tracer for liquid water is based on two assumptions: (1) that water flows under gravity conditions and (2) that it flows from the surface downward. These conditions exclude film adsorption, driven by van der Waals surface forces, and capillary processes, which occur in hyper-arid soils (Or and Tuller, 2000, Tuller and Or, 2005). In the high elevations of the MDV, liquid water may be too scarce to permit the translocation of ${ }^{10} \mathrm{Be}_{\text {met }}$. For example, in University Valley's Quaternary surfaces, the lack of altered mica particles at $>9 \mathrm{~cm}$ depth indicates minimal aqueous alteration, although the presence of hematite and salts indicate that liquid water has played a role in the formation of these secondary phases (Tamppari et al., 2012). A case study in the hyper-arid Atacama Desert of Chile (MAP $<2 \mathrm{~mm}$ ) concluded that ${ }^{10} \mathrm{Be}_{\text {met }}$ was not translocated through the soil under modern conditions, but that it was during wetter El Niño events (Wang et al., 2015).

Additionally, the ${ }^{10} \mathrm{Be}_{\text {met }}$ tracer doesn't take into account that although the surface remains frozen, the permafrost may still contain large quantities of unfrozen water. The presence of unfrozen water in the upper MDV is made possible due to the high salt load in the upper MDV soils. For example, given that soluble salts geochemistry at Friis Hills is similar to sea water and that the $\mathrm{NaCl}$ eutectic point is $\sim-23^{\circ} \mathrm{C}$, a reasonable amount of unfrozen water may persist down to at least $-23^{\circ} \mathrm{C}$, which is the modern-day MAAT at the surface. Additionally, the average ground temperature increases with depth. The permafrost column is therefore above the $\mathrm{NaCl}$ eutectic. It would also be above eutectic during previous interglacial/warm periods and probably also during cold glacial periods. The idea that the upper MDV have remained frozen under hyper-arid conditions is widely incorrect and the presence of unfrozen water in the sediments of the upper MDV has major implications in microbiology.

\subsection{Conclusions}

Based on 40 new samples at both Friis Hills and Table Mountain, the distribution of ${ }^{10} \mathrm{Be}_{\text {met }}$ concentrations of the sites was separated into upper, lower and deep groups with segmentation at $227 \mathrm{~cm}$ for FHDP2C and $349 \mathrm{~cm}$ for TM01-97. The ${ }^{10} \mathrm{Be}_{\text {met }}$ profiles suggested two distinct closure ages: the upper group had a closure age of $6.0 \pm 0.5 \mathrm{Ma}$ for both sites while the lower groups had a maximum closure age dating back to the mid-Miocene. The following conclusions were derived from the ${ }^{10} \mathrm{Be}_{\text {met }}$ concentration profiles and associated closure ages at Friis Hills and Table Mountain: 
1. Concerns of Valletta et al. (2015) regarding the aggressive leaching and possible contamination from in-situ ${ }^{10} \mathrm{Be}$ in Table Mountain samples, have shown to be negligible, restoring the validity of the $\mathrm{Be}_{\mathrm{am}-\mathrm{ox}}$ leach of the early studies in the MDV.

2. Based on the assumptions that the flux of ${ }^{10} \mathrm{Be}_{\text {met }}$ is comparable at both sites and that ${ }^{10} \mathrm{Be}_{\text {met }}$ stopped migrating in the soil profiles at the same time, calculated erosion rates were $0.011 \mathrm{~m} \mathrm{Ma}^{-1}$ at Table Mountain and $0.095 \mathrm{~m} \mathrm{Ma}^{-1}$ at Friis Hills.

3. The presence of ${ }^{10} \mathrm{Be}_{\text {met }}$ in the upper profile reflects a time when translocation of clays was possible in a warmer and wetter climate, which allowed the translocation of fine particles through the active layer and into the permafrost. The closure age of $6.0 \pm 0.5$ Ma challenges the idea that the upper MDV have remained frozen under hyper-arid climate since the MMCT.

4. The closure ages associated with ${ }^{10} \mathrm{Be}_{\text {met }}$ concentrations in the lower profiles of FHDP2C and TM01-97 and in deep Friis Hills samples suggest that the ice has formed more or less simultaneously with the deposition of the earth material (i.e. syngenetic ground ice).

5. Based on the erosion-corrected paleo-active layer depth at Friis Hills, a MAAT ranging from -12 to $-9^{\circ} \mathrm{C}$ was calculated, implying much warmer condition than the modern $\operatorname{MAAT}\left(-22.7 \pm 1.3^{\circ} \mathrm{C}\right)$ at $6.0 \pm 0.5 \mathrm{Ma}$.

6. Emplacement of ground ice in the upper MDV through evaporated snowmelt has been occurring well after the last infiltration of ${ }^{10} \mathrm{Be}_{\mathrm{met}}, 6.0 \mathrm{Ma}$. This shows the limitations of using ${ }^{10} \mathrm{Be}_{\text {met }}$ as a tracer for liquid water in a hyper-arid environment, where liquid water movement is not solely dictated by gravity. The presence of unfrozen water in the upper MDV is made possible due to the high salt load in the upper MDV soils 


\section{Chapter 6}

\section{Myr of changes in the Friis Hills: synthesis and future research directions}

\subsection{Synthesis and paleoenvironmental implications}

In 2016, the Friis Hills Drilling Project (FHDP) retrieved five cores of mid-Miocene-age permafrost that represent $15 \mathrm{Myr}$ of geological history in the high elevations of the McMurdo Dry Valleys (MDV) of Antarctica. The geochemistry of the sediments, organics and ice encased in these cores, particularly in the FHDP2C core, provides valuable information on the paleoenvironmental changes during the Neogene and Quaternary. These changes range from the tundra environment of the Miocene Climatic Optimum (MCO; 17-15 Ma) to the present-day hyper-arid desert conditions. The major paleoenvironmental changes can be divided into three important periods: (1) the mid-Miocene (15.1-12.5 Ma), a period when the high elevations of the MDV transitioned from having tundra-dominated interglacial periods to the extinction of vegetation; (2) the mid-late Miocene (12.5-6.0 Ma), a period when the high elevations transitioned to a hyper-arid environment with minimal liquid water; and (3) the modern (6.0 Ma-present) period, when the high elevations have remained stable under frozen hyper-arid conditions.

\subsubsection{Mid-Miocene sediment deposition in the Friis Hills basin and syn- genetic ice (15.1-12.5 Ma)}

Sediment deposition at Friis Hills spanned over two important periods of the mid-Miocene: (1) the latter stages of the MCO ( 17-15 Ma), the warmest interval of the Neogene (e.g. 
Miller et al., 1991, Zachos et al., 2001, Shevenell et al., 2008, Holbourn et al., 2015) and (2) the mid-Miocene climate transition (MMCT; $\sim 14.8-13.8 \mathrm{Ma}$ ), which marked the beginning of progressive cooling during the late Miocene (e.g. Shevenell et al., 2004, Miller et al., 2005, Zachos et al., 2008, Levy et al., 2016). During the MCO, atmospheric $\mathrm{CO}_{2}$ concentrations reached between 300-600 ppmv (e.g. Foster et al., 2017), mean annual sea surface temperatures were 3 to $4^{\circ} \mathrm{C}$ higher than present (e.g. You et al., 2009) and mean annual air temperatures at mid-latitudes were $6^{\circ} \mathrm{C}$ warmer than today (Flower and Kennett, 1994). This thesis provides information on the paleoenvironmental response of the high elevations of the MDV to this period of climatic shift and more specifically to the period associated with the deposition of core FHDP2C, $14.4-14.0$ Ma.

\section{Mid-Miocene tundra environment}

Consistent with other marine and terrestrial records in the Ross Sea region (e.g. Raine and Askin, 2001, Warny et al., 2009, Feakins et al., 2012, Lewis and Ashworth, 2015, Chorley, 2020), paleoenvironmental reconstructions of interglacial periods support a tundralike environment at Friis Hills through the mid-Miocene (Chapter 2). The similar diatom and macrofossil assemblage throughout FHDP2C, along with the geochemical similarities between the two shallow pond units, suggest that the interglacial periods did not undergo major paleoenvironmental shifts from $\sim 14.4-14.0 \mathrm{Ma}$ (Chapter 2). Interglacial periods remained warm and wet enough to support plant growth such as lichens, liverworts, mosses, grasses and sedges, dicots and Nothofagaceae (Chapter 2). Similar plant assemblages are widespread in the modern Arctic, for example in west Greenland (Fig. 6.1), but also south of the treeline in Tierra del Fuego, South America (e.g. Peri et al., 2012, 2019, Schaeffer et al., 2013). The unusually high concentrations of $\delta^{15} \mathrm{~N}$ provides further information on the organisation of the ecosystem in the high elevations of the MDV during the mid-Miocene and suggests an ecosystem with up to three trophic levels (Chapter 2). This is supported by the presence of insects, feathers barbs (birds) and tardigrade fragments within the sediment. Although insect fragments have been found in different mid-Miocene terrestrial deposits in the Transantarctic Mountains (TAM; e.g. Lewis et al., 2008, Lewis and Ashworth, 2015, Ashworth and Erwin, 2016), the high $\delta^{15} \mathrm{~N}$ suggests an even more complex food chain, most likely including birds at Friis Hills at least until 14.0 Ma.

Geologic records from other sites suggest the extinction of vegetation from high elevations of the MDV at the end of the MMCT (Lewis et al., 2008, Lewis and Ashworth, 2015). Through model simulations, Chorley (2020) suggests that the extension of vegetation in the high elevations of the MDV may coincide with uplift in the TAM coupled with decreasing 
$\mathrm{CO}_{2}$ levels, which may explain how vegetation persisted at lower elevations of the TAM beyond the MMCT (e.g. DVDP 10-11; Ohneiser et al., 2020). This isostatic uplift combined with glacial downcutting placed the Friis Hills above the level of glacial erosion. Minimal erosion rates associated with a relatively cold and dry environment enhanced the preservation of the sediment record (Lewis and Ashworth, 2015).

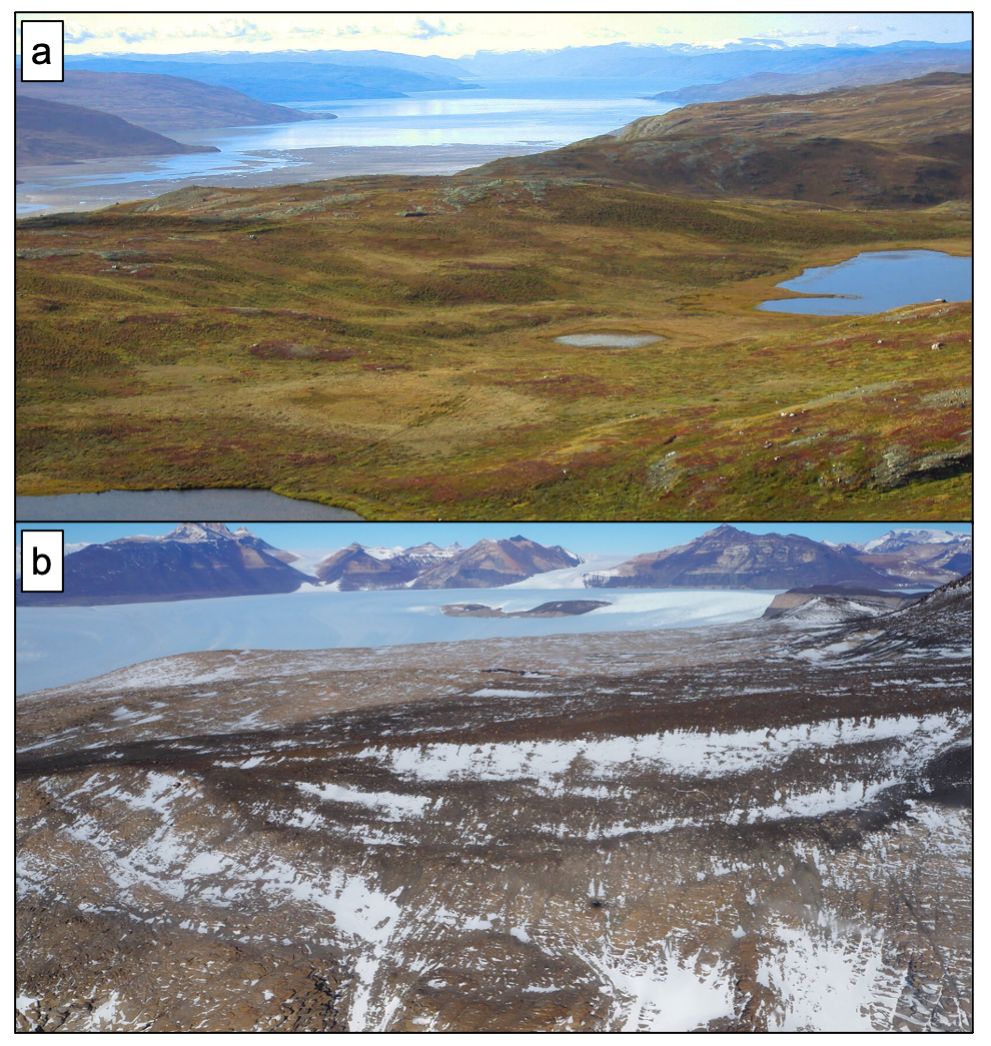

Fig. 6.1 Landscape comparison between west Greenland and Friis Hills. a. west Greenland as a modern landscape analogue for mid-Miocene interglacial periods at Friis Hills (photo credit: University of Maine). b. modern landscape at Friis Hills (photo credit: T. Naish)

\section{Mid-Miocene paleoclimate based on geochemical proxies}

The $\delta^{13} \mathrm{C}$ signal of $\mathrm{C} 3$ plants $(-25.5 \pm 0.7 \%$ VPDB) in the lower section of FHDP2C corresponds to a semi-arid environment with mean annual precipitation (MAP) ranging from 300 to $850 \mathrm{~mm} \mathrm{yr}^{-1}$ during interglacial periods, which is similar to that found in modern tundra analogues (Chapter 2). This is much lower than the upper limit of $3000 \mathrm{~mm} \mathrm{yr}^{-1}$ at Friis Hills proposed by Lewis and Ashworth (2015) for the same period but closer to estimates calculated from the detrital geochemistry in Antarctic continental margin drill-core U1356 (750 mm yr ${ }^{-1}$ ) and Cape Roberts Project site in the Ross Sea region (600 $\mathrm{mm} \mathrm{yr}^{-1}$; 
Passchier et al., 2013). Sediments from the U1356 drill-core originated from the Wilkes Land Basin region, which receives up to $300-400 \mathrm{~mm} \mathrm{yr}^{-1}$ more precipitation than the MDV under modern climatic conditions (e.g. Thomas et al., 2017). Assuming minimal changes in atmospheric circulation, this would indicate that based on U1356, the MAP in the MDV would be around 350 to $450 \mathrm{~mm} \mathrm{yr}^{-1}$. The MAP during the mid-Miocene (14.4-14.0 Ma), derived from the $\delta^{13} \mathrm{C}$ signal of $\mathrm{C} 3$ plants reported in this thesis, is therefore in line with the different off-shore analogues.

The ice lenses and their meteoric signature in the deeper sections of the FHDP cores ( $>$ $30 \mathrm{~m}$ depth) suggest a near-saturated active layer during the mid-Miocene, similar to presentday high-Arctic sites, where evaporation in the active layer is limited (Chapter 3). These ground conditions imply that a minimal lag time exists between sediment deposition and freezing of ground ice. The closure ages associated with ${ }^{10} \mathrm{Be}_{\text {met }}$ concentrations in the lower Friis Hills and Table Mountain cores show that the ice formed more or less simultaneously with the deposition of the sediment (i.e. syngenetic ground ice; Chapter 4 ) at $\sim 12.5 \mathrm{Ma}$ at Friis Hills. The minimal lag time could be due to the adjustment of permafrost to the paraglacial environment or geomorphologic imbalance caused by deglaciation. Temperature reconstructions based on the corrected $\delta^{18} \mathrm{O}$ value of the deep ground ice and change in paleogeography suggest that the mid-Miocene mean annual air temperature (MAAT) was 6 to $11^{\circ} \mathrm{C}$ warmer, which would correspond to a MAAT between -17 and $-12^{\circ} \mathrm{C}$ (in the range of that in present-day high Arctic). However, this estimate remains heavily dependent on elevation, which is poorly constrained in the TAM region (Chapters 3 and 4). Additionally, without directly dating the ice lenses, it is not possible to infer if the ice is exactly synchronous to the time of sediment deposition.

\subsubsection{Mid to late Miocene and transition to a hyper-arid environment (12.5-6.0 Ma)}

The presence of ${ }^{10} \mathrm{Be}_{\text {met }}$ in the upper section of the Friis Hills and Table Mountain cores reflects a time when translocation of clays was possible in a warm and wet climate, similar to the current conditions in the Arctic. Since the translocation of fine particles requires enough water to percolate through a near-saturated active layer, such conditions must have been present until 6.0 Ma in Friis Hills and Table Mountain (Chapter 4). This finding challenges the idea that the upper elevations of the MDV have remained frozen under hyper-arid climate since the MMCT and instead supports the hypothesis that while the Miocene has undergone progressive cooling, the onset of polar aridity did not occur until between 7 and $5.4 \mathrm{Ma}$ 
(Herbert et al., 2016). However, it is not possible to infer, from data reported in this thesis, if such conditions prevailed throughout all the late Miocene period and ended at 6.0 Ma or if a single warm period punctuated the late Miocene cooling trend at 6.0 Ma. Supporting evidence from late Miocene facies in core ANDRILL-1B indicates increased subglacial meltwater and terrigenous sediment supply in the Ross Embayment and EAIS outlet glaciers (McKay et al., 2009). In addition, glacial meltwater facies crop out in Prydz Bay (Hambrey and McKelvey, 2000) and significant glacial outwash are found in the Totten Glacier region of East Antarctica (Gulick et al., 2017). Although this sedimentological evidence suggests a significantly warmer and wetter glacial regime through the late Miocene, it is poorly constrained by the lack of a continuous record. The presence of ${ }^{10} \mathrm{Be}_{\text {met }}$ in the near-surface sediment at Friis Hills and Table Mountain provides evidence that the late Miocene warm period extended throughout the high elevations of the MDV.

\section{Late Miocene paleo-temperatures based on paleo-active layer thickness}

At the time the active layer was the deepest $\sim 6.0 \mathrm{Ma}$, the erosion-corrected depth of the paleoactive layer suggests a MAAT ranging from -12 to $-9^{\circ} \mathrm{C}$ and a mean summer air temperature (MSAT) ranging from 6 to $12^{\circ} \mathrm{C}$ (Chapter 4). Based on lipid biomarkers, temperature reconstructions of the Sirius Group in Olivers Bluff (850 km from the MDV), show that the Antarctic MSAT was around $5^{\circ} \mathrm{C}$ through the late Neogene, which is significantly higher than present and allowed a low diversity plant community to exist at low elevations (Rees-Owen et al., 2018). A MSAT of $5^{\circ} \mathrm{C}$ was also calculated based on magnetic minerals and organic geochemical records in core DVDP-11 in Taylor Valley (Ohneiser et al., 2020). Ohneiser et al. (2020) established that a transition to cooler conditions in Taylor Valley occurred between 4.1 and 2.6 Ma. Longer-term temperature records throughout the Neogene suggest that continental MSAT ranged between 4 and $12{ }^{\circ} \mathrm{C}$ (Prebble et al., 2006, Warny et al., 2009) and tundra vegetation persisted on the Antarctic Peninsula until 5.3 Ma (Anderson et al., 2011). The climatic shift at 6.0 Ma in the upper elevations of the MDV, as inferred in this thesis, could have been a precursor of the subsequent paleoenvironmental cooling observed in lower elevations of Antarctica throughout the late Miocene and early Pliocene.

\subsubsection{Modern hyper-arid conditions (6.0 Ma-present)}

Since the closure age of $6.0 \mathrm{Ma}$, there has been insufficient liquid water to translocate ${ }^{10} \mathrm{Be}_{\mathrm{met}}$ in the sediment column (Chapter 4). Movement of water still occurs through vapour-diffusion and infiltration of evaporated snowmelt in the near-surface, a process which occurs on a 
regional scale in the MDV (Chapter 3). Emplacement of ground ice in the upper MDV sediment has therefore been occurring well after the last infiltration of ${ }^{10} \mathrm{Be}_{\text {met }}$ at $6.0 \mathrm{Ma}$, but the amount of liquid water has been insufficient to translocate ${ }^{10} \mathrm{Be}_{\text {met }}$ in the sediment column for at least $2.97 \mathrm{Ma}$ (e.g. Schiller et al., 2009, 2019). Given that the soluble salts geochemistry at Friis Hills was similar to sea water and that the $\mathrm{NaCl}$ eutectic point is $\sim-23^{\circ} \mathrm{C}$, a reasonable amount of unfrozen water may persist down to at least $-23^{\circ} \mathrm{C}$, which is the modern-day MAAT at the surface. The conformity of dry permafrost samples to biological ratios suggests that the modern environment is regulated by biochemical processes and the current pool of organic carbon in the dry permafrost appeared to be in equilibrium with a modern climate and ecosystem (Chapter 2). The average ground temperature increases with depth which may allow for the permafrost column to remain above the $\mathrm{NaCl}$ eutectic, as it would have during previous interglacial/warm periods and likely also during cold glacial periods.

\subsubsection{Summary of mid-Miocene permafrost}

At Friis Hills, during the mid-Miocene, sedimentation occured primarily through the deposition of glacial sediment during glacial periods. During interglacial periods, the site was covered by lakes (or ponds) or a semi-arid tundra with a multi-trophic ecosystem. During these interglacial periods, the paraglacial environment (i.e. glaciated landscape responding to non-glacial conditions; Slaymaker, 2009) stabilized and permafrost aggraded, enclosing meteoric ground ice with minimal lag time. Similar to modern Arctic periglacial environments, a near-saturated active layer, which thaws seasonally, formed below the surface. Through the mid- to late Miocene, as the site underwent the MMCT and progressive uplift, sedimentation was halted at Friis Hills and the tundra vegetation likely became extinct. An active layer existed during the late Miocene (6.0 Ma), indicating that either a single warm period punctuated the late Miocene or a warm climate persistent throughout the mid-late

Miocene, enough to displace ${ }^{10} \mathrm{Be}_{\text {met }}$. The late Miocene marked the onset of permanent aridity. Under modern conditions, the icy permafrost is overlain by dry permafrost and the depth of the ice table is in equilibrium with modern hyper-arid conditions. The original meteoric signature of ground ice is preserved below the depth of maximal thermal amplitude. The ground ice above this point is redistributed through vapour-diffusion over millions of years, creating a nearly dry zone around 10-15 m depth. Near-surface ground ice is emplaced through infiltration of evaporated snowmelt (Fig. 6.2). 


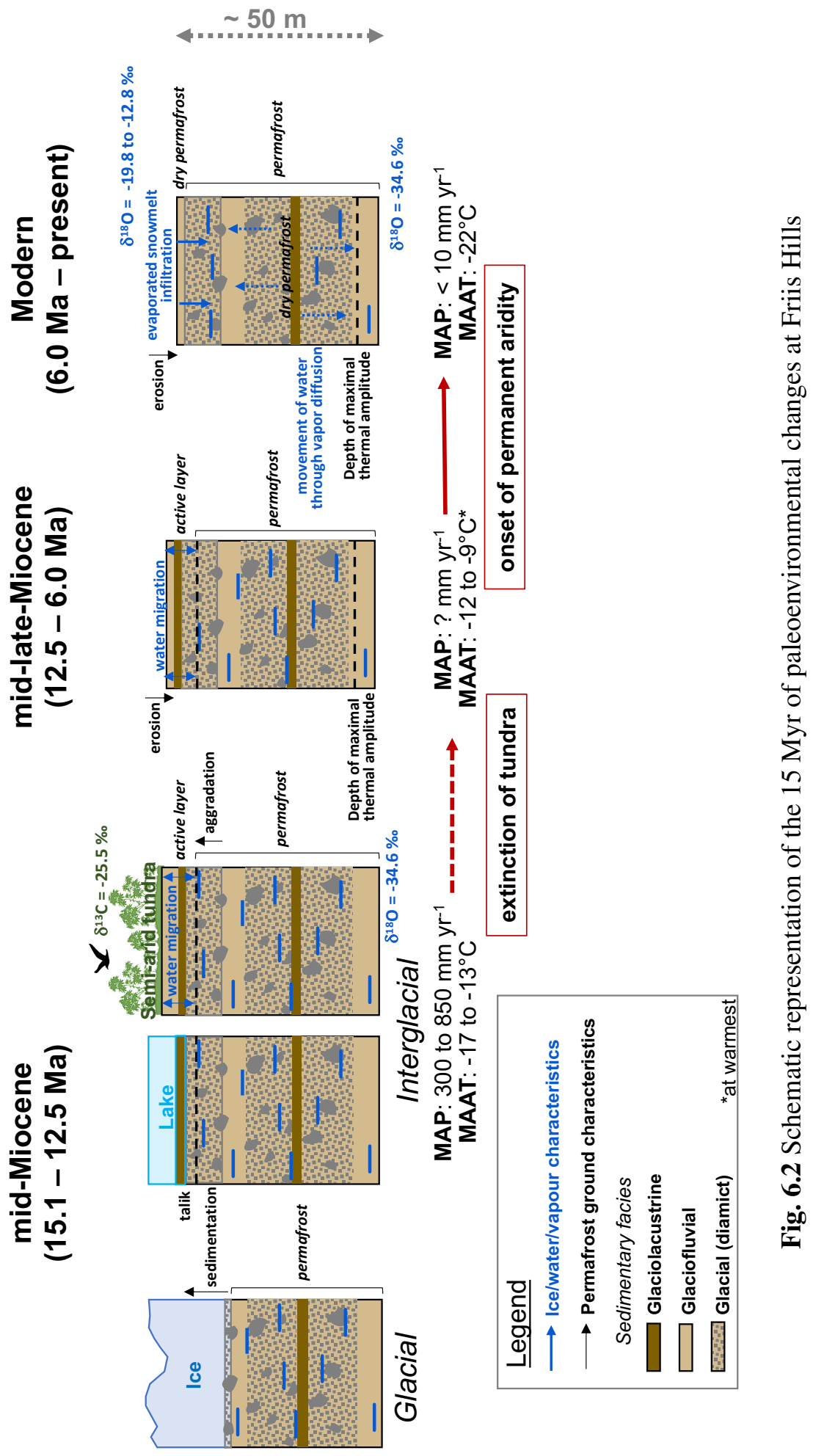




\subsection{Future geochemical research directions in the McMurdo Dry Valleys}

This thesis used geochemical paleoenvironmental proxies that have rarely been used in Antarctic terrestrial records to characterize the sediments, organics and ground ice of the FHDP cores. Some of these analyses have highlighted areas for further research and potential future work in the MDV.

\subsubsection{Carbon stock and impacts of warming temperatures}

Organic carbon and nitrogen in the dry permafrost layer conform to biological ratios, which suggests that the modern environment is regulated by bacterial action. Additionally, the sharp enrichment in $\delta^{13} \mathrm{C}$ in the upper meter, suggests that bacterial action extends beyond the limit of the ice table. Both observations raise questions about microbial life in a hyper-arid environment like the upper MDV. Microbial activity in Quaternary-age surfaces of University Valley was undetectable under ambient conditions, showing that permafrost in the high elevations is not sufficiently exposed to clement conditions to permit microbial metabolism or growth (Goordial et al., 2016). However, Friis Hills is slightly lower in elevation than University Valley and sediments are much older, implying that microbial activity could have been reactivated during a warmer period between the late Miocene and Quaternary, such as the $6 \mathrm{Ma}$ period inferred in this thesis. The timing of this microbial activity in the permafrost is unknown and so is its response to future climate change.

To further understand the bioavailability of organic matter in the permafrost under future warming temperatures, ${ }^{13} \mathrm{C}$-nuclear magnetic resonance (NMR) and X-ray photoelectron spectroscopy analyses are commonly used in Arctic permafrost (e.g. Gentsch et al., 2015). However, the carbon stock at Friis Hills is too low for these analyses. Lipid biomarkers could provide an alternative to test the overprint of modern biochemical processes in the surficial meters of permafrost (e.g. Hutchings et al., 2019). The mid-Miocene permafrost at Friis Hills has a unique tundra-dominated signature that is free of reworked old organic matter (i.e. coal), which could contaminate a biomarker study. The surficial section of Friis Hills could have potentially preserved the shift from a plant-dominated signature to a bacteria-dominated signature. Bacteria-dominated environments tend to yield lower chain alkanes and fatty acids than plant-dominated environments, and contribute to unique biomarkers such as hopanes and branched-GDGTs. Analyzing the general distributions, concentrations and ratios of these biomarkers would clarify the shift from the mid-Miocene tundra to the subsequent 
bacteria-dominated environment. Lipid biomarkers would provide more information on the environmental global impacts of warming temperatures on Antarctic thawing permafrost.

\subsubsection{Salt concentrations as an indicator for fjord-like conditions dur- ing the mid-Miocene}

The soluble ions measured in the thawed ground ice samples had a different geochemical signature in near-surface samples than in deep ice samples: the ground ice in the uppermost $1 \mathrm{~m}$ was characterized by $\mathrm{Na}-\mathrm{Cl}$ geochemical facies and high solute load (3.9 to $14.3 \mathrm{mg}$ $\mathrm{g}^{-1}$ dry soils), while the ground ice below $30 \mathrm{~m}$ was characterized by $\mathrm{Ca}-\mathrm{SO}_{4}$ geochemical facies and lower solute load ( 0.3 to $0.5 \mathrm{mg} \mathrm{g}^{-1}$ dry soils). While the solute load disparity can be explained by the origin of the ice (the near-surface ice originated from evaporated snowmelt, which makes the ice enriched in salts and the deep ground ice originated from meteoric water), the shift in geochemical facies is not fully understood.

Salts that are deposited through precipitation of snow and dry fallout become concentrated and remain near the surface due to the hyper-arid environment in which evaporation/sublimation exceeds precipitation (Marchant and Head III, 2007, Jackson et al., 2016). Salt concentrations in sediments of the MDV tend to be dependent on the proximity of the source. For example, $\mathrm{Cl}^{-}$is more dominant near the coast, due to the influence of $\mathrm{Cl}^{-}$rich marine sea-spray aerosols, whereas $\mathrm{SO}_{4}{ }^{2-}$ and $\mathrm{NO}_{3}{ }^{-}$, derived from nitrogen and sulfur compounds that have been oxidized in the upper atmosphere (Bao et al., 2000, Michalski et al., 2005), precipitated onto the EAIS and transported by katabatic winds (Fountain et al., 2010), are more concentrated near the Polar Plateau (Claridge and Campbell, 1968, Keys and Williams, 1981). Based on this premise, the shift in soluble ions in ice that was deposited during the mid-Miocene (deep ground ice) relative to the ice that has been depositing during modern times (near-surface ground ice) could therefore suggest a different paleo-geography at Friis Hills during the mid-Miocene, possibly suggesting fjord-like conditions.

Recent models estimate relative sea level increased by 30 to $36 \mathrm{~m}$ during the mid-Miocene (Miller et al., 2005) and even assuming minimal uplift, the distance to Ross Sea coast could have been reduced to $<20 \mathrm{~km}$. Cores drilled at the mouth of Taylor Valley (DVDP 10 and 11) contained marine deposits, suggesting fjord-like conditions in lower Taylor Valley during the warmer periods of the late Miocene and/or early Pliocene (Porter and Beget, 1981, Levy et al., 2012). Similar conditions could have prevailed during the MCO. Many studies have also proposed Miocene seawater as the initial source of salts in Lake Bonney, the western-most lake in Taylor Valley (e.g. Higgins et al., 2000, Lyons et al., 2005, Mikucki et al., 2004) and 
of Lake Vanda, in Wright Valley (DVDP 4; e.g. Webb, 1972, Nakai et al., 1975), supporting the hypothesis that Friis Hills were much closer to Ross Sea during the MCO. The shift from when fjords dominated the MDV during the MCO and retreated during the MMCT should be noticeable in the salt record of the Friis Hills cores. To test this hypothesis, salts could be leached from the dry sediment (e.g. Toner et al., 2013) throughout the FHDP cores at regular intervals and they may record a shift in geochemical facies which could be attributed to a change in sea extent in the MDV.

\subsubsection{Meteoric deep ground ice as a paleo-temperature proxy and dat- ing ground ice}

Ice wedges, and more recently pore ice, with $\delta^{18} \mathrm{O}$ composition that preserve a meteoric signature, have been widely used as paleo-temperature proxies in the Arctic (e.g. Porter and Opel, 2020). However, depending on the genesis of ground ice (superimposed or inherited), interpreting the geochemistry of ground ice from permafrost can be quite complex. The rate of accumulation of the sediment is not necessarily constant and infiltration of water may lead to missing isotopic record or replacement with more contemporary ice (Stuiver et al., 1976). This may occur when: (1) temperatures are not sufficiently low to enable permafrost aggradation; (2) the active layer is not near saturation; (3) post-depositional melting erased the record; or (4) vapour-diffusion altered the record. In Antarctica, particularly in the MDV, temperatures have remained cold enough to sustain continuous permafrost (MAAT $<6-8^{\circ} \mathrm{C}$; Smith and Riseborough, 2002) at least since the mid-Miocene with a near-saturated active

layer. The cryostratigraphy of the FHDP core (Chapter 3) and the ${ }^{10} \mathrm{Be}_{\text {met }}$ concentration profile (Chapter 4) do not suggest extensive melting within the permafrost record, and warm periods have only affected the upper-most 2 to $3 \mathrm{~m}$ of permafrost (Chapter 4 ). The dominant mechanism that would potentially alter the ground ice record is vapour-diffusion. However, using the REGO model (Chapter 3), it was possible to determine the depth of zero thermal amplitude, which is the depth where vapour-diffusion from surface diurnal and annual temperature cycles does not alter ground ice (Fisher et al., 2016). Although this depth is dependent on thermal properties of the ground, it implies that drilling deep ( $>30$ $\mathrm{m}$ ) into Antarctic permafrost would potentially uncover meteoric ground ice that kept its original isotopic signature. This finding offers the potential to use meteoric ground ice as a paleotemperature proxy dating back to the age of the sediment. In the MDV, this could involve finding ice that dates back to the early Miocene, which extends beyond the oldest ice core record (currently 2.7 Ma ice from Allan Hills; Yan et al., 2019). 
However, it is important to understand the restrictions of interpreting geochemical properties of ground ice, as there is currently no suitable method to directly date million-year old ice. Using ${ }^{10} \mathrm{Be}_{\text {met }}$ as a tracer for water infiltration helps constrain the timing of the emplacement of the ground ice (Chapter 5), but still relies on a complete understanding of the periglacial history for interpretation. Development of a suitable isotope method for dating old ice will be required in order to make more direct interpretations. The use of ${ }^{129} \mathrm{I}$, widely used in ancient ground water dating, may become a potential method (half-life of $16 \mathrm{Ma}$ ) for dating old bodies of ground ice, if the sensitivity of instruments eventually require a smaller volume of sample (currently around 1L). Additionally, to establish a strong temperature proxy based on meteoric ground ice, a better understanding of uplift rates and the paleogeography of the MDV and the TAM is necessary.

\subsubsection{Refinement of the aggressive ${ }^{10} \mathrm{Be}_{\text {met }}$ leaching method}

One of the outcomes of this thesis was also to validate the ${ }^{10} \mathrm{Be}_{\text {met }}$ results derived from the aggressive leaching method used in early investigations in the MDV (e.g. Graham et al., 2002, Schiller, 2007, Schiller et al., 2009, Dickinson et al., 2012). This leaching method consisted of using $6 \mathrm{M} \mathrm{HCl}$ for $1 \mathrm{~h}$ at $100^{\circ} \mathrm{C}$ (Graham et al., 2001, Ditchburn and Graham, 2002) and was criticized due to the possibility of liberating in situ ${ }^{10} \mathrm{Be}$ via partial decomposition of clay minerals (Valletta et al., 2015). However, the five TM01 samples that were duplicated for method testing yielded ${ }^{10} \mathrm{Be}_{\text {met }}$ concentrations between 1.50 and 1.66 (avg. 1.57) times higher using the mild leaching method than the values obtained using the aggressive method (Chapter 4). It is still unclear why higher concentrations were measured using the mild leach. One hypothesis is that the crystalline oxide-bound Beryllium $\left(\mathrm{Be}_{\mathrm{ex}-\mathrm{ox}}\right)$ extracted by adding $10 \mathrm{ml}$ of $1 \mathrm{M}$ hydroxylamine-hydrochloride solution (in $1 \mathrm{M} \mathrm{HCl}$ ) was not extracted by the aggressive $\mathrm{HCl}$ leach. It would be interesting to test this hypothesis by doing mild leach for the amorphous oxide-bound Beryllium $\left(\mathrm{Be}_{\mathrm{am}-\mathrm{ox}} ; 0.5 \mathrm{M} \mathrm{HCl}\right.$ and gently shaking at room temperature for $24 \mathrm{~h}$ ) and omitting the step for $\mathrm{Be}_{\mathrm{ex}-\mathrm{ox}}$. If this hypothesis is true, the early ${ }^{10} \mathrm{Be}_{\text {met }}$ studies could be corrected for $\mathrm{Be}_{\mathrm{ex}-\mathrm{ox}}$, similarly to what was done in this thesis. However, since the offset was found to be consistent throughout samples of the same site, the relative concentrations of ${ }^{10} \mathrm{Be}_{\text {met }}$ remain valid in the early studies, refuting the hypothesis proposed by Valletta et al. (2015). 


\subsection{The not-so stable upper McMurdo Dry Valleys: a new perspective on paleoclimate evolution through the Neo- gene}

Despite evidence for EAIS retreat through the late Miocene has been found in offshore marine records (e.g. Williams et al., 2010, Cook et al., 2013, Patterson et al., 2014), the hypothesis that the upper elevations of the MDV remained under a hyper-arid polar climate since the MMCT have persisted. One of the main findings of this thesis invalidates this hypothesis of permanent polar aridity, suggested by a large body of literature (e.g. Denton et al., 1993, Sugden et al., 1995, Marchant and Denton, 1996, Summerfield et al., 1999, Valletta et al., 2015). Most of this evidence was based on geomorphology and tephrochronology (e.g. Marchant et al., 1996), along with the preservation of cold-based glacial tills (e.g. Marchant and Denton, 1996), all of which support a relatively stable EAIS but do not exclude the presence of liquid water in the upper MDV.

The ${ }^{10} \mathrm{Be}_{\text {met }}$ study by Valletta et al. (2015) at Friis Hills relied on a single sample in the blank range to support permanent aridity. Although it is unclear why this sample was in the blank range, this thesis provides more than 40 samples, from two different locations and 5 different boreholes, using two chemical protocols and two different AMS laboratories, all supporting the presence of liquid water post-MMCT. In addition, samples from the Table Mountain study by Dickinson et al. (2012) were validated. At Table Mountain, Dickinson et al. (2012) compared the ${ }^{10} \mathrm{Be}_{\text {met }}$ concentration profiles of two different cores (TM01TM04), while in Chapter 4, the comparison was extended to the Friis Hills site (FHDP2C), reinforcing the idea that the climatic conditions sustaining liquid water up to $6.0 \mathrm{Ma}$ or a punctuated event near 6.0 Ma were present on a regional scale in the upper MDV. This new finding provides strong evidence that the climatic conditions have not remained stable since the MMCT and that the MDV may be more susceptible to future climate change than anticipated. 


\section{References}

Aanderud, Z. T., Saurey, S., Ball, B. A., Wall, D. H., Barrett, J. E., Muscarella, M. E., Griffin, N. A., Virginia, R. A., Barberán, A., and Adams, B. J. (2018). Stoichiometric shifts in soil C:N:P promote bacterial taxa dominance, maintain biodiversity, and deconstruct community assemblages. Frontiers in Microbiology, 9:1401.

Aislabie, J. M., Chhour, K.-L., Saul, D. J., Miyauchi, S., Ayton, J., Paetzold, R. F., and Balks, M. R. (2006). Dominant bacteria in soils of Marble Point and Wright Valley, Victoria Land, Antarctica. Soil Biology and Biochemistry, 38(10):3041-3056.

Allibone, A. H., Cox, S. C., Graham, I. J., Smellie, R. W., Johnstone, R. D., Ellery, S. G., and Palmer, K. (1993). Granitoids of the Dry Valleys area, Southern Victoria Land, Antarctica: plutons, field relationships, and isotopic dating. New Zealand Journal of Geology and Geophysics, 36(3):281-297.

Altuhafi, F. and Baudet, B. A. (2011). A hypothesis on the relative roles of crushing and abrasion in the mechanical genesis of a glacial sediment. Engineering Geology, 120(14):1-9.

Andersland, O. and Anderson, D. (1978). Geotechnical Engineering for Cold Regions. McGraw-Hill College.

Anderson, J. B., Warny, S., Askin, R. A., Wellner, J. S., Bohaty, S. M., Kirshner, A. E., Livsey, D. N., Simms, A. R., Smith, T. R., and Ehrmann, W. (2011). Progressive Cenozoic cooling and the demise of Antarctica's last refugium. Proceedings of the National Academy of Sciences, 108(28):11356-11360.

Antony, R., Grannas, A. M., Willoughby, A. S., Sleighter, R. L., Thamban, M., and Hatcher, P. G. (2014). Origin and sources of dissolved organic matter in snow on the East Antarctic Ice Sheet. Environmental Science \& Technology, 48(11):6151-6159.

Ashworth, A. C. and Erwin, T. L. (2016). Antarctotrechus balli sp. n.(Carabidae, Trechini): the first ground beetle from Antarctica. Zookeys, (635):109-122.

Astakhov, V. I. and Isayeva, L. L. (1988). The "Ice Hill": an example of "retarded deglaciation" in Siberia. Quaternary Science Reviews, 7(1):29-40.

Bakermans, C., Skidmore, M. L., Douglas, S., and McKay, C. P. (2014). Molecular characterization of bacteria from permafrost of the Taylor Valley, Antarctica. FEMS Microbiology Ecology, 89(2):331-346. 
Balco, G. and Shuster, D. L. (2009). Production rate of cosmogenic ${ }^{21} \mathrm{Ne}$ in quartz estimated from ${ }^{10} \mathrm{Be},{ }^{26} \mathrm{Al}$, and ${ }^{21} \mathrm{Ne}$ concentrations in slowly eroding Antarctic bedrock surfaces. Earth and Planetary Science Letters, 281(1-2):48-58.

Balco, G., Stone, J. O., Sliwinski, M. G., and Todd, C. (2014). Features of the glacial history of the Transantarctic Mountains inferred from cosmogenic ${ }^{26} \mathrm{Al},{ }^{10} \mathrm{Be}$ and ${ }^{21} \mathrm{Ne}$ concentrations in bedrock surfaces. Antarctic Science, 26(6):708-723.

Balco, G. A. (2004). The sedimentary record of subglacial erosion beneath the Laurentide Ice Sheet. PhD thesis, University of Washington, United States.

Balks, M., Campbell, D., Campbell, I., and Claridge, G. (1995). Interim results of 1993/94 soil climate, active layer and permafrost investigations at Scott Base, Vanda and Beacon Heights, Antarctica. University of Waikato, Antarctic Research Unit Special Report, $1: 1-64$.

Ball, B. A. and Levy, J. (2015). The role of water tracks in altering biotic and abiotic soil properties and processes in a polar desert in Antarctica. Journal of Geophysical Research: Biogeosciences, 120(2):270-279.

Bannister, M. T., Nobes, D. C., Godfrey, M. J., and Sletten, R. S. (2019). Imaging buried massive ice in Victoria Valley, Antarctica, with multi-electrode electrical resistivity and ground penetrating radar. In SEG Technical Program Expanded Abstracts 2019, pages 2828-2832. Society of Exploration Geophysicists.

Bao, H., Campbell, D. A., Bockheim, J. G., and Thiemens, M. H. (2000). Origins of sulphate in Antarctic Dry Valley soils as deduced from anomalous ${ }^{17} \mathrm{O}$ compositions. Nature, 407(6803):499-502.

Bao, H. and Marchant, D. R. (2006). Quantifying sulfate components and their variations in soils of the McMurdo Dry Valleys, Antarctica. Journal of Geophysical Research: Atmospheres, 111(D16301).

Barker, J. D., Grottoli, A. G., and Lyons, W. B. (2018). Stable isotope evidence for the biogeochemical transformation of ancient organic matter beneath Suess Glacier, Antarctica. Arctic, Antarctic, and Alpine Research, 50(1):E1448643.

Barrett, J., Page, M., Gooseff, M., and Takacs-Vebach, C. (2010). The legacy of aqueous environments on soils of the McMurdo Dry Valleys: context for future exploration of Martian soils. Life in Antarctic Deserts and other Cold Dry Environments: Astrobiological Analogs, 5:78-109.

Barrett, J., Virginia, R., Parsons, A., and Wall, D. (2006). Soil carbon turnover in the McMurdo Dry Valleys, Antarctica. Soil Biology and Biochemistry, 38(10):3065-3082.

Barrett, J., Virginia, R., Wall, D., Doran, P., Fountain, A., Welch, K., and Lyons, W. (2008). Persistent effects of a discrete warming event on a polar desert ecosystem. Global Change Biology, 14(10):2249-2261. 
Barrett, J., Virginia, R. A., Lyons, W. B., McKnight, D. M., Priscu, J. C., Doran, P. T., Fountain, A. G., Wall, D. H., and Moorhead, D. (2007a). Biogeochemical stoichiometry of Antarctic Dry Valley ecosystems. Journal of Geophysical Research: Biogeosciences, 112(G01010).

Barrett, P. (1981). History of the Ross Sea region during the deposition of the Beacon Supergroup 400-180 million years ago. Journal of the Royal Society of New Zealand, 11(4):447-458.

Barrett, P. (1987). Oligocene sequence cored at CIROS-1, western McMurdo Sound. New Zealand Antarctic Record, 7(3):1-7.

Barrett, P. (1989). Antarctic Cenozoic history from the CIROS-1 drillhole, McMurdo Sound. DRIS Publishing.

Barrett, P. (2013). Resolving views on Antarctic Neogene glacial history-the Sirius debate. Earth and Environmental Science Transactions of the Royal Society of Edinburgh, 104(1):31-53.

Barrett, P., Hambrey, M., Christoffersen, P., Glasser, N., and Hubbart, B. (2007b). Cenozoic climate and sea level history from glacimarine strata off the Victoria Land coast, Cape Roberts Project, Antarctica. In Glacial sedimentary processes and products, volume 39, pages 259-287. International Association of Sedimentologists.

Bate, D., Barrett, J., Poage, M., and Virginia, R. (2008). Soil phosphorus cycling in an Antarctic polar desert. Geoderma, 144(1-2):21-31.

Behrendt, J. C. and Cooper, A. (1991). Evidence of rapid Cenozoic uplift of the shoulder escarpment of the Cenozoic West Antarctic rift system and a speculation on possible climate forcing. Geology, 19(4):315-319.

Bengtsson, L., Enell, M., and Berglund, B. (1986). Handbook of Holocene Palaeoecology and Palaeohydrology. Chemical Analysis, pages 423-451.

Berman, E. S., Levin, N. E., Landais, A., Li, S., and Owano, T. (2013). Measurement of $\delta^{18} \mathrm{O}, \delta^{17} \mathrm{O}$, and ${ }^{17} \mathrm{O}$-excess in water by off-axis integrated cavity output spectroscopy and isotope ratio mass spectrometry. Analytical Chemistry, 85(21):10392-10398.

Billups, K. and Schrag, D. (2002). Paleotemperatures and ice volume of the past $27 \mathrm{Myr}$ revisited with paired $\mathrm{Mg} / \mathrm{Ca}$ and ${ }^{18} \mathrm{O} /{ }^{16} \mathrm{O}$ measurements on benthic foraminifera. Paleoceanography, 17(1):1003.

Blinov, A., Alfimov, V., Beer, J., Gilichinsky, D., Schirrmeister, L., Kholodov, A., Nikolskiy, P., Opel, T., Tikhomirov, D., and Wetterich, S. (2009). Ratio of ${ }^{36} \mathrm{Cl} / \mathrm{Cl}$ in ground ice of east Siberia and its application for chronometry. Geochemistry, Geophysics, Geosystems, 10(11).

Bliss, A. K., Cuffey, K. M., and Kavanaugh, J. L. (2011). Sublimation and surface energy budget of Taylor Glacier, Antarctica. Journal of Glaciology, 57(204):684-696. 
Blott, S. J. and Pye, K. (2001). GRADISTAT: a grain size distribution and statistics package for the analysis of unconsolidated sediments. Earth Surface Processes and Landforms, 26(11):1237-1248.

Blott, S. J. and Pye, K. (2012). Particle size scales and classification of sediment types based on particle size distributions: Review and recommended procedures. Sedimentology, 59(7):2071-2096.

Bockheim, J. (1979). Ice core and ice cement effects on soil development, eastern Wright Valley, Antarctica. New Zealand Journal of Geology and Geophysics, 22(4):487-493.

Bockheim, J. (1982). Properties of a chronosequence of ultraxerous soils in the TransAntarctic Mountains. Geoderma, 28(3-4):239-255.

Bockheim, J. (1983). Use of soils in studying the behaviour of the McMurdo ice dome. In Antarctic Earth Science: Fourth International Symposium, pages 457-460. Cambridge University Press New York.

Bockheim, J. (1990). Soil development rates in the Transantarctic Mountains. Geoderma, 47(1-2):59-77.

Bockheim, J. and Ackert Jr, R. P. (2007). Implications of soils on mid-Miocene-aged drifts in the McMurdo Dry Valleys for ice sheet history and paleoclimate reconstruction. Geomorphology, 92(1-2):12-24.

Bockheim, J., Campbell, I., and McLeod, M. (2008). Use of soil chronosequences for testing the existence of high-water-level lakes in the McMurdo Dry Valleys, Antarctica. Catena, 74(2):144-152.

Bockheim, J., Campbell, I. B., and McLeod, M. (2007). Permafrost distribution and activelayer depths in the McMurdo Dry Valleys, Antarctica. Permafrost and periglacial processes, 18(3):217-227.

Bockheim, J., Tarnocai, C., and Lewkowicz, A. (1998). Nature, occurrence and origin of dry permafrost. In Proceedings of the 7th International Conference on Permafrost, pages $57-64$.

Boike, J., Hagedorn, B., and Roth, K. (2008). Heat and water transfer processes in permafrost affected soils: A review of field and modeling based studies for the Arctic and Antarctic. In Proceedings of the 9th International Conference on Permafrost, volume 1, pages 149-154.

Bokhorst, S., Huiskes, A., Convey, P., and Aerts, R. (2007). External nutrient inputs into terrestrial ecosystems of the Falkland Islands and the Maritime Antarctic region. Polar Biology, 30(10):1315-1321.

Bomblies, A., McKnight, D., and Andrews, E. (2001). Retrospective simulation of lake-level rise in Lake Bonney based on recent 21-year record: indication of recent climate change in the McMurdo Dry Valleys, Antarctica. Journal of Paleolimnology, 25(4):477-492.

Boschi, V. L. (2016). Characterization of the Physical and Chemical Controls on the Environmental Geochemical Behavior of Beryllium. PhD thesis, University of Pennsylvania, United States. 
Bourlès, D., Klinkhammer, G., Campbell, A., Brown, E., and Edmond, J. (1989). Beryllium in marine pore waters: geochemical and geochronological implications. Nature, 341(6244):731-733.

Brook, E. J., Brown, E. T., Kurz, M. D., Ackert Jr, R. P., Raisbeck, G. M., and Yiou, F. (1995). Constraints on age, erosion, and uplift of Neogene glacial deposits in the Transantarctic Mountains determined from in situ cosmogenic ${ }^{10} \mathrm{Be}$ and ${ }^{26} \mathrm{Al}$. Geology, 23(12):1063-1066.

Brown, E., Edmond, J. M., Raisbeck, G. M., Bourlès, D. L., Yiou, F., and Measures, C. I. (1992). Beryllium isotope geochemistry in tropical river basins. Geochimica et Cosmochimica Acta, 56(4):1607-1624.

Brown, L., Pavich, M. J., Hickman, R., Klein, J., and Middleton, R. (1988). Erosion of the eastern United States observed with ${ }^{10} \mathrm{Be}$. Earth Surface Processes and Landforms, 13(5):441-457.

Burkins, M. B., Virginia, R. A., Chamberlain, C. P., and Wall, D. H. (2000). Origin and distribution of soil organic matter in Taylor Valley, Antarctica. Ecology, 81(9):2377-2391.

Burkins, M. B., Virginia, R. A., and Wall, D. H. (2001). Organic carbon cycling in Taylor Valley, Antarctica: quantifying soil reservoirs and soil respiration. Global Change Biology, 7(1):113-125.

Burn, C. R. (1997). Cryostratigraphy, paleogeography, and climate change during the early Holocene warm interval, western Arctic coast, Canada. Canadian Journal of Earth Sciences, 34(7):912-925.

Buurman, P., Jongmans, A., and PiPujol, M. (1998). Clay illuviation and mechanical clay infiltration-is there a difference? Quaternary International, 51:66-69.

Bölter, M. and Beyer, L. (2002). Maritime and continental antarctic: the sites of investigation in context. In Geoecology of Antarctic Ice-Free Coastal Landscapes, pages 17-22. Springer.

Bölter, M., Beyer, L., and Stonehouse, B. (2002). Antarctic coastal landscapes: characteristics, ecology and research. In Geoecology of Antarctic Ice-Free Coastal Landscapes, pages 5-15. Springer.

Campbell, I. (2003). Soil characteristics at a long-term ecological research site in Taylor Valley, Antarctica. Soil Research, 41(3):351-364.

Campbell, I. and Claridge, G. (1987). Antarctica: soils, weathering processes and environment. Elsevier.

Campbell, I., Claridge, G., and Balks, M. (1998a). Short-and long-term impacts of human disturbances on snow-free surfaces in Antarctica. Polar Record, 34(188):15-24.

Campbell, I., Claridge, G., Balks, M., and Campbell, D. (1997). Moisture content in soils of the McMurdo Sound and Dry Valley region of Antarctica. In Ecosystem processes in Antarctic ice-free landscapes. Proceedings of an International workshop on Polar Desert Ecosystems, Christchurch New Zealand, 1-4 July 1996, pages 61-76. 
Campbell, I., Claridge, G., and Balks, M. R. (1994). The effect of human activities on moisture content of soils and underlying permafrost from the McMurdo Sound region, Antarctica. Antarctic Science, 6(3):307-314.

Campbell, I. and Claridge, G. G. (2006). Permafrost properties, patterns and processes in the Transantarctic Mountains region. Permafrost and Periglacial Processes, 17(3):215-232.

Campbell, I., Claridge, G. G., Campbell, D. I., and Balks, M. R. (1998b). The Soil Environment of the McMurdo Dry Valleys, Antarctica. In Ecosystem Dynamics in a Polar Desert: the Mcmurdo Dry Valleys, Antarctica, Antarctic Research Series, pages 297-322. American Geophysical Union, Washington, DC.

Cary, S. C., McDonald, I. R., Barrett, J. E., and Cowan, D. A. (2010). On the rocks: the microbiology of Antarctic Dry Valley soils. Nature Reviews Microbiology, 8:129-138.

Cerling, T. E., Harris, J. M., MacFadden, B. J., Leakey, M. G., Quade, J., Eisenmann, V., and Ehleringer, J. R. (1997). Global vegetation change through the Miocene/Pliocene boundary. Nature, 389(6647):153-158.

Chan-Yam, K., Goordial, J., Greer, C., Davila, A., McKay, C. P., and Whyte, L. G. (2019). Microbial activity and habitability of an Antarctic Dry Valley water track. Astrobiology, 19(6):757-770.

Chinn, T. J. (1993). Physical hydrology of the Dry Valley lakes. In Physical and Biogeochemical Processes in Antarctic Lakes, pages 1-51. American Geophysical Union (AGU).

Chorley, H. (2020). Antarctic ice sheet and climate evolution during the mid-Miocene. $\mathrm{PhD}$ thesis, Victoria University of Wellington, New Zealand.

Chorley, H., Levy, R., Naish, T., Lewis, A., Cox, S., Hemming, S., Ohneiser, C., Gorman, A., Harper, M., Prebble, J., Verret, M., Dickinson, W., Florindo, F., Golledge, N., Halberstadt, A., Kowalewski, D., McKay, R., Myers, S., and Pyne, R. (in review). Antarctic ice sheet evolution and variability during the mid-Miocene climate transition $(\sim 15.1-13.8 \mathrm{Ma})$, from the Friis Hills, Antarctica. Geological Society of America Bulletin.

Claridge, G. and Campbell, I. (1968). Origin of nitrate deposits. Nature, 217(5127):428-430.

Claridge, G. and Campbell, I. (1977). The salts in Antarctic soils, their distribution and relationship to soil processes. Soil Science, 123(6):377-384.

Cleveland, C. C. and Liptzin, D. (2007). C:N:P stoichiometry in soil: is there a "Redfield ratio" for the microbial biomass? Biogeochemistry, 85(3):235-252.

Conovitz, P. A., McKnight, D. M., MacDonald, L. H., and Fountain, A. G. (1998). Hydrological processes influencing streamflow variation in Fryxell Basin, Antarctica. In Ecosystem Dynamics in a Polar Desert: The McMurdo Dry Valleys, Antarctica, volume 72, page 93-108. Wiley Online Library, Washington, DC.

Cook, C. P., Van De Flierdt, T., Williams, T., Hemming, S. R., Iwai, M., Kobayashi, M., Jimenez-Espejo, F. J., Escutia, C., González, J. J., and Khim, B.-K. (2013). Dynamic behaviour of the East Antarctic Ice Sheet during Pliocene warmth. Nature Geoscience, 6(9):765-769. 
Coulombe, S., Fortier, D., Lacelle, D., Kanevskiy, M., and Shur, Y. (2019). Origin, burial and preservation of late Pleistocene-age glacier ice in Arctic permafrost (Bylot Island, NU, Canada). The Cryosphere, 13(1):97-111.

Courtright, E. M., Wall, D. H., and Virginia, R. A. (2001). Determining habitat suitability for soil invertebrates in an extreme environment: the McMurdo Dry Valleys, Antarctica. Antarctic Science, 13(1):9-17.

Cowan, D. A., Makhalanyane, T. P., Dennis, P. G., and Hopkins, D. W. (2014). Microbial ecology and biogeochemistry of continental Antarctic soils. Frontiers in Microbiology, $5: 154$.

Cowan, D. A., Sohm, J. A., Makhalanyane, T. P., Capone, D. G., Green, T., Cary, S., and Tuffin, I. (2011). Hypolithic communities: important nitrogen sources in Antarctic desert soils. Environmental Microbiology Reports, 3(5):581-586.

Craig, H. (1961). Isotopic variations in meteoric waters. Science, 133(3465):1702-1703.

Craig, H. (1965). The measurement of oxygen isotope paleotemperatures. In Stable Isotopes in Oceanographic Studies and Paleotemperatures. Proceedings of the Third Spoleto Conference, Spoleto, Italy, pages 161-182.

Craig, H., Gordon, L., and Horibe, Y. (1963). Isotopic exchange effects in the evaporation of water: 1. low-temperature experimental results. Journal of Geophysical Research, 68(17):5079-5087.

Craig, H. and Gordon, L. I. (1965). Deuterium and oxygen 18 variations in the ocean and the marine atmosphere. In Stable isotopes in oceanographic studies and paleotemperatures, Laboratorio di Geologia Nucleare, Pisa.

Criss, R. (1999). Principles of stable isotope distribution. Oxford University.

Dahl-Jensen, D., Albert, M., Aldahan, A., Azuma, N., Balslev-Clausen, D., Baumgartner, M., Berggren, A.-M., Bigler, M., Binder, T., and Blunier, T. (2013). Eemian interglacial reconstructed from a Greenland folded ice core. Nature, 493(7433):489-494.

Dansgaard, W. (1964). Stable isotopes in precipitation. Tellus, 16(4):436-468.

Darvill, C. M. (2013). Cosmogenic nuclide analysis. In Geomorphological Techniques. London, UK : British Society for Geomorphology, pages 1-25.

De Angelis, R., Melino, S., Prosposito, P., Casalboni, M., Lamastra, F. R., Nanni, F., Bruno, L., and Congestri, R. (2016). The diatom Staurosirella pinnata for photoactive material production. PloS one, 11(11):E0165571.

De Boer, B., Van de Wal, R., Bintanja, R., Lourens, L., and Tuenter, E. (2010). Cenozoic global ice-volume and temperature simulations with 1-D ice-sheet models forced by benthic $\delta^{18} \mathrm{O}$ records. Annals of Glaciology, 51(55):23-33.

Delmas, R. J., Legrand, M., Aristarain, A. J., and Zanolini, F. (1985). Volcanic deposits in Antarctic snow and ice. Journal of Geophysical Research: Atmospheres, 90(D7):1290112920. 
Delord, K., Kato, A., Tarroux, A., Orgeret, F., Cotté, C., Ropert-Coudert, Y., Cherel, Y., and Descamps, S. (2020). Antarctic petrels 'on the ice rocks': wintering strategy of an Antarctic seabird. Royal Society Open Science, 7(4):191429.

Dennis, P. G., Sparrow, A. D., Gregorich, E. G., Novis, P. M., Elberling, B., Greenfield, L. G., and Hopkins, D. W. (2013). Microbial responses to carbon and nitrogen supplementation in an Antarctic Dry Valley soil. Antarctic Science, 25(1):55-61.

Denton, G., Prentice, M. L., Kellogg, D. E., and Kellogg, T. B. (1984). Late Tertiary history of the Antarctic ice sheet: Evidence from the Dry Valleys. Geology, 12(5):263-267.

Denton, G. and Sugden, D. (2005). Meltwater features that suggest Miocene ice-sheet overriding of the Transantarctic Mountains in Victoria Land, Antarctica. Geografiska Annaler: Series A, Physical Geography, 87(1):67-85.

Denton, G., Sugden, D. E., Marchant, D., Hall, B. L., and Wilch, T. I. (1993). East Antarctic ice sheet sensitivity to Pliocene climatic change from a Dry Valleys perspective. Geografiska Annaler: Series A, Physical Geography, 75(4):155-204.

Dickinson, W. W. and Rosen, M. R. (2003). Antarctic permafrost: an analogue for water and diagenetic minerals on Mars. Geology, 31(3):199-202.

Dickinson, W. W., Schiller, M., Ditchburn, B. G., Graham, I. J., and Zondervan, A. (2012). Meteoric Be-10 from Sirius Group suggests high elevation McMurdo Dry Valleys permanently frozen since 6 Ma. Earth and Planetary Science Letters, 355:13-19.

Diefendorf, A. F., Mueller, K. E., Wing, S. L., Koch, P. L., and Freeman, K. H. (2010). Global patterns in leaf ${ }^{13} \mathrm{C}$ discrimination and implications for studies of past and future climate. Proceedings of the National Academy of Sciences, 107(13):5738-5743.

Ditchburn, R. G. and Graham, I. (2002). Preparation procedures for the ${ }^{10}$ Be analysis of marine deposits. Institute of Geological \& Nuclear Sciences science report 2003/10, Lower Hutt, NZ.

Doran, P. T., McKay, C. P., Clow, G. D., Dana, G. L., Fountain, A. G., Nylen, T., and Lyons, W. (2002). Valley floor climate observations from the McMurdo Dry Valleys, Antarctica, 1986-2000. Journal of Geophysical Research: Atmospheres, 107(D24):ACL13 1-12.

Dredge, L., Kerr, D., and Wolfe, S. (1999). Surficial materials and related ground ice conditions, Slave Province, N.W.T., Canada. Canadian Journal of Earth Sciences, 36(1):12271238.

Dunai, T. (2001). Influence of secular variation of the geomagnetic field on production rates of in situ produced cosmogenic nuclides. Earth and Planetary Science Letters, 193(1-2):197-212.

Dunbar, G. B., Naish, T., Barrett, P. J., Fielding, C. R., and Powell, R. (2008). Constraining the amplitude of late Oligocene bathymetric changes in Western Ross Sea during orbitallyinduced oscillations in the East Antarctic Ice Sheet:(1) implications for glacimarine sequence stratigraphic models. Palaeogeography, Palaeoclimatology, Palaeoecology, 260(1-2):50-65. 
Dunton, K. H. (2001). $\delta^{15} \mathrm{~N}$ and $\delta^{13} \mathrm{C}$ measurements of Antarctic Peninsula fauna: trophic relationships and assimilation of benthic seaweeds. American Zoologist, 41(1):99-112.

Dyke, A. S. and Savelle, J. M. (2000). Major end moraines of Younger Dryas age on Wollaston Peninsula, Victoria Island, Canadian Arctic: implications for paleoclimate and for formation of hummocky moraine. Canadian Journal of Earth Sciences, 37(4):601-619.

Ebert, K., Willenbring, J., Norton, K. P., Hall, A., and Hättestrand, C. (2012). Meteoric ${ }^{10}$ Be concentrations from saprolite and till in northern Sweden: implications for glacial erosion and age. Quaternary Geochronology, 12:11-22.

Ehleringer, J. R. and Monson, R. K. (1993). Evolutionary and ecological aspects of photosynthetic pathway variation. Annual Review of Ecology and Systematics, 24(1):411-439.

Elberling, B., Gregorich, E., Hopkins, D., Sparrow, A., Novis, P., and Greenfield, L. (2006). Distribution and dynamics of soil organic matter in an Antarctic Dry Valley. Soil Biology and Biochemistry, 38(10):3095-3106.

Elston, D. and Bressler, S. (1981). Magneto-stratigraphic studies in Neogene deposits of Taylor Valley and McMurdo Sound, Antarctica. Journal of the Royal Society of New Zealand, 11(4):481-486.

Elston, D., Rieck, H., and Robinson, P. (1983). Dry Valleys/McMurdo Sound magnetostratigraphy and sedimentology. Antarctic Journal of the US, 18(5):29-31.

Evans, D., Phillips, E., Hiemstra, J., and Auton, C. (2006). Subglacial till: formation, sedimentary characteristics and classification. Earth-Science Reviews, 78(1-2):115-176.

Everett, K. (1971). Soils of the Meserve Glacier area, Wright Valley, south Victoria Land, Antarctica. Soil Science, 112(6):425-438.

Farquhar, G. D., von Caemmerer, S., and Berry, J. (1980). A biochemical model of photosynthetic $\mathrm{CO}_{2}$ assimilation in leaves of C3 species. Planta, 149(1):78-90.

Faucher, B. (2017). Distribution, Source and Cycling of Organic Carbon and Nitrogen in the Icy Soils of University Valley (McMurdo Dry Valleys of Antarctica). Masters thesis.

Faucher, B., Lacelle, D., Davila, A., Pollard, W., Fisher, D., and McKay, C. P. (2017). Physicochemical and biological controls on carbon and nitrogen in permafrost from an ultraxerous environment, McMurdo Dry Valleys of Antarctica. Journal of Geophysical Research: Biogeosciences, 122(10):2593-2604.

Feakins, S. J., Warny, S., and Lee, J.-E. (2012). Hydrologic cycling over Antarctica during the middle Miocene warming. Nature Geoscience, 5(8):557-560.

Feng, X., Simpson, A. J., Gregorich, E. G., Elberling, B., Hopkins, D. W., Sparrow, A. D., Novis, P. M., Greenfield, L. G., and Simpson, M. J. (2010). Chemical characterization of microbial-dominated soil organic matter in the Garwood Valley, Antarctica. Geochimica et Cosmochimica Acta, 74(22):6485-6498.

Field, A. B. (1975). The geochemistry of soluble salts in the Wright and Taylor Valleys, South Victoria Land, Antarctica. PhD thesis, University of Waikato, New Zealand. 
Field, C. V., Schmidt, G. A., Koch, D., and Salyk, C. (2006). Modeling production and climate-related impacts on ${ }^{10} \mathrm{Be}$ concentration in ice cores. Journal of Geophysical Research: Atmospheres, 111(D15).

Fielding, C. R., Browne, G. H., Field, B., Florindo, F., Harwood, D. M., Krissek, L. A., Levy, R. H., Panter, K. S., Passchier, S., and Pekar, S. F. (2011). Sequence stratigraphy of the ANDRILL AND-2A drillcore, Antarctica: a long-term, ice-proximal record of Early to Mid-Miocene climate, sea-level and glacial dynamism. Palaeogeography, Palaeoclimatology, Palaeoecology, 305(1-4):337-351.

Fielding, C. R., Harwood, D. M., Winter, D. M., and Francis, J. E. (2012). Neogene stratigraphy of Taylor Valley, Transantarctic Mountains, Antarctica: evidence for climate dynamism and a vegetated early Pliocene coastline of McMurdo Sound. Global and Planetary Change, 96:97-104.

Finegold, L. (1996). Molecular and biophysical aspects of adaptation of life to temperatures below the freezing point. Advances in Space Research, 18(12):87-95.

Finkel, R. and Nishiizumi, K. (1997). Beryllium-10 concentrations in the Greenland Ice Sheet Project 2 ice core from 3-40 ka. Journal of Geophysical Research: Oceans, 102(C12):26699-26706.

Fisher, D. (2005). A process to make massive ice in the Martian regolith using long-term diffusion and thermal cracking. Icarus, 179(2):387-397.

Fisher, D., Lacelle, D., and Pollard, W. (2019). A model of unfrozen water content and its transport in icy permafrost soils: effects on ground ice content and permafrost stability. Permafrost and Periglacial Processes, 31(1):1-16.

Fisher, D., Lacelle, D., Pollard, W., Davila, A., and McKay, C. P. (2016). Ground surface temperature and humidity, ground temperature cycles and the ice table depths in University Valley, McMurdo Dry Valleys of Antarctica. Journal of Geophysical Research: Earth Surface, 121(11):2069-2084.

Fisher, D., Wake, C., Kreutz, K., Yalcin, K., Steig, E., Mayewski, P., Anderson, L., Zheng, J., Rupper, S., and Zdanowicz, C. (2004). Stable isotope records from Mount Logan, Eclipse ice cores and nearby Jellybean Lake. Water cycle of the North Pacific over 2000 years and over five vertical kilometres: sudden shifts and tropical connections. Géographie physique et Quaternaire, 58(2-3):337-352.

Fisher, D. A., Lacelle, D., Pollard, W., and Faucher, B. (2020). A model for stable isotopes of residual liquid water and ground ice in permafrost soils using arbitrary water chemistries and soil-specific empirical residual water functions. Permafrost and Periglacial Processes.

Fitzgerald, P. (1992). The Transantarctic Mountains of southern Victoria Land: the application of apatite fission track analysis to a rift shoulder uplift. Tectonics, 11(3):634-662.

Fitzgerald, P. (2002). Tectonics and landscape evolution of the Antarctic plate since the breakup of Gondwana, with an emphasis on the West Antarctic Rift System and the Transantarctic Mountains. Royal Society of New Zealand Bulletin, 35:453-469. 
Flower, B. P. and Kennett, J. P. (1994). The middle Miocene climatic transition: East Antarctic Ice Sheet development, deep ocean circulation and global carbon cycling. Palaeogeography, Palaeoclimatology, Palaeoecology, 108(3-4):537-555.

Fortner, S. K., Tranter, M., Fountain, A., Lyons, W. B., and Welch, K. A. (2005). The geochemistry of supraglacial streams of Canada Glacier, Taylor Valley (Antarctica), and their evolution into proglacial waters. Aquatic Geochemistry, 11(4):391-412.

Foster, G. L., Lear, C. H., and Rae, J. W. (2012). The evolution of $\rho \mathrm{CO}_{2}$, ice volume and climate during the middle Miocene. Earth and Planetary Science Letters, 341:243-254.

Foster, G. L., Royer, D. L., and Lunt, D. J. (2017). Future climate forcing potentially without precedent in the last 420 million years. Nature Communications, 8:14845.

Fountain, A. and Doran, P. (2016). Mcmurdo Dry Valleys Friis Hills meteorological station daily averages. Environmental Data Initiative. DOI: 10.6073/pasta/9dda244e95ce8dfcdbd9b94d2289ef1d.

Fountain, A., Lyons, W. B., Burkins, M. B., Dana, G. L., Doran, P. T., Lewis, K. J., McKnight, D. M., Moorhead, D. L., Parsons, A. N., and Priscu, J. C. (1999). Physical controls on the Taylor Valley ecosystem, Antarctica. Bioscience, 49(12):961-971.

Fountain, A., Nylen, T. H., MacClune, K. L., and Dana, G. L. (2006). Glacier mass balances (1993-2001), Taylor Valley, McMurdo Dry Valleys, Antarctica. Journal of Glaciology, 52(178):451-462.

Fountain, A., Nylen, T. H., Monaghan, A., Basagic, H. J., and Bromwich, D. (2010). Snow in the McMurdo Dry Valleys, Antarctica. International Journal of Climatology: A Journal of the Royal Meteorological Society, 30(5):633-642.

Francis, J. E. and Hill, R. S. (1996). Fossil plants from the Pliocene Sirius Group, Transantarctic Mountains; evidence for climate from growth rings and fossil leaves. Palaios, 11(4):389396.

French, H. (2017). The periglacial environment. chapter Ground Ice and Cryostratigraphy, pages 111-137. John Wiley \& Sons, 4th edition.

French, H. and Harry, D. (1990). Observations on buried glacier ice and massive segregated ice, western Arctic coast, Canada. Permafrost and Periglacial Processes, 1(1):31-43.

French, H. and Shur, Y. (2010). The principles of cryostratigraphy. Earth-Science Reviews, 101(3-4):190-206.

Friedmann, E., Gilichinsky, D., Wilson, G., Ostroumov, V., Vorobyova, E., Soina, V., Shcherbakova, V., Vishnivetskaya, T., Chanton, J., and Friedmann, R. (1996). Viable bacteria, methane and high ice content in Antarctic permafrost: relevance to Mars. Origins of Life and Evolution of the Biosphere, 26(3):303-303.

Friedmann, E. I. (1978). Melting snow in the Dry Valleys is a source of water for endolithic microorganisms. Antarctic Journal of the United States, 13(4):162-163. 
Friedmann, E. I. (1982). Endolithic microorganisms in the Antarctic cold desert. Science, 215(4536):1045-1053.

Friedmann, E. I., Kappen, L., Meyer, M., and Nienow, J. A. (1993). Long-term productivity in the cryptoendolithic microbial community of the Ross Desert, Antarctica. Microbial Ecology, 25(1):51-69.

Friedmann, E. I. and Ocampo, R. (1976). Endolithic blue-green algae in the Dry Valleys: primary producers in the Antarctic desert ecosystem. Science, 193(4259):1247-1249.

Fritz, M., Wetterich, S., Meyer, H., Schirrmeister, L., Lantuit, H., and Pollard, W. H. (2011). Origin and characteristics of massive ground ice on Herschel Island (western Canadian Arctic) as revealed by stable water isotope and hydrochemical signatures. Permafrost and Periglacial Processes, 22(1):26-38.

Gasson, E., DeConto, R. M., and Pollard, D. (2016). Modeling the oxygen isotope composition of the Antarctic ice sheet and its significance to Pliocene sea level. Geology, 44(10):827-830.

Gentsch, N., Mikutta, R., Shibistova, O., Wild, B., Schnecker, J., Richter, A., Urich, T., Gittel, A., Šantrůčková, H., and Barta, J. (2015). Properties and bioavailability of particulate and mineral-associated organic matter in Arctic permafrost soils, Lower Kolyma Region, Russia. European Journal of Soil Science, 66(4):722-734.

Gibson, E. K., Wentworth, S. J., and McKay, D. S. (1983). Chemical weathering and diagenesis of a cold desert soil from Wright Valley, Antarctica: an analog of Martian weathering processes. Journal of Geophysical Research: Solid Earth, 88(S02):A912A928.

Gilichinsky, D., Nolte, E., Basilyan, A., Beer, J., Blinov, A., Lazarev, V., Kholodov, A., Meyer, H., Nikolskiy, P., and Schirrmeister, L. (2007a). Dating of syngenetic ice wedges in permafrost with ${ }^{36} \mathrm{Cl}$. Quaternary Science Reviews, 26(11-12):1547-1556.

Gilichinsky, D., Vishnivetskaya, T., Petrova, M., Spirina, E., Mamykin, V., and Rivkina, E. (2008). Bacteria in permafrost. In Psychrophiles: from biodiversity to biotechnology, pages 83-102. Springer.

Gilichinsky, D., Wagener, S., and Vishnevetskaya, T. (1995). Permafrost microbiology. Permafrost and Periglacial Processes, 6(4):281-291.

Gilichinsky, D., Wilson, G., Friedmann, E., McKay, C., Sletten, R., Rivkina, E., Vishnivetskaya, T., Erokhina, L., Ivanushkina, N., and Kochkina, G. (2007b). Microbial populations in Antarctic permafrost: biodiversity, state, age, and implication for astrobiology. Astrobiology, 7(2):275-311.

Goff, J. R., Jennings, I. W., and Dickinson, W. W. (2002). Depositional environment of Sirius Group sediments, Table mountain, Dry Valleys area, Antarctica. Geografiska Annaler: Series A, Physical Geography, 84(1):11-24.

Gonfiantini, R. (1986). Environmental isotopes in lake studies. Handbook of environmental isotope geochemistry, 2:113-168. 
Goordial, J., Davila, A., Lacelle, D., Pollard, W., Marinova, M. M., Greer, C. W., DiRuggiero, J., McKay, C. P., and Whyte, L. G. (2016). Nearing the cold-arid limits of microbial life in permafrost of an upper Dry Valley, Antarctica. The ISME journal, 10(7):1613-1624.

Gooseff, M. N., Barrett, J. E., Doran, P. T., Fountain, A. G., Lyons, W. B., Parsons, A. N., Porazinska, D. L., Virginia, R. A., and Wall, D. H. (2003). Snow-patch influence on soil biogeochemical processes and invertebrate distribution in the McMurdo Dry Valleys, Antarctica. Arctic, Antarctic, and Alpine Research, 35(1):91-99.

Gooseff, M. N., Lyons, W., McKnight, D. M., Vaughn, B. H., Fountain, A. G., and Dowling, C. (2006). A stable isotopic investigation of a polar desert hydrologic system, McMurdo Dry Valleys, Antarctica. Arctic, Antarctic, and Alpine Research, 38(1):60-71.

Gooseff, M. N., McKnight, D. M., Lyons, W. B., and Blum, A. E. (2002). Weathering reactions and hyporheic exchange controls on stream water chemistry in a glacial meltwater stream in the McMurdo Dry Valleys. Water Resources Research, 38(12):15-1-15-17.

Gosse, J. C. and Phillips, F. M. (2001). Terrestrial in situ cosmogenic nuclides: theory and application. Quaternary Science Reviews, 20(14):1475-1560.

Graham, I., Ditchburn, R., and Whitehead, N. (2001). Be isotope analysis of a 0-500 ka loess-paleosol sequence from Rangitatau East, New Zealand. Quaternary International, 76:29-42.

Graham, I., Ditchburn, R. G., Claridge, G. G., Whitehead, N. E., Zondervan, A., and Sheppard, D. S. (2002). Dating Antarctic soils using atmosphere-derived ${ }^{10} \mathrm{Be}$ and nitrate. In Antarctica at the close of a millennium: proceedings of the 8th International Symposium on Antarctic Earth Sciences, Wellington 1999.

Graly, J. A., Corbett, L. B., Bierman, P. R., Lini, A., and Neumann, T. A. (2018). Meteoric ${ }^{10} \mathrm{Be}$ as a tracer of subglacial processes and interglacial surface exposure in Greenland. Quaternary Science Reviews, 191:118-131.

Greenfield, L. (1997). Nitrogen in soil Nostoc mats: forms, release and implications for nutrient cycling in Antarctica. New Zealand Natural Sciences, 23:101-107.

Greenfield, S., Tighe, S. W., Bai, Y., Goerlitz, D. S., Von Turkovich, M., Taatjes, D. J., Dragon, J. A., and Johnson, S. S. (2020). Life and its traces in Antarctica's McMurdo Dry Valley paleolakes: a survey of preservation. Micron, 131:102818.

Greenop, R., Foster, G. L., Wilson, P. A., and Lear, C. H. (2014). Middle Miocene climate instability associated with high-amplitude $\mathrm{CO}_{2}$ variability. Paleoceanography, 29(9):845853.

Grootes, P. M., Steig, E. J., Stuiver, M., Waddington, E. D., Morse, D. L., and Nadeau, M.-J. (2001). The Taylor Dome Antarctic ${ }^{18} \mathrm{O}$ record and globally synchronous changes in climate. Quaternary Research, 56(3):289-298.

Guelke-Stelling, M. and von Blanckenburg, F. (2012). Fe isotope fractionation caused by translocation of iron during growth of bean and oat as models of strategy I and II plants. Plant and Soil, 352(1-2):217-231. 
Guglielmin, M. (2012). Advances in permafrost and periglacial research in Antarctica: a review. Geomorphology, 155:1-6.

Gulick, S. P., Shevenell, A. E., Montelli, A., Fernandez, R., Smith, C., Warny, S., Bohaty, S. M., Sjunneskog, C., Leventer, A., and Frederick, B. (2017). Initiation and long-term instability of the East Antarctic Ice Sheet. Nature, 552(7684):225-229.

Hagedorn, B., Sletten, R. S., and Hallet, B. (2007). Sublimation and ice condensation in hyperarid soils: modeling results using field data from Victoria Valley, Antarctica. Journal of Geophysical Research: Earth Surface, 112(F3).

Hagedorn, B., Sletten, R. S., Hallet, B., McTigue, D. F., and Steig, E. J. (2010). Ground ice recharge via brine transport in frozen soils of Victoria Valley, Antarctica: insights from modeling $\delta^{18} \mathrm{O}$ and $\delta \mathrm{D}$ profiles. Geochimica et Cosmochimica Acta, 74(2):435-448.

Haldorsen, S. (1981). Grain-size distribution of subglacial till and its realation to glacial crushing and abrasion. Boreas, 10(1):91-105.

Hall, B. L., Denton, G. H., Lux, D. R., and Bockheim, J. G. (1993). Late Tertiary Antarctic paleoclimate and ice-sheet dynamics inferred from surficial deposits in Wright Valley. Geografiska Annaler: Series A, Physical Geography, 75(4):239-267.

Hambrey, M. (1997). Cape Roberts Project: core logging manual, volume 21 of Antarctic data series. Victoria University of Wellington, Research School of Earth Sciences.

Hambrey, M. J. and McKelvey, B. (2000). Major Neogene fluctuations of the East Antarctic Ice Sheet: stratigraphic evidence from the Lambert Glacier region. Geology, 28(10):887890.

Hare, V. J., Loftus, E., Jeffrey, A., and Ramsey, C. B. (2018). Atmospheric $\mathrm{CO}_{2}$ effect on stable carbon isotope composition of terrestrial fossil archives. Nature communications, 9(1):1-8.

Harris, C. and Murton, J. B. (2005). Interactions between glaciers and permafrost: an introduction. Geological Society, London, Special Publications, 242(1):1-9.

Harris, S., French, H., Heginbottom, J., Johnston, G., Ladanyi, B., Sego, D., and Van Everdingen, R. (1988). Glossary of permafrost and related ground-ice terms. Number 142 in Technical Memorandum. National Research Council Canada.

Hassinger, J. M. and Mayewski, P. A. (1983). Morphology and dynamics of the rock glaciers in southern Victoria Land, Antarctica. Arctic and Alpine Research, 15(3):351-368.

Heikkilä, U. (2007). Modeling of the atmospheric transport of the cosmogenic radionuclides ${ }^{10} \mathrm{Be}$ and ${ }^{7} \mathrm{Be}$ using the ECHAM5-HAM general circulation model. PhD thesis, ETH Zurich, Switzerland.

Heikkilä, U., Beer, J., Abreu, J., and Steinhilber, F. (2013). On the atmospheric transport and deposition of the cosmogenic radionuclides $\left({ }^{10} \mathrm{Be}\right)$ : a review. Space Science Reviews, 176(1-4):321-332. 
Heikkilä, U. and Von Blanckenburg, F. (2015). The global distribution of Holocene meteoric ${ }^{10} \mathrm{Be}$ fluxes from atmospheric models. Distribution maps for terrestrial Earth surface applications. GFZ Data Services. DOI: 10.5880/GFZ.3.4.2015.001.

Heiri, O., Lotter, A. F., and Lemcke, G. (2001). Loss on ignition as a method for estimating organic and carbonate content in sediments: reproducibility and comparability of results. Journal of Paleolimnology, 25(1):101-110.

Heldmann, J., Marinova, M., Williams, K., Lacelle, D., McKay, C., Davila, A., Pollard, W., and Andersen, D. (2012). Formation and evolution of buried snowpack deposits in Pearse Valley, Antarctica, and implications for Mars. Antarctic Science, 24(3):299-316.

Heldmann, J., Pollard, W., McKay, C., Marinova, M., Davila, A., Williams, K., Lacelle, D., and Andersen, D. (2013). The high elevation Dry Valleys in Antarctica as analog sites for subsurface ice on Mars. Planetary and Space Science, 85:53-58.

Herbert, T. D., Lawrence, K. T., Tzanova, A., Peterson, L. C., Caballero-Gill, R., and Kelly, C. S. (2016). Late Miocene global cooling and the rise of modern ecosystems. Nature Geoscience, 9(11):843-847.

Herod, M. N., Clark, I. D., Kieser, W., Agosta, S., and Zhao, X.-L. (2013). ${ }^{129}$ I dispersion and sources in Northwest Canada. Nuclear Instruments and Methods in Physics Research Section B: Beam Interactions with Materials and Atoms, 294:552-558.

Herold, N., Huber, M., Müller, R., and Seton, M. (2012). Modeling the Miocene climatic optimum: ocean circulation. Paleoceanography, 27(1).

Higgins, S. M., Hendy, C. H., and Denton, G. H. (2000). Geochronology of Bonney drift, Taylor Valley, Antarctica: evidence for interglacial expansions of Taylor Glacier. Geografiska Annaler: Series A, Physical Geography, 82(2-3):391-409.

Hindmarsh, R., Van der Wateren, F., and Verbers, A. L. (1998). Sublimation of ice through sediment in Beacon Valley, Antarctica. Geografiska Annaler: Series A, Physical Geography, 80(3-4):209-219.

Hobson, K. A. and Welch, H. E. (1992). Determination of trophic relationships within a high Arctic marine food web using $\delta^{13} \mathrm{C}$ and $\delta^{15} \mathrm{~N}$ analysis. Marine Ecology Progress Series, 84:9-18.

Hogg, A. G., Heaton, T. J., Hua, Q., Palmer, J. G., Turney, C. S., Southon, J., Bayliss, A., Blackwell, P. G., Boswijk, G., and Ramsey, C. B. (2020). SHCal20 Southern Hemisphere calibration, 0-55,000 years cal BP. Radiocarbon, 62(4):759-778.

Holbourn, A., Kuhnt, W., Kochhann, K. G., Andersen, N., and Sebastian Meier, K. (2015). Global perturbation of the carbon cycle at the onset of the Miocene Climatic Optimum. Geology, 43(2):123-126.

Hopkins, D., Sparrow, A., Elberling, B., Gregorich, E., Novis, P., Greenfield, L., and Tilston, E. (2006a). Carbon, nitrogen and temperature controls on microbial activity in soils from an Antarctic Dry Valley. Soil Biology and Biochemistry, 38(10):3130-3140. 
Hopkins, D., Sparrow, A., Gregorich, E., Elberling, B., Novis, P., Fraser, F., Scrimgeour, C., Dennis, P., Meier-Augenstein, W., and Greenfield, L. (2009). Isotopic evidence for the provenance and turnover of organic carbon by soil microorganisms in the Antarctic Dry Valleys. Environmental Microbiology, 11(3):597-608.

Hopkins, D., Sparrow, A., Novis, P., Gregorich, E., Elberling, B., and Greenfield, L. (2006b). Controls on the distribution of productivity and organic resources in Antarctic Dry Valley soils. Proceedings of the Royal Society B: Biological Sciences, 273(1602):2687-2695.

Horita, J., Wesolowski, D. J., and Cole, D. R. (1993). The activity-composition relationship of oxygen and hydrogen isotopes in aqueous salt solutions: I. Vapor-liquid water equilibration of single salt solutions from 50 to $100^{\circ} \mathrm{C}$. Geochimica et Cosmochimica Acta, 57(12):27972817.

Horrocks, C., Newsham, K., Cox, F., Garnett, M., Robinson, C., and Dungait, J. (2020). Predicting climate change impacts on maritime Antarctic soils: a space-for-time substitution study. Soil Biology and Biochemistry, 141:107682.

Hrbáček, F., Vieira, G., Oliva, M., Balks, M., Guglielmin, M., de Pablo, M. A., Molina, A., Ramos, M., Goyanes, G., and Meiklejohn, I. (2018). Active layer monitoring in Antarctica: an overview of results from 2006 to 2015. Polar Geography, pages 1-15.

Hutchings, J., Bianchi, T., Kaufman, D. S., Kholodov, A., Vaughn, D., and Schuur, E. (2019). Millennial-scale carbon accumulation and molecular transformation in a permafrost core from Interior Alaska. Geochimica et Cosmochimica Acta, 253:231-248.

Iavorivska, L., Boyer, E. W., and DeWalle, D. R. (2016). Atmospheric deposition of organic carbon via precipitation. Atmospheric Environment, 146:153-163.

Ishiwatari, R. and Uzaki, M. (1987). Diagenetic changes of lignin compounds in a more than 0.6 million-year-old lacustrine sediment (Lake Biwa, Japan). Geochimica et Cosmochimica Acta, 51(2):321-328.

Ivy-Ochs, S., Schlüchter, C., Kubik, P. W., Dittrich-Hannen, B., and Beer, J. (1995). Minimum ${ }^{10} \mathrm{Be}$ exposure ages of early Pliocene for the Table Mountain plateau and the Sirius Group at Mount Fleming, Dry Valleys, Antarctica. Geology, 23(11):1007-1010.

Jackson, A., Davila, A. F., Böhlke, J. K., Sturchio, N. C., Sevanthi, R., Estrada, N., Brundrett, M., Lacelle, D., McKay, C. P., and Poghosyan, A. (2016). Deposition, accumulation, and alteration of $\mathrm{Cl}^{-}, \mathrm{NO}_{3}{ }^{-}, \mathrm{ClO}_{4}{ }^{-}$and $\mathrm{ClO}_{3}{ }^{-}$salts in a hyper-arid polar environment: mass balance and isotopic constraints. Geochimica et Cosmochimica Acta, 182:197-215.

Jacobs, B. F., Kingston, J. D., and Jacobs, L. L. (1999). The origin of grass-dominated ecosystems. Annals of the Missouri Botanical Garden, 86(2):590-643.

James, N. P. and Walker, R. G. (1992). Facies models: response to sea level change. Geological Association of Canada, 2nd edition.

Jelinski, N. A. (2014). Problems of physical movement in soil genesis: application of meteoric Beryllium-10 as a component of multi-tracer analysis. PhD thesis, University of Minnesota, United States. 
John, C. M., Karner, G. D., Browning, E., Leckie, R. M., Mateo, Z., Carson, B., and Lowery, C. (2011). Timing and magnitude of Miocene eustasy derived from the mixed siliciclasticcarbonate stratigraphic record of the northeastern Australian margin. Earth and Planetary Science Letters, 304(3-4):455-467.

Jouzel, J., Masson-Delmotte, V., Cattani, O., Dreyfus, G., Falourd, S., Hoffmann, G., Minster, B., Nouet, J., Barnola, J.-M., and Chappellaz, J. (2007). Orbital and millennial Antarctic climate variability over the past 800,000 years. Science, 317(5839):793-796.

Jouzel, J. and Souchez, R. (1982). Melting-refreezing at the glacier sole and the isotopic composition of the ice. Journal of Glaciology, 28(98):35-42.

Jull, A. T., Scott, E. M., and Bierman, P. (2015). The CRONUS-Earth inter-comparison for cosmogenic isotope analysis. Quaternary Geochronology, 26:3-10.

Kane, D. L., Hinkel, K. M., Goering, D. J., Hinzman, L. D., and Outcalt, S. I. (2001). Non-conductive heat transfer associated with frozen soils. Global and Planetary Change, 29(3-4):275-292.

Kaplanskaya, F. and Tarnogradskiy, V. (1986). Remnants of the Pleistocene ice sheets in the permafrost zone as an object for paleoglaciological research. Polar Geography, 10(4):257-266.

Kelly, W. C. and Zumberge, J. H. (1961). Weathering of a quartz diorite at Marble Point, McMurdo Sound, Antarctica. The Journal of Geology, 69(4):433-446.

Kennedy, K., Froese, D., Zazula, G., and Lauriol, B. (2010). Last Glacial Maximum age for the northwest Laurentide maximum from the Eagle River spillway and delta complex, northern Yukon. Quaternary Science Reviews, 29(9-10):1288-1300.

Keys, J. (1980). Salts and their distribution in the McMurdo region, Antarctica. $\mathrm{PhD}$ thesis, Victoria University of Wellington, New Zealand.

Keys, J. H. and Williams, K. (1981). Origin of crystalline, cold desert salts in the McMurdo region, Antarctica. Geochimica et Cosmochimica Acta, 45(12):2299-2309.

Kim, M., Lee, W., Suresh Kumar, K., Shin, K., Robarge, W., Kim, M., and Lee, S. R. (2016). Effects of $\mathrm{HCl}$ pretreatment, drying, and storage on the stable isotope ratios of soil and sediment samples. Rapid Communications in Mass Spectrometry, 30(13):1567-1575.

Koerner, R. and Fisher, D. (1982). Acid snow in the Canadian high Arctic. Nature, 295(5845):137-140.

Kohn, M. J. (2010). Carbon isotope compositions of terrestrial C3 plants as indicators of (paleo) ecology and (paleo) climate. Proceedings of the National Academy of Sciences, 107(46):19691-19695.

Kokelj, S. V., Lantz, T. C., Tunnicliffe, J., Segal, R., and Lacelle, D. (2017). Climatedriven thaw of permafrost preserved glacial landscapes, northwestern Canada. Geology, 45(4):371-374. 
Kowalewski, D. E., Marchant, D., Head III, J. W., and Jackson, D. W. (2012). A 2D model for characterising first-order variability in sublimation of buried glacier ice, Antarctica: assessing the influence of polygon troughs, desert pavements and shallow subsurface salts. Permafrost and Periglacial Processes, 23(1):1-14.

Kowalewski, D. E., Marchant, D. R., Swanger, K. M., and Head III, J. W. (2011). Modeling vapor diffusion within cold and dry supraglacial tills of Antarctica: implications for the preservation of ancient ice. Geomorphology, 126(1-2):159-173.

Kulhanek, D. K., Levy, R. H., Clowes, C. D., Prebble, J. G., Rodelli, D., Jovane, L., Morgans, H. E., Kraus, C., Zwingmann, H., and Griffith, E. M. (2019). Revised chronostratigraphy of DSDP Site 270 and late Oligocene to early Miocene paleoecology of the Ross Sea sector of Antarctica. Global and planetary change, 178:46-64.

Körner, C. (1998). A re-assessment of high elevation treeline positions and their explanation. Oecologia, 115(4):445-459.

Lacelle, D. (2011). On the $\delta^{18} \mathrm{O}, \delta \mathrm{D}$ and D-excess relations in meteoric precipitation and during equilibrium freezing: theoretical approach and field examples. Permafrost and Periglacial Processes, 22(1):13-25.

Lacelle, D., Bjornson, J., Lauriol, B., Clark, I., and Troutet, Y. (2004). Segregated-intrusive ice of subglacial meltwater origin in retrogressive thaw flow headwalls, Richardson Mountains, NWT, Canada. Quaternary Science Reviews, 23(5-6):681-696.

Lacelle, D., Davila, A. F., Fisher, D., Pollard, W. H., DeWitt, R., Heldmann, J., Marinova, M. M., and McKay, C. P. (2013a). Excess ground ice of condensation-diffusion origin in University Valley, Dry Valleys of Antarctica: evidence from isotope geochemistry and numerical modeling. Geochimica et Cosmochimica Acta, 120:280-297.

Lacelle, D., Davila, A. F., Pollard, W. H., Andersen, D., Heldmann, J., Marinova, M., and McKay, C. P. (2011). Stability of massive ground ice bodies in University Valley, McMurdo Dry Valleys of Antarctica: using stable $\mathrm{O}-\mathrm{H}$ isotope as tracers of sublimation in hyper-arid regions. Earth and Planetary Science Letters, 301(1-2):403-411.

Lacelle, D., Fisher, D. A., Coulombe, S., Fortier, D., and Frappier, R. (2018). Buried remnants of the Laurentide Ice Sheet and connections to its surface elevation. Scientific Reports, 8(1):1-10.

Lacelle, D., Fontaine, M., Pellerin, A., Kokelj, S. V., and Clark, I. D. (2019). Legacy of Holocene landscape changes on soil biogeochemistry: a perspective from paleoactive layers in northwestern Canada. Journal of Geophysical Research: Biogeosciences, 124(9):2662-2679.

Lacelle, D., Lapalme, C., Davila, A. F., Pollard, W., Marinova, M., Heldmann, J., and McKay, C. P. (2016). Solar radiation and air and ground temperature relations in the cold and hyper-arid Quartermain Mountains, McMurdo Dry Valleys of Antarctica. Permafrost and Periglacial Processes, 27(2):163-176.

Lacelle, D., Lauriol, B., Zazula, G., Ghaleb, B., Utting, N., and Clark, I. D. (2013b). Timing of advance and basal condition of the Laurentide Ice Sheet during the last glacial maximum in the Richardson Mountains, NWT. Quaternary Research, 80(2):274-283. 
Lacelle, D., St-Jean, M., Lauriol, B., Clark, I. D., Lewkowicz, A., Froese, D. G., Kuehn, S. C., and Zazula, G. (2009). Burial and preservation of a 30,000 year old perennial snowbank in Red Creek valley, Ogilvie Mountains, central Yukon, Canada. Quaternary Science Reviews, 28(27-28):3401-3413.

Lacelle, D. and Vasil'chuk, Y. K. (2013). Recent progress (2007-2012) in permafrost isotope geochemistry. Permafrost and Periglacial Processes, 24(2):138-145.

Lachniet, M. S., Lawson, D. E., and Sloat, A. R. (2012). Revised ${ }^{14}$ C dating of ice wedge growth in interior Alaska (USA) to MIS 2 reveals cold paleoclimate and carbon recycling in ancient permafrost terrain. Quaternary Research, 78(2):217-225.

Lal, D. (1991). Cosmic ray labeling of erosion surfaces: in situ nuclide production. Earth and Planetary Science Letters, 104:424-439.

Lal, D. (2007). Recycling of cosmogenic nuclides after their removal from the atmosphere; special case of appreciable transport of ${ }^{10} \mathrm{Be}$ to polar regions by aeolian dust. Earth and Planetary Science Letters, 264(1-2):177-187.

Lal, D. and Peters, B. (1967). Cosmic ray produced radioactivity on the earth. In Kosmische Strahlung II/Cosmic Rays II, Handbuch der Physik / Encyclopedia of Physics, pages 551-612. Springer.

Lamb, A. L., Wilson, G. P., and Leng, M. J. (2006). A review of coastal palaeoclimate and relative sea-level reconstructions using $\delta^{13} \mathrm{C}$ and $\mathrm{C} / \mathrm{N}$ ratios in organic material. Earth-Science Reviews, 75(1-4):29-57.

Lancaster, N. (2002). Flux of eolian sediment in the McMurdo Dry Valleys, Antarctica: a preliminary assessment. Arctic, Antarctic, and Alpine Research, 34(3):318-323.

Lapalme, C., Lacelle, D., Pollard, W., Fisher, D., Davila, A., and Mckay, C. P. (2017a). Distribution and origin of ground ice in University Valley, McMurdo Dry Valleys, Antarctica. Antarctic Science, 29(2):183-198.

Lapalme, C., Lacelle, D., Pollard, W., Fortier, D., Davila, A., and McKay, C. P. (2017b). Cryostratigraphy and the sublimation unconformity in permafrost from an ultraxerous environment, University Valley, McMurdo Dry Valleys of Antarctica. Permafrost and Periglacial Processes, 28(4):649-662.

Lawson, J., Doran, P. T., Kenig, F., and Priscu, J. C. (2004). Stable carbon and nitrogen isotopic composition of benthic and pelagic organic matter in lakes of the McMurdo Dry Valleys, Antarctica. Aquatic Geochemistry, 10(3-4):269-301.

Lee, C., Barbier, B. A., Bottos, E. M., McDonald, I. R., and Cary, S. C. (2012). The intervalley soil comparative survey: the ecology of Dry Valley edaphic microbial communities. The ISME Journal, 6(5):1046-1057.

Lee, X., Feng, Z., Guo, L., Wang, L., Jin, L., Huang, Y., Chopping, M., Huang, D., Jiang, W., Jiang, Q., et al. (2005). Carbon isotope of bulk organic matter: A proxy for precipitation in the arid and semiarid central East Asia. Global Biogeochemical Cycles, 19(4). 
Lee, Y. I., Lim, H. S., and Yoon, H. I. (2009). Carbon and nitrogen isotope composition of vegetation on King George Island, maritime Antarctic. Polar Biology, 32(11):1607-1615.

Legrand, M., Preunkert, S., Jourdain, B., Guilhermet, J., Faïn, X., Alekhina, I., and Petit, J. (2013). Water-soluble organic carbon in snow and ice deposited at Alpine, Greenland, and Antarctic sites: a critical review of available data and their atmospheric relevance. Past, 9:2195-2211.

Lenz, J., Wetterich, S., Jones, B. M., Meyer, H., Bobrov, A., and Grosse, G. (2016). Evidence of multiple thermokarst lake generations from an 11800 -year-old permafrost core on the northern Seward Peninsula, Alaska. Boreas, 45(4):584-603.

Levy, J. S., Marchant, D., and Head, J. W. (2010). Thermal contraction crack polygons on Mars: a synthesis from HiRISE, Phoenix, and terrestrial analog studies. Icarus, 206(1):229-252.

Levy, R., Cody, R., Crampton, J., Fielding, C., Golledge, N., Harwood, D., Henrys, S., Mckay, R., Naish, T., and Ohneiser, C. (2012). Reprint of: Late Neogene climate and glacial history of the Southern Victoria Land coast from integrated drill core, seismic and outcrop data. Global and Planetary Change, 96:157-180.

Levy, R., Harwood, D., Florindo, F., Sangiorgi, F., Tripati, R., Von Eynatten, H., Gasson, E., Kuhn, G., Tripati, A., and DeConto, R. (2016). Antarctic Ice Sheet sensitivity to atmospheric $\mathrm{CO}_{2}$ variations in the early to mid-Miocene. Proceedings of the National Academy of Sciences, 113(13):3453-3458.

Lewis, A. and Ashworth, A. C. (2015). An early to middle Miocene record of ice-sheet and landscape evolution from the Friis Hills, Antarctica. Geological Society of America Bulletin, 128(5-6):719-738.

Lewis, A., Marchant, D., Ashworth, A., Hemming, S., and Machlus, M. (2007). Major middle Miocene global climate change: evidence from East Antarctica and the Transantarctic Mountains. Geological Society of America Bulletin, 119(11-12):1449-1461.

Lewis, A., Marchant, D., Ashworth, A. C., Hedenäs, L., Hemming, S. R., Johnson, J. V., Leng, M. J., Machlus, M. L., Newton, A. E., and Raine, J. I. (2008). Mid-Miocene cooling and the extinction of tundra in continental Antarctica. Proceedings of the National Academy of Sciences, 105(31):10676-10680.

Lewis, A., Marchant, D., Kowalewski, D. E., Baldwin, S. L., and Webb, L. E. (2006). The age and origin of the Labyrinth, western Dry Valleys, Antarctica: evidence for extensive middle Miocene subglacial floods and freshwater discharge to the Southern Ocean. Geology, 34(7):513-516.

Liebrand, D., Lourens, L., Hodell, D., De Boer, B., Van de Wal, R., and Pälike, H. (2011). Antarctic Ice Sheet and oceanographic response to eccentricity forcing during the early Miocene. Climate of the Past, 7(3):869-880.

Linkletter, G. (1971). Weathering and soil formation in the Dry Valleys of southern Victoria Land. Antarctic Journal of the United States VI, 5:214. 
Liu, L., Sletten, R. S., Hagedorn, B., Hallet, B., McKay, C. P., and Stone, J. O. (2015). An enhanced model of the contemporary and long-term (200 ka) sublimation of the massive subsurface ice in Beacon Valley, Antarctica. Journal of Geophysical Research: Earth Surface, 120(8):1596-1610.

Liu, L., Sletten, R. S., Hallet, B., and Waddington, E. D. (2018). Thermal regime and properties of doils and ice-rich permafrost in Beacon Valley, Antarctica. Journal of Geophysical Research: Earth Surface, 123(8):1797-1810.

Longton, R. (1967). Vegetation in the Maritime Antarctic. Philosophical Transactions of the Royal Society of London. Series B, Biological Sciences, 252(777):213-235.

Lorrain, R. and Demeur, P. (1985). Isotopic evidence for relic Pleistocene glacier ice on Victoria Island, Canadian Arctic archipelago. Arctic and Alpine Research, 17(1):89-98.

Lorrain, R., Sleewaegen, S., Fitzsimons, S., and Stievenard, M. (2002). Ice formation in an Antarctic glacier-dammed lake and implications for glacier-lake interactions. Arctic, Antarctic, and Alpine Research, 34(2):150-158.

Lyons, W., Welch, K. A., and Doggett, J. K. (2007). Organic carbon in Antarctic snow. Geophysical Research Letters, 34(2).

Lyons, W., Welch, K. A., Fountain, A. G., Dana, G. L., Vaughn, B. H., and McKnight, D. M. (2003). Surface glaciochemistry of Taylor Valley, southern Victoria Land, Antarctica and its relationship to stream chemistry. Hydrological Processes, 17(1):115-130.

Lyons, W., Welch, K. A., Neumann, K., Toxey, J. K., Mcarthur, R., Williams, C., Mcknight, D. M., and Moorhead, D. (1998). Geochemical linkages among glaciers, streams and lakes within the Taylor Valley, Antarctica. Antarctic Research Series, 72:77-92.

Lyons, W., Welch, K. A., Snyder, G., Olesik, J., Graham, E. Y., Marion, G. M., and Poreda, R. J. (2005). Halogen geochemistry of the McMurdo Dry Valleys lakes, Antarctica: clues to the origin of solutes and lake evolution. Geochimica et Cosmochimica Acta, 69(2):305-323.

Mackay, J. (1983). Oxygen isotope variations in permafrost, Tuktoyaktuk Peninsula area, Northwest Territories. In Current Research Part B, number Paper 83-1B, pages 67-74. Geological Survey of Canada.

Mackay, J. (1990). Seasonal growth bands in pingo ice. Canadian Journal of Earth Sciences, 27(8):1115-1125.

Mackay, J. and Black, R. F. (1973). Origin, composition, and structure of perennially frozen ground and ground ice: a review. In North American Contribution, Permafrost Second International Conference, pages 185-192.

Mackay, J. and Dallimore, S. R. (1992). Massive ice of the Tuktoyaktuk area, western Arctic coast, Canada. Canadian Journal of Earth Sciences, 29(6):1235-1249.

Marchant, D. and Denton, G. (1996). Miocene and Pliocene paleoclimate of the Dry Valleys region, southern Victoria Land: a geomorphological approach. Marine Micropaleontology, 27(1-4):253-271. 
Marchant, D., Denton, G., Sugden, D. E., and Swisher III, C. C. (1993a). Miocene glacial stratigraphy and landscape evolution of the western Asgard Range, Antarctica. Geografiska Annaler: Series A, Physical Geography, 75(4):303-330.

Marchant, D., Denton, G., Swisher III, C. C., and Potter Jr, N. (1996). Late Cenozoic Antarctic paleoclimate reconstructed from volcanic ashes in the Dry Valleys region of southern Victoria Land. Geological Society of America Bulletin, 108(2):181-194.

Marchant, D., Denton, G. H., Bockheim, J. G., Wilson, S. C., and Kerr, A. R. (1994). Quaternary changes in level of the upper Taylor Glacier, Antarctica: implications for paleoclimate and East Antarctic Ice Sheet dynamics. Boreas, 23(1):29-43.

Marchant, D. and Head III, J. W. (2007). Antarctic Dry Valleys: microclimate zonation, variable geomorphic processes, and implications for assessing climate change on Mars. Icarus, 192(1):187-222.

Marchant, D., Lewis, A. R., Phillips, W. M., Moore, E., Souchez, R., Denton, G. H., Sugden, D., Potter Jr, N., and Landis, G. P. (2002). Formation of patterned ground and sublimation till over Miocene glacier ice in Beacon Valley, southern Victoria Land, Antarctica. Geological Society of America Bulletin, 114(6):718-730.

Marchant, D., Swisher, C. C., Lux, D. R., West, D. P., and Denton, G. H. (1993b). Pliocene paleoclimate and East Antarctic Ice Sheet history from surficial ash deposits. Science, 260(5108):667-670.

Margerison, H., Phillips, W., Stuart, F., and Sugden, D. (2005). Cosmogenic ${ }^{3} \mathrm{He}$ concentrations in ancient flood deposits from the Coombs Hills, northern Dry Valleys, East Antarctica: interpreting exposure ages and erosion rates. Earth and Planetary Science Letters, 230(1-2):163-175.

Marinova, M. M., Mckay, C. P., Pollard, W. H., Heldmann, J. L., Davila, A. F., Andersen, D. T., Jackson, W. A., Lacelle, D., Paulsen, G., and Zacny, K. (2013). Distribution of depth to ice-cemented soils in the high-elevation Quartermain Mountains, McMurdo Dry Valleys, Antarctica. Antarctic Science, 25(4):575-582.

Marrero, S. M., Hein, A. S., Naylor, M., Attal, M., Shanks, R., Winter, K., Woodward, J., Dunning, S., Westoby, M., and Sugden, D. (2018). Controls on subaerial erosion rates in Antarctica. Earth and Planetary Science Letters, 501:56-66.

Martin, A., Cooper, A., Price, R., Turnbull, R., and Roberts, N. (2015). The petrology, geochronology and significance of Granite Harbour Intrusive Complex xenoliths and outcrop sampled in western McMurdo Sound, Southern Victoria Land, Antarctica. New Zealand Journal of Geology and Geophysics, 58(1):33-51.

Masarik, J. and Beer, J. (1999). Simulation of particle fluxes and cosmogenic nuclide production in the Earth's atmosphere. Journal of Geophysical Research: Atmospheres, 104(D10).

Masarik, J. and Beer, J. (2009). An updated simulation of particle fluxes and cosmogenic nuclide production in the Earth's atmosphere. Journal of Geophysical Research: Atmospheres, 114(D11). 
Matsubaya, O., Sakai, H., Torii, T., Burton, H., and Kerry, K. (1979). Antarctic saline lakes-stable isotopic ratios, chemical compositions and evolution. Geochimica et Cosmochimica Acta, 43(1):7-25.

Matsumoto, G. I., Friedmann, E. I., and Gilichinsky, D. A. (1995). Geochemical characteristics of organic compounds in a permafrost sediment core sample from northeast Siberia, Russia. In Proceedings of the NIPR Symposium on Antarctic Geosciences, volume 8, pages $258-267$.

Matsumoto, G. I., Hirai, A., Hirota, K., and Watanuki, K. (1990). Organic geochemistry of the McMurdo Dry Valleys soil, Antarctica. Organic Geochemistry, 16(4-6):781-791.

Matsumoto, G. I., Honda, E., Sonoda, K., Yamamoto, S., and Takemura, T. (2010). Geochemical features and sources of hydrocarbons and fatty acids in soils from the McMurdo Dry Valleys in the Antarctic. Polar Science, 4(2):187-196.

Mazur, P. (1980). Limits to life at low temperatures and at reduced water contents and water activities. In Limits of Life, pages 1-23. Springer.

McGinnis, L. D. (1981). Dry Valley drilling project, volume 33 of Antarctic Research Series. American Geophysical Union Washington, DC.

McHargue, L. and Damon, P. (1991). The global Beryllium-10 cycle. Reviews of Geophysics, 29(2):141-158.

McKay, C. P. (2009). Snow recurrence sets the depth of dry permafrost at high elevations in the McMurdo Dry Valleys of Antarctica. Antarctic Science, 21(1):89.

McKay, C. P., Mellon, M. T., and Friedmann, E. I. (1998). Soil temperatures and stability of ice-cemented ground in the McMurdo Dry Valleys, Antarctica. Antarctic Science, 10(1):31-38.

McKay, R., Browne, G., Carter, L., Cowan, E., Dunbar, G., Krissek, L., Naish, T., Powell, R., Reed, J., and Talarico, F. (2009). The stratigraphic signature of the late Cenozoic Antarctic Ice Sheets in the Ross Embayment. Geological Society of America Bulletin, 121(11-12):1537-1561.

McKay, R., Naish, T., Carter, L., Riesselman, C., Dunbar, R., Sjunneskog, C., Winter, D., Sangiorgi, F., Warren, C., and Pagani, M. (2012). Antarctic and Southern Ocean influences on Late Pliocene global cooling. Proceedings of the National Academy of Sciences, 109(17):6423-6428.

McKnight, D. and Andrews, E. (1993). Hydrologic and geochemical processes at the streamlake interface in a permanently ice-covered lake in the McMurdo Dry Valleys, Antarctica. Internationale Vereinigung für theoretische und angewandte Limnologie: Verhandlungen, 25(2):957-959.

McKnight, D., Niyogi, D. K., Alger, A. S., Bomblies, A., Conovitz, P. A., and Tate, C. M. (1999). Dry Valley streams in Antarctica: ecosystems waiting for water. Bioscience, 49(12):985-995. 
McQueen, D. (1976). The ecology of Nothofagus and associated vegetation in South America. Part I. Vegetation and soils in Southern Patagonia and Tierra del Fuego. Part II. The mid latitude forests of Chile. Tuatara: Journal of the Biological Society, 22(1):38-42.

Merlivat, L. and Coantic, M. (1975). Study of mass transfer at the air-water interface by an isotopic method. Journal of Geophysical Research, 80(24):3455-3464.

Meyer, H., Dereviagin, A., Siegert, C., Schirrmeister, L., and Hubberten, H. (2002). Palaeoclimate reconstruction on Big Lyakhovsky Island, North Siberia-hydrogen and oxygen isotopes in ice wedges. Permafrost and Periglacial Processes, 13(2):91-105.

Meyers, P. A. and Ishiwatari, R. (1993). Lacustrine organic geochemistry: an overview of indicators of organic matter sources and diagenesis in lake sediments. Organic Geochemistry, 20(7):867-900.

Michalski, G., Bockheim, J. G., Kendall, C., and Thiemens, M. (2005). Isotopic composition of Antarctic Dry Valley nitrate: implications for $\mathrm{NO}_{\mathrm{y}}$ sources and cycling in Antarctica. Geophysical Research Letters, 32(13).

Michel, F. (1983). Isotope investigations of permafrost waters in Northern Canada. PhD thesis, University of Waterloo, Canada.

Michel, F. (2011). Isotope characterisation of ground ice in northern Canada. Permafrost and Periglacial Processes, 22(1):3-12.

Michener, R. and Lajtha, K. (2008). Stable Isotopes in Ecology and Environmental Science. John Wiley \& Sons, 2nd edition.

Middleton, J. L., Ackert Jr, R. P., and Mukhopadhyay, S. (2012). Pothole and channel system formation in the McMurdo Dry Valleys of Antarctica: new insights from cosmogenic nuclides. Earth and Planetary Science Letters, 355:341-350.

Mikucki, J. A., Foreman, C. M., Sattler, B., Lyons, W., and Priscu, J. C. (2004). Geomicrobiology of Blood Falls: an iron-rich saline discharge at the terminus of the Taylor Glacier, Antarctica. Aquatic Geochemistry, 10(3-4):199-220.

Miller, K., Kominz, M. A., Browning, J. V., Wright, J. D., Mountain, G. S., Katz, M. E., Sugarman, P. J., Cramer, B. S., Christie-Blick, N., and Pekar, S. F. (2005). The Phanerozoic record of global sea-level change. Science, 310(5752):1293-1298.

Miller, K., Wright, J. D., Browning, J. V., Kulpecz, A., Kominz, M., Naish, T. R., Cramer, B. S., Rosenthal, Y., Peltier, W. R., and Sosdian, S. (2012). High tide of the warm Pliocene: implications of global sea level for Antarctic deglaciation. Geology, 40(5):407-410.

Miller, K. G., Wright, J. D., and Fairbanks, R. G. (1991). Unlocking the ice house: OligoceneMiocene oxygen isotopes, eustasy, and margin erosion. Journal of Geophysical Research: Solid Earth, 96(B4):6829-6848.

Miller, L. G. and Aiken, G. R. (1996). Effects of glacial meltwater inflows and moat freezing on mixing in an ice-covered Antarctic lake as interpreted from stable isotope and tritium distributions. Limnology and Oceanography, 41(5):966-976. 
Miller, S., Fitzgerald, P. G., and Baldwin, S. L. (2010). Cenozoic range-front faulting and development of the Transantarctic Mountains near Cape Surprise, Antarctica: thermochronologic and geomorphologic constraints. Tectonics, 29(1).

Monteiro, M., S Baptista, M., Séneca, J., Torgo, L., K Lee, C., Cary, S. C., and Magalhães, C. (2020). Understanding the response of nitrifying communities to disturbance in the McMurdo Dry Valleys, Antarctica. Microorganisms, 8(3):404.

Moorhead, D. L. (2007). Mesoscale dynamics of ephemeral wetlands in the Antarctic Dry Valleys: implications to production and distribution of organic matter. Ecosystems, 10(1):87-95.

Moorman, B. J., Michel, F. A., and Wilson, A. (1996). ${ }^{14} \mathrm{C}$ dating of trapped gases in massive ground ice, Western Canadian Arctic. Permafrost and Periglacial Processes, 7(3):257-266.

Morgan, D. J., Putkonen, J., Balco, G., and Stone, J. (2011). Degradation of glacial deposits quantified with cosmogenic nuclides, Quartermain Mountains, Antarctica. Earth Surface Processes and Landforms, 36(2):217-228.

Morikawa, H., Minato, I., and Ossaka, J. (1975). Origin of magnesium and potassium ions in Lake Vanda, Antarctica. Nature, 254(5501):583-584.

Murton, J. (2013). Ground ice and cryostratigraphy. In Treatise on Geomorphology. Glacial and Periglacial Geomorphology, pages 173-201. Academic Press, San Diego.

Murton, J., Edwards, M. E., Lozhkin, A. V., Anderson, P. M., Savvinov, G. N., Bakulina, N., Bondarenko, O. V., Cherepanova, M. V., Danilov, P. P., and Boeskorov, V. (2017). Preliminary paleoenvironmental analysis of permafrost deposits at Batagaika megaslump, Yana Uplands, northeast Siberia. Quaternary Research, 87(2):314-330.

Murton, J. and French, H. (1994). Cryostructures in permafrost, Tuktoyaktuk coastlands, western Arctic Canada. Canadian Journal of Earth Sciences, 31(4):737-747.

Murton, J., Goslar, T., Edwards, M. E., Bateman, M. D., Danilov, P. P., Savvinov, G. N., Gubin, S. V., Ghaleb, B., Haile, J., and Kanevskiy, M. (2015). Palaeoenvironmental interpretation of Yedoma silt (ice complex) deposition as cold-climate loess, Duvanny Yar, northeast Siberia. Permafrost and Periglacial Processes, 26(3):208-288.

Murton, J., Waller, R. I., Hart, J. K., Whiteman, C. A., Pollard, W. H., and Clark, I. D. (2004). Stratigraphy and glaciotectonic structures of permafrost deformed beneath the northwest margin of the Laurentide Ice Sheet, Tuktoyaktuk Coastlands, Canada. Journal of Glaciology, 50(170):399-412.

Murton, J., Whiteman, C., Waller, R., Pollard, W., Clark, I., and Dallimore, S. (2005). Basal ice facies and supraglacial melt-out till of the Laurentide Ice Sheet, Tuktoyaktuk Coastlands, western Arctic Canada. Quaternary Science Reviews, 24(5-6):681-708.

Naish, T., Barrett, P., Dunbar, G., Woolfe, K., Dunn, A., Henrys, S., Claps, M., Powell, R., and Fielding, C. R. (2001). Sedimentary cyclicity in CRP drillcore, Victoria Land Basin, Antarctica. Terra Antartica, 8(3):225-244. 
Nakai, N., Wada, H., Kiyosu, Y., and Takimoto, M. (1975). Stable isotope of water and studies on the origin and geological history salts in the Lake Vanda area, Antarctica. Geochemical Journal, 9(1):7-24.

Niederberger, T. D., Sohm, J. A., Gunderson, T., Tirindelli, J., Capone, D. G., Carpenter, E. J., and Cary, S. C. (2015a). Carbon-fixation rates and associated microbial communities residing in arid and ephemerally wet Antarctic Dry Valley soils. Frontiers in Microbiology, $6: 1347$.

Niederberger, T. D., Sohm, J. A., Gunderson, T. E., Parker, A. E., Tirindelli, J., Capone, D. G., Carpenter, E. J., and Cary, S. C. (2015b). Microbial community composition of transiently wetted Antarctic Dry Valley soils. Frontiers in Microbiology, 6:9.

Nishiizumi, K., Elmore, D., Ma, X., and Arnold, J. (1984). ${ }^{10} \mathrm{Be}$ and ${ }^{36} \mathrm{Cl}$ depth profiles in an Apollo 15 drill core. Earth and Planetary Science Letters, 70(2):157-163.

Nishiizumi, K., Imamura, M., Caffee, M. W., Southon, J. R., Finkel, R. C., and McAninch, J. (2007). Absolute calibration of ${ }^{10} \mathrm{Be}$ AMS standards. Nuclear Instruments and Methods in Physics Research Section B: Beam Interactions with Materials and Atoms, 258(2):403413.

Nishiizumi, K., Kohl, C., Arnold, J., Klein, J., Fink, D., and Middleton, R. (1991). Cosmic ray produced ${ }^{10} \mathrm{Be}$ and ${ }^{26} \mathrm{Al}$ in Antarctic rocks: exposure and erosion history. Earth and Planetary Science Letters, 104(2-4):440-454.

Nolte, E., Beer, J., Blinov, A., Gilichinsky, D., Hubberten, H.-W., Kholodov, A., Kubik, P., Lazarev, V., Meyer, H., and Schirrmeister, L. (2005). Dating of permafrost by cosmogenic radionuclides. In 2nd European Conference on Permafrost EUCOP II, Potsdam, Germany, June 12-16.

Novis, P. M., Whitehead, D., Gregorich, E. G., Hunt, J. E., Sparrow, A. D., Hopkins, D. W., Elberling, B., and Greenfield, L. G. (2007). Annual carbon fixation in terrestrial populations of Nostoc commune (Cyanobacteria) from an Antarctic Dry Valley is driven by temperature regime. Global Change Biology, 13(6):1224-1237.

Oelbermann, M., English, M., and Schiff, S. L. (2008). Evaluating carbon dynamics and microbial activity in Arctic soils under warmer temperatures. Canadian Journal of Soil Science, 88(1):31-44.

Ohneiser, C., Wilson, G. S., Beltran, C., Dolan, A. M., Hill, D. J., and Prebble, J. G. (2020). Warm fjords and vegetated landscapes in early Pliocene East Antarctica. Earth and Planetary Science Letters, 534:116045.

Or, D. and Tuller, M. (2000). Flow in unsaturated fractured porous media: hydraulic conductivity of rough surfaces. Water Resources Research, 36(5):1165-1177.

Outcalt, S. I. and Hinkel, K. M. (1996). The response of near-surface permafrost to seasonal regime transitions in tundra terrain. Arctic and Alpine Research, 28(3):274-283.

Outcalt, S. I., Nelson, F. E., and Hinkel, K. M. (1990). The zero-curtain effect: heat and mass transfer across an isothermal region in freezing soil. Water Resources Research, 26(7):1509-1516. 
O'Neill, H. B. and Burn, C. R. (2012). Physical and temporal factors controlling the development of near-surface ground ice at Illisarvik, western Arctic coast, Canada. Canadian Journal of Earth Sciences, 49(9):1096-1110.

Pannewitz, S., Green, T. A., Maysek, K., Schlensog, M., Seppelt, R., Sancho, L. G., Türk, R., and Schroeter, B. (2005). Photosynthetic responses of three common mosses from continental Antarctica. Antarctic Science, 17(3):341-352.

Parker, B. C., Simmons Jr, G. M., Seaburg, K. G., Cathey, D. D., and Allnutt, F. (1982). Comparative ecology of plankton communities in seven Antarctic oasis lakes. Journal of Plankton Research, 4(2):271-286.

Parnikoza, I., Kozeretska, I., and Kunakh, V. (2011). Vascular plants of the Maritime Antarctic: origin and adaptation. American Journal of Plant Sciences, 2(3):381-395.

Parsons, A. N., Barrett, J., Wall, D. H., and Virginia, R. A. (2004). Soil carbon dioxide flux in Antarctic Dry Valley ecosystems. Ecosystems, 7(3):286-295.

Passchier, S., Bohaty, S. M., Jiménez-Espejo, F., Pross, J., Röhl, U., van de Flierdt, T., Escutia, C., and Brinkhuis, H. (2013). Early Eocene to middle Miocene cooling and aridification of East Antarctica. Geochemistry, Geophysics, Geosystems, 14(5):1399-1410.

Passchier, S., Browne, G., Field, B., Fielding, C., Krissek, L., Panter, K., Pekar, S., and Team, A.-S. S. (2011). Early and middle Miocene Antarctic glacial history from the sedimentary facies distribution in the AND-2A drill hole, Ross Sea, Antarctica. Geological Society of America Bulletin, 123(11-12):2352-2365.

Pastor, J. and Bockheim, J. (1980). Soil development on moraines of Taylor Glacier, lower Taylor Valley, Antarctica. Soil Science Society of America Journal, 44(2):341-348.

Patterson, M. O., McKay, R., Naish, T., Escutia, C., Jimenez-Espejo, F., Raymo, M., Meyers, S., Tauxe, L., Brinkhuis, H., and IODP Expedition (2014). Orbital forcing of the East Antarctic Ice Sheet during the Pliocene and Early Pleistocene. Nature Geoscience, 7(11):841-847.

Pavich, M. J., Brown, L., Harden, J., Klein, J., and Middleton, R. (1986). ${ }^{10}$ Be distribution in soils from Merced River terraces, California. Geochimica et Cosmochimica Acta, 50(8):1727-1735.

Paxman, G. J., Jamieson, S. S., Hochmuth, K., Gohl, K., Bentley, M. J., Leitchenkov, G., and Ferraccioli, F. (2019). Reconstructions of Antarctic topography since the Eocene-Oligocene boundary. Palaeogeography, Palaeoclimatology, Palaeoecology, 535:109346.

Pearsall, D. M. (2015). Paleoethnobotany: a handbook of procedures. Left Coast Press, 3rd edition.

Pekar, S. F. and DeConto, R. M. (2006). High-resolution ice-volume estimates for the early Miocene: evidence for a dynamic ice sheet in Antarctica. Palaeogeography, Palaeoclimatology, Palaeoecology, 231(1-2):101-109. 
Pekar, S. F., DeConto, R. M., and Harwood, D. M. (2006). Resolving a late Oligocene conundrum: deep-sea warming and Antarctic glaciation. Palaeogeography, Palaeoclimatology, Palaeoecology, 231(1-2):29-40.

Peri, P. L., Ladd, B., Pepper, D. A., Bonser, S. P., Laffan, S. W., and Amelung, W. (2012). Carbon $\left(\delta^{13} \mathrm{C}\right)$ and nitrogen $\left(\delta^{15} \mathrm{~N}\right)$ stable isotope composition in plant and soil in Southern Patagonia's native forests. Global Change Biology, 18(1):311-321.

Peri, P. L., Rosas, Y. M., Ladd, B., Toledo, S., Lasagno, R. G., and Martínez Pastur, G. (2019). Modeling soil nitrogen content in South Patagonia across a climate gradient, vegetation type, and grazing. Sustainability, 11(9):2707.

Pole, M. (1994). Deciduous Nothofagus leaves from the Miocene of Cornish Head, New Zealand. Alcheringa: An Australasian Journal of Palaeontology, 18(1-2):79-83.

Pollard, W., Doran, P., and Wharton, R. (2002). The nature and significance of massive ground ice in Ross Sea Drift, Garwood Valley, McMurdo Sound. In Antarctica at the close of a millennium: proceedings of the 8th International Symposium on Antarctic Earth Sciences, Wellington 1999.

Porter, S. and Beget, J. E. (1981). Provenance and depositional environments of Late Cenozoic sediments in permafrost cores from lower Taylor Valley, Antarctica. In Dry Valley drilling project, volume 33 of Antarctic Research Series, pages 351-363.

Porter, T. and Opel, T. (2020). Recent advances in paleoclimatological studies of Arctic wedge-and pore-ice stable-water isotope records. Permafrost and Periglacial Processes, 31(3):429-441.

Prebble, J., Raine, J., Barrett, P., and Hannah, M. (2006). Vegetation and climate from two Oligocene glacioeustatic sedimentary cycles (31 and $24 \mathrm{Ma}$ ) cored by the Cape Roberts Project, Victoria Land Basin, Antarctica. Palaeogeography, Palaeoclimatology, Palaeoecology, 231(1-2):41-57.

Pringle, D., Dickinson, W., Trodahl, H., and Pyne, A. (2003). Depth and seasonal variations in the thermal properties of Antarctic Dry Valley permafrost from temperature time series analysis. Journal of Geophysical Research: Solid Earth, 108(B10).

Putkonen, J., Balco, G., and Morgan, D. (2008). Slow regolith degradation without creep determined by cosmogenic nuclide measurements in Arena Valley, Antarctica. Quaternary Research, 69(2):242-249.

Raffi, R. and Stenni, B. (2011). Isotopic composition and thermal regime of ice wedges in northern Victoria Land, East Antarctica. Permafrost and Periglacial Processes, 22(1):6583.

Raine, J. (1998). Terrestrial palynomorphs from Cape Roberts Project drillhole CRP-1, Ross Sea, Antarctica. Terra Antartica, 5(3):539-548.

Raine, J. and Askin, R. (2001). Terrestrial palynology of Cape Roberts Project drillhole CRP-3, Victoria Land Basin, Antarctica. Terra Antartica, 8(4):389-400. 
Raisbeck, G., Yiou, F., Fruneau, M., Loiseaux, J., Lieuvin, M., Ravel, J., and Lorius, C. (1981). Cosmogenic ${ }^{10} \mathrm{Be}$ concentrations in Antarctic ice during the past 30,000 years. Nature, 292(5826):825-826.

Ravelo, A. C., Andreasen, D. H., Lyle, M., Lyle, A. O., and Wara, M. W. (2004). Regional climate shifts caused by gradual global cooling in the Pliocene epoch. Nature, 429(6989):263-267.

Rebesco, M., Camerlenghi, A., Geletti, R., and Canals, M. (2006). Margin architecture reveals the transition to the modern Antarctic Ice Sheet ca. 3 Ma. Geology, 34(4):301-304.

Redfield, A. (1934). On the proportions of organic derivatives in sea water and their relation to the composition of plankton. In James Johnstone Memorial Volume, pages 176-192. University Press of Liverpool.

Redfield, A. (1958). The biological control of chemical factors in the environment. American Scientist, 46(3):205-221.

Rees-Owen, R. L., Gill, F. L., Newton, R. J., Ivanović, R. F., Francis, J. E., Riding, J. B., Vane, C. H., and dos Santos, R. A. L. (2018). The last forests on Antarctica: reconstructing flora and temperature from the Neogene Sirius Group, Transantarctic Mountains. Organic Geochemistry, 118:4-14.

Rees-Owen, R. L., Newton, R. J., Ivanovic, R. F., Francis, J. E., Riding, J. B., and Marca, A. D. (2021). A calibration of cellulose isotopes in modern prostrate Nothofagus and its application to fossil material from Antarctica. Science of the Total Environment, $754: 142247$.

Rego, A., Raio, F., Martins, T. P., Ribeiro, H., Sousa, A. G., Séneca, J., Baptista, M. S., Lee, C. K., Cary, S. C., and Ramos, V. (2019). Actinobacteria and cyanobacteria diversity in terrestrial Antarctic microenvironments evaluated by culture-dependent and independent methods. Frontiers in Microbiology, 10:1018.

Reiners, W. A. (1986). Complementary models for ecosystems. The American Naturalist, 127(1):59-73.

Roser, B. and Pyne, A. R. (1989). Wholerock geochemistry. In Antarctic Cenozoic History from the CIROS-1 Drillhole, McMurdo Sound, DSIR Bulletin, volume 245, pages 175-184.

Roy, C. (2019). The Origin of Massive Ground Ice in Raised Marine Sediments Along the Eureka Sound lowlands, Nunavut, Canada. PhD thesis, McGill University, Canada.

Runkel, R. L., McKnight, D. M., and Andrews, E. D. (1998). Analysis of transient storage subject to unsteady flow: diel flow variation in an Antarctic stream. Journal of the North American Benthological Society, 17(2):143-154.

Russell, N. (1990). Cold adaptation of microorganisms. Philosophical Transactions of the Royal Society of London. B, Biological Sciences, 326(1237):595-611.

Salzmann, U., Williams, M., Haywood, A. M., Johnson, A. L., Kender, S., and Zalasiewicz, J. (2011). Climate and environment of a Pliocene warm world. Palaeogeography, Palaeoclimatology, Palaeoecology, 309(1-2):1-8. 
Sardans, J., Rivas-Ubach, A., and Penuelas, J. (2012). The elemental stoichiometry of aquatic and terrestrial ecosystems and its relationships with organismic lifestyle and ecosystem structure and function: a review and perspectives. Biogeochemistry, 111(1-3):1-39.

Schaeffer, S. M., Sharp, E., Schimel, J. P., and Welker, J. M. (2013). Soil-plant N processes in a High Arctic ecosystem, NW Greenland are altered by long-term experimental warming and higher rainfall. Global Change Biology, 19(11):3529-3539.

Scherer, R. P., DeConto, R. M., Pollard, D., and Alley, R. B. (2016). Windblown Pliocene diatoms and East Antarctic Ice Sheet retreat. Nature Communications, 7(1):1-9.

Schiller, M. (2007). Testing the antiquity of McMurdo Dry Valley soil surfaces with atmospheric ${ }^{10} \mathrm{Be} . \mathrm{PhD}$ thesis, Victoria University of Wellington, New Zealand.

Schiller, M., Dickinson, W., Ditchburn, R., Graham, I., and Zondervan, A. (2009). Atmospheric ${ }^{10} \mathrm{Be}$ in an Antarctic soil: implications for climate change. Journal of Geophysical Research: Earth Surface, 114(F1).

Schiller, M., Dickinson, W., Iverson, N., and Baker, J. (2019). A re-evaluation of the Hart Ash, an important stratigraphic marker: Wright Valley, Antarctica. Antarctic Science, 31(3):139-149.

Schiller, M., Dickinson, W., Zondervan, A., Ditchburn, R., and Wang, N. (2014). Rapid soil accumulation in a frozen landscape. Geology, 42(4):335-338.

Schorghofer, N. and Aharonson, O. (2005). Stability and exchange of subsurface ice on Mars. Journal of Geophysical Research: Planets, 110(E5).

Schwamborn, G., Meyer, H., Fedorov, G., Schirrmeister, L., and Hubberten, H.-W. (2006). Ground ice and slope sediments archiving late Quaternary paleoenvironment and paleoclimate signals at the margins of El'gygytgyn Impact Crater, NE Siberia. Quaternary Research, 66(2):259-272.

Schwarz, A., Green, T., and Seppelt, R. (1992). Terrestrial vegetation at Canada Glacier, Southern Victoria Land, Antarctica. Polar Biology, 12(3-4):397-404.

Schweizer, M. K., Wooller, M. J., Toporski, J., Fogel, M. L., and Steele, A. (2006). Examination of an Oligocene lacustrine ecosystem using $\mathrm{C}$ and $\mathrm{N}$ stable isotopes. Palaeogeography, Palaeoclimatology, Palaeoecology, 230(3-4):335-351.

Schäfer, J. M., Ivy-Ochs, S., Wieler, R., Leya, I., Baur, H., Denton, G. H., and Schlüchter, C. (1999). Cosmogenic noble gas studies in the oldest landscape on earth: surface exposure ages of the Dry Valleys, Antarctica. Earth and Planetary Science Letters, 167(3-4):215226 .

Seppelt, R. and Green, T. (1998). A bryophyte flora for southern Victoria Land, Antarctica. New Zealand Journal of Botany, 36(4):617-635.

Sharpe, D. R. (1992). Quaternary geology of Wollaston Peninsula, Victoria Island, Northwest Territories. Memoir 432, Geological Survey of Canada. 
Shaw, E. A. (2018). Trophic relationships in soil communities: how abiotic stress affects biotic interactions in the McMurdo Dry Valleys, Antarctica. PhD thesis.

Shaw, E. A., Adams, B. J., Barrett, J. E., Lyons, W. B., Virginia, R. A., and Wall, D. H. (2018). Stable C and N isotope ratios reveal soil food web structure and identify the nematode Eudorylaimus antarcticus as an omnivore-predator in Taylor Valley, Antarctica. Polar Biology, 41(5):1013-1018.

Sher, A. (1997). Yedoma as a store of paleoenvironmental records in Beringia. In Beringia Paleoenvironmental Workshop, pages 92-94.

Sher, A., Kuzmina, S. A., Kuznetsova, T. V., and Sulerzhitsky, L. (2005). New insights into the Weichselian environment and climate of the East Siberian Arctic, derived from fossil insects, plants, and mammals. Quaternary Science Reviews, 24(5-6):533-569.

Shevenell, A. E., Kennett, J. P., and Lea, D. W. (2004). Middle Miocene Southern Ocean cooling and Antarctic cryosphere expansion. Science, 305(5691):1766-1770.

Shevenell, A. E., Kennett, J. P., and Lea, D. W. (2008). Middle Miocene ice sheet dynamics, deep-sea temperatures, and carbon cycling: a Southern Ocean perspective. Geochemistry, Geophysics, Geosystems, 9(2).

Skrzypek, G., Wojtuń, B., Richter, D., Jakubas, D., Wojczulanis-Jakubas, K., and SameckaCymerman, A. (2015). Diversification of nitrogen sources in various tundra vegetation types in the High Arctic. PLoS One, 10(9):e0136536.

Slagoda, E., Opokina, O., Kurchatova, A., and Rogov, V. (2012). Structure and composition of complex massive ice bodies in Late Pleistocene-Holocene sediments of the Marre-Sale Cape, West Yamal. In Proceedings of the Tenth International Conference on Permafrost, pages 25-29.

Slaymaker, O. (2009). Proglacial, periglacial or paraglacial? Geological Society, London, Special Publications, 320(1):71-84.

Sletten, R., Hallet, B., and Fletcher, R. (2003). Resurfacing time of terrestrial surfaces by the formation and maturation of polygonal patterned ground. Journal of Geophysical Research: Planets, 108(E4).

Smith, M. and Riseborough, D. (2002). Climate and the limits of permafrost: a zonal analysis. Permafrost and Periglacial Processes, 13(1):1-15.

Sofer, Z. and Gat, J. (1972). Activities and concentrations of Oxygen-18 in concentrated aqueous salt solutions: analytical and geophysical implications. Earth and Planetary Science Letters, 15(3):232-238.

Sofer, Z. and Gat, J. (1975). The isotope composition of evaporating brines: effect of the isotopic activity ratio in saline solutions. Earth and Planetary Science Letters, 26(2):179186.

Sokratov, S. A. and Golubev, V. N. (2009). Snow isotopic content change by sublimation. Journal of Glaciology, 55(193):823-828. 
St-Onge, D. and McMartin, I. (1999). The Bluenose Lake Moraine, a moraine with a glacier ice core. Géographie physique et Quaternaire, 53(2):287-295.

Staiger, J., Marchant, D., Schaefer, J., Oberholzer, P., Johnson, J., Lewis, A., and Swanger, K. (2006). Plio-Pleistocene history of Ferrar Glacier, Antarctica: implications for climate and ice sheet stability. Earth and Planetary Science Letters, 243(3-4):489-503.

Stefan, J. (1891). Über die theorie der eisbildung, insbesondere über die eisbildung im polarmeere. Annalen der Physik, 278(2):269-286.

Steig, E., Morse, D. L., Waddington, E. D., Stuiver, M., Grootes, P. M., Mayewski, P. A., Twickler, M. S., and Whitlow, S. I. (2000). Wisconsinan and Holocene climate history from an ice core at Taylor Dome, western Ross Embayment, Antarctica. Geografiska Annaler: Series A, Physical Geography, 82(2-3):213-235.

Steig, E., Polissar, P., Stuiver, M., Grootes, P., and Finkel, R. (1996). Large amplitude solar modulation cycles of ${ }^{10} \mathrm{Be}$ in Antarctica: implications for atmospheric mixing processes and interpretation of the ice core record. Geophysical Research Letters, 23(5):523-526.

Steig, E., Stuiver, M., and Polissar, P. (1995). Cosmogenic isotope concentrations at Taylor Dome, Antarctica. Antarctic Journal of the United States, 30:95-97.

Stenni, B., Genoni, L., Flora, O., and Guglielmin, M. (2007). An oxygen isotope record from the Foscagno rock-glacier ice core, Upper Valtellina, Italian Central Alps. The Holocene, 17(7):1033-1039.

Stenni, B., Masson-Delmotte, V., Selmo, E., Oerter, H., Meyer, H., Röthlisberger, R., Jouzel, J., Cattani, O., Falourd, S., and Fischer, H. (2010). The deuterium excess records of EPICA Dome C and Dronning Maud Land ice cores (East Antarctica). Quaternary Science Reviews, 29(1-2):146-159.

Stern, T., Baxter, A., and Barrett, P. (2005). Isostatic rebound due to glacial erosion within the Transantarctic Mountains. Geology, 33(3):221-224.

Stichler, W., Schotterer, U., Fröhlich, K., Ginot, P., Kull, C., Gäggeler, H., and Pouyaud, B. (2001). Influence of sublimation on stable isotope records recovered from highaltitude glaciers in the tropical Andes. Journal of Geophysical Research: Atmospheres, 106(D19):22613-22620.

Stroeven, A. P. and Prentice, M. L. (1997). A case for Sirius Group alpine glaciation at Mount Fleming, South Victoria Land, Antarctica: a case against Pliocene East Antarctic Ice Sheet reduction. Geological Society of America Bulletin, 109(7):825-840.

Stuiver, M., Yang, I. C., and Denton, G. H. (1976). Permafrost oxygen isotope ratios and chronology of three cores from Antarctica. Nature, 261(5561):547-550.

Stuiver, M., Yang, I. C., Denton, G. H., Kellogg, T. B., and McGinnis, L. D. (1981). Oxygen isotope ratios of Antarctic permafrost and glacier ice. In Dry Valley drilling project, volume 33 of Antarctic Research Series, pages 131-139. 
Sturm, C., Zhang, Q., and Noone, D. (2010). An introduction to stable water isotopes in climate models: benefits of forward proxy modelling for paleoclimatology. Climate of the Past, 6(1).

Sugden, D. E. (1996). The East Antarctic Ice Sheet: unstable ice or unstable ideas? Transactions of the Institute of British Geographers, 21(3):443-454.

Sugden, D. E., Denton, G. H., and Marchant, D. R. (1991). Subglacial meltwater channel systems and ice sheet overriding, Asgard Range, Antarctica. Geografiska Annaler: Series A, Physical Geography, 73(2):109-121.

Sugden, D. E., Marchant, D., Potter, N., Souchez, R. A., Denton, G. H., Swisher III, C. C., and Tison, J.-L. (1995). Preservation of Miocene glacier ice in East Antarctica. Nature, 376(6539):412-414.

Sugden, D. E., Summerfield, M. A., Denton, G. H., Wilch, T. I., McIntosh, W. C., Marchant, D., and Rutford, R. H. (1999). Landscape development in the Royal Society Range, southern Victoria Land, Antarctica: stability since the mid-Miocene. Geomorphology, 28(3-4):181-200.

Summerfield, M., Stuart, F., Cockburn, H., Sugden, D., Denton, G., Dunai, T., and Marchant, D. (1999). Long-term rates of denudation in the Dry Valleys, Transantarctic Mountains, southern Victoria Land, Antarctica based on in-situ-produced cosmogenic ${ }^{21} \mathrm{Ne}$. Geomorphology, 27(1-2):113-129.

Super, J. R., Thomas, E., Pagani, M., Huber, M., O’Brien, C., and Hull, P. M. (2018). North Atlantic temperature and $\rho \mathrm{CO}_{2}$ coupling in the early-middle Miocene. Geology, 46(6):519-522.

Svendsen, J. I., Alexanderson, H., Astakhov, V. I., Demidov, I., Dowdeswell, J. A., Funder, S., Gataullin, V., Henriksen, M., Hjort, C., and Houmark-Nielsen, M. (2004). Late Quaternary ice sheet history of northern Eurasia. Quaternary Science Reviews, 23(11-13):1229-1271.

Swanger, K. M. (2017). Buried ice in Kennar Valley: a late Pleistocene remnant of Taylor Glacier. Antarctic Science, 29(3):239-251.

Swanger, K. M., Babcock, E., Winsor, K., and Valletta, R. D. (2019). Rock glaciers in Pearse Valley, Antarctica record outlet and alpine glacier advance from MIS 5 through the Holocene. Geomorphology, 336:40-51.

Swanger, K. M., Marchant, D., Kowalewski, D. E., and Head III, J. W. (2010). Viscous flow lobes in central Taylor Valley, Antarctica: origin as remnant buried glacial ice. Geomorphology, 120(3-4):174-185.

Swanger, K. M., Marchant, D., Schaefer, J. M., Winckler, G., and Head III, J. W. (2011). Elevated East Antarctic outlet glaciers during warmer-than-present climates in southern Victoria Land. Global and Planetary Change, 79(1-2):61-72.

Tahmasebi, F., Longstaffe, F. J., and Zazula, G. (2018). Nitrogen isotopes suggest a change in nitrogen dynamics between the Late Pleistocene and modern time in Yukon, Canada. PloS one, 13(2):E0192713. 
Takamatsu, N., Kato, N., Matsumoto, G. I., and Torii, T. (1993). Salt origin viewed from lithium distributions in lake and pond waters in the McMurdo Dry Valleys, Antarctica. Internationale Vereinigung für theoretische und angewandte Limnologie: Verhandlungen, 25(2):954-956.

Takamatsu, N., Matsumoto, G. I., Nakaya, S., and Torii, T. (1988). Origin of salts in pond waters of the Ladyrinth in Southern Victoria Land, Antarctica: a study on lithium and boron abundances. Antarctic Record, 32(2):103-112.

Tamppari, L., Anderson, R., Archer, P., Douglas, S., Kounaves, S., McKay, C., Ming, D., Moore, Q., Quinn, J., and Smith, P. (2012). Effects of extreme cold and aridity on soils and habitability: McMurdo Dry Valleys as an analogue for the Mars Phoenix landing site. Antarctic Science, 24(3):211-228.

Taylor, T. P., Ding, M., Ehler, D. S., Foreman, T. M., Kaszuba, J. P., and Sauer, N. N. (2003). Beryllium in the environment: a review. Journal of Environmental Science and Health, Part A, 38(2):439-469.

Tessier, A., Campbell, P. G., and Bisson, M. (1979). Sequential extraction procedure for the speciation of particulate trace metals. Analytical chemistry, 51(7):844-851.

Thomas, E. R., Melchior Van Wessem, J., Roberts, J., Isaksson, E., Schlosser, E., Fudge, T. J., Vallelonga, P., Medley, B., Lenaerts, J., and Bertler, N. (2017). Regional Antarctic snow accumulation over the past 1000 years. Climate of the Past, 13(11):1491-1513.

Thomas, H. R., Cleall, P., Li, Y.-C., Harris, C., and Kern-Luetschg, M. (2009). Modelling of cryogenic processes in permafrost and seasonally frozen soils. Geotechnique, 59(3):173184.

Tieszen, L. L. (1991). Natural variations in the carbon isotope values of plants: implications for archaeology, ecology, and paleoecology. Journal of Archaeological Science, 18(3):227248.

Tipple, B. J., Meyers, S. R., and Pagani, M. (2010). Carbon isotope ratio of Cenozoic $\mathrm{CO}_{2}$ : A comparative evaluation of available geochemical proxies. Paleoceanography, 25(3).

Toner, J. D. and Sletten, R. S. (2013). The formation of Ca-Cl-rich groundwaters in the Dry Valleys of Antarctica: field measurements and modeling of reactive transport. Geochimica et Cosmochimica Acta, 110:84-105.

Toner, J. D., Sletten, R. S., and Prentice, M. L. (2013). Soluble salt accumulations in Taylor Valley, Antarctica: implications for paleolakes and Ross Sea Ice Sheet dynamics. Journal of Geophysical Research: Earth Surface, 118(1):198-215.

Torii, T. (1981). A review of the Dry Valley Drilling Project, 1971-76. Polar record, 20(129):533-541.

Trinh-Le, C. A. (2017). Dry sedimentation processes in the high-elevation McMurdo Dry Valleys, Antarctica: a case study in University Valley. Masters thesis, Victoria University of Wellington, New Zealand. 
Tuller, M. and Or, D. (2005). Water films and scaling of soil characteristic curves at low water contents. Water Resources Research, 41(9).

Tuniz, C., Pal, D., Moniot, R., Savin, W., Kruse, T., Herzog, G., and Evans, J. (1983). Recent cosmic ray exposure history of ALHA 81005. Geophysical Research Letters, 10(9):804-806.

Uxa, T., Kř́̌žek, M., and Hrbáček, F. (2020). PERICLIMv1.0: a model deriving palaeo-air temperatures from thaw depth in past permafrost regions. Geoscientific Model Development Discussions, pages 1-22.

Valletta, R. D., Willenbring, J. K., Lewis, A. R., Ashworth, A. C., and Caffee, M. (2015). Extreme decay of meteoric Beryllium-10 as a proxy for persistent aridity. Scientific reports, $5: 17813$.

van der Meer, J. J. and Menzies, J. (2011). The micromorphology of unconsolidated sediments. Sedimentary Geology, 238(3-4):213-232.

Van Goethem, M. W., Vikram, S., Hopkins, D. W., Hall, G., Woodborne, S., Aspray, T. J., Hogg, I. D., Cowan, D. A., and Makhalanyane, T. P. (2020). Nutrient parsimony shapes diversity and functionality in hyper-oligotrophic Antarctic soils. bioRxiv.

Van Tatenhove, F. G. and Olesen, O. B. (1994). Ground temperature and related permafrost characteristics in West Greenland. Permafrost and Periglacial Processes, 5(4):199-215.

Veblen, T. T. (2007). Temperate forests of the Southern Andean region. The physical geography of South America, 13:217-231.

Veldkamp, T. (1999). Soils and geomorphology. Soil Science, 164(10):772-773.

Verret, M., Wang, Y., Bjornson, J., and Lacelle, D. (2019). Hummocks in alpine tundra, northern British Columbia, Canada: distribution, morphology and organic carbon composition. Arctic Science, 5(3):127-147.

Vesely, J., Norton, S., Skrivan, P., Majer, V., Kram, P., Navratil, T., and Kaste, J. (2002). Environmental chemistry of beryllium. Reviews in Mineralogy and Geochemistry, 50(1):291317.

Vieira, G., Bockheim, J., Guglielmin, M., Balks, M., Abramov, A. A., Boelhouwers, J., Cannone, N., Ganzert, L., Gilichinsky, D. A., and Goryachkin, S. (2010). Thermal state of permafrost and active-layer monitoring in the antarctic: advances during the international polar year 2007-2009. Permafrost and Periglacial Processes, 21(2):182-197.

Vishnivetskaya, T. A., Buongiorno, J., Bird, J., Krivushin, K., Spirina, E. V., Oshurkova, V., Shcherbakova, V. A., Wilson, G., Lloyd, K. G., and Rivkina, E. M. (2018). Methanogens in the Antarctic Dry Valley permafrost. FEMS Microbiology Ecology, 94(8):fiy 109.

von Blanckenburg, F., Belshaw, N., and O’Nions, R. (1996). Separation of ${ }^{9} \mathrm{Be}$ and cosmogenic ${ }^{10} \mathrm{Be}$ from environmental materials and SIMS isotope dilution analysis. Chemical Geology, 129(1-2):93-99. 
von Blanckenburg, F. and Bouchez, J. (2014). River fluxes to the sea from the ocean's ${ }^{10} \mathrm{Be} /{ }^{9} \mathrm{Be}$ ratio. Earth and Planetary Science Letters, 387:34-43.

von Blanckenburg, F., Bouchez, J., Ibarra, D. E., and Maher, K. (2015). Stable runoff and weathering fluxes into the oceans over Quaternary climate cycles. Nature Geoscience, 8(7):538-542.

von Blanckenburg, F., Bouchez, J., and Wittmann, H. (2012). Earth surface erosion and weathering from the ${ }^{10} \mathrm{Be}$ (meteoric) $/{ }^{9} \mathrm{Be}$ ratio. Earth and Planetary Science Letters, 351:295-305.

Von Guerard, P., McKnight, D. M., Harnish, R., Gartner, J., and Andrews, E. (1995). Streamflow, water-temperature, and specific-conductance data for selected streams draining into Lake Fryxell, Lower Taylor Valley, Victoria Land, Antarctica, 1990-92. Report 23311258, US Geological Survey: USGS Earth Science Information Center.

Wada, E., Shibata, R., and Torii, T. (1981). ${ }^{15} \mathrm{~N}$ abundance in Antarctica: origin of soil nitrogen and ecological implications. Nature, 292(5821):327-329.

Wada, E., Terazaki, M., Kabaya, Y., and Nemoto, T. (1987). ${ }^{15} \mathrm{~N}$ and ${ }^{13} \mathrm{C}$ abundances in the Antartic Ocean with emphasis on the biogeochemical structure of the food web. Deep Sea Research Part A. Oceanographic Research Papers, 34(5-6):829-841.

Wang, F., Michalski, G., Seo, J.-H., Granger, D. E., Lifton, N., and Caffee, M. (2015). Beryllium-10 concentrations in the hyper-arid soils in the Atacama Desert, Chile: implications for arid soil formation rates and El Niño driven changes in Pliocene precipitation. Geochimica et Cosmochimica Acta, 160:227-242.

Wang, Y., Hou, S., Masson-Delmotte, V., and Jouzel, J. (2009). A new spatial distribution map of $\delta^{18} \mathrm{O}$ in Antarctic surface snow. Geophysical Research Letters, 36(6).

Warny, S., Askin, R. A., Hannah, M. J., Mohr, B. A., Raine, J. I., Harwood, D. M., Florindo, F., and Team, S. S. (2009). Palynomorphs from a sediment core reveal a sudden remarkably warm Antarctica during the middle Miocene. Geology, 37(10):955-958.

Watanabe, K. and Mizoguchi, M. (2002). Amount of unfrozen water in frozen porous media saturated with solution. Cold Regions Science and Technology, 34(2):103-110.

Webb, P. (1972). Wright Fjord, Pliocene marine invasion of an Antarctic Dry Valley. Antarctic Journal of the United States, 7:226-234.

Wehr, J. D., Sheath, R. G., and Kociolek, J. P. (2015). Freshwater algae of North America: ecology and classification. Elsevier.

Wentworth, S. J., Gibson, E. K., Velbel, M. A., and McKay, D. S. (2005). Antarctic Dry Valleys and indigenous weathering in Mars meteorites: implications for water and life on Mars. Icarus, 174(2):383-395.

Wharton Jr, R. A., Lyons, W. B., and Des Marais, D. J. (1993). Stable isotopic biogeochemistry of carbon and nitrogen in a perennially ice-covered Antarctic lake. Chemical Geology, 107(1-2):159-172. 
Wilch, T. I., Lux, D. R., Denton, G. H., and McIntosh, W. C. (1993). Minimal PliocenePleistocene uplift of the Dry Valleys sector of the Transantarctic Mountains: a key parameter in ice-sheet reconstructions. Geology, 21(9):841-844.

Willenbring, J. K. and von Blanckenburg, F. (2010). Meteoric cosmogenic Beryllium-10 adsorbed to river sediment and soil: applications for Earth-surface dynamics. EarthScience Reviews, 98(1-2):105-122.

Williams, M., Siveter, D. J., Ashworth, A. C., Wilby, P. R., Horne, D. J., Lewis, A. R., and Marchant, D. R. (2008). Exceptionally preserved lacustrine ostracods from the middle Miocene of Antarctica: implications for high-latitude palaeoenvironment at 77 south. Proceedings of the Royal Society B: Biological Sciences, 275(1650):2449-2454.

Williams, T., van de Flierdt, T., Hemming, S. R., Chung, E., Roy, M., and Goldstein, S. L. (2010). Evidence for iceberg armadas from East Antarctica in the Southern Ocean during the late Miocene and early Pliocene. Earth and Planetary Science Letters, 290(3-4):351361.

Wilson, A. (1979). Geochemical problems of the Antarctic dry areas. Nature, 280(5719):205208.

Wilson, G., Barron, J., Ashworth, A., Askin, R., Carter, J., Curren, M., Dalhuisen, D., Friedmann, E., Fyodorov-Davidov, D., and Gilichinsky, D. (2002). The Mount Feather Diamicton of the Sirius Group: an accumulation of indicators of Neogene Antarctic glacial and climatic history. Palaeogeography, Palaeoclimatology, Palaeoecology, 182(1-2):117131.

Wilson, G., Braddock, P., Forman, S. L., Friedmann, E. I., Rivkina, E. M., Chanton, J. P., Gilichinsky, D. A., Fyodorov-Davidov, D. G., Ostroumov, V. E., and Sorokovikov, V. (1996). Coring for microbial records of Antarctic climate. Antarctic Journal of the United States, 31:83-85.

Wilson, G. S. (1995). The Neogene East Antarctic Ice Sheet: a dynamic or stable feature? Quaternary Science Reviews, 14(2):101-123.

Witherow, R. A., Lyons, W., Bertler, N. A., Welch, K. A., Mayewski, P. A., Sneed, S. B., Nylen, T., Handley, M. J., and Fountain, A. (2006). The aeolian flux of calcium, chloride and nitrate to the McMurdo Dry Valleys landscape: evidence from snow pit analysis. Antarctic Science, 18(4):497-505.

Wittmann, H., von Blanckenburg, F., Bouchez, J., Dannhaus, N., Naumann, R., Christl, M., and Gaillardet, J. (2012). The dependence of meteoric ${ }^{10} \mathrm{Be}$ concentrations on particle size in Amazon River bed sediment and the extraction of reactive ${ }^{10} \mathrm{Be} /{ }^{9} \mathrm{Be}$ ratios. Chemical Geology, 318:126-138.

Wooller, M. J., Zazula, G. D., Edwards, M., Froese, D. G., Boone, R. D., Parker, C., and Bennett, B. (2007). Stable carbon isotope compositions of Eastern Beringian grasses and sedges: investigating their potential as paleoenvironmental indicators. Arctic, Antarctic, and Alpine Research, 39(2):318-331. 
Yallop, M. L., Anesio, A. M., Perkins, R. G., Cook, J., Telling, J., Fagan, D., MacFarlane, J., Stibal, M., Barker, G., and Bellas, C. (2012). Photophysiology and albedo-changing potential of the ice algal community on the surface of the Greenland Ice Sheet. The ISME journal, 6(12):2302-2313.

Yan, Y., Bender, M. L., Brook, E. J., Clifford, H. M., Kemeny, P. C., Kurbatov, A. V., Mackay, S., Mayewski, P. A., Ng, J., and Severinghaus, J. P. (2019). Two-million-year-old snapshots of atmospheric gases from Antarctic ice. Nature, 574(7780):663-666.

You, Y., Huber, M., Müller, R., Poulsen, C., and Ribbe, J. (2009). Simulation of the middle Miocene climate optimum. Geophysical Research Letters, 36(4).

Zachos, J., Dickens, G. R., and Zeebe, R. E. (2008). An early Cenozoic perspective on greenhouse warming and carbon-cycle dynamics. Nature, 451(7176):279-283.

Zachos, J., Pagani, M., Sloan, L., Thomas, E., and Billups, K. (2001). Trends, rhythms, and aberrations in global climate 65 Ma to present. science, 292(5517):686-693.

Zhang, T., Barry, R. G., Knowles, K., Heginbottom, J., and Brown, J. (1999). Statistics and characteristics of permafrost and ground ice distribution in the Northern Hemisphere. Polar Geography, 23(2):132-154.

Zhang, Y. G., Pagani, M., Liu, Z., Bohaty, S. M., and DeConto, R. (2013). A 40-millionyear history of atmospheric $\mathrm{CO}_{2}$. Philosophical Transactions of the Royal Society A: Mathematical, Physical and Engineering Sciences, 371(2001):20130096.

Zhi, J., Jing, C., Lin, S., Zhang, C., Liu, Q., DeGloria, S. D., and Wu, J. (2014). Estimating soil organic carbon stocks and spatial patterns with statistical and GIS-based methods. PloS one, 9(5).

Zondervan, A., Poletti, M., Purcell, C. R., and Sparks, R. J. (2007). Accelerator and beamline upgrades at the AMS facility of GNS Science, New Zealand. Nuclear Instruments and Methods in Physics Research Section B: Beam Interactions with Materials and Atoms, 259(1):47-49. 


\section{Appendix A}

\section{GRADISTAT Particle size classification}

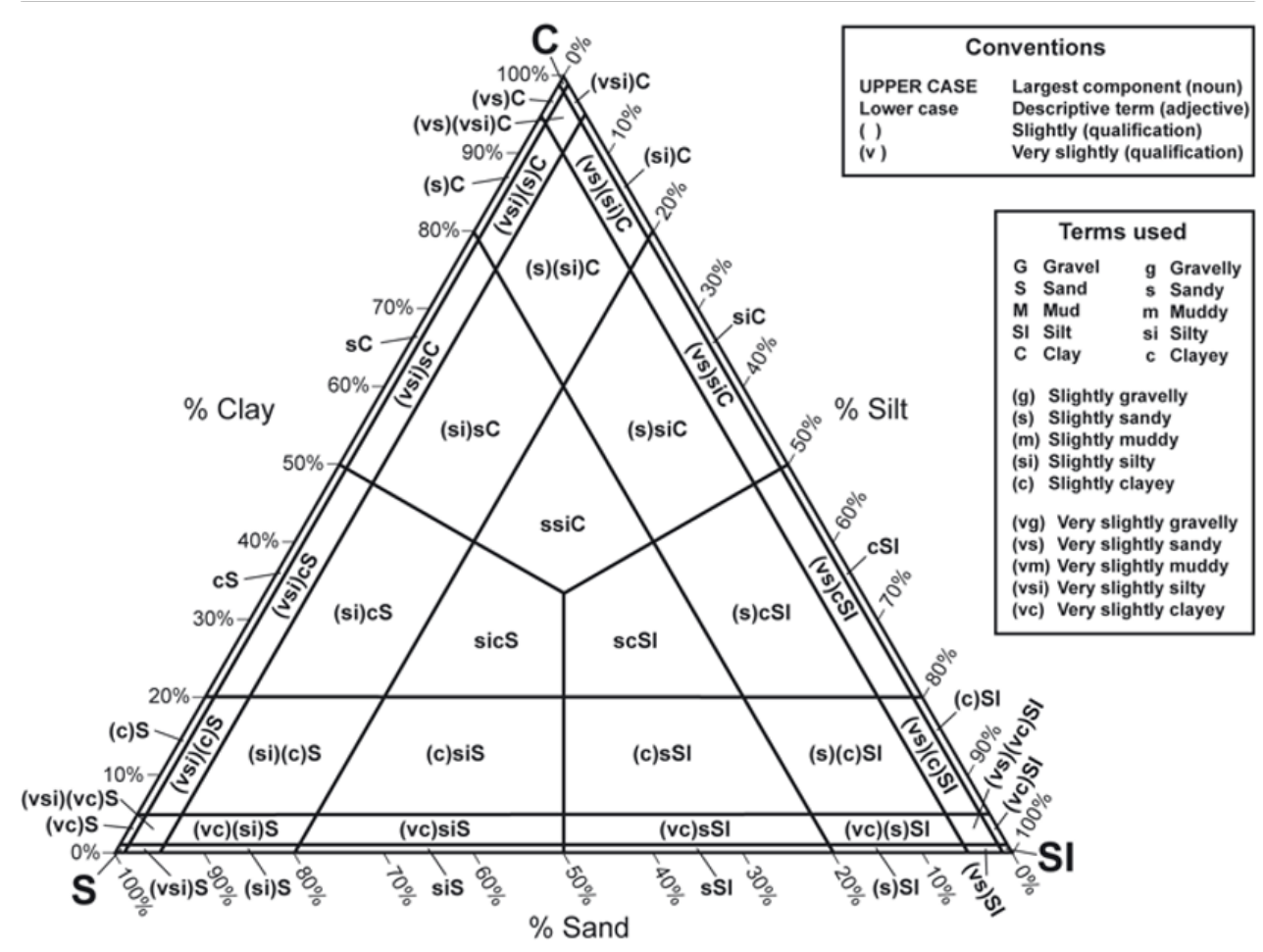

Fig. A.1 Particle size distribution classification based on the percentages of sand, silt and clay (Blott and Pye, 2012) 



\section{Appendix B}

\section{Multiple comparison tests for grain-size}

Table B.1 Multiple comparison test ( $p$-values) of $\%$ clay of core FHDP2C ( $p \geq 0.05$ in bold)

\begin{tabular}{cccccccc}
\hline & $\mathbf{D P}$ & $\mathbf{1}$ & $\mathbf{2}$ & $\mathbf{3}$ & $\mathbf{4}$ & $\mathbf{5}$ & $\mathbf{6}$ \\
\hline $\mathbf{1}$ & $9.5 \mathrm{e}^{-8}$ & & & & & & \\
\hline $\mathbf{2}$ & $1.1 \mathrm{e}^{-5}$ & $\mathbf{0 . 6 3}$ & & & & & \\
\hline $\mathbf{3}$ & $\mathbf{0 . 9 9}$ & $1.2 \mathrm{e}^{-6}$ & 0.00022 & & & & \\
\hline $\mathbf{4}$ & $7.8 \mathrm{e}^{-8}$ & 0.03 & $\mathbf{0 . 9 2}$ & $9.4 \mathrm{e}^{-5}$ & & & \\
\hline $\mathbf{5}$ & $\mathbf{0 . 5 5}$ & $2.1 \mathrm{e}^{-7}$ & $6.7 \mathrm{e}^{-5}$ & $\mathbf{0 . 6 8}$ & $6.0 \mathrm{e}^{-8}$ & & \\
\hline $\mathbf{6}$ & $5.9 \mathrm{e}^{-8}$ & $\mathbf{0 . 9 9}$ & $\mathbf{0 . 6 6}$ & $6.2 \mathrm{e}^{-8}$ & $9.7 \mathrm{e}^{-8}$ & $6.0 \mathrm{e}^{-8}$ & \\
\hline $\mathbf{7}$ & $\mathbf{0 . 9 9}$ & $1.8 \mathrm{e}^{-7}$ & $4.5 \mathrm{e}^{-5}$ & $\mathbf{0 . 9 8}$ & $7.9 \mathrm{e}^{-8}$ & $\mathbf{0 . 9 5}$ & $6.0 \mathrm{e}^{-8}$ \\
\hline
\end{tabular}

Table B.2 Multiple comparison test ( $\mathrm{p}$-values) of $\%$ silt of core FHDP2C ( $\mathrm{p} \geq 0.05$ in bold)

\begin{tabular}{cccccccc}
\hline & DP & $\mathbf{1}$ & $\mathbf{2}$ & $\mathbf{3}$ & $\mathbf{4}$ & $\mathbf{5}$ & $\mathbf{6}$ \\
\hline $\mathbf{1}$ & 0.0024 & & & & & & \\
\hline $\mathbf{2}$ & $\mathbf{0 . 4 7}$ & $\mathbf{0 . 4 2}$ & & & & & \\
\hline $\mathbf{3}$ & $\mathbf{0 . 8 8}$ & 0.00043 & 0.094 & & & & \\
\hline $\mathbf{4}$ & $\mathbf{0 . 9 9}$ & 0.00010 & $\mathbf{0 . 1 3}$ & $\mathbf{0 . 8 7}$ & & & \\
\hline $\mathbf{5}$ & 0.040 & $8.5 \mathrm{e}^{-8}$ & $7.1 \mathrm{e}^{-5}$ & $\mathbf{0 . 9 9}$ & $1.7 \mathrm{e}^{-6}$ & & \\
\hline $\mathbf{6}$ & 0.00014 & $\mathbf{0 . 8 9}$ & $\mathbf{0 . 8 0}$ & 0.00017 & $6.0 \mathrm{e}^{-8}$ & $6.0 \mathrm{e}^{-8}$ & \\
\hline $\mathbf{7}$ & $\mathbf{0 . 0 8 0}$ & $2.2 \mathrm{e}^{-7}$ & 0.00030 & $\mathbf{0 . 9 9}$ & 0.0047 & $\mathbf{0 . 9 9}$ & $6.0 \mathrm{e}^{-8}$ \\
\hline
\end{tabular}


Table B.3 Multiple comparison test ( $\mathrm{p}$-values) of $\%$ sand of core FHDP2C ( $\mathrm{p} \geq 0.05$ in bold)

\begin{tabular}{cccccccc}
\hline & DP & $\mathbf{1}$ & $\mathbf{2}$ & $\mathbf{3}$ & $\mathbf{4}$ & $\mathbf{5}$ & $\mathbf{6}$ \\
\hline $\mathbf{1}$ & $1.6 \mathrm{e}^{-5}$ & & & & & & \\
\hline $\mathbf{2}$ & 0.02 & $\mathbf{0 . 4 1}$ & & & & & \\
\hline $\mathbf{3}$ & $\mathbf{0 . 9 6}$ & $1.5 \mathrm{e}^{-5}$ & 0.0070 & & & & \\
\hline $\mathbf{4}$ & $\mathbf{0 . 2 4}$ & 0.00033 & $\mathbf{0 . 2 9}$ & $\mathbf{0 . 1 0}$ & & & \\
\hline $\mathbf{5}$ & $\mathbf{0 . 8 4}$ & $6.6 \mathrm{e}^{-8}$ & $1.8 \mathrm{e}^{-5}$ & $\mathbf{0 . 9 9}$ & $6.0 \mathrm{e}^{-8}$ & & \\
\hline $\mathbf{6}$ & $6.4 \mathrm{e}^{-8}$ & $\mathbf{0 . 9 4}$ & $\mathbf{0 . 6 9}$ & $8.24 \mathrm{e}^{-7}$ & $6.0 \mathrm{e}^{-8}$ & $6.0 \mathrm{e}^{-8}$ & \\
\hline $\mathbf{7}$ & $\mathbf{0 . 6 9}$ & $8.0 \mathrm{e}^{-8}$ & $4.3 \mathrm{e}^{-5}$ & $\mathbf{0 . 9 9}$ & $2.3 \mathrm{e}^{-5}$ & $\mathbf{0 . 9 9}$ & $6.0 \mathrm{e}^{-8}$ \\
\hline
\end{tabular}

Table B.4 Stratigraphic units that have statistically indistinct clay (\%), silt (\%) and sand (\%) proportions in core FHDP2C

\begin{tabular}{llllllll}
\hline & DP & $\mathbf{1}$ & $\mathbf{2}$ & $\mathbf{3}$ & $\mathbf{4}$ & $\mathbf{5}$ & $\mathbf{6}$ \\
\hline $\mathbf{1}$ & & & & & & & \\
\hline $\mathbf{2}$ & & $\mathrm{X}$ & & & & \\
\hline $\mathbf{3}$ & $\mathrm{X}$ & & & & & \\
\hline $\mathbf{4}$ & & & $\mathrm{X}$ & & & \\
\hline $\mathbf{5}$ & & & & $\mathrm{X}$ & & \\
\hline $\mathbf{6}$ & & $\mathrm{X}$ & $\mathrm{X}$ & & & \\
\hline 7 & $\mathrm{X}$ & & & $\mathrm{X}$ & & $\mathrm{X}$ \\
\hline
\end{tabular}




\section{Appendix C}

\section{Multiple comparison tests for major elements}

Table C.1 Multiple comparison test ( $\mathrm{p}$-values) of Mg of core FHDP2C ( $\mathrm{p} \geq 0.05$ in bold)

\begin{tabular}{cccccccc}
\hline & DP & $\mathbf{1}$ & $\mathbf{2}$ & $\mathbf{3}$ & $\mathbf{4}$ & $\mathbf{5}$ & $\mathbf{6}$ \\
\hline $\mathbf{1}$ & $6.0 \mathrm{e}^{-8}$ & & & & & & \\
\hline $\mathbf{2}$ & $6.0 \mathrm{e}^{-8}$ & 0.038 & & & & & \\
\hline $\mathbf{3}$ & $1.2 \mathrm{e}^{-3}$ & $5.0 \mathrm{e}^{-8}$ & 0.00053 & & & & \\
\hline $\mathbf{4}$ & $6.0 \mathrm{e}^{-8}$ & $3.7 \mathrm{e}^{-8}$ & $3.1 \mathrm{e}^{-6}$ & $\mathbf{0 . 9 7}$ & & & \\
\hline $\mathbf{5}$ & $6.0 \mathrm{e}^{-8}$ & $3.7 \mathrm{e}^{-8}$ & $8.2 \mathrm{e}^{-8}$ & $\mathbf{0 . 9 9}$ & $\mathbf{0 . 1 4}$ & & \\
\hline $\mathbf{6}$ & $6.0 \mathrm{e}^{-8}$ & $6.9 \mathrm{e}^{-5}$ & $\mathbf{0 . 8 4}$ & 0.00077 & $3.7 \mathrm{e}^{-8}$ & $3.7 \mathrm{e}^{-8}$ & \\
\hline $\mathbf{7}$ & $6.0 \mathrm{e}^{-8}$ & $3.8 \mathrm{e}^{-8}$ & 0.00028 & $\mathbf{0 . 9 3}$ & $\mathbf{0 . 9 9}$ & $\mathbf{0 . 4 1}$ & $1.58 \mathrm{e}^{-5}$ \\
\hline
\end{tabular}

Table C.2 Multiple comparison test ( $\mathrm{p}$-values) of Al of core FHDP2C ( $\mathrm{p} \geq 0.05$ in bold)

\begin{tabular}{cccccccc}
\hline & $\mathbf{D P}$ & $\mathbf{1}$ & $\mathbf{2}$ & $\mathbf{3}$ & $\mathbf{4}$ & $\mathbf{5}$ & $\mathbf{6}$ \\
\hline $\mathbf{1}$ & $6.0 \mathrm{e}^{-8}$ & & & & & & \\
\hline $\mathbf{2}$ & $6.0 \mathrm{e}^{-8}$ & $\mathbf{0 . 8 8}$ & & & & & \\
\hline $\mathbf{3}$ & $6.0 \mathrm{e}^{-8}$ & $2.0 \mathrm{e}^{-6}$ & $3.6 \mathrm{e}^{-5}$ & & & & \\
\hline $\mathbf{4}$ & $6.0 \mathrm{e}^{-8}$ & $2.6 \mathrm{e}^{-7}$ & $2.8 \mathrm{e}^{-6}$ & $\mathbf{0 . 6 0}$ & & & \\
\hline $\mathbf{5}$ & $6.0 \mathrm{e}^{-8}$ & $3.7 \mathrm{e}^{-8}$ & $3.7 \mathrm{e}^{-7}$ & $\mathbf{0 . 9 6}$ & $3.7 \mathrm{e}^{-8}$ & & \\
\hline $\mathbf{6}$ & $6.0 \mathrm{e}^{-8}$ & $1.2 \mathrm{e}^{-7}$ & $1.0 \mathrm{e}^{-6}$ & $\mathbf{0 . 8 5}$ & $\mathbf{0 . 9 4}$ & $2.99 \mathrm{e}^{-6}$ & \\
\hline $\mathbf{7}$ & $6.0 \mathrm{e}^{-8}$ & $3.7 \mathrm{e}^{-8}$ & $3.7 \mathrm{e}^{-8}$ & $\mathbf{0 . 5 0}$ & $5.5 \mathrm{e}^{-8}$ & $\mathbf{0 . 5 1}$ & $4.1 \mathrm{e}^{-6}$ \\
\hline
\end{tabular}


Table C.3 Multiple comparison test ( $\mathrm{p}$-values) of Ca of core FHDP2C ( $\mathrm{p} \geq 0.05$ in bold)

\begin{tabular}{cccccccc}
\hline & DP & $\mathbf{1}$ & $\mathbf{2}$ & $\mathbf{3}$ & $\mathbf{4}$ & $\mathbf{5}$ & $\mathbf{6}$ \\
\hline $\mathbf{1}$ & $\mathbf{0 . 2 0}$ & & & & & & \\
\hline $\mathbf{2}$ & $\mathbf{0 . 8 4}$ & $\mathbf{0 . 8 8}$ & & & & & \\
\hline $\mathbf{3}$ & $\mathbf{0 . 9 2}$ & 0.022 & $\mathbf{0 . 2 2}$ & & & & \\
\hline $\mathbf{4}$ & 0.043 & $1.8 \mathrm{e}^{-5}$ & 0.00042 & $\mathbf{0 . 9 9}$ & & & \\
\hline $\mathbf{5}$ & 0.0065 & $\mathbf{0 . 9 9}$ & $\mathbf{0 . 8 1}$ & 0.0015 & $3.7 \mathrm{e}^{-8}$ & & \\
\hline $\mathbf{6}$ & 0.00030 & $\mathbf{0 . 9 9}$ & $\mathbf{0 . 3 2}$ & 0.00014 & $3.7 \mathrm{e}^{-8}$ & $\mathbf{0 . 6 0}$ & \\
\hline $\mathbf{7}$ & 0.0040 & $\mathbf{0 . 9 9}$ & $\mathbf{0 . 4 7}$ & 0.0006 & $3.7 \mathrm{e}^{-8}$ & $\mathbf{0 . 9 1}$ & $\mathbf{0 . 9 9}$ \\
\hline
\end{tabular}

Table C.4 Multiple comparison test ( $p$-values) of Fe of core FHDP2C ( $\mathrm{p} \geq 0.05$ in bold)

\begin{tabular}{cccccccc}
\hline & $\mathbf{D P}$ & $\mathbf{1}$ & $\mathbf{2}$ & $\mathbf{3}$ & $\mathbf{4}$ & $\mathbf{5}$ & $\mathbf{6}$ \\
\hline $\mathbf{1}$ & $6.0 \mathrm{e}^{-8}$ & & & & & & \\
\hline $\mathbf{2}$ & $1.7 \mathrm{e}^{-7}$ & $\mathbf{0 . 1 1}$ & & & & & \\
\hline $\mathbf{3}$ & $\mathbf{0 . 6 7}$ & $3.7 \mathrm{e}^{-8}$ & $8.0 \mathrm{e}^{-8}$ & & & & \\
\hline $\mathbf{4}$ & $\mathbf{0 . 2 7}$ & $3.7 \mathrm{e}^{-8}$ & $1.2 \mathrm{e}^{-6}$ & 0.01 & & & \\
\hline $\mathbf{5}$ & $\mathbf{0 . 4 0}$ & $3.7 \mathrm{e}^{-8}$ & $3.7 \mathrm{e}^{-8}$ & $\mathbf{0 . 9 9}$ & $3.7 \mathrm{e}^{-8}$ & & \\
\hline $\mathbf{6}$ & $\mathbf{6 . 0 \mathrm { e } ^ { - 8 }}$ & 0.00041 & $\mathbf{0 . 8 2}$ & $4.5 \mathrm{e}^{-8}$ & $3.7 \mathrm{e}^{-8}$ & $3.7 \mathrm{e}^{-8}$ & \\
\hline $\mathbf{7}$ & $\mathbf{0 . 6 4}$ & $3.7 \mathrm{e}^{-8}$ & $3.7 \mathrm{e}^{-8}$ & $\mathbf{0 . 9 9}$ & $2.1 \mathrm{e}^{-5}$ & $\mathbf{0 . 9 9}$ & $3.7 \mathrm{e}^{-8}$ \\
\hline
\end{tabular}

Table C.5 Multiple comparison test ( $\mathrm{p}$-values) of Si of core FHDP2C ( $\mathrm{p} \geq 0.05$ in bold)

\begin{tabular}{cccccccc}
\hline & $\mathbf{D P}$ & $\mathbf{1}$ & $\mathbf{2}$ & $\mathbf{3}$ & $\mathbf{4}$ & $\mathbf{5}$ & $\mathbf{6}$ \\
\hline $\mathbf{1}$ & 0.00011 & & & & & & \\
\hline $\mathbf{2}$ & $2.9 \mathrm{e}^{-7}$ & $\mathbf{0 . 9 9}$ & & & & & \\
\hline $\mathbf{3}$ & $6.0 \mathrm{e}^{-8}$ & 0.0050 & 0.009 & & & & \\
\hline $\mathbf{4}$ & $6.0 \mathrm{e}^{-8}$ & 0.00082 & 0.00067 & $\mathbf{0 . 9 6}$ & & & \\
\hline $\mathbf{5}$ & $6.0 \mathrm{e}^{-8}$ & $1.8 \mathrm{e}^{-7}$ & $5.4 \mathrm{e}^{-8}$ & $\mathbf{0 . 9 0}$ & $1.4 \mathrm{e}^{-7}$ & & \\
\hline $\mathbf{6}$ & $6.0 \mathrm{e}^{-8}$ & 0.0042 & 0.0053 & $\mathbf{0 . 8 7}$ & $\mathbf{0 . 9 7}$ & $6.0 \mathrm{e}^{-7}$ & \\
\hline $\mathbf{7}$ & $6.0 \mathrm{e}^{-8}$ & $3.8 \mathrm{e}^{-8}$ & $3.7 \mathrm{e}^{-8}$ & $\mathbf{0 . 1 3}$ & $5.0 \mathrm{e}^{-8}$ & $\mathbf{0 . 0 6}$ & $4.9 \mathrm{e}^{-8}$ \\
\hline & & & & & & &
\end{tabular}


Table C.6 Multiple comparison test ( $p$-values) of Sr of core FHDP2C ( $p \geq 0.05$ in bold)

\begin{tabular}{cccccccc}
\hline & DP & $\mathbf{1}$ & $\mathbf{2}$ & $\mathbf{3}$ & $\mathbf{4}$ & $\mathbf{5}$ & $\mathbf{6}$ \\
\hline $\mathbf{1}$ & $8.0 \mathrm{e}^{-6}$ & & & & & & \\
\hline $\mathbf{2}$ & 0.023 & $\mathbf{0 . 1 7}$ & & & & & \\
\hline $\mathbf{3}$ & $\mathbf{0 . 9 9}$ & $1.4 \mathrm{e}^{-5}$ & 0.021 & & & & \\
\hline $\mathbf{4}$ & $\mathbf{0 . 9 9}$ & $4.2 \mathrm{e}^{-8}$ & 0.00017 & $\mathbf{0 . 9 9}$ & & & \\
\hline $\mathbf{5}$ & 0.020 & 0.00078 & $\mathbf{0 . 7 9}$ & $\mathbf{0 . 0 5 7}$ & $3.7 \mathrm{e}^{-7}$ & & \\
\hline $\mathbf{6}$ & $6.0 \mathrm{e}^{-8}$ & $\mathbf{0 . 9 8}$ & $\mathbf{0 . 1 1}$ & $1.9 \mathrm{e}^{-7}$ & $3.7 \mathrm{e}^{-8}$ & $3.7 \mathrm{e}^{-8}$ & \\
\hline $\mathbf{7}$ & $\mathbf{0 . 0 6 4}$ & 0.0047 & $\mathbf{0 . 9 3}$ & $\mathbf{0 . 0 7 8}$ & $4.3 \mathrm{e}^{-5}$ & $\mathbf{0 . 9 9}$ & $6.7 \mathrm{e}^{-6}$ \\
\hline
\end{tabular}

Table C.7 Multiple comparison test ( $\mathrm{p}$-values) of Ti of core FHDP2C ( $\mathrm{p} \geq 0.05$ in bold)

\begin{tabular}{cccccccc}
\hline & $\mathbf{D P}$ & $\mathbf{1}$ & $\mathbf{2}$ & $\mathbf{3}$ & $\mathbf{4}$ & $\mathbf{5}$ & $\mathbf{6}$ \\
\hline $\mathbf{1}$ & $6.0 \mathrm{e}^{-8}$ & & & & & & \\
\hline $\mathbf{2}$ & $2.1 \mathrm{e}^{-6}$ & $\mathbf{0 . 4 8}$ & & & & & \\
\hline $\mathbf{3}$ & $\mathbf{0 . 9 9}$ & $1.4 \mathrm{e}^{-5}$ & 0.0032 & & & & \\
\hline $\mathbf{4}$ & $\mathbf{1 . 0 0}$ & $3.7 \mathrm{e}^{-8}$ & $4.1 \mathrm{e}^{-8}$ & $\mathbf{0 . 9 7}$ & & & \\
\hline $\mathbf{5}$ & 0.0013 & $1.1 \mathrm{e}^{-5}$ & 0.0090 & $\mathbf{0 . 5 0}$ & $3.7 \mathrm{e}^{-8}$ & & \\
\hline $\mathbf{6}$ & 0.0051 & $7.9 \mathrm{e}^{-6}$ & 0.0062 & $\mathbf{0 . 6 2}$ & $4.5 \mathrm{e}^{-8}$ & $\mathbf{0 . 9 9}$ & \\
\hline $\mathbf{7}$ & $1.8 \mathrm{e}^{-5}$ & 0.0091 & $\mathbf{0 . 6 6}$ & 0.048 & $3.7 \mathrm{e}^{-8}$ & $\mathbf{0 . 1 8}$ & $\mathbf{0 . 1 2}$ \\
\hline
\end{tabular}

Table C.8 Element concentrations that are statistically indistinct in stratigraphic units (numbered 1-7) of core FHDP2C. Units with $\geq 5$ elements in common in bold

\begin{tabular}{|c|c|c|c|c|c|c|c|}
\hline & DP & 1 & 2 & 3 & 4 & 5 & 6 \\
\hline 1 & $\mathrm{Ca}$ & & & & & & \\
\hline 2 & $\mathrm{Ca}$ & $\begin{array}{c}\mathrm{Al}, \mathrm{Ca}, \mathrm{Fe}, \\
\mathrm{Si}, \mathrm{Sr}, \mathrm{Ti}\end{array}$ & & & & & \\
\hline 3 & $\mathrm{Ca}, \mathrm{Fe}, \mathrm{Sr}, \mathrm{Ti}$ & & $\mathrm{Ca}$ & & & & \\
\hline 4 & $\mathrm{Fe}, \mathrm{Sr}, \mathrm{Ti}$ & & & $\begin{array}{c}\text { Ca, Mg, Al, } \\
\text { Si, Sr, Ti }\end{array}$ & & & \\
\hline 5 & $\mathrm{Fe}$ & $\mathrm{Ca}$ & $\mathrm{Ca}, \mathrm{Sr}$ & $\begin{array}{c}\mathrm{Mg}, \mathrm{Al}, \mathrm{Fe}, \\
\mathrm{Si}, \mathrm{Sr}, \mathrm{Ti}\end{array}$ & $\mathrm{Mg}$ & & \\
\hline 6 & & $\mathrm{Ca}, \mathrm{Sr}$ & $\mathrm{Mg}, \mathrm{Fe}, \mathrm{Ca}, \mathrm{Sr}$ & $\mathrm{Al}, \mathrm{Si}, \mathrm{Ti}$ & $\mathrm{Al}, \mathrm{Si}$ & $\mathrm{Ca}, \mathrm{Ti}$ & \\
\hline 7 & $\mathrm{Fe}, \mathrm{Sr}$ & $\mathrm{Ca}$ & $\mathrm{Ca}, \mathrm{Sr}, \mathrm{Ti}$ & $\begin{array}{l}\mathrm{Mg}, \mathrm{Al}, \mathrm{Fe}, \\
\mathrm{Si}, \mathrm{Sr}\end{array}$ & $\mathrm{Mg}$ & ALL & $\mathrm{Ca}, \mathrm{Ti}$ \\
\hline
\end{tabular}





\section{Appendix D}

\section{Multiple comparison tests for organics}

Table D.1 Multiple comparison test ( $\mathrm{p}$-values) of SOM of core FHDP2C ( $\mathrm{p} \geq 0.05$ in bold)

\begin{tabular}{cccccccc}
\hline & DP & $\mathbf{1}$ & $\mathbf{2}$ & $\mathbf{3}$ & $\mathbf{4}$ & $\mathbf{5}$ & $\mathbf{6}$ \\
\hline $\mathbf{1}$ & $4.7 \mathrm{e}^{-7}$ & & & & & & \\
\hline $\mathbf{2}$ & $6.7 \mathrm{e}^{-4}$ & $\mathbf{0 . 9 5}$ & & & & & \\
\hline $\mathbf{3}$ & $\mathbf{0 . 4 2}$ & $\mathbf{0 . 2 1}$ & $\mathbf{0 . 7 5}$ & & & & \\
\hline $\mathbf{4}$ & $6.0 \mathrm{e}^{-8}$ & $\mathbf{1 . 0 0}$ & $\mathbf{0 . 4 4}$ & 0.0073 & & & \\
\hline $\mathbf{5}$ & $\mathbf{1 . 0 0}$ & $4.3 \mathrm{e}^{-6}$ & $4.3 \mathrm{e}^{-5}$ & $\mathbf{0 . 3 4}$ & $6.0 \mathrm{e}^{-8}$ & & \\
\hline $\mathbf{6}$ & $6.3 \mathrm{e}^{-8}$ & $\mathbf{0 . 9 9}$ & $\mathbf{1 . 0 0}$ & $\mathbf{0 . 2 2}$ & 0.042 & $6.0 \mathrm{e}^{-8}$ & \\
\hline $\mathbf{7}$ & $\mathbf{0 . 7 0}$ & $1.3 \mathrm{e}^{-7}$ & $6.2 \mathrm{e}^{-7}$ & 0.020 & $6.0 \mathrm{e}^{-8}$ & $\mathbf{0 . 1 6}$ & $6.0 \mathrm{e}^{-8}$ \\
\hline
\end{tabular}

Table D.2 Multiple comparison test ( $\mathrm{p}$-values) of carbonates of core FHDP2C ( $\mathrm{p} \geq 0.05$ in bold)

\begin{tabular}{cccccccc}
\hline & DP & $\mathbf{1}$ & $\mathbf{2}$ & $\mathbf{3}$ & $\mathbf{4}$ & $\mathbf{5}$ & $\mathbf{6}$ \\
\hline $\mathbf{1}$ & $\mathbf{0 . 3 4}$ & & & & & & \\
\hline $\mathbf{2}$ & $\mathbf{0 . 1 5}$ & $\mathbf{1 . 0 0}$ & & & & & \\
\hline $\mathbf{3}$ & $\mathbf{1 . 0 0}$ & $\mathbf{0 . 6 5}$ & $\mathbf{0 . 4 9}$ & & & & \\
\hline $\mathbf{4}$ & 0.0025 & $\mathbf{1 . 0 0}$ & $\mathbf{1 . 0 0}$ & $\mathbf{0 . 2 2}$ & & & \\
\hline $\mathbf{5}$ & $\mathbf{0 . 9 7}$ & 0.034 & 0.0030 & $\mathbf{0 . 9 9}$ & $6.0 \mathrm{e}^{-8}$ & & \\
\hline $\mathbf{6}$ & $7.1 \mathrm{e}^{-6}$ & $\mathbf{0 . 9 3}$ & $\mathbf{0 . 8 7}$ & 0.012 & 0.04 & $6.0 \mathrm{e}^{-8}$ & \\
\hline $\mathbf{7}$ & $\mathbf{0 . 5 7}$ & 0.0084 & 0.0007 & $\mathbf{0 . 8 1}$ & $6.1 \mathrm{e}^{-8}$ & $\mathbf{0 . 8 5}$ & $6.0 \mathrm{e}^{-8}$ \\
\hline
\end{tabular}


Table D.3 Multiple comparison test ( $p$-values) of $\mathrm{C}_{\text {org }}$ of core FHDP2C ( $\mathrm{p} \geq 0.05$ in bold)

\begin{tabular}{cccccccc}
\hline & DP & $\mathbf{1}$ & $\mathbf{2}$ & $\mathbf{3}$ & $\mathbf{4}$ & $\mathbf{5}$ & $\mathbf{6}$ \\
\hline $\mathbf{1}$ & 0.0069 & & & & & & \\
\hline $\mathbf{2}$ & 0.0001 & $\mathbf{0 . 1 0}$ & & & & & \\
\hline $\mathbf{3}$ & 0.0029 & $\mathbf{1 . 0 0}$ & $\mathbf{1 . 0 0}$ & & & & \\
\hline $\mathbf{4}$ & $6.0 \mathrm{e}^{-8}$ & $\mathbf{0 . 9 1}$ & $\mathbf{0 . 1 0}$ & $\mathbf{0 . 9 8}$ & & & \\
\hline $\mathbf{5}$ & $4.5 \mathrm{e}^{-7}$ & $\mathbf{1 . 0 0}$ & $\mathbf{0 . 9 6}$ & $\mathbf{0 . 1 0}$ & 0.0006 & & \\
\hline $\mathbf{6}$ & 0.0001 & $\mathbf{0 . 9 8}$ & $\mathbf{0 . 5 2}$ & $\mathbf{0 . 9 1}$ & $9.3 \mathrm{e}^{-7}$ & $\mathbf{0 . 5 5}$ & \\
\hline $\mathbf{7}$ & 0.0025 & $\mathbf{0 . 9 8}$ & $\mathbf{0 . 6 0}$ & $\mathbf{0 . 9 2}$ & 0.0017 & $\mathbf{0 . 8 5}$ & $\mathbf{1 . 0 0}$ \\
\hline
\end{tabular}

Table D.4 Multiple comparison test ( $p$-values) of N of core FHDP2C ( $p \geq 0.05$ in bold)

\begin{tabular}{cccccccc}
\hline & DP & $\mathbf{1}$ & $\mathbf{2}$ & $\mathbf{3}$ & $\mathbf{4}$ & $\mathbf{5}$ & $\mathbf{6}$ \\
\hline $\mathbf{1}$ & $5.2 \mathrm{e}^{-7}$ & & & & & & \\
\hline $\mathbf{2}$ & $6.0 \mathrm{e}^{-8}$ & $\mathbf{0 . 1 0}$ & & & & & \\
\hline $\mathbf{3}$ & $9.0 \mathrm{e}^{-8}$ & $\mathbf{0 . 1 0}$ & $\mathbf{1 . 0 0}$ & & & & \\
\hline $\mathbf{4}$ & $6.0 \mathrm{e}^{-8}$ & $\mathbf{0 . 7 6}$ & $\mathbf{0 . 9 9}$ & $\mathbf{0 . 9 8}$ & & & \\
\hline $\mathbf{5}$ & $6.0 \mathrm{e}^{-8}$ & $\mathbf{1 . 0 0}$ & $\mathbf{0 . 8 4}$ & $\mathbf{0 . 9 7}$ & $2.3 \mathrm{e}^{-6}$ & & \\
\hline $\mathbf{6}$ & $6.0 \mathrm{e}^{-8}$ & $\mathbf{0 . 9 2}$ & $\mathbf{0 . 2 2}$ & $\mathbf{0 . 5 7}$ & $6.0 \mathrm{e}^{-8}$ & $\mathbf{0 . 3 4}$ & \\
\hline $\mathbf{7}$ & $9.5 \mathrm{e}^{-7}$ & $\mathbf{0 . 4 7}$ & 0.03 & $\mathbf{0 . 1 6}$ & $7.8 \mathrm{e}^{-8}$ & 0.03 & $\mathbf{0 . 7 5}$ \\
\hline
\end{tabular}

Table D.5 Multiple comparison test ( $p$-values) of C:N of core FHDP2C ( $p \geq 0.05$ in bold)

\begin{tabular}{cccccccc}
\hline & DP & 1 & 2 & 3 & 4 & 5 & 6 \\
\hline 1 & 1.00 & & & & & & \\
\hline 2 & 0.96 & 1.00 & & & & & \\
\hline 3 & 0.95 & 1.00 & 1.00 & & & & \\
\hline 4 & 0.0004 & $\mathbf{0 . 3 4}$ & $\mathbf{0 . 3 1}$ & $\mathbf{0 . 7 1}$ & & & \\
\hline 5 & 0.94 & 1.00 & 1.00 & 1.00 & $1.0 \mathrm{e}^{-7}$ & & \\
\hline 6 & 1.00 & 1.00 & 1.00 & 1.00 & $2.2 \mathrm{e}^{-7}$ & 1.00 & \\
\hline 7 & 1.00 & 1.00 & 0.97 & 0.96 & $4.8 \mathrm{e}^{-5}$ & 0.96 & $\mathbf{1 . 0 0}$
\end{tabular}

Table D.6 Multiple comparison test ( $\mathrm{p}$-values) of $\delta^{13} \mathrm{C}_{\mathrm{org}}$ of core FHDP2C ( $\mathrm{p} \geq 0.05$ in bold)

\begin{tabular}{cccccccc}
\hline & DP & $\mathbf{1}$ & $\mathbf{2}$ & $\mathbf{3}$ & $\mathbf{4}$ & $\mathbf{5}$ & $\mathbf{6}$ \\
\hline $\mathbf{1}$ & $\mathbf{0 . 9 3}$ & & & & & & \\
\hline $\mathbf{2}$ & $\mathbf{0 . 9 8}$ & $\mathbf{0 . 5 6}$ & & & & & \\
\hline $\mathbf{3}$ & $\mathbf{1 . 0 0}$ & $\mathbf{0 . 9 6}$ & $\mathbf{0 . 9 9}$ & & & & \\
\hline $\mathbf{4}$ & $6.0 \mathrm{e}^{-8}$ & $4.3 \mathrm{e}^{-6}$ & $6.0 \mathrm{e}^{-8}$ & $6.6 \mathrm{e}^{-6}$ & & & \\
\hline $\mathbf{5}$ & $6.0 \mathrm{e}^{-8}$ & $7.7 \mathrm{e}^{-5}$ & $6.0 \mathrm{e}^{-8}$ & $2.2 \mathrm{e}^{-5}$ & $\mathbf{0 . 5 9}$ & & \\
\hline $\mathbf{6}$ & $6.0 \mathrm{e}^{-8}$ & $6.7 \mathrm{e}^{-4}$ & $6.0 \mathrm{e}^{-8}$ & $2.2 \mathrm{e}^{-6}$ & $\mathbf{0 . 0 8 0}$ & $\mathbf{0 . 9 3}$ & \\
\hline $\mathbf{7}$ & $6.0 \mathrm{e}^{-8}$ & $1.0 \mathrm{e}^{-7}$ & $6.0 \mathrm{e}^{-8}$ & $8.9 \mathrm{e}^{-8}$ & $\mathbf{1 . 0 0}$ & $\mathbf{0 . 6 6}$ & $\mathbf{0 . 2 2}$ \\
\hline
\end{tabular}


Table D.7 Multiple comparison test ( $\mathrm{p}$-values) of $\delta^{15} \mathrm{~N}$ of core FHDP2C ( $\mathrm{p} \geq 0.05$ in bold)

\begin{tabular}{cccccccc}
\hline & DP & 1 & 2 & 3 & 4 & 5 & 6 \\
\hline 1 & 0.99 & & & & & & \\
\hline 2 & 1.00 & 0.95 & & & & & \\
\hline 3 & 1.00 & 0.99 & 1.00 & & & & \\
\hline 4 & 0.83 & 1.00 & 0.67 & 0.99 & & & \\
\hline 5 & 0.06 & 0.08 & 0.59 & 0.40 & $6.0 \mathrm{e}^{-8}$ & & \\
\hline 6 & 0.51 & 0.34 & 0.97 & 0.83 & $5.2 \mathrm{e}^{-7}$ & 0.74 & \\
\hline 7 & 0.08 & 0.07 & 0.51 & 0.34 & $1.4 \mathrm{e}^{-6}$ & $\mathbf{1 . 0 0}$ & $\mathbf{0 . 7 4}$ \\
\hline
\end{tabular}



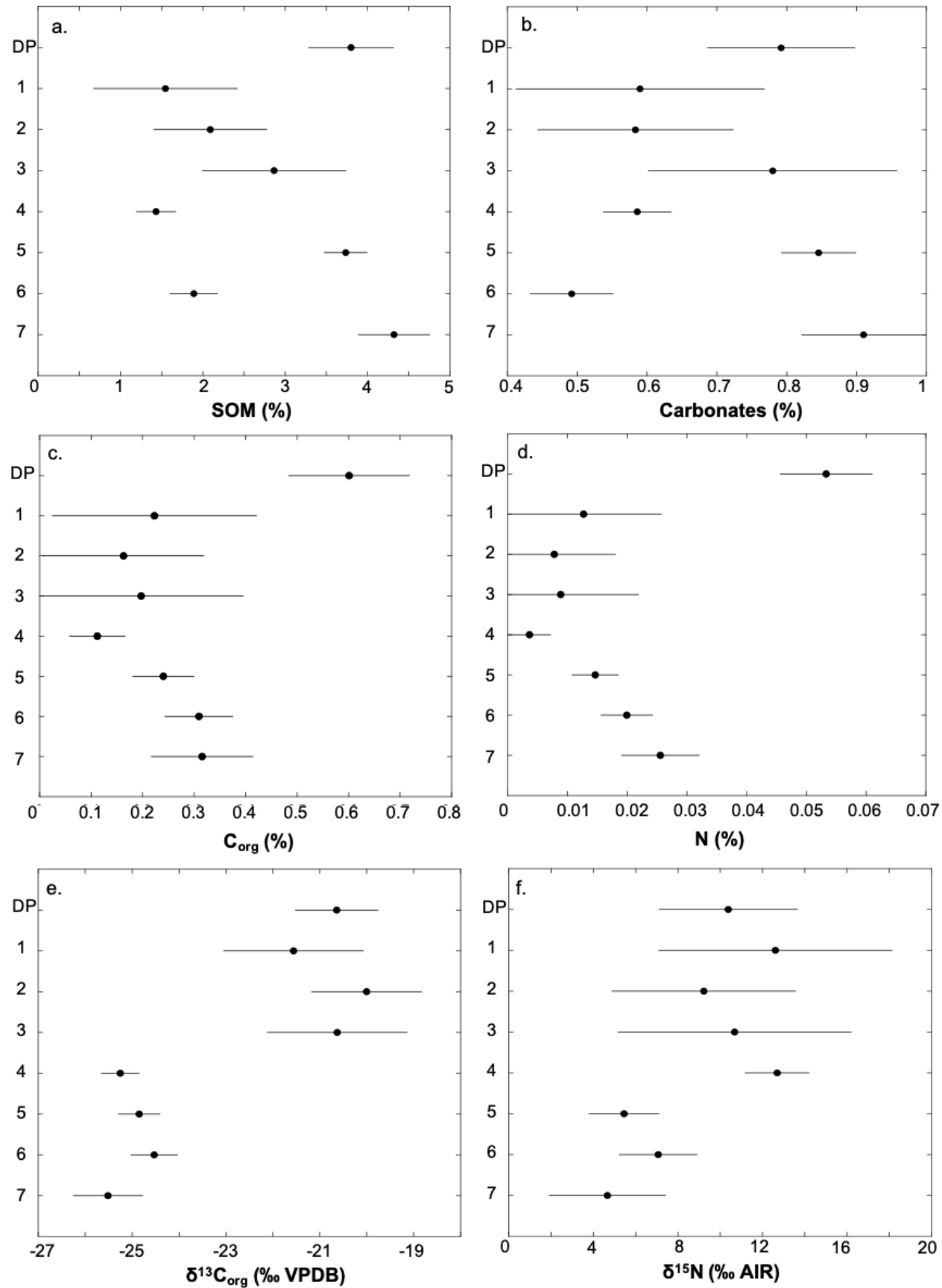

Fig. D.1 Multiple comparison of average a. SOM, b. Carbonates, c. $\mathrm{C}_{\text {org }}$, d. N, e. $\delta^{13} \mathrm{C}_{\text {org }}$ and f. $\delta^{15} \mathrm{~N}$ in different stratigraphic units of core FHDP2C 


\section{Appendix E}

\section{Diatom pictures and counts in core FHDP2C}
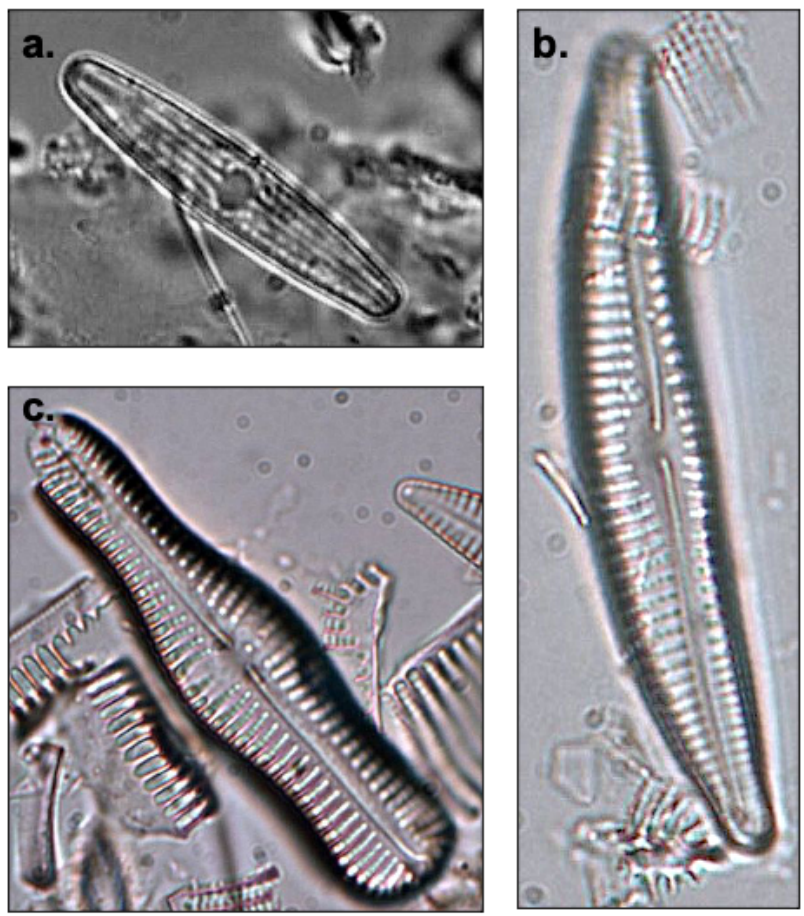

Fig. E.1 Pictures of diatoms in FHDP cores (M. Harper, personal comm. 08/2019). a. Brachysira spp., b. Encyonema spp., c. Gomphonema spp. 
Table E.1 Diatom counts per genera in samples of FHDP2C (M. Harper, personal comm. 08/2019)

\begin{tabular}{|c|c|c|c|c|c|c|c|c|c|c|c|}
\hline SAMPLE ID & 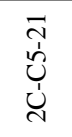 & 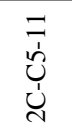 & 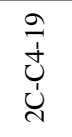 & $\begin{array}{l}m \\
\stackrel{n}{J} \\
\bigcup_{d}^{\prime}\end{array}$ & $\begin{array}{l}Z \\
\underset{J}{J} \\
\text { J }\end{array}$ & $\begin{array}{l}\frac{n}{1} \\
\frac{U}{U} \\
\stackrel{d}{\prime}\end{array}$ & $\begin{array}{l}\frac{m}{I} \\
\frac{U}{U} \\
\end{array}$ & $\begin{array}{l}\text { I } \\
\text { Ù } \\
\text { ' }\end{array}$ & $\frac{\stackrel{I}{U}}{\bigcup_{N}^{\prime}}$ & $\frac{N}{\stackrel{J}{J}}$ & 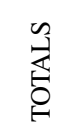 \\
\hline Depth (m) & 5.15 & 4.88 & 3.63 & 3.46 & 3.42 & 0.71 & 0.67 & 0.50 & 0.42 & 0.38 & \\
\hline Achnanthidium & 1 & 3 & 0 & 1 & 0 & 0 & 0 & 1 & 2 & 9 & 17 \\
\hline Adlafia & 34 & 0 & 0 & 0 & 0 & 0 & 0 & 0 & 0 & 1 & 35 \\
\hline Aulacoseira spp & 0 & 20 & 12 & 9 & 50 & 2 & 1 & 0 & 0 & 58 & 152 \\
\hline Brachysira spp. & 0 & 1 & 0 & 0 & 3 & 0 & 0 & 0 & 2 & 45 & 51 \\
\hline Caloneis spp. & 0 & 2 & 0 & 0 & 0 & 0 & 0 & 0 & 0 & 0 & 2 \\
\hline Chamaepinnularia spp. & 0 & 0 & 2 & 0 & 0 & 0 & 0 & 0 & 0 & 1 & 3 \\
\hline Cymbella spp. & 0 & 5 & 5 & 11 & 0 & 6 & 0 & 2 & 1 & 3 & 33 \\
\hline Diatoma aff. anceps & 0 & 0 & 0 & 0 & 0 & 0 & 0 & 0 & 0 & 1 & 1 \\
\hline Encyonema spp. & 0 & 5 & 10 & 10 & 3 & 0 & 1 & 0 & 6 & 30 & 65 \\
\hline Eunotia spp. & 324 & 12 & 7 & 1 & 2 & 0 & 0 & 0 & 0 & 19 & 365 \\
\hline Fragilaria cf. capucina & 0 & 0 & 0 & 0 & 0 & 0 & 0 & 0 & 0 & 2 & 2 \\
\hline Fragilariforma spp. & 0 & 14 & 2 & 0 & 1 & 0 & 0 & 0 & 0 & 0 & 17 \\
\hline Frustulia spp. & 0 & 18 & 10 & 0 & 6 & 0 & 0 & 0 & 0 & 12 & 46 \\
\hline Gomphonema spp. & 0 & 21 & 0 & 2 & 10 & 0 & 0 & 0 & 0 & 5 & 38 \\
\hline Humidophila spp. & 1 & 17 & 5 & 3 & 12 & 6 & 0 & 0 & 9 & 14 & 67 \\
\hline Muelleria spp. & 0 & 3 & 4 & 1 & 5 & 0 & 0 & 0 & 0 & 8 & 21 \\
\hline Navicula sp1 & 0 & 0 & 0 & 0 & 0 & 0 & 0 & 0 & 0 & 1 & 1 \\
\hline Neidium spp. & 0 & 0 & 0 & 0 & 1 & 0 & 0 & 0 & 0 & 0 & 1 \\
\hline Nitzschia spp. & 0 & 0 & 0 & 0 & 2 & 0 & 0 & 0 & 0 & 4 & 6 \\
\hline Nupela spp. & 0 & 0 & 0 & 0 & 0 & 0 & 0 & 0 & 0 & 7 & 7 \\
\hline Parlibellus sp1 & 0 & 0 & 0 & 0 & 0 & 0 & 0 & 0 & 0 & 4 & 4 \\
\hline Pinnularia spp. & 0 & 6 & 8 & 3 & 8 & 0 & 2 & 4 & 0 & 12 & 43 \\
\hline Placoneis spp. & 0 & 5 & 1 & 0 & 0 & 0 & 0 & 0 & 0 & 1 & 7 \\
\hline Psammothidium spp. & 0 & 0 & 0 & 0 & 1 & 0 & 0 & 1 & 3 & 7 & 12 \\
\hline Pseudostaurosira sp1 & 0 & 0 & 1 & 0 & 0 & 0 & 0 & 0 & 0 & 0 & 1 \\
\hline Sellaphora spp. & 0 & 1 & 0 & 0 & 0 & 1 & 0 & 0 & 0 & 0 & 2 \\
\hline Stauroneis spp. & 0 & 0 & 0 & 0 & 0 & 0 & 0 & 0 & 0 & 1 & 1 \\
\hline Staurosira spp . & 1 & 9 & 6 & 3 & 31 & 15 & 19 & 8 & 12 & 66 & 170 \\
\hline Staurosirella spp & 0 & 104 & 98 & 185 & 53 & 317 & 258 & 211 & 216 & 9 & 1451 \\
\hline Tetracyclus spp & 0 & 7 & 5 & 3 & 1 & 0 & 0 & 0 & 0 & 2 & 18 \\
\hline "Boreo"[aff. Achnanthes sp] & 0 & 1 & 2 & 0 & 4 & 0 & 0 & 0 & 0 & 0 & 7 \\
\hline "Biremis sl" [aff. Biremis sp] & 0 & 1 & 1 & 2 & 7 & 0 & 0 & 0 & 0 & 6 & 17 \\
\hline [aff. Pinnularia sp4] & 0 & 0 & 0 & 0 & 0 & 0 & 0 & 0 & 0 & 1 & 1 \\
\hline Unknown genus sp1 & 0 & 0 & 1 & 0 & 0 & 0 & 0 & 0 & 0 & 0 & 1 \\
\hline Unknown genus sp2 & 0 & 0 & 0 & 0 & 0 & 0 & 0 & 0 & 0 & 1 & 1 \\
\hline Veigaludwigia sp & 0 & 1 & 0 & 0 & 0 & 0 & 0 & 0 & 0 & 0 & 1 \\
\hline DIATOM TOTAL & 361 & 256 & 180 & 234 & 200 & 347 & 281 & 227 & 251 & 330 & 2667 \\
\hline Chryso cysts & 38 & 38 & 66 & 19 & 82 & 53 & 2 & 2 & 6 & 49 & 355 \\
\hline siliceous algae & 399 & 294 & 246 & 250 & 282 & 400 & 283 & 229 & 257 & 379 & 3019 \\
\hline
\end{tabular}




\section{Appendix F}

\section{Radiocarbon calibration curve}

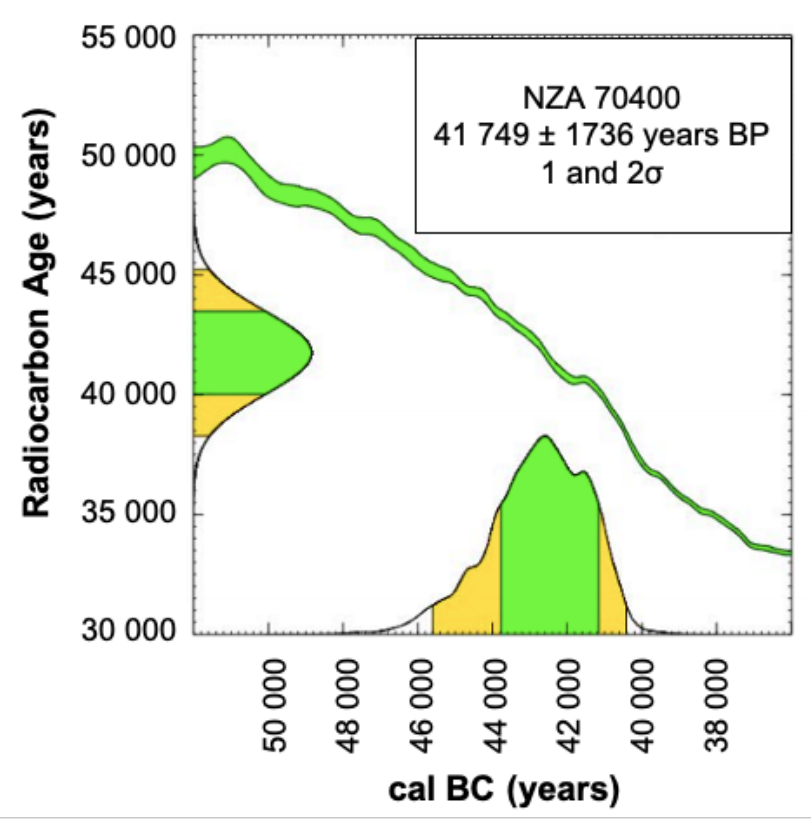

Fig. F.1 Radiocarbon age calibration plot. Calibrated with SHCal20 (Hogg et al., 2020) 



\section{Appendix G}

\section{Input parameters for the REGO model}

Table G.1 Values of parameters used in REGO ensemble modelling $(\mathrm{n}=36)$.

\begin{tabular}{cccc}
\hline Parameter & Component & Values (n) & Numerical Experiment 1 \\
\hline MAT $(\mathrm{K})$ & Thermal & 1 & 250 \\
\hline $\mathrm{T}_{\text {amp }}(\mathrm{K})$ & Thermal & 1 & 20 \\
\hline GRAD $\left(\mathrm{K} 100 \mathrm{~m}^{-1}\right)$ & Thermal & 1 & 2 \\
\hline DIFUST $\left(\mathrm{m}^{2}\right.$ yr $\left.^{-1}\right)$ & Thermal & 2 & 30,62 \\
\hline Kpaterson & Creep & 1 & 3 \\
\hline KTENSE & Stress & 1 & 0 \\
\hline KTENS $(\mathrm{VdW})$ & Stress & 1 & 6 \\
\hline LINE (\#) (fig. 1 in Fisher et al. (2019) & Permeability & 1 & $-6.32 \mathrm{E}-18$ \\
\hline Hamaker constant & Permeability & 3 & $1,10,100$ \\
\hline $\mathrm{R}_{\text {soil }}(\mu \mathrm{m})$ & Mean soil particle radius & 2 & $0.17,0.13$ \\
\hline $\mathrm{S}_{\mathrm{L} \text { thrsh }}$ & Liquid water threshold for VdW forces & 2 & $0.42,0.5$ \\
\hline FDIN & Porosity & 1 & Fujinomori \\
\hline KSOIL & Soil types used & Seawater \\
\hline KBASE & Base water chemistry & 1 & 0.1 \\
\hline FRACTB & Base chemistry strength fraction & 1 & \\
\hline
\end{tabular}

Note: For further explanation of the variables and methods, see Fisher et al. (2019). VdW = Van der Waals. 



\section{Appendix H}

\section{Input parameters for the Craig-Gordon/ Sofer \& Gat model}

Table H.1 Input parameters for the evaporation isotope model that calculates the stable isotopes of hydrogen and oxygen for snow melt seeping downwards in summer through salty soil above the ice table. Based on Sofer and Gat (1975), Craig et al. (1963) and Craig (1965)

\begin{tabular}{|c|c|}
\hline Parameter & Value \\
\hline \multicolumn{2}{|l|}{ Chemistry $(0.1 \times$ seawater $)$} \\
\hline $\mathrm{MgCl}_{2}\left(\mathrm{~mol} \mathrm{~L}^{-1}\right)$ & 5.49E-03 \\
\hline $\mathrm{NaCl}\left(\mathrm{mol} \mathrm{L}^{-1}\right)$ & $4.87 \mathrm{E}-02$ \\
\hline $\mathrm{CaCl}_{2}\left(\mathrm{~mol} \mathrm{~L}^{-1}\right)$ & $9.53 \mathrm{E}-04$ \\
\hline $\mathrm{KCl}\left(\mathrm{mol} \mathrm{L}^{-1}\right)$ & $1.06 \mathrm{E}-03$ \\
\hline \multicolumn{2}{|l|}{ Water isotopes and fractionation factors } \\
\hline$\delta^{18} \mathrm{Ow}(\%)$ & -35 \\
\hline$\delta \mathrm{Dw}(\%)$ & -270 \\
\hline$\delta^{18} \mathrm{Ov}(\%)$ & -28 to -26 \\
\hline$\delta \mathrm{Dv}(\%)$ & -285 to -253 \\
\hline Resistance at the bulk water surface for ${ }^{18} \mathrm{O}$ & 0.189 \\
\hline Resistance at the bulk water surface for D & 0.189 \\
\hline Resistance at the $\mathrm{H}_{2} \mathrm{O}$ surface to air boundary for ${ }^{18} \mathrm{O}$ & 1.032 \\
\hline Resistance at the $\mathrm{H}_{2} \mathrm{O}$ surface to air boundary for $\mathrm{D}$ & 1.016 \\
\hline \multicolumn{2}{|l|}{ Dry lag conditions } \\
\hline Summer temperature in lag above ice table $\left({ }^{\circ} \mathrm{C}\right)$ & 0 \\
\hline Relative humidity (\%) in lag & $90-95$ \\
\hline
\end{tabular}

Note: Equilibrium fractionation factor $(\alpha)$ used for temperature $\left(\mathrm{T}=\mathrm{T}_{\mathrm{lag}}\right)$.

For water equilibrium, $\mathrm{T} \geq$ surface ice set at $-25^{\circ} \mathrm{C}$ in this example. $\alpha^{18} \mathrm{O}=\mathrm{EXP}\left(\left(1137 / \mathrm{T}^{2}\right)-(0.4156 / \mathrm{T})-0.0020667\right)(\mathrm{T}$ in kelvin $)$. $\alpha \mathrm{D}$ $=\operatorname{EXP}\left(\left(24844 / \mathrm{T}^{2}\right)-(76.248 / \mathrm{T})+0.052612\right)(\mathrm{T}$ in kelvin $)$.

For ice equilibrium, $\mathrm{T}<$ surface ice, $25^{\circ} \mathrm{C}$ in this example, $\mathrm{T}$ in kelvin. $\alpha^{18} \mathrm{O}=\mathrm{EXP}(11.839 / \mathrm{T}-0.028224)(\mathrm{T}$ in kelvin $) . \alpha \mathrm{D}=$ $\operatorname{EXP}(129.667 / \mathrm{T}-0.351366)(\mathrm{T}$ in kelvin). 